\title{
Childhood fever in out-of-hours general practice
}

\author{
Citation for published version (APA):
}

de Bont, E. G. P. M. (2018). Childhood fever in out-of-hours general practice. [Doctoral Thesis, Maastricht University]. Maastricht University. https://doi.org/10.26481/dis.20181116eb

Document status and date:

Published: 01/01/2018

DOI:

10.26481/dis.20181116eb

Document Version:

Publisher's PDF, also known as Version of record

\section{Please check the document version of this publication:}

- A submitted manuscript is the version of the article upon submission and before peer-review. There can be important differences between the submitted version and the official published version of record.

People interested in the research are advised to contact the author for the final version of the publication, or visit the DOI to the publisher's website.

- The final author version and the galley proof are versions of the publication after peer review.

- The final published version features the final layout of the paper including the volume, issue and page numbers.

Link to publication

\footnotetext{
General rights rights.

- You may freely distribute the URL identifying the publication in the public portal. please follow below link for the End User Agreement:

www.umlib.nl/taverne-license

Take down policy

If you believe that this document breaches copyright please contact us at:

repository@maastrichtuniversity.nl

providing details and we will investigate your claim.
}

Copyright and moral rights for the publications made accessible in the public portal are retained by the authors and/or other copyright owners and it is a condition of accessing publications that users recognise and abide by the legal requirements associated with these

- Users may download and print one copy of any publication from the public portal for the purpose of private study or research.

- You may not further distribute the material or use it for any profit-making activity or commercial gain

If the publication is distributed under the terms of Article $25 \mathrm{fa}$ of the Dutch Copyright Act, indicated by the "Taverne" license above, 
Childhood fever

in out-of-hours general practice 
The work presented in this dissertation was supported by the SBOH, employer of GP trainees and by unrestricted grants from the Netherlands Organisation for Health Research and Development (ZonMw)

\section{SBPHK}

voor artsen in opleiding

\section{Colophon}

Cover design: $\quad$ Sander Janssen

Illustrations: Prelum

Lay-out: $\quad$ Eefje de Bont

Printed by: Gildeprint

ISBN: $\quad 9789463233705$

(C) Eefje G.P.M. de Bont, Maastricht 2018

The research presented in this dissertation was conducted at CAPHRI, Care and Public Health Research Institute, Department of Family Medicine, Maastricht University. CAPHRI participates in the Netherlands School of Public Health and Care Research (CaRe), acknowledged by the Royal Dutch Academy of Science (KNAW).

All rights are reserved. No part of this book may be reproduced or transmitted in any form or by any means, without the written permission from the author or, where appropriate, the publisher of the article. 


\title{
Childhood fever
}

\section{in out-of-hours general practice}

\author{
PROEFSCHRIFT \\ ter verkrijging van de graad van doctor aan de Universiteit Maastricht, \\ op gezag van de Rector Magnificus, Prof. dr. Rianne M. Letschert, \\ volgens het besluit van het College van Decanen, in het openbaar te verdedigen \\ op vrijdag 16 november 2018, om 14:00 uur \\ door
}

Evelien Geertruida Petronella Maria de Bont 


\section{Promotores}

Prof. dr. J.W.L. Cals

Prof. dr. G.J. Dinant

\section{Beoordelingscommissie}

Prof. dr. J.F.M. Metsemakers (voorzitter)

Prof. dr. M.Y. Berger (Rijksuniversiteit Groningen)

Prof. dr. E. Dompeling

Dr. J.Y. Verbakel (Katholieke Universiteit Leuven) 
"If you can't explain it simply, you don't understand it well enough" (Albert Einstein)

Voor papa en mama 


\section{CONTENTS}

CHAPTER 1 General Introduction

CHAPTER 2 Oral and topical antibiotic prescriptions for children in general 25 practice

Arch Dis Child. 2013;98:228-31

CHAPTER 3 Workload and management of childhood fever at general practice 39 out-of-hours care: an observational cohort study

BMJ Open. 2015;5:e007365

CHAPTER 4 Parents' knowledge, attitudes, and practice in childhood fever: an 57 internet-based survey Br J Gen Pract. 2014;64(618):e10-6

CHAPTER 5 Childhood fever: a qualitative study on parents' expectations and 73 experiences during general practice out-of-hours care consultations

BMC Fam Pract. 2015;16(1):131

CHAPTER 6 Childhood fever: a qualitative study on GPs' experiences during 93 out-of-hours care

Fam Pract. 2015; 32:449-55

CHAPTER 7 Patient information leaflets to reduce antibiotic use and 113 reconsultation rates in general practice: a systematic review BMJ Open. 2015;5(6):e007612

CHAPTER 8 An illness-focussed interactive booklet to optimise management and medication for childhood fever and infections in out-of-hours primary care: study protocol for a cluster randomised trial Trials. 2016;17:547

CHAPTER 9 An illness-focussed interactive booklet to optimize management and medication for childhood fever and infections in out-of-hours 
primary care: a cluster randomized controlled trial

Ann Fam Med. 2018;16(4):314-321

CHAPTER 10 Medication management of febrile children: a qualitative study on

pharmacy employees' experiences

Int J Clin Pharm. 2016;38:1200-9

CHAPTER 11 Risks and benefits of paracetamol in children with fever

Ned Tijdschr Geneeskd. 2014;158(2):A6636

CHAPTER 12 Amoxicillin and paracetamol dosing in children: playing safe

Ned Tijdschr Geneeskd. 2016;160:D345

CHAPTER 13 General Discussion

Valorisation

Summary

Samenvatting

Dankwoord

Publications

Curriculum Vitae 



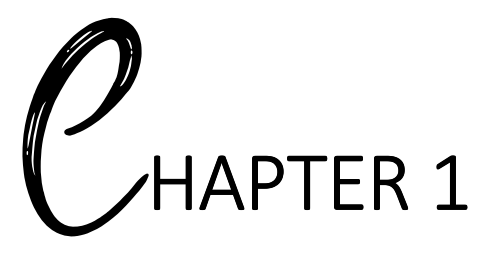

General introduction 



\section{Childhood fever in general practice}

Fever is the most common reason for a child to be taken to a general practitioner (GP). ${ }^{1}$ Childhood infections constitute $60 \%$ of the annual general practice consultation rates for children under 1 year old and approximately 30\% for children up to 15 years of age. ${ }^{2}$ Since many parents work during the day, and fever typically rises in the early evening, these rates are even higher during out-of-hours care. ${ }^{2,3}$

Consultations are generally driven by parental concerns about harmful consequences of fever and serious infections. ${ }^{4}$ In many cases these concerns are the result of a lack of experience and knowledge about fever among parents. Misconceptions are likely reinforced by conflicting information on how to manage fever from different health care providers, websites or people in parents' surroundings. ${ }^{5}$ Previous studies have demonstrated that antibiotic prescriptions resulting from consultations are subsequently influenced by patients' expectations, and that GPs experience pressure from patients to prescribe antibiotics. ${ }^{6}$ It is likely that this is also the case in childhood fever related consultations.

In most cases, fever is caused by a benign (viral) infection and general recommendations given by the GP are sufficient. However, one in three children who visit a GP out-of-hours centre because of a fever receive an antibiotic prescription. Most often, this is unnecessary and not recommended in guidelines. ${ }^{7}$ Additionally, these prescription rates are nearly twice as high as prescription rates during routine office hours. ${ }^{8}$ All these factors combined can contribute to antibiotic resistance in the community and unwanted drug-related side effects in this vulnerable group of patients.

The aim of this thesis is therefore to examine current management of childhood fever during out-of-hours care and stakeholders' experiences with childhood fever in general and during out-of-hours care specifically in order to identify ways of improving these consultations. By doing so, we hope to elicit barriers and facilitators of good quality care and develop an intervention that can enhance appropriate antibiotic prescribing rates and parental self-management strategies. Ultimately, if an intervention can be developed and turns out to be effective, potential ways of implementation and future development of the intervention will be discussed in the general discussion. However, in this introduction, I will first introduce why childhood fever related consultations during out-of-hours care are probably more complex than daytime consultations and propose potential ways of improving these consultations. 


\section{Childhood fever during general practice out-of-hours care - Why is it (more) complex?}

Since the year 2000 GP out-of-hours services in the Netherlands are organized in largescale cooperatives or centres. ${ }^{9}$ These centres cover the primary care by rotating shifts of General Practitioners (GPs) during evening, nights, and weekends. More than 95\% of GPs participate in an out-of-hours centre, which means that patients receive care from their own GP only in incidental out-of-hours contacts. In most cases, they receive care by another GP who also participates in the same centre. ${ }^{10}$ Patients and parents who contact an out-of-hours GP centre are triaged by telephone by trained assistants to determine if a face-to-face contact is needed. The assistant then determines if alarming signs are present based on the Dutch triage system (NTS). ${ }^{11}$ Furthermore, Dutch GPs function as gatekeepers for secondary care. Because of this, most children that are seen by a doctor during out-ofhours care in the Netherlands are assessed by a GP. One in five consultations at a GP outof-hours centre concerns children younger than five years of age and in almost half of these children fever is the reason for encounter. ${ }^{12}$ Only those children who need treatment from a paediatrician will be referred in case the GP decides this is medically indicated.

Childhood fever related consultations at a GP out-of-hours centre are potentially complex for several reasons. First, GPs and parents do not know each other and do not have a longterm parent-GP relationship. This is complicating because a trusting relationship between GPs and patients is one of the founding pillars of general practice. ${ }^{13}$ In theory, it might be more difficult for parents to trust a GP's advice if this trust is lacking. From the GP's perspective, it can be a diagnostic challenge to take a medical history without having any prior knowledge about a family and their (psycho-) social circumstances. In addition to the lack of a long-term parent-GP relationship, GPs also have to trust a colleague, they might or might not know, to take care of adequate follow-up during out-of-hours care. This is caused by the fact that they are usually not available if a parent re-consults the centre the next day or the same day. Handing over this responsibility together with a lacking prior relationship might cause a more defensive way of working during out-of-hours care. This could increase antibiotic prescriptions for children, for who an adequate follow-up advice might have been sufficient during the day in their own GP's practice. However, one might argue that this is the case for all patients during out-of-hours care and childhood fever related consultations are, in this way, not so different.

Then why do GPs see so many children because of a fever during out-of-hours care? Part of this answer is probably biological and the other part societal. The biological reason is fairly straightforward. Children experience more frequent fever episodes since their immune system is not fully developed yet. ${ }^{2}$ When this happens, the circadian temperature pattern 
of the body is set in such a way that the temperature naturally increases in the early evening. ${ }^{14}$ The height of a fever itself, is a known trigger for parents to seek medical help. ${ }^{5}$ This means that many children have frequent fever episodes, and that when they have a fever, the peak temperature is there in the early evening when parents do not have their own GP to turn to. Therefore, they contact the GP out-of-hours centre.

Next to this biological reason there is probably also a societal side to the number of fever related consultations during out-of-hours care. "Fever phobia" among parents has been described more than 30 years ago., ${ }^{4,15}$ Known factors contributing to fever related (re)consultations are lack of knowledge among parents, anxiety about fever, experience of inconsistencies in the approach of different health care professionals and a feeling of lack of control. ${ }^{16,17}$ While these factors influence the fact if parents decide to consult a GP, the decision when to consult is probably also influenced by changes in society. Out-of-hours GP care is becoming more and more crowded over the last decade. In 2005 one in five people contacted an out-of-hours centre at least once a year while in 2016 this number had already increased to one in four. ${ }^{18}$ Households where both parents work during the day have also become more common over the last decades and the chance of parents noticing or acting on a fever during out-of-hours hours instead of during the day has thereby probably increased as well.

In summary, the fact that many children experience fever episodes, parents are worried about the consequences of a fever, more parents work during the day and children experience their peak temperature in the early evening probably drives out-of-hours contact rates. Alongside the high number of consultations, management of children with fever can be further complicated for GPs, because of (perceived) parental expectations and anxiety. ${ }^{4}$ Especially, since GPs typically have no knowledge of the child's medical history or background during out-of-hours care. We believe GPs often feel pressured to prescribe antibiotics, whilst only a limited number of parents actually expect a prescription. ${ }^{19}$ This could imply that GPs' assumptions are not always in line with expectations of consulting parents. All these factors together probably drive unnecessary antibiotic prescribing and referrals and decrease (parental) self-management.

\section{Improving childhood fever management - Where and how?}

Our goal is to first assess the need for improvement by studying current management and stakeholders' experiences. Subsequently, we intend to use this information to develop an intervention. We wish to include all stakeholders during GP out-of-hours care to make sure 
the intervention is user-centred and corresponds to experienced difficulties in daily practice.

Illness-focused interventions recognise the importance of non-medical influences on the decision to consult or to prescribe antibiotics. Exploring the illness experience of parents of children with fever and infections may have potential as it specifically addresses the concerns and questions that parents have when their child is sick. ${ }^{20}$ An illness-focussed intervention can potentially also provide a disease-focussed solution to GPs by providing them with a way to enable parents their self-management and thereby reduce diagnostic uncertainty in these children, leading to fewer "better safe than sorry" antibiotic prescriptions. $^{21}$

Previous research has shown that a good example of such an illness-focused intervention is an interactive information leaflet which can be used during consultations. Such an interactive leaflet or booklet can be used to tailor expectations and questions of parents and potentially elicit parental concerns, provide sustainable information and can create a safety net for both parents and GPs. ${ }^{22,23}$ Although this study was performed in regular GPs practices and was not aimed at childhood fever, we believe this could subsequently guide judicious antibiotic, referral decisions and inform (re)consultations in the GP out-of-hours services among children with a fever as well. Moreover, previous studies have shown that one of the reasons that GPs hand-out an unnecessary prescription is the fact that they feel they need to offer something to patients when they consult. ${ }^{24}$ An information exchangetool can potentially replace a prescription in this case because it can be physically handed over to parents. Another benefit of an information exchange tool has is the fact that it can facilitate consistent advice. If this proves to be effective, a next step could be to tailor that information for secondary care when children are referred, but also in the general public, before children get sick. Thereby creating one, universal and consistent flow of information for parents about the most common symptom in children.

\section{Aim of this thesis and main research questions}

In this thesis I aim to find these answers by first examining what happens at present by a combined quantitative and qualitative approach. Secondly, if and how there is room for improvement using an intervention. And third, if such an intervention can effectively reduce antibiotic prescriptions and (re-)consultations, improve satisfaction of all stakeholders without causing complications. Our main research questions are therefore: 
1. What is the current GP workload in childhood fever consultations during GP outof-hours care, and how are these consultations managed in terms of antibiotic prescriptions and referrals to secondary care?

2. How do parents and GPs experience fever in children and general practice consultations for childhood fever and common infections, with a specific focus on out-of-hours care and how can these consultations be improved?

3. What is the effect of GP use of an interactive booklet in childhood fever related consultations for children $<12$ years, during GP out-of-hours care consultations on antibiotic prescriptions, (re)consultations and parental satisfaction?

4. How can GPs improve medication management in childhood fever and common infections in terms of antipyretic, analgesics and antibiotic use and advice? 


\section{THESIS OUTLINE}

\section{Workload and current management of childhood fever \\ $\infty$ CHAPTER 2}

Monitoring trends in antibiotic prescribing using a cohort study is important to assess the necessity of interventions aimed at antibiotic resistance. In this chapter we investigate antibiotic prescription rates over time and for different age categories for oral and topical antibiotics among children ( $\leq 12$ years) between 2000-2010 using data from a large GP database.

\section{$\infty \quad$ CHAPTER 3}

The next step is to zoom in on GP out-of-hours care. In order to develop interventions to increase parental self-management strategies it is important to know how childhood fever contacts are currently managed during out-of-hours care. Therefore, we performed another cohort study assessing the number of childhood fever related contacts and consultations, resulting antibiotic prescriptions, paediatric referrals and reconsultations for children under the age of 12 during out-of-hours care at a large GP out-of-hours centre in the Netherlands.

\section{Development of the hypothesis and interactive booklet}

\section{$\infty \quad$ CHAPTER 4}

Decisions on medication and healthcare-seeking behaviour in acute illness are shaped by public beliefs and knowledge. It is therefore important to understand why and when parents actually consult with their feverish child, what self-management activities they practice, and which information gaps they experience, to better target information at parents both within the consultation as well as outside acute care. Consequently, in this chapter we aim to determine public parental knowledge, attitudes, and practices in fever in young children in a nationwide online survey among parents with young children in the general population.

\section{$\infty \quad$ CHAPTER 5}

One of the primary stakeholders in childhood fever consultations are parents. Insight into expectations and experiences of parents who have consulted during out-of-hours GP care with their feverish child could provide insights for future interventions. Using in-depth semi-structured interviews, we aim to provide an in-depth overview why parents consult a GP out-of-hours, what they generally experience and expect, and how they use and would desire information to be given before, during and after a consultation for childhood fever. 


\section{$\infty$ CHAPTER 6}

In order to enhance appropriate antibiotic prescribing and management in febrile children during GP out-of-hours care, it is crucial to answer the question: how do GPs experience childhood fever related consultations during out-of-hours care and how do they believe that these consultations can be improved? In this qualitative chapter describing the results of our focus-group discussions we therefore aim to explore the experiences of GPS regarding childhood fever consultations during out-of-hours care, thereby eliciting barriers and facilitators of good quality care including appropriate antibiotic prescribing rates and enhanced parental self-management.

\section{$\infty \quad$ CHAPTER 7}

A potential intervention that might improve childhood fever related out-of-hours consultations that was mentioned by both GPs and parents was the use of evidence-based information leaflets. The use of information leaflets to assist a consultation may be a useful tool to convey information, increase patient knowledge and possibly restrict antibiotic prescriptions. The aim of the systematic review in chapter seven is therefore to study the effect of using patient information leaflets on antibiotic use and reconsultation rates in general practice consultations for common infections.

\section{Effect of the interactive booklet on childhood fever}

\section{$\infty$ CHAPTER 8 and 9}

By integrating the prior quantitative and qualitative studies that are described in the previous chapters, we were able to develop an intervention in the form of an interactive illness-focused booklet on childhood fever aimed at parents. The content of the booklet was developed bottom-up in a multistage process using the described nationwide survey among parents, focus group sessions and semi-structured interviews with parents, GPs and triage nurses, extensive literature research and expert discussions. The main content of the booklet is a traffic light system for childhood fever aimed at parents with advice on when to consult a GP (red symptoms) and information on self-management strategies, as well as specific traffic lights for infections of the upper respiratory tract (cough, cold and sore throat), acute otitis media (earache) and gastrointestinal symptoms (abdominal pain, vomiting and diarrhoea). In chapter 8 we describe the study protocol of a cluster randomized controlled trial on the effect of the pragmatic use of an interactive booklet in childhood fever related GP out-of-hours care consultations for children $<12$ years. 
Subsequently, in chapter nine results are presented of the cluster randomised trial evaluating GP use of the interactive booklet in childhood fever related consultations for children $<12$ years, during GP out-of-hours care consultations on antibiotic prescriptions, (re)consultations and parental satisfaction. Twenty GP out-of-hours centres across the Netherlands providing care for 3557206 residents participated in this trial from Nov 2015 to June 2016. GPs at ten intervention sites had access to the illness-focussed interactive booklet.

\section{Medication management in childhood fever and common infections: what can be improved? $\infty$ CHAPTER 10}

Because dosing of antibiotics in children is complex, the pharmacy exerts an important role in medication management for children. They also play a central role in advising parents on correct antibiotics administration and how to deal with side effects. However, evidence with regards to what happens at the pharmacy following a GPs' consultation is lacking. In chapter ten, we therefore describe pharmacy employees' experiences with medication management for childhood fever in the pharmacy using focus group discussions.

\section{$\infty \quad$ CHAPTER 11}

(Self-)management advice in childhood fever often involves advice on antipyretic and analgesics use. Worldwide, paracetamol is the most commonly used antipyretic for children and the drug of first choice for reducing fever named in the majority of practice guidelines. Chapter eleven is a review article describing the risk and benefits of paracetamol in children with fever.

$\infty \quad$ CHAPTER 12

This thesis primarily focuses on reducing unnecessary antibiotic prescriptions. However, when GPs do decide to prescribe an antibiotic it is important that prescriptions are correct, consistent and safe. The same goes for advice on how and when to use paracetamol. In chapter 12 we describe how we believe amoxicillin and paracetamol dosing can be improved. 


\section{General discussion}

\section{$\infty$ CHAPTER 13}

In the general discussion of this thesis the results of all chapters are put into perspective, compared to existing literature, and recommendations for clinical practice and research are formulated. 


\section{REFERENCES}

1. Hay AD, Heron J, Ness A. The prevalence of symptoms and consultations in preschool children in the Avon Longitudinal Study of Parents and Children (ALSPAC): a prospective cohort study. Fam Pract. 2005;22:367-74.

2. National Institute of Clinical Excellence. NICE guideline: feverish illness in children. London: National Institute of Clinical Excellence; 2013.

3. Walsh A, Edwards H, Fraser J. Parents' childhood fever management: community survey and instrument development. J Adv Nurs. 2008;63:376-88.

4. Crocetti M, Moghbeli N, Serwint J. Fever phobia revisited: have parental misconceptions about fever changed in 20 years? Pediatrics. 2001;107:1241-6.

5. Walsh A, Edwards H. Management of childhood fever by parents: literature review. J Adv Nurs. 2006;54:217-27.

6. Macfarlane J, Holmes W, Macfarlane R, Britten N. Influence of patients' expectations on antibiotic management of acute lower respiratory tract illness in general practice: questionnaire study. BMJ. 1997;315:1211-4.

7. Elshout G, Kool M, Van der Wouden JC, Moll HA, Koes BW, Berger MY. Antibiotic Prescription in Febrile Children: A Cohort Study during Out-of-Hours Primary Care. J Am Board Fam Med. 2012;25:810-8.

8. Otters HB, van der Wouden JC, Schellevis FG, van Suijlekom-Smit LW, Koes BW. Trends in prescribing antibiotics for children in Dutch general practice. I Antimicrob Chemother. 2004;53:361-6.

9. Huibers L, Giesen P, Wensing M, Grol R. Out-of-hours care in western countries: assessment of different organizational models. BMC Health Serv Res. 2009;9:105.

10. Giesen P. SM, Huibers L., Grol R., Wensing M. Quality of after-hours primary care: As narrative review of the Dutch solution. Ann Intern Med. 2011;155:108-13.

11. van lerland $Y$, van Veen $M$, Huibers L, Giesen P, Moll HA. Validity of telephone and physical triage in emergency care: the Netherlands Triage System. Fam Pract. 2011;28:33441.

12. Elshout $G$, van lerland $Y$, Bohnen AM, de Wilde M, Oostenbrink R, Moll HA, et al. Alarm signs and antibiotic prescription in febrile children in primary care: an observational cohort study. Br J Gen Pract. 2013;63:e437-44.

13. Fugelli P. James Mackenzie Lecture. Trust--in general practice. Br J Gen Pract. 2001;51:575-9.

14. Manfredini R, Vergine G, Boari B, Faggioli R, Borgna-Pignatti C. Circadian and seasonal variation of first febrile seizures. J Pediatr. 2004;145:838-9.

15. Kai J. What worries parents when their preschool children are acutely ill, and why: a qualitative study. Br Med J. 1996;313:983-6.

16. Enarson MC, Ali S, Vandermeer B, Wright RB, Klassen TP, Spiers JA. Beliefs and expectations of Canadian parents who bring febrile children for medical care. Pediatrics. 2012;130:e905-12.

17. Blumenthal I. What parents think of fever. Fam Pract. 1998;15:513-8.

18. Ineen. Benchmarkbulletin huisartsenposten 20162017 [01-01-2018]. Available from:

https://ineen.nl/assets/files/assets/uploads/170824_Benchmarkbulletin_2016_Huisartsenp osten.pdf. 
19. Kallestrup P, Bro F. Parents' beliefs and expectations when presenting with a febrile child at an out-of-hours general practice clinic. Br J Gen Pract. 2003;53:43-4.

20. Jones $\mathrm{CH}$, Neill S, Lakhanpaul M, Roland D, Singlehurst-Mooney H, Thompson M. Information needs of parents for acute childhood illness: determining 'what, how, where and when' of safety netting using a qualitative exploration with parents and clinicians. BMJ Open. 2014;4:e003874.

21. Horwood J, Cabral C, Hay AD, Ingram J. Primary care clinician antibiotic prescribing decisions in consultations for children with RTIs: a qualitative interview study. $\mathrm{Br} \mathrm{J}$ Gen Pract. 2016;66:e207-13.

22. Francis NA, Butler CC, Hood K, Simpson S, Wood F, Nuttall J. Effect of using an interactive booklet about childhood respiratory tract infections in primary care consultations on reconsulting and antibiotic prescribing: a cluster randomised controlled trial. BMJ. 2009;339:b2885.

23. Francis NA, Phillips R, Wood F, Hood K, Simpson S, Butler CC. Parents' and clinicians' views of an interactive booklet about respiratory tract infections in children: a qualitative process evaluation of the EQUIP randomised controlled trial. BMC Fam Pract. 2013;14:182.

24. Butler CC, Rollnick S, Pill R, Maggs-Rapport F, Stott N. Understanding the culture of prescribing: qualitative study of general practitioners' and patients' perceptions of antibiotics for sore throats. BMJ. 1998;317:637-42. 

Workload and current management of childhood fever 



\section{Oral and topical antibiotic prescriptions for children in general practice}

Eefje G.P.M. de Bont Inge H.M. van Loo

Nicole H.T.M. Dukers-Muijrers Christian J.P.A. Hoebe

Catharina A. Bruggeman

Geert-Jan Dinant Jochen W.L. Cals

Arch Dis Child. 2013;98:228-31. 



\section{ABSTRACT \\ Objective}

Most primary care clinical guidelines recommend restrictive antibiotic use for childhood infections. We investigated antibiotic prescription rates over time for oral and topical antibiotics for children ( $\leq 12$ years) in the period 2000-2010.

\section{Design, Setting and Patients}

Longitudinal observational study among children ( $\leq 12$ years) in a large Dutch general practice database in the period 2000-2010.

\section{Main outcome measures}

Oral and topical antibiotic prescribing rates per year and independent factors influencing antibiotic prescriptions.

\section{Results}

We analysed 108,555 patient-years during 2000-2010. At least one chronic disease was recorded in $15.8 \%$ of patient-years, with asthma most commonly registered. In $14.8 \%$ of the patient-years at least one antibiotic was prescribed, while $26.3 \%$ of these received two or more prescriptions. Young age and chronic disease had a significant effect on antibiotic prescriptions. Prescriptions for oral and topical antibiotics increased $4.9 \%$ and $1.8 \%$, respectively, during 2000-2005 ( $p<0.001)$. Prescription rates for oral antibiotics decreased 3.3\% during 2006-2010 ( $p<0.001$ ), while topical prescribing rates remained stable.

\section{Conclusions}

One in six children received at least one oral antibiotic prescription per year during 20002010. While topical prescription rates steadily increased during 2005-2010 and remained stable during 2006-2010, prescription rates for oral antibiotics increased significantly during the period 2000-2005 and then significantly decreased during the period 2006-2010. As clinical guidelines remained the same over this period, the effects could be contributed to the initiation of the Dutch nationwide pneumococcal vaccination campaign in 2006. 


\section{INTRODUCTION}

In most developed countries the majority of antibiotics for childhood infections - including infections of the respiratory tract (as well as ear infections), urinary tract and skin - are prescribed in primary care. ${ }^{1}$ Consultations for symptoms related to childhood infections constitute an extensive workload for general practitioners (GPS), in which they are often faced with difficult decisions on the necessity of antibiotic treatment. While most respiratory infections are self-limiting, a small minority of children have a serious infection with a complicated course if left untreated. Clinicians' diagnostic uncertainty combined with parental worries and expectations may lead to over- and misuse of antibiotics. This can contribute to antibiotic resistance in the community and unwanted drug-related side effects. In addition, parents receiving antibiotics after an initial consultation at which antibiotics were not prescribed were less satisfied with care. ${ }^{2}$

Prudent antibiotic use is promoted in most primary care clinical guidelines for childhood infections, including those issued by the Dutch College of GPs, in an attempt to target antibiotics at those children who need them and to contain antibiotic resistance. However, there are limited studies investigating trends in oral antibiotic prescription rates for children in general practice. The current available evidence shows that countries with the highest paediatric prescription rates like Italy and Canada have a fourfold higher rate than countries with lower prescription rates like Denmark. ${ }^{3}$ The Netherlands generally range among the lowest prescribing countries in studies comparing overall outpatient antibiotic prescribing. Yet, besides limited evidence on antibiotic prescribing in children, until now there are no studies on GP prescribing of topical antibiotics. This is striking as topical antibiotics are frequently used for common paediatric skin and eye infections in general practice. ${ }^{4}$ Monitoring trends in antibiotic prescribing is important to assess the necessity of interventions aimed at antibiotic use for the paediatric population.

In this paper we investigate prescription rates over time and for different age categories for oral and topical antibiotics among children ( $\leq 12$ years) in the period 2000-2010 using data from a large GP database. 


\section{MATERIALS AND METHODS}

We retrieved data from the Dutch Registration Network Family Practices (RNH) in 20002010 from children ( $\leq 12$ years). The RNH is a continuous, computerized and anonymous database from 22 rural and urban general practices in the south of the Netherlands, Limburg. 5 The RNH contains information on patient demographics, diagnoses and medication prescription (coded according to the Anatomical Therapeutical Chemical, or ATC classification from the WHO). Diagnoses are registered according to the International Classification of Health in Primary Care and the current Dutch guidelines. Diagnoses are registered as chronic diseases when they are permanent, recurrent, or when they have lasting consequences for the functional status or prognosis of the patient. ${ }^{6}$

We included the following chronic diseases that were considered to be relevant for children and antibiotic prescriptions: leukemia (B73), chronic bronchitis (R91), asthma (R96), diabetes mellitus (T90), constitutional eczema (S87), congenital disorders (A90, D81, H80, R89 and U85) and hypertrophic/chronic infections tonsils/adenoid (R90). ATC code J01 was used for all systemic (oral) antibacterial medication (excluding antifungal or tuberculosis medication) with the following classes: tetracyclines (J01A), beta-lactam antibiotics, including penicillin (J01C), other beta-lactam antibiotics (J01D), sulfonamides and trimethoprim (J01E), macrolides (J01F), aminoglycosides (J01G), fluoroquinolones (J01MA), other quinolones (J01MB), nitrofurantion (J01XE), metronidazole (J01XD), and other systemic antibiotics (J01XX). Finally, D06AX was used for antibiotics for topical use. Current Dutch guidelines for children indicate that there is no indication to prescribe antibiotics from the following specific groups; aminoglycosides (JO1G), (fluor)quinolones (JO1MA/B), tetracyclines below the age of nine years (J01A) and systemic antibacterials other than mentioned in the classes above.

The unit of analysis was patient-year, i.e. a patient contributes one patient-year when he or she is registered as a patient at a $\mathrm{RNH}$ participating general practice. The annual prescription rate was defined as the number of prescriptions (maximum of one per patient per year) divided by the number of patient-years in a given calendar year. Using multivariate logistical regression analyses, time-trends for annual prescription rates were evaluated controlling for age, gender and chronic disease. Using interaction-terms between year and other determinants, it was assessed whether time-trends were similar or different for specific age-groups or other subpopulations. Analyses were performed with the SPSS package V.14.0.2 (SPSS Inc, Chicago, Illinois, USA).

All patients included in the RNH database were informed about the potential anonymous use of their health information. All data in this study are analysed anonymously, and are explicitly not retraceable to individual patients. ${ }^{5,6}$ This study was approved by the Medical 
Chapter 2

Ethics Committee of the Maastricht University Medical Centre (reference number NL12-4053). 


\section{RESULTS}

The study population comprised a total of 108,555 patient-years equally distributed across age and gender in the period 2000-2010. At least one chronic disease was recorded in $15.8 \%$ of patient-years with asthma (47\%) being most common, followed by constitutional eczema (46\%) and hypertrophic/chronic infections tonsils/adenoid (11\%).

In $14.8 \%$ ( $n=16$ 091) of the patient-years at least one oral antibiotic was prescribed. In one out of four of these patient-years $(26.3 \%$; $n=4229)$ two or more oral antibiotics were prescribed. In $5.3 \%(n=5797)$ of the patient-years at least one topical antibiotic was prescribed.

During 2000-2005, a significant increase of $4.9 \%(p<0.001)$ in the prescription rates was observed for both systemic and topical antibiotics (Figure 2.1). Conversely, between 20062010 an average decline of $3.3 \%(p<0.001)$ in the oral antibiotic prescription rates was noted, varying from $4.3 \%$ in children aged $0-4$ years, $3.0 \%$ in children aged $5-8$ years and $1.8 \%$ in children aged $9-12$ years (Figure 2.2). Topical antibiotic prescription remained stable between 2006-2010. Table 2.1 shows factors associated with antibiotic prescriptions. The percentage of oral prescriptions decreased significantly with age $(p<0.001)$, ranging from $27.7 \%$ for 1 -year-olds to $6.2 \%$ for 12 -year-olds. However, we observed a significant interaction between age and gender $(p<0.001)$. In the youngest category boys received more antibiotics, and in the older categories girls received more antibiotics. Furthermore, patients with a recorded chronic disease received more antibiotic prescriptions (18.3\%) than in those without a recorded chronic disease $(14.2 \%, p<0.001)$.

The most frequently described antibiotic drugs were penicillin (86\%), followed by macrolides (18\%) and trimethoprim (3\%) (Table 2.2). Antibiotics for which there is no indication in children in general practice were only incidentally prescribed. For example, in the whole cohort fluoroquinolones were prescribed only 22 times in total to children of different ages and tetracyclines were prescribed only 11 times to children younger than 9 years in the years 2000-2010. 
Table 2.1 Multivariate analysis of factors influencing oral antibiotic prescriptions

\begin{tabular}{ll}
\hline 2000-2005 & Odds Ratio (95\% Cl) \\
Time (calendar years) & $1.07(1.05-1.08)$ \\
Age (years) & $0.87(0.86-0.87)$ \\
Chronic disease & $1.64(1.54-1.74)$ \\
2006-2010 & Odds Ratio (95\% Cl) \\
Time (calendar years) & $0.96(0.94-0.97))$ \\
Age (years) & $0.87(0.86-0.87)$ \\
Chronic disease & $1.49(1.39-1.59)$ \\
\hline
\end{tabular}

$\mathrm{Cl}=$ confidence interval.

Table 2.2 Top 5 prescribed oral antibiotic groups

\begin{tabular}{ll}
\hline Antibiotic group (ATC code) & $\begin{array}{l}\text { Relative percentage of total } \\
\text { prescriptions }\end{array}$ \\
\hline Penicillin (J01C) & $86 \%$ \\
Macrolides (JO1F) & $18 \%$ \\
Trimethoprim (J01E) & $3 \%$ \\
Nitrofurantoin (J01XE) & $1 \%$ \\
Tetracyclines (J01A) & $1 \%$
\end{tabular}

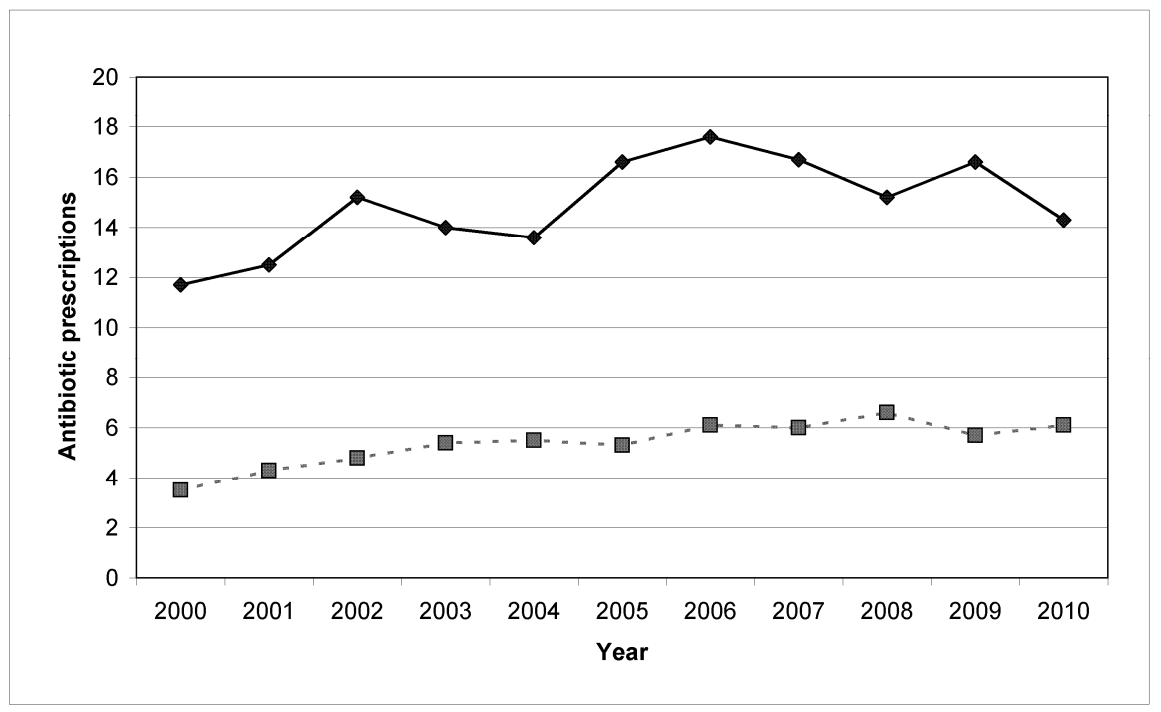

\section{$\multimap$ Oral antibiotics - $\square \cdot$ Topical antibiotics}

Figure 2.1 Prescription rate (\%) for topical and oral antibiotics 2000-2010 


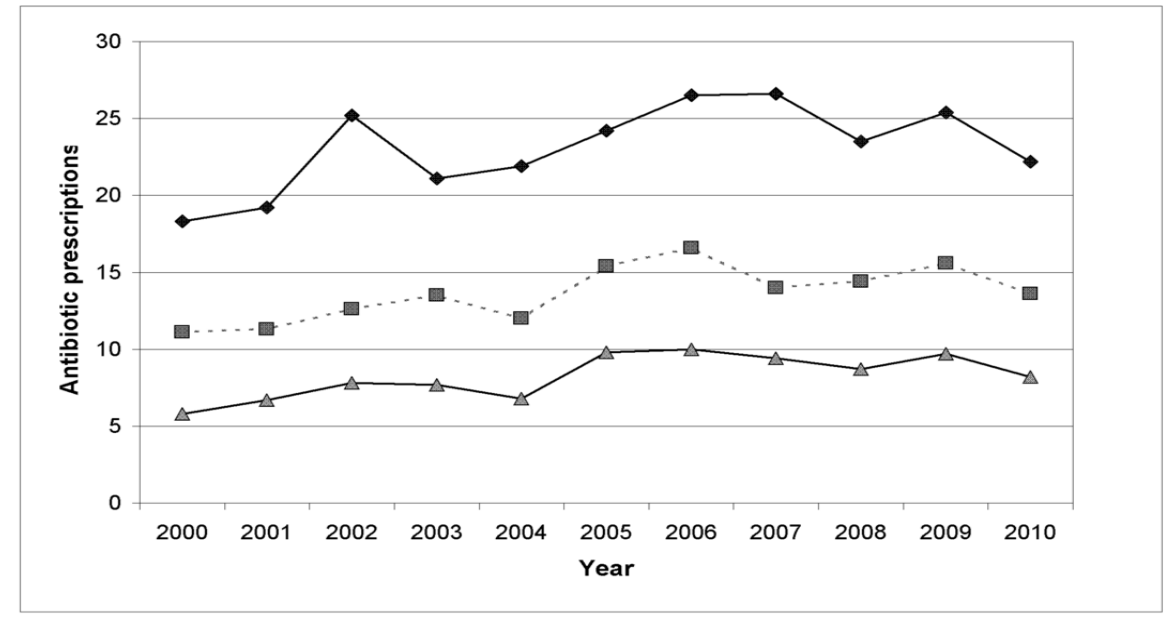

$\longrightarrow-04$ years $\cdots \cdots 5-8$ years $\longrightarrow 9.12$ years

Figure 2.2 Oral antibiotic prescription rate (\%) per age category from 2000-2010 


\section{DISCUSSION}

This large paediatric cohort study shows that almost one in six children received at least one oral antibiotic prescription per year during the period 2000-2010. Of these children one in four received two or more antibiotic prescriptions in a year. We observed a steadily significant increase in prescriptions during the period 2000-2005. However, during the period 2006-2010 a slight but significant decrease in prescriptions for oral antibiotics was observed.

Although Dutch data is limited, one study also showed an increase in prescriptions, based on two point estimates from 1987 and 2001 in a cross sectional survey among GPs. ${ }^{7}$ Another study based on pharmacological database from 1999 to 2005 showed a slightly higher overall prescription rate of $17.8 \%$ and did not show an increase over time during the period 1999-2005. However, this study also included adolescents and was not limited to GPs prescriptions. ${ }^{8}$ An important factor that may have influenced Dutch prescription rates from 2006 onwards is the implementation of the pneumococcal vaccination. All infants in the Netherlands, born after March 2006, received the heptavalent pneumococcal conjugate vaccine at the age of $2,3,4$ and 11 months to protect them against pneumococcal infections (since spring 2011 10-valent vaccine). A recent Norwegian study showed that implementation of this vaccine led to a reduced incidence of respiratory tract infections and acute otitis media. ${ }^{9}$ A similar trend may have occurred in The Netherlands contributing to the reduction in prescription rates from 2005 to 2010 we observed. A recent Dutch study on invasive pneumococcal disease also showed a strong decrease in vaccine serotype pneumococcal disease. ${ }^{10}$ The decrease in prescription rates in older age categories who were not vaccinated may be explained by the so called "herd immunity" effect, as was also observed in previous studies in the USA. ${ }^{11,12}$

Another notable finding was that in the youngest age category boys received more antibiotics than girls, while this was reversed in the older age categories. This was observed in earlier studies as well, and is potentially caused by a higher incidence of respiratory infections in boys during early childhood. The underlying mechanism for this difference has however not been disentangled. ${ }^{7,9,13}$

Prescription rates were significantly higher in children with a chronic disease, of which asthma was the most common. This could be explained by the fact that children with asthma are more prone to respiratory infections. However, it could also implicate that in cases of often self-limiting respiratory infections GPs tend to prescribe more antibiotics in children with comorbidity of asthma. Previous studies have however shown that in these patients earlier treatment with antibiotics does not improve their recovery or risk of 
complications. ${ }^{14}$ Still, since the prescription rates in our database are not linked to consultations - being the major limitation of our data source and thus our study - we can only make assumptions.

Finally, results show that GPs seldom prescribe antibiotics for which there is no indication in general practice. For example, the use of tetracyclines in children younger than 9 years of age is contraindicated and prescribed only 11 times in our study. Previous studies showed prescription rates for tetracyclines that were similarly to the findings in our study. ${ }^{7,15}$ As expected according to guidelines, penicillin was the most frequent prescribed oral antibiotic group. Furthermore, the most frequently described and preferential topical antibiotic in The Netherlands is fusidic acid.

This is the first and only study over a period of ten years which is based on actual GP prescription data to children. Other studies were based on general pharmacological databases or limited to specific diseases or indications. Moreover, this is the first study that provides information on topical antibiotic prescription rates, which is relevant as topical antibiotics are frequently used for common paediatric skin and eye infections in general practice. The key strength of this study is the long study period and the large, representative study population. Reliability of the data is high due to the fact that the database is computerized and GPs and other users of the database are trained on a regular basis. The RNH database has a comparable sociodemographical character to the Dutch population, therefore the data are highly generalizable. ${ }^{5}$ This study does however have some limitations. As previously stated, the most important limitation is that the database does not allow us to match prescription data to diagnostic labels. Another study based on the Netherlands Information Network of General Practice and limited to ear, nose and throat problems stated that incidence rates, antibiotic prescriptions, and referrals of common ear, nose and throat problems remained stable in a period from 2002 to $2008 .^{16}$ On the contrary, another recent study showed that primary care rates in consultations for respiratory tract infections increased considerably from 1995 to $2005 .{ }^{17}$ An increased consultation rate could attribute to the increased prescription rates we observed from 2000 to 2005 , and this should be taken into account when cautiously trying to frame these results in the existing literature.

In summary, this study showed that oral antibiotic prescription rates significantly increased during the period 2000-2005 and significantly decreased during the period 2006-2010, for all age-categories of children $<12$ years. Moreover, we presented that in $5.3 \%$ of the 
Chapter 2

patient-years at least one topical antibiotic was prescribed. With no existing data on topical antibiotic prescribing rates in children, this finding calls for international comparison. 


\section{REFERENCES}

1. Kuyvenhoven MM, van Balen FA, Verheij TJ. Outpatient antibiotic prescriptions from 1992 to 2001 in the Netherlands. J Antimicrob Chemother. 2003;52:675-8.

2. Christakis DA, Wright JA, Taylor JA, Zimmerman FJ. Association between parental satisfaction and antibiotic prescription for children with cough and cold symptoms. Pediatr Infect Dis J. 2005;24:774-7.

3. Clavenna A, Bonati M. Differences in antibiotic prescribing in paediatric outpatients. Arch Dis Child. 2011;96:590-5.

4. Eady EA, Cove JH. Topical antibiotic therapy: current status and future prospects. Drugs Exp Clin Res. 1990;16:423-33.

5. van den Akker MJ, Limonard C, Knotnerus J. General Practice: a gold mine for research: Data and scientific use of the Registration Network Family Practices.: RNH, Department of General Practice, Maastricht University. 2004.

6. Hofmans-Okkes IM, Lamberts $H$. The International Classification of Primary Care (ICPC): new applications in research and computer-based patient records in family practice. Fam Pract. 1996;13:294-302.

7. Otters HB, van der Wouden JC, Schellevis FG, van Suijlekom-Smit LW, Koes BW. Trends in prescribing antibiotics for children in Dutch general practice. J Antimicrob Chemother. 2004;53:361-6.

8. de Jong J, van den Berg PB, de Vries TW, de Jong-van den Berg LT. Antibiotic drug use of children in the Netherlands from 1999 till 2005. Eur J Clin Pharmacol. 2008;64:913-9. 9. Magnus MC, Vestrheim DF, Nystad W, Haberg SE, Stigum H, London SJ, et al. Decline in Early Childhood Respiratory Tract Infections in the Norwegian Mother and Child Cohort Study after Introduction of Pneumococcal Conjugate Vaccination. Pediatr Infect Dis J. 2012;31:951-5.

10. Elberse KE, van der Heide HG, Witteveen S, van de Pol I, Schot CS, van der Ende A, et al. Changes in the composition of the pneumococcal population and in IPD incidence in The Netherlands after the implementation of the 7-valent pneumococcal conjugate vaccine. Vaccine. 2012;30:7644-51.

11. Weil-Olivier C, van der Linden M, de Schutter I, Dagan R, Mantovani L. Prevention of pneumococcal diseases in the post-seven valent vaccine era: A European perspective. BMC Infect Dis. 2012;12:207.

12. Haber M, Barskey A, Baughman W, Barker L, Whitney CG, Shaw KM, et al. Herd immunity and pneumococcal conjugate vaccine: a quantitative model. Vaccine. 2007;25:5390-8. 
13. Jensen-Fangel S, Mohey R, Johnsen SP, Andersen PL, Sorensen HT, Ostergaard L. Gender differences in hospitalization rates for respiratory tract infections in Danish youth. Scand J Infect Dis. 2004;36:31-6.

14. Hopstaken RM, Coenen S, Butler CC, Nelemans P, Muris JW, Rinkens PE, et al. Prognostic factors and clinical outcome in acute lower respiratory tract infections: a prospective study in general practice. Fam Pract. 2006;23:512-9.

15. Majeed A, Moser K. Age- and sex-specific antibiotic prescribing patterns in general practice in England and Wales in 1996. Br J Gen Pract. 1999;49:735-6.

16. Uijen JH, Bindels PJ, Schellevis FG, van der Wouden JC. ENT problems in Dutch children: trends in incidence rates, antibiotic prescribing and referrals 2002-2008. Scand J Prim Health Care. 2011;29:75-9.

17. Van Deursen AM, Verheij TJ, Rovers MM, Veenhoven RH, Groenwold RH, Bonten MJ, et al. Trends in primary-care consultations, comorbidities, and antibiotic prescriptions for respiratory infections in The Netherlands before implementation of pneumococcal vaccines for infants. Epidemiol Infect. 2012;140:823-34. 
HAPTER 3

\section{Workload and management of childhood fever at general practice out-of-hours care: an observational cohort study}

Eefje G.P.M. de Bont Julie M.M. Lepot

Dagmar A.S. Hendrix

Nicole Loonen Yvonne Guldemond-Hecker Geert-Jan Dinant Jochen W.L. Cals

BMJ Open. 2015;5:e007365. 



\section{ABSTRACT \\ Objective}

Even though childhood fever is mostly self-limiting, children with fever constitute a considerable workload in primary care. Little is known about the number of contacts and management during General Practitioners (GPs) out-of-hours care. We investigated all fever related telephone contacts, consultations, antibiotic prescriptions and paediatric referrals of children during GP out-of-hours care within one year.

\section{Design}

Observational cohort study.

\section{Setting and patients}

We performed an observational cohort study at a large Dutch GP out-of-hours service. Children (< 12 years) whose parents contacted the GP out-of-hours service for a fever related illness in 2012 were included.

\section{Main outcome measures}

Number of contacts and consultations, antibiotic prescription rates and paediatric referral rates.

\section{Results}

We observed an average of 14.6 fever related contacts for children per day at GP out-ofhours services, with peaks during winter months. Out of 17170 contacts in 2012, 5343 (31.1\%) were fever related and $70.0 \%$ resulted in a GP consultation. One in four consultations resulted in an antibiotic prescription. Prescriptions increased by age and referrals to secondary care decreased by age $(p<0.001)$. The majority of parents $(89.5 \%)$ contacted the out of hours service only once during a fever episode $(89.5 \%)$ and $7.6 \%$ of children are referred to secondary care.

\section{Conclusions}

This study shows that childhood fever does account for a large workload at GP out-of-hours services. One in three contacts is fever related and $70 \%$ of those febrile children are called in to be assessed by a GP. One in four consultations for childhood fever results in antibiotic prescribing and most consultations are managed in primary care without referral. 


\section{INTRODUCTION}

Fever in children is a common reason for parents to consult in primary care in general and general practice (GP) out-of-hours services in particular. ${ }^{1,2}$ Even though childhood fever is mostly self-limiting and usually does not require treatment, it constitutes to a considerable workload, especially in primary care. ${ }^{3}$ A European study showed that a quarter of the outof-hours consultations are for children under the age of 12 years. Of these consultations, infections and fever are the most common reasons for encounter. ${ }^{2}$

In the Netherlands, GP out-of-hours care is organised in large scale GP cooperatives. ${ }^{4}$ After working hours, parents of a febrile child are referred to these GP cooperatives when they contact their GP. Telephonic contacts are then handled by trained triage nurses who work according to the Dutch Triage System. ${ }^{5,6}$ Parents can either receive advice from the nurse or are offered a consultation with one of the GPs on call.

Though there have been some studies investigating antibiotic prescription rates during GP out-of-hours at present it is largely unknown how great the exact workload of childhood fever during GP out-of-hours care is and which management strategies (telephone advice, medication prescription, referral to a paediatrician) are being executed by GPs and triage nurses on call. In other words, we know something about antibiotic prescriptions and the proportion of fever related consultation rates, but an overall overview what happens with febrile children that visit a GP out-of-hours cooperative is lacking. In order to develop interventions to increase parental self-management strategies, to reduce medicalization of mostly self-limiting common infections and thereby reduce pressure on the workload in general practice, it is important to know how childhood fever contacts are managed during out-of-hours care.

This study assesses the number of childhood fever related contacts, the number of contacts leading to a consultation, resulting antibiotic prescriptions, paediatric referrals and reconsultations for children under the age of 12 during out-of-hours care in the Netherlands. 


\section{METHODS}

\section{Design and setting}

GP out-of-hours services in the Netherlands are organised in large-scale cooperatives. There are 120-130 GP out-of-hours services in the Netherlands, varying from 50-200 GPs. ${ }^{7}$ These cooperatives cover primary care by rotating shifts of GPs during evening, nights and weekends. For this observational study we used the medical record database of the Nightcare GP cooperative out-of-hours service in Heerlen (The Netherlands).The Nightcare GP out-of-hours service, is located in a multi-ethnic, moderate to low socio-economic area, consists of 132 GPs providing care to approximately 270,000 inhabitants living in this South-Eastern district. ${ }^{8}$ As of such it is one of the larger out-of-hours services in the Netherlands.

\section{Data collection and variables}

GPs and triage nurses at the out-of-hours service are obliged to digitally enter all information. The registered patient data consist of information from telephone triage, given advice, consultation report, (working)diagnosis, International Classification for Primary Care (ICPC) code, ${ }^{9}$ treatment and prescribed medication. Children were defined as having fever, and thus eligible for inclusion, if they met one of the following criteria: fever reported by parents at the initial telephone contact, either mentioned or measured; fever mentioned during the consultation or febrile convulsion.

First, we retrieved the anonymised medical records of all children $<12$ years whose parents contacted the GP out-of-hours service between January $1^{\text {th }} 2012$ and December $31^{\text {th }} 2012$. All contacts, including reconsultations of a child during the same episode of illness were selected. A contact (telephonic advice or consultation) occurring within the same fever episode, within 7 days after the initial contact, was considered a reconsultation. To select all children with fever, different procedures were executed. First, we sorted selected contacts by ICPC code and we selected children with fever related ICPC codes. ${ }^{9}$ Contacts where the triage nurse selected fever as key symptom were also selected. We then manually searched the remaining contacts on terms synonym to fever and temperature to ensure no contacts were missing. We distinguished a temperature of $<38^{\circ} \mathrm{C}$ (no fever), $\geq$ $38^{\circ} \mathrm{C}$ (fever) and unknown temperature.

When contacting the out-of-hours service parents could be offered a telephonic advice from a triage nurse or a consultation (face-to-face contact with the GP at the out-of-hours service). For those children receiving a consultation, we classified management into three groups: no medication prescription; prescription for medication; referral to secondary care. 
Prescribed medication was divided in the following groups: antibiotics, over-the-counter medication or other medication.

\section{Data analysis}

Data were analysed using SPSS version 19.0. Analysis was based on frequencies and descriptive statistics and Chi-square $(\chi 2)$ tests were performed to identify independent associations for antibiotic prescriptions (yes/no) and referral to secondary care (yes/no) as independent outcomes. We also analysed the number of contacts per month to examine seasonal influence. 


\section{RESULTS}

\section{Population characteristics}

In 2012, there were 78514 contacts and 39519 consultations in total for all age-categories at the out-of-hours centre. Of these contacts, 17170 contacts were for children $<12$ years, of which 5343 (31.1\%) were fever related (Figure 3.1). Mean age was 2.8 years (SD +/- 2.5 years). Gender and age distribution are presented in Table 3.1. Most fever related contacts were for children of 1-5 years (Table 3.2). In 2012 there were on average 14.6 fever related contacts for children per day, with peaks in workload during the months December to April (Figure 3.2). Seventy per cent of all fever related contacts resulted in a GP consultation (Figure 3.1). The most frequently used ICPC codes were A99.00 (General disease not specified; 74.3\%), A03.00 (Fever; 4.1\%), H71.00 (Acute otitis media; 4.2\%), and R74.00 (Upper respiratory infection acute; $4.8 \%$ ).

Table 3.1 Characteristics of the study population $(n=5343)$

\begin{tabular}{ll}
\hline Characteristics & Number of contacts (\%) \\
Male sex & $2830(53)$ \\
Age distribution & \\
$<1$ month & $13(0.2)$ \\
1-3 months & $207(3.9)$ \\
3-6 months & $310(5.8)$ \\
6-12 months & $902(16.9)$ \\
1-5 years & $2943(55.1)$ \\
$\geq 5$ years & $968(18.1)$ \\
\hline
\end{tabular}

Table 3.2 Fever related contacts: distribution of phone advice and consultation by age

\begin{tabular}{|c|c|c|c|c|c|c|c|}
\hline & $\begin{array}{l}<1 \\
\text { month } \\
n=13\end{array}$ & $\begin{array}{l}1-3 \\
\text { months } \\
n=207\end{array}$ & $\begin{array}{l}3-6 \\
\text { months } \\
n=310\end{array}$ & $\begin{array}{l}6-12 \\
\text { months } \\
n=902\end{array}$ & $\begin{array}{l}1-5 \\
\text { years } \\
n=2943\end{array}$ & $\begin{array}{l}5-12 \\
\text { years } \\
n=968\end{array}$ & $\begin{array}{l}\text { Total } \\
n=5343\end{array}$ \\
\hline $\begin{array}{l}\text { Phone advice } \\
\mathrm{N}(\%)\end{array}$ & $\begin{array}{l}1 \\
(7.7)\end{array}$ & $83(40.1)$ & $88(28.4)$ & $\begin{array}{l}306 \\
(33.9)\end{array}$ & $\begin{array}{l}860 \\
(29.2)\end{array}$ & $\begin{array}{l}267 \\
(27.6)\end{array}$ & $\begin{array}{l}1605 \\
(30.0)\end{array}$ \\
\hline $\begin{array}{l}\text { Consultation } \\
\mathrm{N}(\%)\end{array}$ & $\begin{array}{l}12 \\
(92.3)\end{array}$ & $\begin{array}{l}124 \\
(59.9)\end{array}$ & $\begin{array}{l}222 \\
(71.6)\end{array}$ & $\begin{array}{l}596 \\
(66.1)\end{array}$ & $\begin{array}{l}2083 \\
(70.8)\end{array}$ & $\begin{array}{l}701 \\
(72.4)\end{array}$ & $\begin{array}{l}3738 \\
(70.0)\end{array}$ \\
\hline
\end{tabular}

\section{Management}

GPs prescribed medication in $40.6 \%$ of consultations. One in four consultations for childhood fever resulted in an antibiotic prescription (Table 3.3). Antibiotic prescription increased significantly with age (Table 3.4, p<0.001). Of all fever related contacts 283 (7.6\%) children were referred to secondary care. The number of referrals to secondary care decreased with increasing age, from $66.7 \%$ for children younger than 1 month to $6.0 \%$ for 
children in the age category of $5-12$ years (Table $3.4, p<0.001$ ). We found no relationship between gender and prescription or referral rates.

Table 3.3 Management of fever related consultations for children $<12$ years

\begin{tabular}{|c|c|}
\hline Consultation & $N=3738^{a}(\%)$ \\
\hline No prescription & 1939 (51.9) \\
\hline Prescription ${ }^{b}$ & $1516(40.6)$ \\
\hline - $\quad$ Antibiotics & $936(25.0)$ \\
\hline - $\quad$ OTC & 302 (8.1) \\
\hline - $\quad$ Other medication & $278(7.4)$ \\
\hline Referral to secondary care & $283(7.6)$ \\
\hline
\end{tabular}

Table 3.4 Antibiotic prescriptions and secondary care referrals during consultations, by age group

\begin{tabular}{llll}
\hline Age-category & $\begin{array}{l}\text { Number of GP } \\
\text { consultations }\end{array}$ & $\begin{array}{l}\text { Number of antibiotic } \\
\text { prescriptions (\%) }\end{array}$ & $\begin{array}{l}\text { Number of secondary care } \\
\text { referrals } \mathbf{n}(\%)\end{array}$ \\
\hline 1 month & 12 & $0(0)$ & $8(66.7)$ \\
$1-<3$ months & 124 & $0(0)$ & $27(21.8)$ \\
$3-<6$ months & 222 & $30(13.5)$ & $34(15.3)$ \\
$6-<12$ months & 596 & $114(19.1)$ & $40(6.7)$ \\
$1-<5$ years & 2083 & $573(27.5)$ & $132(6.3)$ \\
$5-<12$ years & 701 & $219(31.2)$ & $42(6.0)$ \\
\hline
\end{tabular}

\section{Temperature and Reconsultations}

GPs failed to report a temperature in one-third of the consultations. There were 3793 individual children accounting for 5343 fever related contacts. This results in an average of 1.3 (SD \pm 0.6$)$ contacts per child for whose parents contacted the out-of-hours service that year. In total $89.5 \%$ of the parents contacted the out-of-hours service only once during a fever episode. For the remaining contacts, the number of reconsultations for one illness episode ranged from 2 to 4 times. 


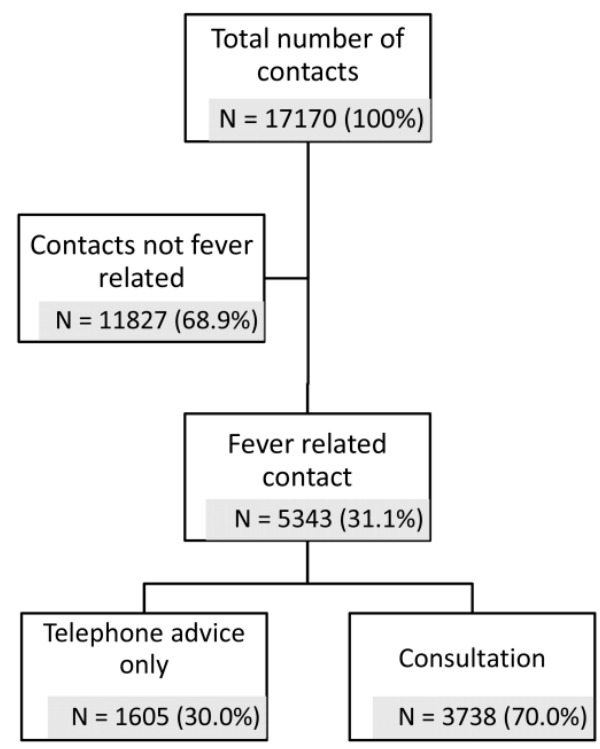

Figure 3.1 Flow chart of all children $<12$ years contacting the GP out-of-hours service

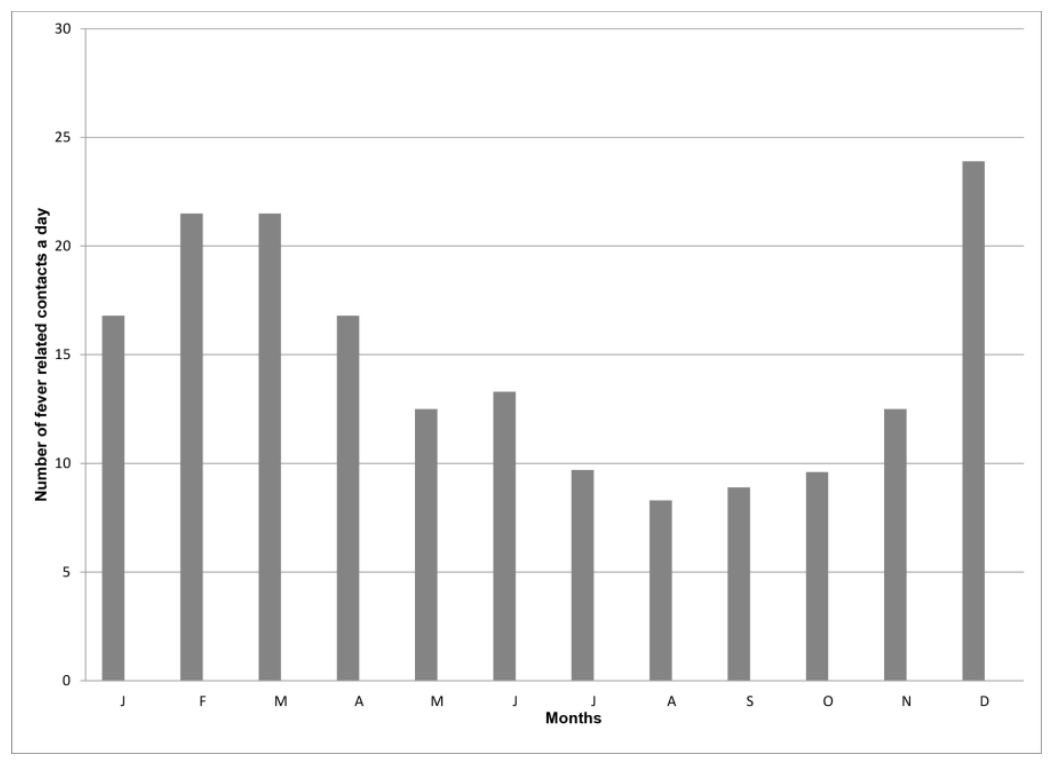

Figure 3.2 Daily distribution per month of contacts of febrile children $<12$ years in 2012 


\section{DISCUSSION}

\section{Main Findings}

This study shows that $31 \%$ of the total 17170 contacts for children under the age of 12 years at GP out-of-hours care are fever related. Most contacts were for children in the age category 1-5 years, and of all fever related contacts $70 \%$ resulted in a GP consultation. During one in four consultations antibiotics were prescribed and more than $92 \%$ of childhood fever consultations were managed by GPs without referral to secondary care. Most parents (89.5\%) contacted the out-of-hours service only once during a fever episode.

\section{Comparison with existing literature}

When examining consultation rates across different age categories, there are several interesting aspects to consider. In agreement with the advice of the Dutch College of General Practitioners to see children $<1$ month with a fever as soon as possible the consultation rate was higher for these children $(92.3 \%) .{ }^{10}$ The small number of children under the age of 1 month ( $n=13$ ) could be explained by the intensive care provided directly after birth by the maternity care centres and the well-baby centres, making parents seek other medical help less often. Surprisingly, consultation rates for children between 1 month and 3 months old were below the average with 59.9\%, even though the advice for this age is to see them within one day. ${ }^{10}$ The difference in consultation rate for this age category could be explained by the fact that in The Netherlands children receive their first vaccination within 6 till 9 weeks after birth, and one of the most common side effects of this specific vaccination is fever. Triage nurses might give more often telephone advice instead of a consultation when fever is related to vaccination, in line with national recommendations. However, GPs and triage nurses should realise that if a fever is not vaccine related children aged 1-3 months should be called in to be assessed by a GP during out-of-hours care. As expected in agreement with the guidelines and incidence rates of infections, the number of referrals to secondary care decreased with age. ${ }^{11}$

We also found that GPs failed to report a temperature in one-third of the consultations. This is in agreement with a previous study that showed that overall documentation of vital signs by GPs is relatively poor in children presenting with acute infections. ${ }^{12}$

The overall prescription rate during consultations was high (40.6\%). Of the prescribed medications, 19.9\% were over-the-counter drugs (OTC). An explanation for prescribing OTC could be that GPs prescribed medication to give parents 'something' instead of leaving them empty-handed. Another explanation could be that by prescribing OTC, GPs and parents experience more certainty that the correct drug was prescribed. The prescription 
of OTC is an underestimation of the use of OTC after the consultation since advices by the GP to use OTC drugs are not included. Since the telephone contacts are handled by triage nurses, there were no telephonic prescriptions. This is different from other countries where (topical) antibiotics are even prescribed by telephone. ${ }^{13}$

The antibiotic prescription rate of $25 \%$ in this study was somewhat lower than previously described $36.3 \%{ }^{14}$ and $36.5 \%{ }^{15}$ in other Dutch studies. A possible explanation for the difference between our study and the two previous Dutch studies could be that we used different inclusion criteria leading to a different illness severity and other prescription behaviour. Both our study and these previous studies describe an increase of antibiotic prescription by age, which is in agreement with a Norwegian study among children with respiratory tract infections during day time GP care. ${ }^{16}$ However, another study among children during regular day time care showed the contrary. ${ }^{17}$ One explanation for this difference could be that older children who are assessed during GP out-of-hours care are potentially more severely ill than those children who are assessed during regular day time GP care. Moreover, parents of young children might be worried sooner resulting in increased and more frequent out-of-hours attendance, with a larger proportion of younger children having self-limiting infections not requiring treatment. This was also found in a study examining which urgent care services parents of febrile children use. ${ }^{18}$ However, there are no studies comparing illness severity of febrile children consulting during daytime and out-of-hours care meaning these are only hypothesis. Moreover, these studies had different inclusion criteria also explaining potential differences.

\section{Strength and Limitations}

This is the first study providing insight into the workload of childhood fever at a GP out-ofhours centre during a full year. The most important strengths of this study were the number of participants and the fact that data of these children were routinely collected during normal GP out-of-hours hours care. GPs and triage nurses did not know we were studying their management and could therefore not adapt their behaviour to desirable outcomes.

The aim of the study was to obtain more detailed insight into fever related contacts for children and the associated workload during GP out-of-hours care. For this reason we chose a broad definition for fever related contacts, namely children who subjectively presented with fever during the initial telephone contact with the out-of-hours service. By selecting children who subjectively presented with fever, these results could be an 
overestimation of the number of children actually having fever. An important limitation of this study is the fact that because we used actual medical records, we are dependent on the individual GPs quality of keeping such medical records. Meaning these data are always dependent on the interpretation of the triage nurses and GPs and their completeness of filling in these records. An important observation that illustrates this is the fact that the most common used ICPC code by far was A99.00 (General disease not specified), which suggests that instead of using the ICPC code to specify a disease it is probably considered as an obligation to fill in. As the data also showed, there is still a lot of room for improvement when it comes to systematically registering, for example, a vital sign as the temperature that was measured. We do not know to what extend this affected the validity of our results. Because registration is sometimes lacking we cannot exclude the possibility that this is an under registration and there are more fever related contacts than we were able to identify. However, we took several steps to enhance the completeness of the data and believe that these data are indispensable to obtain a pragmatic overview of the workload of childhood fever during GP out-of-hours care.

In this study, we only reported reconsultations at the out-of-hours service; data regarding re-contacts during regular hours care are missing. This means that the number of reconsultations is likely an underestimation of the real number of contacts for that common infection episode.

Although we only used data from one GP out-of-hours service, we think that our findings can be generalised to other out-of-hours services in The Netherlands, since all GP out-ofhours services in The Netherlands are organized in the same way and do work with the same Dutch guidelines and triage reporting system. ${ }^{6}$ In addition, the organisation of out-ofhours health care in Scandinavia, Australia and the UK is comparable, at least to a certain extent, making these results also relevant for other countries. ${ }^{4}$ However, it is important to realise that this was a single centre study and that results should be generalized only with great caution, especially considering the fact that the average education level in this region is lower than the national average. ${ }^{19}$

\section{Practice implications}

This study shows that childhood fever constitutes a considerable workload in GP out-ofhours services with many initial contact leading to face-to-face consultations with a GP and we additionally showed that antibiotic prescription rates are still high during out-of-hours care, leaving room for improvement for mostly self-limiting illnesses. 
On the other hand, we acknowledge that although some contacts could potentially be prevented by increasing parental self-management strategies, some children definitely need to be assessed and a subgroup of children presenting to out-of-hours general practice do need antibiotics to treat serious infections. Differentiating these cases from the large group with self-limiting symptoms can be challenging, especially in a setting where the GP typically does not know the child and its family. ${ }^{20}$ Since GPs did not report a temperature in $30 \%$ of the fever related consultations, it is important to draw attention to complete registration of vital characteristics such as temperature, as well as to facilitate the development of better predictors of serious infections in general practice. ${ }^{21}$ Future research should provide insights into the motivations and expectations of (frequent attending) parents when they contact the GP out-of-hours service, alongside the motivations of GPs to prescribe antibiotics in these patients, thereby providing leads for interventions aimed to reduce the number of consultations and antibiotic prescriptions, without increasing complications and while providing proper safety netting for parents who typically seek reassurance. 22,23 Previous studies have shown that an information exchange tool is effective in reducing the number of antibiotic prescriptions and intention to reconsult in children with upper respiratory tract infections ${ }^{24}$ and that such a tool can provide a safety net advice for parents. ${ }^{25}$ We believe that this strategy could also be used in children presenting with a fever.

\section{Conclusion}

This study shows that the GP's perception of seeing many febrile children during out-ofhours care is true as childhood fever does actually account for a large workload at GP outof-hours services. One in three contacts is fever related and $70 \%$ of those febrile children are called in to be assessed by a GP. One in four consultations for childhood fever results in antibiotic prescribing and most consultations are managed in primary care without referral. Future research should provide deeper insights into the motivations and expectations of parents and GPs who prescribe antibiotics in these patients, thereby providing leads for interventions aimed to reduce the number of consultations and antibiotic prescriptions for febrile children during out-of-hours care. 


\section{REFERENCES}

1. Hay AD, Heron J, Ness A. The prevalence of symptoms and consultations in preschool children in the Avon Longitudinal Study of Parents and Children (ALSPAC): a prospective cohort study. Fam Pract. 2005;22:367-74.

2. Huibers LA, Moth G, Bondevik GT, Kersnik J, Huber CA, Christensen MB, et al. Diagnostic scope in out-of-hours primary care services in eight European countries: an observational study. BMC Fam Pract. 2011;12:30.

3. Whitburn S, Costelloe C, Montgomery AA, Redmond NM, Fletcher M, Peters TJ, et al. The frequency distribution of presenting symptoms in children aged six months to six years to primary care. Prim Health Care Res Dev. 2011;12:123-34.

4. Huibers L, Giesen P, Wensing M, Grol R. Out-of-hours care in western countries: assessment of different organizational models. BMC Health Serv Res. 2009;9:105.

5. van lerland Y, van Veen M, Huibers L, Giesen P, Moll HA. Validity of telephone and physical triage in emergency care: the Netherlands Triage System. Fam Pract. 2011;28:33441.

6. De Nederlandse Triage Standaard. http://www.de-nts.nl/ [cited 2014].

7. Giesen P. SM, Huibers L., Grol R., Wensing M. Quality of after-hours primary care: As narrative review of the Dutch solution. Ann Intern Med. 2011;155:108-13.

8. Huisartsen Oostelijk Zuid-Limburg. Organisatie 2013. Available from: http://www.huisartsen-ozl.nl/.

9. World Organization of National Colleges Academies and Academic Associations of General Practitioners. ICPC : international classification of primary care. Oxford England ; New York: Oxford University Press; 1987.

10. Oteman N, Berger MY, Boomsma LJ, Wiersma TJ, Goudswaard AN, Nederlands Huisartsen G. Summary of the practice guideline 'Children with fever' (Second Revision) from the Dutch College of General Practitioners. Ned Tijdschr Geneeskd. 2008;152:2781-6.

11. Van den Bruel A, Bartholomeeusen S, Aertgeerts B, Truyers C, Buntinx F. Serious infections in children: an incidence study in family practice. BMC Fam Pract. 2006;7:23.

12. Blacklock C, Haj-Hassan TA, Thompson MJ. When and how do GPs record vital signs in children with acute infections? A cross-sectional study. $\mathrm{Br} J$ Gen Pract. 2012;62:e679-86.

13. Huibers L, Moth G, Christensen MB, Vedsted P. Antibiotic prescribing patterns in out-of-hours primary care: a population-based descriptive study. Scand J Prim Health Care. 2014;32:200-7. 
14. Elshout G, Kool M, Van der Wouden JC, Moll HA, Koes BW, Berger MY. Antibiotic Prescription in Febrile Children: A Cohort Study during Out-of-Hours Primary Care. J Am Board Fam Med. 2012;25:810-8.

15. Elshout $G$, van lerland $Y$, Bohnen AM, de Wilde M, Oostenbrink R, Moll HA, et al. Alarm signs and antibiotic prescription in febrile children in primary care: an observational cohort study. Br J Gen Pract. 2013;63:e437-44.

16. Fossum GH, Lindbaek M, Gjelstad S, Dalen I, Kvaerner KJ. Are children carrying the burden of broad-spectrum antibiotics in general practice? Prescription pattern for paediatric outpatients with respiratory tract infections in Norway. BMJ Open. 2013;3.

17. de Bont EG, van Loo IH, Dukers-Muijrers NH, Hoebe CJ, Bruggeman CA, Dinant GJ, et al. Oral and topical antibiotic prescriptions for children in general practice. Arch Dis Child. 2013;98:228-31.

18. Maguire S, Ranmal R, Komulainen S, Pearse S, Maconochie I, Lakhanpaul M, et al. Which urgent care services do febrile children use and why? Arch Dis Child. 2011;96:810-6.

19. CBS, PBL, Wageningen UR. Hoogopgeleiden 2014 [November 2014]. Available from: $\quad$ http://www.compendiumvoordeleefomgeving.nl/indicatoren/nl2100Opleidingsniveau-bevolking.html? $\mathrm{i}=15-12$

20. Buntinx F, Mant D, Van den Bruel A, Donner-Banzhof N, Dinant GJ. Dealing with low-incidence serious diseases in general practice. Br J Gen Pract. 2011;61:43-6.

21. Nijman RG, Zwinkels RL, van Veen M, Steyerberg EW, van der Lei J, Moll HA, et al. Can urgency classification of the Manchester triage system predict serious bacterial infections in febrile children? Arch Dis Child. 2011;96:715-22.

22. de Bont EG, Francis NA, Dinant GJ, Cals JW. Parents' knowledge, attitudes, and practice in childhood fever: an internet-based survey. Br J Gen Pract. 2014;64:e10-6.

23. Jones $\mathrm{CH}$, Neill S, Lakhanpaul M, Roland D, Singlehurst-Mooney $\mathrm{H}$, Thompson M. Information needs of parents for acute childhood illness: determining 'what, how, where and when' of safety netting using a qualitative exploration with parents and clinicians. BMJ Open. 2014;4:e003874.

24. Francis N, Butler C, Hood K, Simpson S, Wood F, Nuttall J. Effect of using an interactive booklet about childhood respiratory tract infections in primary care consultations on reconsulting and antibiotic prescribing: a cluster randomised controlled trial. BMJ. 2009;339:b2885-b.

25. Francis NA, Phillips R, Wood F, Hood K, Simpson S, Butler CC. Parents' and clinicians' views of an interactive booklet about respiratory tract infections in children: a qualitative process evaluation of the EQUIP randomised controlled trial. BMC Fam Pract. 2013;14:182. 



\section{Development of the}

hypothesis and

interactive booklet

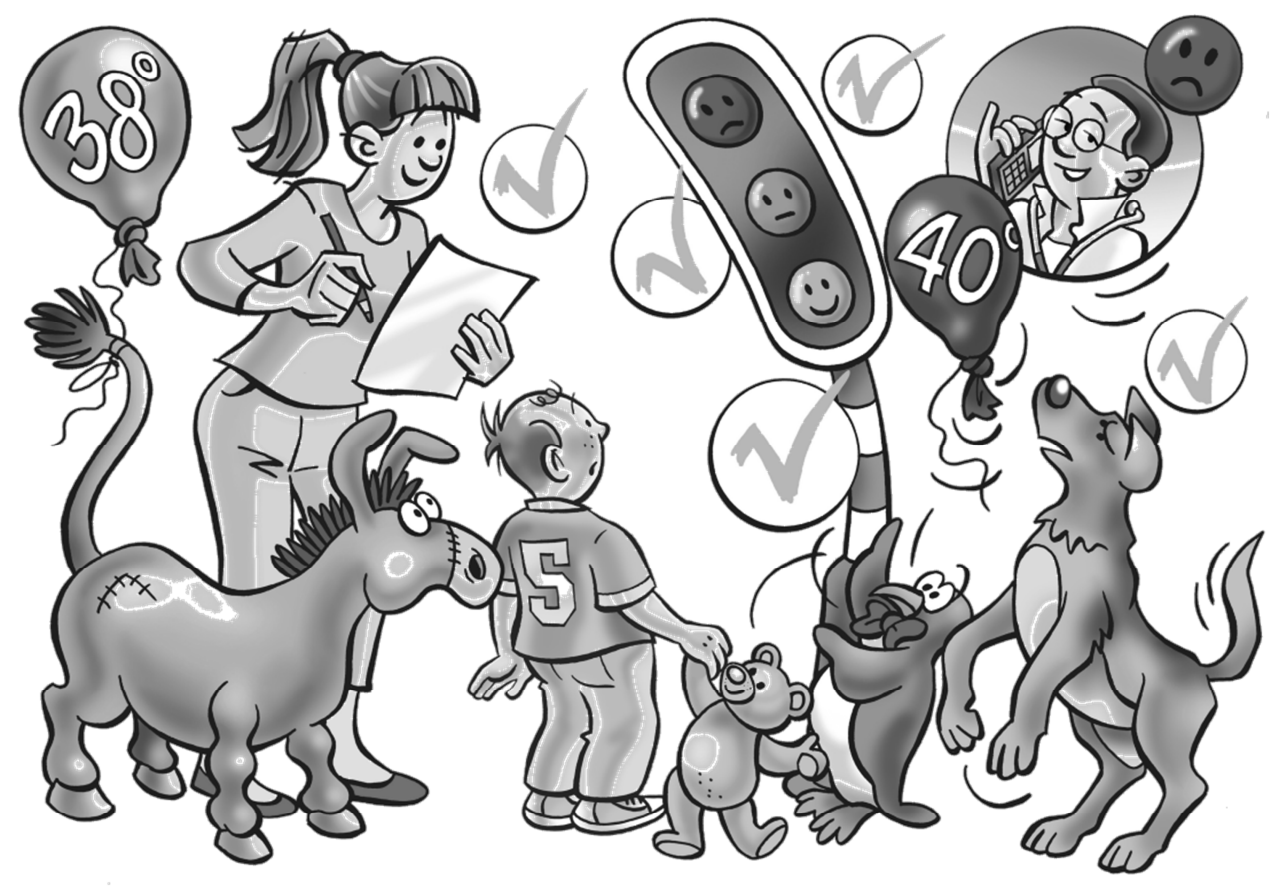



HAPTER 4

\section{Parents' knowledge, attitudes, and practice in childhood fever: an internet- based survey}





\section{ABSTRACT \\ Background}

Fever in children is common and mostly caused by self-limiting infections. However, the number of (re)consultations in primary care is high, driven by lack of knowledge and fear among parents. These drivers have only been studied in parents when consulting with their sick child.

\section{Aim}

To study knowledge, attitudes and practice in childhood fever in parents within the general population.

\section{Design and Setting}

Internet based survey of a sample of 1000 parents from the general population of the Netherlands.

\section{Method}

A 26-item cross-sectional survey was conducted of parents with one or more children ages $<5$ years.

\section{Results}

Of 625 responders (average age 34.9 years) $63.4 \%$ and $43.7 \%$ indicated ever visiting their GP or GP's out-of-hours centre with a febrile child, respectively: 88.3\% knew the definition of fever $\left(>38^{\circ} \mathrm{C}\right), 55.2 \%$ correctly stated that antibiotics are effective in treating bacterial infections and not viral infections, and $72.0 \%$ knew that not every child with a fever needs treatment with antibiotics or paracetamol. When asked to prioritise aspects of a general practitioners consultation $53.6 \%$ considered physical examination as most important. Obtaining a prescription for antibiotics or antipyretics was considered least important.

\section{Conclusion}

Knowledge, attitudes and practices concerning childhood fever varied among parents with young children. Parents generally expect thorough physical examination and information, but not a prescription for medication (antibiotics or antipyretics) when consulting with a feverish child. General practitioners must be aware of these expectations as these provide opportunities to enhance consultations in general and prescription strategies in particular. 


\section{INTRODUCTION}

Fever in children is a common reason to consult in primary care. ${ }^{1,2}$ Most children are diagnosed with self-limiting infections and do not need short-term treatment. However, reconsultation within the same illness episodes is common, especially when fever persists. ${ }^{3}$ Known factors contributing to these (re)consultations are lack of knowledge among parents, anxiety about fever, and experience of inconsistencies in the approach of different health care professionals. ${ }^{4}$ This may lead to parental uncertainty, frustration, dissatisfaction with care and incorrect assumptions about fever in children. Moreover, these factors in combination with a high consultation and reconsultation rate increase health care costs and drive unnecessary antibiotic use.

Since the introduction of the term "fever phobia" 30 years ago, ${ }^{5}$ there have been few studies on changes in parental knowledge and fears, while the availability of information about fever has increased rapidly through use of the internet. The small number of studies that have been conducted were almost exclusively performed in secondary care, and parents were always questioned when children were acutely ill. However, parental knowledge and fear may be strongly influenced by the stressful situation when their child is unwell. Nonetheless, decisions on medication and healthcare-seeking behaviour in acute illness are shaped by public beliefs and knowledge. It is therefore important to understand why and when parents actually consult with their feverish child, what self-management activities they practice, and which information gaps they experience, in order to better target information at parents both within the consultation as well as outside acute care. This study aimed at determining public parental knowledge, attitudes and practices in fever in young children in a nationwide online survey among parents with young children in the general population. 


\section{METHOD}

A cross-sectional internet-based survey was conducted among a randomly selected sample from a community-based nationwide Internet panel of 16,000 individuals (Flycatcher Internet Research BV, Maastricht, the Netherlands) during a 2-week period in December 2012. Six hundred respondents were considered an adequate sample target to ensure generalizability of answers. A response rate of $60 \%$ was expected, 1000 eligible adult respondents (>16 years and all parents) were invited to participate in this study. As consultation for fever in children is highest in the young age-groups, ${ }^{2}$ and to ensure an equal distribution of parity, the sample was divided into two groups of parents: parents with one child ( $\leq 5$ years); and parents with more children, with the youngest being $<5$ years of age. It was hypothesised that parents with more children would express different attitudes and practices based on more experience. The sample that was taken was stratified for gender, age, education level and province to ensure that the sample was an accurate representation of parents with children $<5$ years of age from the Dutch population. Flycatcher is an International Organisation for Standardisation (ISO) certified, independent research organization working according to good clinical practice guidelines, and provides the opportunity to recruit a nationwide sample. Responders receive small rewards for completing surveys, which can be redeemed for vouchers of choice.

The questionnaire was developed by retrieving and defining important domains from literature and by seeking advice from medical experts. Questions to tap these domains were derived from previous international qualitative and quantitative scientific publications and further expert opinion. A pilot among parents was performed to check for face validity, and the wording of some items were modified in the light of this experience. Twenty-six questions with sub-items were included in the final instrument. Response options, including yes/no, agree/disagree and Likert-type scale response items were used as appropriate for each question. The internet-based questionnaire software required respondents to answer a question with sub-items before being able to continue to a next question. There were questions about chronic diseases such as congenital heart and/or lung disease, Down's syndrome, or other conditions that may cause the child to get sick more often or serious than other children. Experiences with severe illnesses in children were queried as it is believed that these events could alter attitudes and practices. A severe illness was defined as an illness requiring hospitalization.

Responders' answers were automatically entered into a data file and were analysed using SPSS (version 19.0). Analysis was based on frequencies and cross tables of pre-selected variables. Chi-square $(\chi 2)$ tests were performed to identify independent associations. 
Predefined dependent variables that were considered relevant were 'accurate knowledge of antibiotic effectiveness' (antibiotics are effective against bacteria but not viruses), 'accurate knowledge of the definition of fever (body temperature higher than $38^{\circ} \mathrm{C}$ based on consensus in international guidelines and literature), 7,8 and 'knowledge on fever treatment' (not every child with a fever needs to be treated with antibiotics or paracetamol). Variables with a p-value $\leq 0.05$ were selected to be included in a multivariate logistic regression model to check for independence of associations. Odds ratios (ORs) with corresponding 95\% confidence intervals (Cls) were calculated. All data were coded and treated according to the "Good Clinical Practice" guidelines. ${ }^{9}$ 


\section{RESULTS}

\section{Participants' characteristics}

Of the 1000 parents who were invited to participate, eight individuals could not be contacted due to incorrect or unavailable e-mail addresses. Of the 992 eligible responders, 625 fully completed the online questionnaire (response rate of 63\%). Response was equally distributed among sex and the predefined parity groups. Parents had a mean age of 34.9 years (SD 5.5, range 19-55 years). Other characteristics are described in table 4.1. Nonresponders had comparable demographic characteristics. Most parents (63.4\%) reported ever visiting a GP with their feverish child, and $43.7 \%$ indicated having visited a GP out-ofhours clinic with their child because of a fever at some point.

Table 4.1 Characteristics of respondents

\begin{tabular}{|c|c|}
\hline Characteristic & Mean/percentage $(n=625)$ \\
\hline Age & 34.9 years, SD 5.5 years \\
\hline Male & $42.9 \%(268)$ \\
\hline \multicolumn{2}{|l|}{ Parity } \\
\hline One child & $51.0 \%(319)$ \\
\hline More children & $49.0 \%(306)$ \\
\hline \multicolumn{2}{|l|}{ Education level } \\
\hline Low & $9.9 \%(62)$ \\
\hline Middle & $42.2 \%(264)$ \\
\hline High & $47.8 \%(299)$ \\
\hline Child with underlying (chronic) condition & $4.6 \%(29)$ \\
\hline Severe illness of child in medical history & $13.0 \%(81)$ \\
\hline Severe illness of child in direct proximity & $23.2 \%(145)$ \\
\hline Ever visited GP with child with fever & $63.4 \%(396)$ \\
\hline Ever visited GP out-of-hours service with child with fever & $43.7 \%(273)$ \\
\hline
\end{tabular}

$S D=$ standard deviation; GP: general practitioner

\section{Knowledge}

Most parents (88.3\%) knew the correct definition of fever (temperature $>38^{\circ} \mathrm{C}$ ). Just over one-half of the participants (55.2\%) correctly stated that antibiotics are effective in treating bacterial infections and not viral infections (Table 4.2). Furthermore, 72\% indicated that not every child with a fever needs to be treated with either antibiotics or paracetamol. These findings were independent of sex, age, or having more than one child (all $p>0.05$ ). However, higher educational level was a predictor for better knowledge on antibiotic effectiveness (high vs. low OR $3.0095 \%$ Cl 1.69 to 5.29, and intermediate vs. low OR 1.96 $95 \% \mathrm{Cl} 1.11$ to 3.48). High education level was also a predictor for better knowledge on fever treatment compared with low education level (OR $3.0195 \% \mathrm{Cl}$ 1.69-5.35). Multivariate analyses were not conducted as level of education was the only eligible variable from univariate analysis. 
Table 4.2 Responders' knowledge and beliefs on fever, and medication in fever and infections

\begin{tabular}{lll}
\hline Statement & Agree ( $\mathbf{n}=)$ & Don't know $(\mathrm{n}=)$ \\
Fever is a temperature $>38^{\circ} \mathrm{C}$ & $88.3 \%(552)$ & - \\
Every child with a fever has an infection & $52.6 \%(329)$ & $8.6 \%(116)$ \\
Antibiotics are effective & & \\
- in treating bacterial but not viral infections & $55.2 \%(345)$ & $9.9 \%(62)$ \\
- in treating infections caused by bacteria & $74.7 \%(467)$ & $12.5 \%(78)$ \\
- in treating infections caused by viruses & $30.4 \%(190)$ & $12.3 \%(77)$ \\
Every child with a fever needs medication (PCM and/or AB) & $28.0 \%(175)$ & $3.2 \%(20)$ \\
Every child with a fever needs paracetamol & $26.9 \%(168)$ & $11.7 \%(73)$ \\
Every child with a fever needs antibiotics & $6.4 \%(40)$ & $5.3 \%(33)$ \\
\hline
\end{tabular}

"-" not applicable, $P C M=$ paracetamol, $A B=$ antibiotics

\section{Attitudes and concerns}

Most parents (81.1\%) acknowledged that they believed fever to cause discomfort for their children. Around one in five (18.4\%) stated that they worried about health consequences of fever in general, and more than one in three indicated that they were afraid fever might cause dehydration (34.9\%) or febrile convulsions (36.8\%). Only $13.3 \%$ of parents were concerned that fever could cause brain damage. No significant difference was observed in attitudes and concerns between parents with one or more children. However, parents who indicated that their child ever experienced a serious illness were more concerned about the possibility of febrile convulsions (OR $1.7295 \% \mathrm{Cl} 1.07$ to 2.75 ). This was also the case for parents who ever saw a child with a serious illness in close proximity necessitating hospital admission (OR $2.2595 \% \mathrm{Cl} 1.54$ to 3.28).

\section{Practice and experience}

Most parents (76.6\%) normally use rectal thermometers. Ear thermometers (17.4\%) and axillary $(1.4 \%)$ or oral $(1.1 \%)$ measurement techniques were less commonly used. Most parents (64.2\%) believed that feeling the forehead or skin can indicate whether their child has fever or not. If unwell, most parents (71.5\%) measure their child's temperature two or three times a day.

Nearly all parents (91.4\%) indicated that they commonly treat their feverish child with antipyretics like paracetamol. Only $2.8 \%$ of parents indicated doing so at a temperature lower than $38^{\circ} \mathrm{C}$, and $86.9 \%$ would use antipyretics without consulting a doctor first. Table 4.3 shows that antipyretic use for fever differed substantially depending on concomitant symptoms. 
The most frequently mentioned symptom combination urging a GP consultation was a fever for more than three days (81.3\%). Only $2.7 \%$ of the parents answered they visit their GP with their child most often or always for a fever in general (Table 4.3).

Table 4.3 Intention to administer paracetamol and/or visit a GP in specific symptom combinations

\begin{tabular}{lll}
\hline Specific situations & Intention to give paracetamol $(\mathrm{n}=)$ & Intention to visit GP $(\mathrm{n}=)$ \\
Fever in general & $20.2 \%(126)$ & $2.7 \%(17)$ \\
Fever and less fluid intake & $27.2 \%(170)$ & $15.5 \%(97)$ \\
Fever and drowsiness & $34.2 \%(214)$ & $40.6 \%(254)$ \\
Fever and a skin rash & $23.4 \%(146)$ & $39.2 \%(245)$ \\
Fever and unstoppable crying & $46.9 \%(293)$ & $34.6 \%(216)$ \\
Fever and in pain & $61.8 \%(386)$ & $45.4 \%(284)$ \\
\hline
\end{tabular}

\section{Parents' expectations and information seeking behaviour}

The elements of a consultation for childhood fever that parents value most (from a list of eight aspects presented to them) are shown in Table 4.4. The most important aspect, prioritised by $53.6 \%$, was a physical examination. Obtaining a prescription for medication like antibiotics or paracetamol was considered least important, with percentages of $1.6 \%$ and $0.3 \%$, respectively.

Almost 90\% (89.1\%) of the parents indicated that they had ever received information about fever in children, mostly through the internet (63.4\%) and their GP (51.8\%) followed by the maternity centre (29.1\%). Most parents prefer to receive information by a GP (67.5\%) when their child is ill, while they prefer information on the internet in general (57.1\%). Many parents $(92.3 \%)$ share experiences about their sick child with family $(84.0 \%)$ and friends (37.0\%).

Table 4.4 Priority list of specific components of a GP consultation according to parents

\begin{tabular}{lll}
\hline Importance & Specific component of consultation & Prioritised as most important \\
& Physical examination & $53.6 \%$ \\
& Information about the cause of the fever & $16.8 \%$ \\
& Reassurance & $11.0 \%$ \\
& Advice on alarm symptoms & $8.6 \%$ \\
& Information about self-management & $6.4 \%$ \\
Least important & Information about the duration of illness & $1.6 \%$ \\
& Obtaining medication (antibiotics) & $1.6 \%$ \\
\hline
\end{tabular}




\section{DISCUSSION}

\section{Summary}

This study allowed more insight into parental knowledge, attitudes and practices in children with fever before children actually become unwell and parents consult. Knowledge on the definition of fever and the indications for antibiotic and antipyretic treatment varied widely among an internet-based sample of parents with young children. Most parents visited their own GP or a GP out-of-hours clinic with their child during a past episode of fever, and $91.4 \%$ indicated they commonly treat their child with antipyretics. More than one-half of the parents (53.6\%) prioritised a thorough physical examination as the most important aspect of a GP consultation, whereas obtaining a prescription for medication like antibiotics or paracetamol was considered least important.

\section{Strengths and limitations}

The strengths of this study are the large sample size and high response rate. A limitation of any survey is the potential for recall and response bias. The internet-based questionnaire may have introduced selection bias, as only internet users were able to participate in the study. However, it is likely that the percentage of internet users among the target population (parents with young children) is high. Comparing the levels of education of the study sample with the Dutch and UK population shows that the percentage of people with a lower level of education is somewhat lower in the study sample (9.9\%) compared with general population levels (UK 15.3\%, Netherlands 17.1\%), and the percentage of people having a higher educational level is somewhat higher in the present study sample (47.8\%) compared to the Dutch population (42.3\%), but corresponds well with the UK population (47.1\%). ${ }^{10}$ The slight underrepresentation of lower educated people is something we expected to an extent considering the fact that an internet panel was used. However, this may have contributed to the relatively high level of knowledge and is something to take into account when interpreting the results. Furthermore, parents were not asked about antipyretics other than paracetamol as Dutch parents are advised not to give ibuprofen or other non-steroidal anti-inflammatory drugs (NSAIDs) to their children. This is also recommended in the guidelines of the Dutch College of GPs and advised at pharmacies and drugstores as paracetamol and ibuprofen have a comparable effect on reducing body temperature in children ${ }^{8}$ and the risk of adverse events or dosage miscalculations is considered to be too great to advise the use of Ibuprofen or other antipyretics in children. ${ }^{11}$ An unexpected $23 \%$ of parents indicated that their child was ever seriously ill due to a fever related illness. A recent study at Dutch GP-out-of-hours services showed that only $3.2 \%$ of 
children develop a severe illness due to a fever related illness and only 3.8\% got admitted at initial presentation. ${ }^{12}$ Some parents may have perceived more minor illnesses, such as a child that was examined in hospital but considered a minor illness, as being serious. However, it is parents' self-reported perception of serious previous illnesses which we have captured in this survey, and it is believed that it is these perceptions that will shape anxiety and future help-seeking behaviour, and are therefore relevant to measure in this study. Consultation behaviour and self-management will be shaped by general beliefs parents have. It is believed that these beliefs have been captured, which is a specific strength of the study. In the non-clinical setting, attitudes and concerns may be more realistic than when being asked at the point of acute care. This is only the second study ever to question parents with a survey in a non-acute setting, without possible influence of the stressful situation of their child being sick. The first study in a non-acute setting had a smaller sample size, a focus more directed at fever management and the main purpose was to develop an instrument to measure parents' fever management practices. ${ }^{13}$ The absence of evidence on parental attitudes towards fever management in primary care is striking, considering the number of consultations annually.

\section{Comparison with existing literature}

It was found that $88 \%$ of parents could correctly define fever. Previous studies, performed in acute care settings in secondary care, showed a range of $44-84 \%$ of parents not knowing the correct definition of fever $\left(>38^{\circ} \mathrm{C}\right) .{ }^{6,14-16}$ Generally, it is known that parents' knowledge about fever and antipyretics is poor. ${ }^{17}$ This is in line with the present finding that almost one in three of the parents thought that every child with a fever needs to be treated with paracetamol or antibiotics. On the other hand, only $2.8 \%$ of parents indicated treating their child with paracetamol for a temperature $<38^{\circ} \mathrm{C}$, in contrast to $25 \%$ of parents reporting doing so in another study. ${ }^{18}$

Parental knowledge on fever and antipyretics seems to be better than in most previous studies. One explanation could be that the educational level was relatively high in the present population (Table 4.1) and it was also shown that the level of education is an independent predictor for better knowledge on fever and antipyretics.

It was found that $55.2 \%$ of the participants correctly stated that antibiotics are effective in treating bacterial infections and not viral infections, which is somewhat higher than the percentage of $44.6 \%$ derived from identical questions in the survey on public beliefs of antibiotics and respiratory infections using the same internet panel. ${ }^{19}$ However, the present 
research population (parents with young children) is not directly comparable to that survey, which targeted the general adult population.

It is important to acknowledge that preferred temperature measurement techniques often differ between different countries. The guideline by the Dutch College of GPs states that rectal temperature measurements are preferable, but from a practical point of view tympanic measurements are also acceptable. ${ }^{8}$ However, the NICE guideline for feverish illness in children advises against the use of rectal measurements because of safety concerns and indicates tympanic or axillary methods are preferred despite of less accuracy. This is probably in agreement with daily practice of healthcare professionals in the UK. ${ }^{7}$ In line with these differences between the Dutch and UK guidelines it is important to realise that knowledge and beliefs about fever in children are likely to be influenced by cultural aspects and health care systems. ${ }^{14}$ This is also something to bear in mind when developing interventions to improve parental knowledge and practice regarding childhood fever.

Interestingly, the most important reason for parents to consult a GP was if the child had a fever for more than 3 days. This is in agreement with one of the alarm symptoms of the guideline 'children with a fever' from the Dutch College of GPs, which states that children who have a fever for more than three days need to be seen by a GP the same day. ${ }^{8}$ The NICE guideline states that on the basis of existing evidence, duration of fever cannot be used to help predict serious illness. However, since a fever of more than 5 days is one of the diagnostic criteria for Kawasaki disease, such a duration is not included as a red flag but is included as an intermediate risk factor for having a serious illness. ${ }^{7}$

Strikingly, when we asked parents to prioritise eight common features of a GP consultation, parents indicated that a thorough physical examination was far more important than obtaining a prescription for antibiotics or antipyretics, which they indicated as least important. This is in line with previous studies ${ }^{20,21}$ that have shown that GPs' assumptions about patients' expectations for a prescription are often misguided. These expectations could be an important target for interventions aimed at reducing antibiotic prescriptions, especially in an out-of-hours centre as it is known that prescribing figures in out-of-hours care are higher than during routine GP care, with one in three children visiting a GP out-ofhours centre receiving an antibiotic prescription. ${ }^{22}$ Although illness severity could be higher in that specific population, it is unlikely that such a high proportion of these infections are infections that are likely to benefit from treatment with antibiotics. So are prescriptions a result of patients' expectations or GPs' assumptions about those expectations? 


\section{Implications for research and practice}

To improve managing febrile children and accompanying parental self-management strategies and information to parents, it is important to know parents' knowledge, attitudes and practices in childhood fever. Dutch parents seem to have realistic attitudes and concerns at the moment their child is not sick, but parents whose child ever experienced a serious illness might need extra attention since they are more concerned about febrile convulsions. This was also found in other studies. ${ }^{23,24}$

When parents consult with their febrile child, they consider a physical examination as most important and obtaining a prescription for antibiotics or paracetamol least important. Particularly in an out-of-hours setting, where antibiotic prescribing rates are still relatively high, this provides ample opportunities to enhance prescribing and improve satisfaction by eliciting parental expectations and opinions and conducting an appropriate physical examination. When providing information about the need for treatment, GPs should bear in mind that more than one in four parents believe that every child with a fever should receive paracetamol or antibiotics. Finally, parents prefer the internet for information when their child is not sick and the GP when their child is sick. This should be taken into account when designing future interventions aimed at improving information on childhood fever and treatment. 


\section{REFERENCES}

1. Bruijnzeels MA, Foets $M$, van der Wouden JC, van den Heuvel WJ, Prins $A$. Everyday symptoms in childhood: occurrence and general practitioner consultation rates. Br J Gen Pract. 1998;48:880-4.

2. Hay AD, Heron J, Ness A. The prevalence of symptoms and consultations in preschool children in the Avon Longitudinal Study of Parents and Children (ALSPAC): a prospective cohort study. Fam Pract. 2005;22:367-74.

3. Huibers LA, Moth G, Bondevik GT, Kersnik J, Huber CA, Christensen MB, et al. Diagnostic scope in out-of-hours primary care services in eight European countries: an observational study. BMC Fam Pract. 2011;12:30.

4. Blumenthal I. What parents think of fever. Fam Pract. 1998;15:513-8.

5. Schmitt BD. Fever phobia: misconceptions of parents about fevers. Am J Dis Child. 1980;134:176-81.

6. Taveras EM, Durousseau S, Flores G. Parents' Beliefs and Practices Regarding Childhood Fever. Pediatr Emerg Care. 2004;20:579-87.

7. National Institute of Clinical Excellence. NICE guideline: feverish illness in children. London: National Institute of Clinical Excellence; 2013.

8. Oteman N, Berger MY, Boomsma LJ, Wiersma TJ, Goudswaard AN. Summary of the practice guideline 'Children with fever' from the Dutch College of General Practitioners. Ned Tijdschr Geneeskd. 2008;152:2781-6.

9. $\mathrm{ICH}$. Guideline for good clinical practice 1996. Available from: http://www.ich.org/products/guidelines/efficacy/article/efficacy-guidelines.html.

10. European Commission. Eurostat database: persons with a given education attainment, by age and sex 2012 [May 1st 2013]. Available from: http://epp.eurostat.ec.europa.eu/portal/page/portal/education/data/database.

11. Sarrell EM, Wielunsky E, Cohen HA. Antipyretic treatment in young children with fever: acetaminophen, ibuprofen, or both alternating in a randomized, double-blind study. Arch Pediatr Adolesc Med. 2006;160:197-202.

12. Kool M, Elshout G, Moll HA, Koes BW, van der Wouden JC, Berger MY. Duration of Fever and course of symptoms in young febrile children presenting with uncomplicated illness. Journal of the American Board of Family Medicine: JABFM. 2013;26:445-52.

13. Walsh A, Edwards $H$, Fraser J. Parents' childhood fever management: community survey and instrument development. J Adv Nurs. 2008;63:376-88.

14. Cohee LMS, Crocetti MT, Serwint JR, Sabath B, Kapoor S. Ethnic differences in parental perceptions and management of childhood fever. Clin Pediatr (Phila). 2010;49:221-7. 
15. Al-Eissa YA, Al-Sanie AM, Al-Alola SA, Al-Shaalan MA, Ghazal SS, Al-Harbi AH, et al. Parental perceptions of fever in children. Annals of Saudi medicine. 2000;20:202-5.

16. Kramer MS, Naimark L, Leduc DG. Parental fever phobia and its correlates. Pediatrics. 1985;75:1110-3.

17. Walsh A, Edwards H. Management of childhood fever by parents: literature review. J Adv Nurs. 2006;54:217-27.

18. Crocetti M, Moghbeli N, Serwint J. Fever phobia revisited: have parental misconceptions about fever changed in 20 years? Pediatrics. 2001;107:1241-6.

19. Cals JW, Boumans D, Lardinois RJ, Gonzales R, Hopstaken RM, Butler CC, et al. Public beliefs on antibiotics and respiratory tract infections: an internet-based questionnaire study. Br J Gen Pract. 2007;57:942-7.

20. Butler CC, Rollnick S, Pill R, Maggs-Rapport F, Stott N. Understanding the culture of prescribing: qualitative study of general practitioners' and patients' perceptions of antibiotics for sore throats. BMJ. 1998;317:637-42.

21. Cockburn J, Pit S. Prescribing behaviour in clinical practice: patients' expectations and doctors' perceptions of patients' expectations--a questionnaire study. BMJ. 1997;315:520-3.

22. Elshout G, Kool M, Van der Wouden JC, Moll HA, Koes BW, Berger MY. Antibiotic Prescription in Febrile Children: A Cohort Study during Out-of-Hours Primary Care. J Am Board Fam Med. 2012;25:810-8.

23. Stephenson MJ, Rosencrantz A, Kneller P. Childhood Fever: parental beliefs and management. Can Fam Physician. 1988;34:63-6.

24. Walsh A, Edwards H, Fraser J. Influences on parents' fever management: beliefs, experiences and information sources. J Clin Nurs. 2007;16:2331-40. 

HAPTER 5

\section{Childhood fever: a qualitative study on parents' expectations and experiences \\ during general practice out-of-hours care \\ consultations}

Eefje G.P.M. de Bont

Nicole Loonen

Dagmar A.S. Hendrix

Julie M.M. Lepot

Geert-Jan Dinant

Jochen W.L. Cals 



\section{ABSTRACT \\ Background}

Fever in children is common and mostly caused by benign self-limiting infections. Yet consultation rates in primary care are high, especially during GP out-of-hours care. Therefore, we aimed to explore experiences of parents when having visited GP out-ofhours services with their febrile child.

\section{Methods}

We performed a qualitative study using 20 semi-structured interviews among parents from different backgrounds presenting to GP out-of-hours care with a febrile child $<12$ years. Questions were directed at parental motivations, expectations and experiences when visiting the GP out-of-hours centre with a febrile child. Interviews were audio-recorded, transcribed and analysed using constant comparison technique.

\section{Results}

We identified four main categories emerging from the data; (1) cautiously seeking care, (2) discrepancy between rationality and emotion, (3) expecting reassurance from a professional and (4) a need for consistent, reliable information. Not one symptom, but a combination of fever with other symptoms, made parents anxious and drove care seeking. Although parents carefully considered when to seek care, they experienced increased anxiety with increases in their child's temperature. Because parents work during the day and fever typically rises during the early evening, the decision to seek care was often made during out-of-hours care. When parents consulted a GP they did not have any set expectations other than seeking reassurance, however a proper physical examination diminished their anxiety. Parents did not demand antibiotics, but trusted on the expertise of the GP to assess necessity. Parents requested consistent, reliable information on fever and self-management strategies.

\section{Conclusions}

Parents were inexperienced in self-management strategies and had a subsequent desire for reassurance; this played a pivotal role in out-of-hours help seeking for childhood fever. These factors provide clues to optimise information exchange between GPs and parents, by providing written, tailored, consistent information on self-management strategies for current and future fever episodes. GPs' had incorrect assumptions that parents expected antibiotic treatment. 


\section{BACKGROUND}

Fever is the most common reason for a child to be taken to the general practitioner (GP) and, in the absence of the safety net of their own GP, out of hours care. ${ }^{1,2}$ Still, it is largely unknown what parents expect when consulting out of hours care and only limited evidence about what drives these consultations exists. Previous studies were quantitatively structured using mainly closed questions or performed in a different setting like an emergency department or the general public. ${ }^{3-9}$ In an emergency department setting it is likely that children are more seriously ill than in a primary care setting, thereby influencing parental worries and decisions. Additionally, most consultations for childhood fever take place in primary care. Despite this, one in three GP out-of-hours consultations for children are fever related and more than $92 \%$ of these children are managed by GPs without referral to secondary care. ${ }^{10}$ The low referral rate highlights the general self-limiting nature of childhood fever in general practice. Despite of this, one in three children with a fever receives an antibiotic when visiting the GP out-of-hours centre. ${ }^{11,12}$

Insight into expectations and experiences of parents who have consulted with out-of-hours GPs with their feverish child could provide insights for future interventions targeted at increasing parental self-management, decreasing the number of (re-)consultations and potential overuse of antibiotics for febrile children during GP out-of- hours care where most febrile children are evaluated. Therefore, it is important to understand why parents consult a GP out-of-hours, what they generally experience and expect, and how they use and would desire information to be given before, during and after a consultation for childhood fever.

This qualitative descriptive study aimed to provide an in-depth overview of these factors, by exploring parental motivations, expectations and experiences with GP out-of-hours consultations for childhood fever. 


\section{METHODS}

We performed a qualitative study based on naturalistic inquiry using semi-structured interviews to study parents' expectations and experiences towards consultations with their febrile children at a GP out-of-hours centre. ${ }^{13}$ We applied the consolidated criteria for reporting qualitative research (COREQ) and adhered to RATS guidelines for reporting qualitative research. ${ }^{14}$

\section{Setting}

GP out-of-hours services in the Netherlands are organized in large-scale cooperatives. ${ }^{15}$ These cooperatives cover the primary care by rotating shifts of GPs during evening, nights and all weekends. All out-of-hours services in the Netherlands have a triage centre in which trained nurses conduct telephone triage under supervision of a GP and divide all contacts into either telephone advice, GP consultation, home visits by GPs. More than 95\% of GPs provide out-of-hours care through this system.

The study was carried out at a large GP cooperative in Heerlen, the province of Limburg, the Netherlands. The Nightcare GP out-of-hours service in Heerlen, located in a multiethnic, moderate to low socio-economic area, is a Dutch GP out-of-hours service providing care to approximately 270.000 inhabitants. ${ }^{16}$

\section{Participants}

All parents presenting to the GP out-of-hours centre with a febrile child under the age of 12 years in November 2013, were eligible for inclusion and were asked prior to consultations to participate in a semi-structured interview. Parents were approached at the desk of the GP out-of-hours centre by a member of staff and asked to voluntarily sign up. We used purposive sampling based on gender, age, parity, education level and cultural background. There were no exclusion criteria. Low educational level was defined as vocational school or lower, intermediate as higher national diploma or Bachelor's degree and high as a Master's degree or higher.

\section{Data collection}

Data were collected between November 2013 and January 2014. An interview guide was prepared using sensitizing concepts. ${ }^{17}$ Questions were derived from existing literature and a priori expert discussion. The questions were directed at parental motivations, expectations and experiences when visiting the GP out-of-hours centre with a febrile child. A pilot study consisting of two, one hour lasting focus groups, facilitated by an experienced and independent moderator, were performed to check for face validity. Based on this pilot 
study minor changes were made to the interview guide. The purpose of these focus groups was to test the interview guide, therefore they were not used during the analysis.

Based on the adapted interview guide, three trained researchers ( $\mathrm{DH}, \mathrm{NL}$ and JL) conducted face-to-face semi-structured interviews. The interviews, which lasted around 30-45 minutes, were conducted in the participants' homes or at the GP out-of-hours centre depending on the preference of the parent, within two weeks after the consultation. Since their children were sick at the moment they were approached, we believed it would be unethical and undesirable to perform the interview immediately after the consultation. Data saturation was achieved after 14 interviews but to ensure maximum variation 20 semi-structured interviews were performed. The interviews were audio recorded and transcribed verbatim by $\mathrm{DH}, \mathrm{NL}$ and JL.

\section{Analysis}

Data were analysed using constant comparison technique, coding and analysing took place simultaneously. $^{18}$ Inductive analysis was used, by using open and finally axial coding schemes using NVivo software version 9.0. ${ }^{19,20}$ Inconsistencies about coding were discussed and resolved by consensus.

\section{Trustworthiness}

Data triangulation was enhanced by using parents of different ages, education levels, gender and parity and socio-economic areas and combining interview transcripts with research diaries. Hereby we were able to recruit fathers as well. Previous studies suggested fathers frequently play an important role in decision making about consultation of a doctor. $^{21}$ In addition, all researchers used a research diary to take notes on their observations and ideas about the interviews and coding scheme. This was used during interpretation and coding of the interviews and peer debriefings with the whole research team. Furthermore, a member check of the written transcript was performed among all participating parents. We provided detailed information about the methodology and background information of the parents, to help others decide whether the results are transferable to their context.

\section{Ethical considerations}

All participants received written information and provided written informed consent to participate in this study. Data were used anonymously. The study was approved by the Medical Ethics committee of the Maastricht University Medical Centre (ref. number NL 134-060.4). 


\section{RESULTS}

Of 63 parents who visited the GP out-of-hours service with a febrile child were approached in person, 51 parents consented to receive more information about participating. From these 51, 6 parents participated in the pilot study and 20 parents participated in a semistructured interview. Of the parents who participated in the semi-structured interviews, there were 7 fathers and average age was 32.2 years (range 22-44 years). None of the parents wanted to alter the transcript after the member check. In table 5.1 the main characteristics of the participating parents are described.

We identified four main categories emerging from the data; (1) cautiously seeking care, (2) discrepancy between rationality and emotion, (3) expecting reassurance from a professional and (4) a need for consistent, reliable information. These main categories will be discussed in further detail. We did not observe any distinct differences between parents of different gender, age or education level. Figure 5.1 shows a graphical overview of the categories that were found.

Table 5.1 Characteristics of the participating parents $(n=20)$

\begin{tabular}{ll}
\hline Characteristics of parents & Number of parents \\
Male sex, $\mathrm{n}(\%)$ & 7 (35) \\
Age (years) & 8 \\
$20-29$ & 7 \\
$30-39$ & 5 \\
$40-49$ & \\
Civil state & 1 \\
$\quad$ Single parent & 6 \\
Living together/Unmarried & 13 \\
Married & \\
Number of children & 9 \\
1 & 7 \\
2 & 4 \\
3 & \\
Native country & 16 \\
The Netherlands & 1 \\
Germany & 1 \\
Turkey & 1 \\
Morocco & 1 \\
South-Africa & \\
Education & 17 \\
Low & 1 \\
Intermediate & 15 \\
High & \\
Working parents & \\
\hline
\end{tabular}




\section{Cautiously seeking care}

Parents expressed a range of experiences and emotions caring for their sick child before even considering contacting the GP out-of-hours service. Contacting the GP out-of-hours service is not prompted by the fever itself, but mostly by a combination of symptoms. The additional symptoms were felt to be the main drivers of their worries and subsequently would then lead to help-seeking behaviour. Specific symptoms named by parents were listlessness, weepiness, sleepiness, lower intake of fluids and their child behaving differently than normal.

"If he's still playing I'm not worried. But last time I called the GP because he refused to eat, he wouldn't drink, he wouldn't play, he just laid there listlessly on the couch, and that is not my son." (15)

Parents reported ongoing fever, fever not responding to antipyretics and the duration of the fever as important factors influencing their decision to contact the GP out-of-hours service.

"If it's only a short fever peak, I'm not worried. But when it [the fever] perseveres for hours, or days, I think that is disturbing." (I1)

Parents said they usually carefully wait and see before actually seeking care, especially during out-of-hours care. When they decided to seek care many described that nothing could persuade them from wanting to see a doctor at that point and that was their main reason for contacting the GP out-of-hours centre and not their own GP.

"Nobody could have stopped me. And nobody could have said to me: no, you do not need to come over right now, just visit your own GP tomorrow." (I5)

Factors influencing this decision were on one side logistical like the fact that their own GP didn't have time that same day, they picked up their child from day-care when their own GP practice was already closed or they wanted to avoid putting the child in the car in the middle of the night.

"Then we picked him up [their child at day care] and my girlfriend called the GP and they didn't have time for an appointment anymore and told us to come over the next day. But I didn't want to wait that long."(I19) 
On the other side there were also other factors which were related to the fact that they experienced that fever most often rises in the early evening. ${ }^{22}$ Parents expressed they were afraid to go to sleep when their child has a fever because they can't monitor their behaviour then.

"I noticed the fever was $39.4{ }^{\circ} \mathrm{C}$ at the beginning of the evening, which means it will only increase and I'm afraid to go to sleep then." (I6)

\section{Discrepancy between rationality and emotion}

Although parents carefully considered when to seek care, they experienced that their anxiety increases with the temperature of their child.

"...if the temperature is $39^{\circ} \mathrm{C}$ I think okay, but if it rises towards $40^{\circ} \mathrm{C} \mathrm{...} \mathrm{I} \mathrm{panic."(I13)}$

This may be explained by the fact that most parents believed the height of the temperature directly correlates with the illness severity of their child. They explained that in their eyes, a higher temperature correlated with a more serious illness and therefore a higher risk of complications.

"If it is higher than $40^{\circ} \mathrm{C}$, then you are talking about another, yes another severity." (14)

However, there were also parents who acknowledged that their emotions would often take over from rational reasoning at these instances.

"Rationally I think it does not matter $38^{\circ} \mathrm{C}, 39^{\circ} \mathrm{C}$ or $39.5^{\circ} \mathrm{C}$, but emotionally I feel the higher the fever, the sooner something [complications] might happen."(I7)

This discrepancy between rationality and emotion was also something that was reported in relationship to a longer duration of illness.

"Initially I usually don't panic... but if the symptoms last longer I'm not as sensible and I tend to get on the emotional side of the story." (I1) 
Underlying, this was possibly related to the fact that parents were willing to await spontaneous improvement to a certain extent. However, if symptoms lasted longer they sought reassurance that they were correctly caring for their child.

"The GP reassured me at that moment [during a consultation when symptoms lasted for more than three days]. He reassured us that we were on the right track and we just had the keep going caring for our child the way we were doing. That my child would recover by himself." (14)

The only influencing background characteristic of the participating parents we found was the fact that experienced parents (i.e. with older children) were less anxious, perhaps because they had experienced uncomplicated infections and fever with their other children and hence perceived these symptoms as a normal part of childhood.

"I also hear this from other parents. That it developed like that. They also say, I was a mess back then. And now, with my second child, it's okay. I'm not that afraid anymore."(I10)

\section{Expecting reassurance from a professional}

The next category that came forward when elaborating on reasons to contact the GP outof-hours service was the desire to be reassured. The first reassurance as mentioned in the previous category was the reassurance that they were caring for their child in a correct way and there was nothing else that they could do. Some parents just wanted general reassurance from a professional. Parents would formulate this in in different ways.

"... when the GP says, it's okay, then it's okay." (I10)

Others specifically wanted to know the cause of the fever and reassurance that their child did not suffer from a serious illness, and was therefore not at risk of complications.

"...It is looking for confirmation, having the idea that it's nothing serious... And having that confirmed by a doctor." (I8)

When asked what the most reassuring aspect of a GP's consultation was, the most often mentioned contributing factor was a physical examination by a GP. 
"The GP successfully reassured us. He performed a good physical examination and took us seriously. I believe that's important."(I7)

The position of a GP as an expert in advice on how to care for their child's health was also described by parents when they were asked about their expectations of medication prescriptions. Parents did not expect medication, but relied on the expertise of the GP to determine what was needed. None of the parents expected antibiotics.

"...We prefer no medication. But when it is necessary, so when the GP advises medication, we would have given this."(17)

During GP out-of-hours care in the Netherlands, patients are most likely to be seen by another GP than their own GP during daytime care. Yet, seeing a different GP does not bother them, as long as their child is seen by a doctor who takes them seriously and who can treat their child correctly.

"A doctor is a doctor, he [my child] just needs help."(I13)

Parents noticed that they are used to frequently seeing another doctor during daytime care because they attend a GP group practice. Moreover, some parents experienced a consultation with a different doctor as positive considering it as a second opinion.

\section{A need for consistent, reliable information}

Parents consulted other parents or relatives, as well as the internet as an information source before contacting the GP out-of-hours service. Conversely, this did not necessarily lead to reassurance. Some parents even pointed out searching for information on the internet led to increased anxiety.

"Sometimes I search for information on the internet, but as I have just said, I try to avoid it most of the time... Because I just read too much and then I get anxious." (II)

Most parents did not receive written information from the GP during the consultation. Some parents suggested that information about alarm symptoms and self-management strategies would be helpful when they return home since they did not think about all the questions they had at that exact moment during a consultation. 
"...Written information would be helpful. Because, most often during a consultation you do not think about all the questions you want to ask. And once you are at home you think to yourself $\mathrm{hmmm}$ (sighs) I should have asked that..." (I1)

Additionally, parents described they could use this information for future illnesses before contacting the GP out-of-hours service.

"For example he diagnosed an ear infection and I believe this is common in small children. If there was a booklet describing this, what an ear infection is and with a picture of the localisation...I would keep that. And I would take a look at it if he gets another ear infection. To recall what's going on in case I don't completely remember." (I13)

However, parents experienced that it would be important that this information came from one, comprehensible and reliable information source without inconsistencies.

"There is a need for one good information source which is clear and consistent, not in doctor language because normal human beings don't understand that." (I6) 


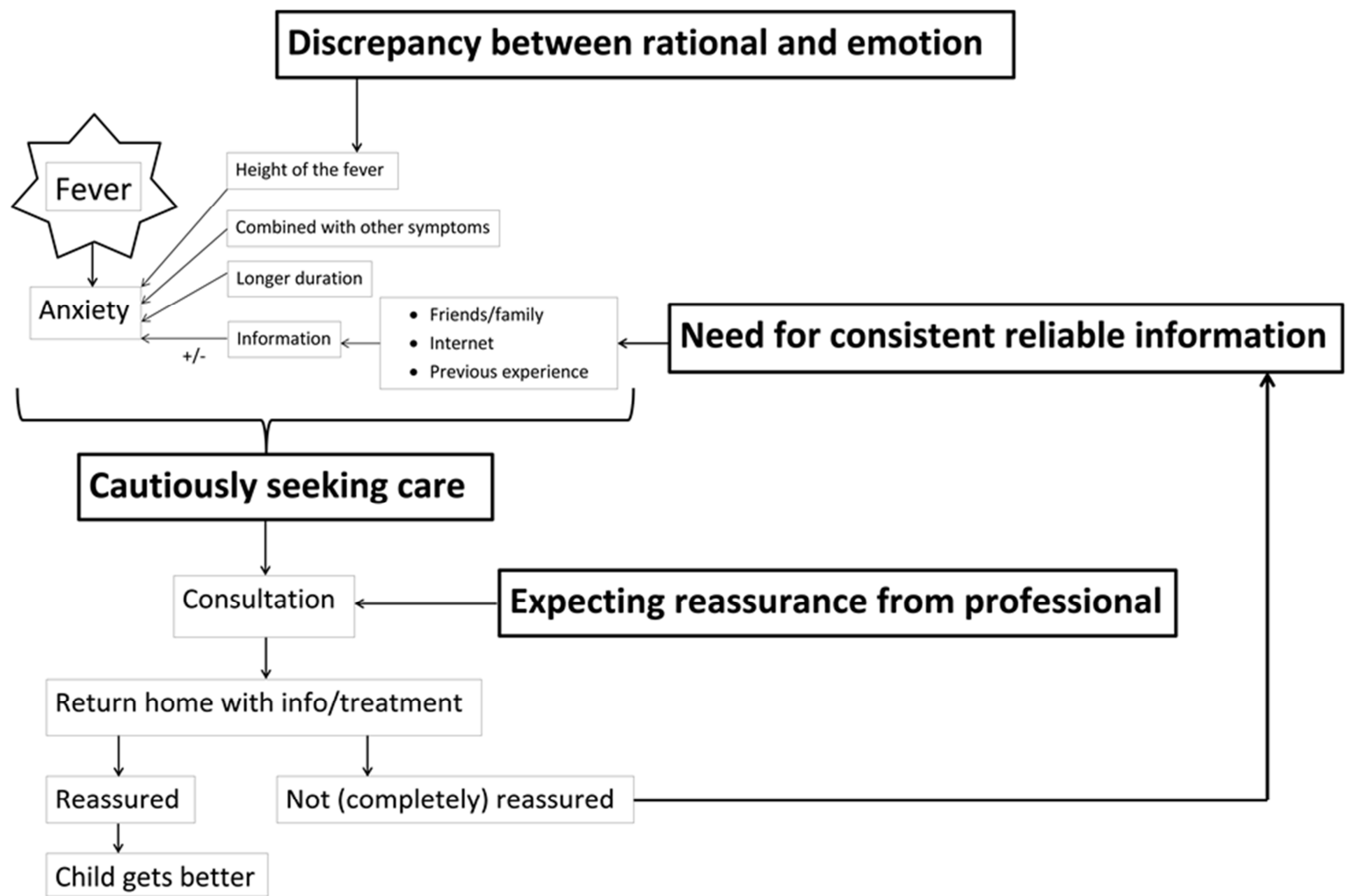

Fig. 5.1 Categories and their relationship.

Main categories are put in Bold 


\section{DISCUSSION}

\section{Main Findings}

Parents generally cautiously wait and see before contacting GP out-of-hours care when their child has a fever. Not one specific symptom, but a combination of fever with other symptoms, makes them anxious and drives care seeking. Because parents work during the day and fever typically rises during the early evening, the decision to seek care was often made during out-of-hours care. When contacting a GP out-of-hours service, parents did not expect antibiotics but sought reassurance from a professional, which parents felt could be achieved by a thorough physical examination. Finally, they believed that there is a lack of reliable consistent information on (self-management strategies for) childhood fever before, during and after a consultation.

\section{Comparison with existing literature}

The degree of fever alone has previously shown to have a low predictive value for the severity of an illness in children. ${ }^{1}$ Interestingly parents mentioned a higher temperature would indicate a more severe illness, sometimes even mentioning a specific limit. This belief is in accordance with previous research, indicating that parents still believe high fever is harmful. ${ }^{2,23,24}$ There are studies that show that by increasing parental knowledge this misconception can be reduced. ${ }^{25}$ However, some parents were able to describe that their fears were not based on their rational knowledge but mostly on their emotions. This means there were also parents who acknowledged they rationally knew that a higher temperature did not indicate a more severe illness, but emotionally their anxiety increased when the body temperature increased. Some secondary care studies describe that despite increasing knowledge, anxiety remains. ${ }^{26}$ However, to our understanding this is the first study in which parents actually described this discrepancy between rational and emotions themselves. Education and information about fever might therefore only reduce anxiety to a certain extent. This is something to take into account when developing interventions to reduce anxiety among parents of febrile children.

The need for reassurance from an expert was expressed by all parents and is in accordance with other literature. ${ }^{3,27,28}$ This reassurance can, at least partly, be obtained by a physical examination. Previous research already showed a physical examination is valued as an important component of a GP consultation and parents feel reassured when they know what's going on with their child. ${ }^{3,9,27,28}$ Parents rely on a GP for their expertise, as reported in a Scandinavian study which was aimed at studying when parents with an ill child consult a physician. ${ }^{9,27}$ 
In accordance with existing literature, we found that parents' expectations of a GP's consultation were not specific and parents generally do not expect antibiotics. ${ }^{3}$ However, in agreement with a recent study our data suggests that parents consult because of a perceived threat to their child's health, which then in turn prompts clinicians to prescribe antibiotics. $^{29,30}$ In contrast, only a small percentage of children presenting with a fever actually requires treatment based on the incidence of serious bacterial infections. ${ }^{31}$ However, a recent Dutch study showed that one in three children with fever who visit the GP out-of-hours service receive antibiotics, ${ }^{11}$ suggesting that antibiotic prescribing is still higher than warranted. As in adults with acute cough, one explanation could be that GPS assume patients or in this case parents expect antibiotics. ${ }^{32}$ This study underlines the fact that parents indeed do not expect antibiotics.

Parents actively search for information before contacting a GP. ${ }^{27}$ As suggested previously, we found that this information did not always reassure parents, but even raised anxiety in some cases. ${ }^{2}$ A relatively new finding of this study in comparison to previous research is the usage of the internet as a main source of information for parents. One of the challenges in the usage of internet as an information source is the fact that parents expressed that there is a lack of reliable consistent information on the internet. ${ }^{33}$

Another important aspect of information provided to parents of febrile children that is suggested in previous studies is the fact that reliable, consistent information can potentially provide parents with better knowledge ${ }^{34}$ and with a safety net. ${ }^{7}$ By providing parents information on what to do and when to consult when their child has fever in accordance with the NICE 2013 traffic light system, ${ }^{1}$ their self-management can be increased without leading to complications for their children. ${ }^{7}$ As suggested earlier, this may very well be even more effective if the same information that is provided at the point-of-care during a consultation, is also provided to parents in the general public before their children get sick. ${ }^{2}$

\section{Strengths and limitations}

This is the first qualitative describing study enrolled in a GP out-of-hours setting that gives in-depth insight into the motivations, expectations and experiences of parents when they visit a GP out-of-hours with their febrile child. This setting is important because most consultations are handled by GPs without referral to secondary care and many consultations take place during out-of-hours care. ${ }^{10}$

Despite efforts to make parents feel comfortable and safe by letting them choose the location of the interview, parents may have given socially acceptable answers, thereby holding back valuable information. Because interviews were not executed immediately after the consultation there was some risk of recall bias. We did however perform the 
interviews within two weeks and feel this was the most ethical and pragmatic approach since it is undesirable to execute an interview with parents' their sick child being present. Although we attempted to describe the motivation, expectations and experiences of parents, there may be potential underlying and influencing factors, which were not discovered during this study.

The different perspectives, member check, peer debriefings and investigator and data triangulation helped to increase trustworthiness. However, all researchers had a medical background with an interest in general practice and infections which might have influenced their views and interpretation of the data. As only parents who visited the out-of-hours service were included, we are missing data from parents who stayed at home with their febrile child. It is possible these parents have different expectations and experiences considering fever. Additionally, since health care systems and illness experience are culturally different, we do not know to what extent these results are generalizable to other countries. Nevertheless, we believe that these results are at least to some extent generalizable to Western countries with similar health care systems. In addition, we provided information about the methodology and background information of parents to help others decide whether the results of this study are transferable to their context.

\section{Implications for practice}

Lacking self-management strategies seem to influence parental consultations which do then in turn potentially thrive antibiotic prescriptions. ${ }^{29,30}$ It is previously shown that an information exchange tool is effective in reducing the number of antibiotic prescriptions and intention to re-consult in children with upper respiratory tract infections and that such a tool can increase parental and clinician confidence in managing these illnesses. ${ }^{21,35}$ We believe that this strategy could also be used in children presenting with a fever. Therefore, future research should focus on improving information on childhood fever provided in the consulting room in a consistent, tailored, written way. However, this might be challenging during out-of-hours care where there is no pre-existing relationship between GPs and parents and where time is limited. ${ }^{30}$ Therefore, we believe that future studies should also focus on providing consistent parental education to parents in the general public, thereby improving parental confidence and self-management when their child has a fever.

\section{CONCLUSIONS}

Parents of febrile children are still anxious and search for reassurance from a GP as a professional when fever is accompanied by other symptoms. They sought reassurance that they were correctly caring for their child and were additionally reassured when a thorough 
physical examination was conducted. This study demonstrates, in accordance with previous research, that parents of a febrile child do not expect antibiotics and are in search of consistent, reliable information about fever and specific symptoms. Enhancing parental knowledge may provide parents with a safety net, ${ }^{7}$ thereby influencing self-management and the parental need for consultations. In addition, by making this information available in the consulting room it may facilitate communication about caring for a febrile child and address misconceptions GPs still hold about parents and patients expecting antibiotics. 


\section{REFERENCES}

1. National Institute of Clinical Excellence. NICE guideline: feverish illness in children. London: National Institute of Clinical Excellence; 2013.

2. Walsh A, Edwards H, Fraser J. Influences on parents' fever management: beliefs, experiences and information sources. J Clin Nurs. 2007;16:2331-40.

3. Kallestrup P, Bro F. Parents' beliefs and expectations when presenting with a febrile child at an out-of-hours general practice clinic. Br J Gen Pract. 2003;53:43-4.

4. Enarson MC, Ali S, Vandermeer B, Wright RB, Klassen TP, Spiers JA. Beliefs and expectations of Canadian parents who bring febrile children for medical care. Pediatrics. 2012;130:e905-12.

5. Betz MG, Grunfeld AF. 'Fever phobia' in the emergency department : a survey of children 's caregivers. Eur J Emerg Med. 2004:129-33.

6. Karwowska A, Nijssen-Jordan C, Johnson D, Davies HD. Parental and health care provider understanding of childhood fever: a Canadian perspective. CJEM. 2002;4:394-400. 7. Jones $\mathrm{CH}$, Neill S, Lakhanpaul $\mathrm{M}$, Roland $\mathrm{D}$, Singlehurst-Mooney $\mathrm{H}$, Thompson $\mathrm{M}$. Information needs of parents for acute childhood illness: determining 'what, how, where and when' of safety netting using a qualitative exploration with parents and clinicians. BMJ Open. 2014;4:e003874.

8. Taveras EM, Durousseau S, Flores G. Parents' Beliefs and Practices Regarding Childhood Fever. Pediatr Emerg Care. 2004;20:579-87.

9. de Bont EG, Francis NA, Dinant GJ, Cals JW. Parents' knowledge, attitudes, and practice in childhood fever: an internet-based survey. Br J Gen Pract. 2014;64:e10-6.

10. de Bont EG, Lepot JM, Hendrix DA, Loonen N, Guldemond-Hecker Y, Dinant GJ, et al. Workload and management of childhood fever at general practice out-of-hours care: an observational cohort study. BMJ Open. 2015;5:e007365.

11. Elshout G, Kool M, Van der Wouden JC, Moll HA, Koes BW, Berger MY. Antibiotic Prescription in Febrile Children: A Cohort Study during Out-of-Hours Primary Care. J Am Board Fam Med. 2012;25:810-8.

12. Elshout $G$, van lerland $Y$, Bohnen AM, de Wilde $M$, Oostenbrink R, Moll HA, et al. Alarm signs and antibiotic prescription in febrile children in primary care: an observational cohort study. Br J Gen Pract. 2013;63:e437-44.

13. Lincoln Y, Guba G. Naturalistic Inquiry: SAGE Publications; 1985.

14. Tong A, Sainsbury P, Craig J. Consolidated criteria for reporting qualitative research (COREQ): a 32-item checklist for interviews and focus groups. Int J Qual Health Care. 2007; 19:349-57. 
15. Huibers L, Giesen P, Wensing M, Grol R. Out-of-hours care in western countries: assessment of different organizational models. BMC Health Serv Res. 2009;9:105.

16. Huisartsen Oostelijk Zuid-Limburg. Organisation 2013. Available from: http://www.huisartsen-ozl.nl/.

17. Bowen GA. Grounded theory and sensitizing concepts. Int J Qual Methods. 2006;5.

18. Pope C, Ziebland S, Mays N. Qualitative research in health care. Analysing qualitative data. BMJ. 2000;320:114-6.

19. Corbin J, Straus A. Basics of Qualitative Research: SAGE Publications; 2008. 9781412906449.

20. Charmaz K. Constructing grounded theory: SAGE Publications; 2006. 9780761973539.

21. Francis N, Wood F, Simpson S, Hood K, Butler CC. Developing an 'interactive' booklet on respiratory tract infections in children for use in primary care consultations. Patient Educ Couns. 2008;73:286-93.

22. Manfredini R, Vergine G, Boari B, Faggioli R, Borgna-Pignatti C. Circadian and seasonal variation of first febrile seizures. J Pediatr. 2004;145:838-9.

23. Sarrell M, Cohen HA, Kahan E. Physicians', nurses', and parents' attitudes to and knowledge about fever in early childhood. Patient Educ Couns. 2002;46:61-5.

24. Lagerlov P, Helseth S, Holager T. Childhood illnesses and the use of paracetamol (acetaminophen): a qualitative study of parents' management of common childhood illnesses. Fam Pract. 2003;20:717-23.

25. O'Neill-Murphy K, Liebman M, Barnsteiner JH. Fever education: does it reduce parent fever anxiety? Pediatr Emerg Care. 2001;17:47-51.

26. Crocetti M, Moghbeli N, Serwint J. Fever phobia revisited: have parental misconceptions about fever changed in 20 years? Pediatrics. 2001;107:1241-6.

27. Ertmann RK, Soderstrom M, Reventlow S. Parents' motivation for seeing a physician. Scand J Prim Health Care. 2005;23:154-8.

28. Ingram J, Cabral C, Hay AD, Lucas PJ, Horwood J, team T. Parents' information needs, self-efficacy and influences on consulting for childhood respiratory tract infections: a qualitative study. BMC Fam Pract. 2013;14:106.

29. Cabral C, Lucas PJ, Ingram J, Hay AD, Horwood J. "It's safer to ..." parent consulting and clinician antibiotic prescribing decisions for children with respiratory tract infections: An analysis across four qualitative studies. Soc Sci Med. 2015;136-137:156-64.

30. de Bont EG, Peetoom KK, Moser A, Francis NA, Dinant GJ, Cals JW. Childhood fever: a qualitative study on GPs' experiences during out-of-hours care. Fam Pract. 2015. 
31. Van den Bruel A, Bartholomeeusen S, Aertgeerts B, Truyers C, Buntinx F. Serious infections in children: an incidence study in family practice. BMC Fam Pract. 2006;7:23.

32. Coenen S, Michiels B, Renard D, Denekens J, Van Royen P. Antibiotic prescribing for acute cough: the effect of perceived patient demand. Br J Gen Pract. 2006;56:183-90.

33. Walsh AM, Hyde MK, Hamilton K, White KM. Predictive modelling: parents' decision making to use online child health information to increase their understanding and/or diagnose or treat their child's health. BMC Med Inform Decis Mak. 2012;12:144.

34. Sarrell M, Kahan E. Impact of a single-session education program on parental knowledge of and approach to childhood fever. Patient Educ Couns. 2003;51:59-63.

35. Francis NA, Phillips R, Wood F, Hood K, Simpson S, Butler CC. Parents' and clinicians' views of an interactive booklet about respiratory tract infections in children: a qualitative process evaluation of the EQUIP randomised controlled trial. BMC Fam Pract. 2013;14:182. 
HAPTER 6

Childhood fever: a qualitative study on GPs' experiences during out-of-hours

care

Eefje G.P.M. de Bont

Kirsten K.B. Peetoom

Albine Moser

Nick A. Francis

Geert-Jan Dinant

Jochen W.L. Cals

Fam Pract. 2015; 32:449-55. 



\section{ABSTRACT \\ Background}

Fever in children is common and mostly caused by self-limiting infections. However, parents of febrile children often consult in general practice, in particular during out-ofhours care. To improve management it is important to understand experiences of GPS managing these consultations.

\section{Objective}

To describe GPs' experiences regarding management of childhood fever during out-ofhours care.

\section{Methods}

A descriptive qualitative study using purposeful sampling, 5 focus group discussions were held among 37 GPs. Analysis was based on constant comparative technique using open and axial coding.

\section{Results}

Main categories were: (1) Workload and general experience, (2) GPs' perceptions of determinants of consulting behaviour, (3) Parents' expectations from the GP's point of view, (4) Antibiotic prescribing decisions (5) Uncertainty of GPs versus uncertainty of parents, (6) Information exchange during the consultation. GPs felt management of childhood fever imposes a considerable workload. They perceived a mismatch between parental concerns and their own impression of illness severity, which combined with timepressure can lead to frustration. Diagnostic uncertainty is driven by low incidences of serious infections and dealing with parental demand for antibiotics is still challenging.

\section{Conclusion}

Children with a fever account for a high workload during out-of-hours GP care which provides a diagnostic challenge due to the low incidence of serious illnesses and lacking long-term relationship. This can lead to frustration and drives antibiotics prescription rates. Improving information exchange during consultations and in the general public to young parents, could help provide a safety net thereby enhancing self-management, reducing consultations and workload, and subsequent antibiotic prescriptions. 


\section{BACKGROUND}

Febrile illnesses are the most common reason for a child to be taken to the doctor. Childhood infections in general practice represent $60 \%$ of all consultations for children under 1 year of age and $\sim 30 \%$ for children up to 15 years. ${ }^{1,2}$ Most guidelines are conservative concerning the use of antibiotics in these self-limiting infections. ${ }^{3}$ However, antibiotic prescription rates for febrile children in the out-of-hours setting are on average $30-40 \%,{ }^{4}$ nearly twice as high as prescription rates during routine office hours. ${ }^{5}$

Since the year 2000 GP out-of-hours services in the Netherlands are organized in largescale cooperatives. ${ }^{6}$ These cooperatives cover the primary care by rotating shifts of General Practitioners (GPs) during evening, nights, and weekends. More than 95\% of GPs participate in a cooperative, which means that patients receive care from their own GP only in a few out-of-hours contacts. In most cases, they receive care by another GP who also participates in a cooperative. ${ }^{7}$ Furthermore, Dutch GPs function as gatekeepers for secondary care. Only those children who need treatment from a paediatrician will be referred in case the GP decides this is medically indicated.

Alongside the high number of consultations, management of children with fever can be further complicated for GPs, because of (perceived) parental expectations and anxiety. 8 During out-of-hours care GPs typically have no knowledge of the child's medical history or background, further complicating these often time-pressured consultations. We believe GPs often feel pressured to prescribe antibiotics, whilst only a limited number of parents actually expect a prescription. ${ }^{9,10}$ This could imply that GPs' assumptions are not always in line with expectations of consulting parents. All these factors together drive unnecessary antibiotic prescribing and referrals and decrease (parental) self-management.

Though we know childhood fever accounts for many consultations in out-of-hours GP care, we know little about how GPs experience these consultations and what influences their management decisions. ${ }^{1,2,11}$ Actual evidence on whether they believe that the amount of consultations for febrile children create a burden during out-of-hours care and their considerations how management could generally be improved is lacking.

In order to enhance appropriate antibiotic prescribing and management in febrile children during GP out-of-hours care it is crucial to answer the question: how do GPs experience childhood fever related consultations during out-of-hours care and how do they believe that these consultations can be improved?

This qualitative study aims to explore the experiences of GPs regarding childhood fever consultations during out-of-hours care, thereby eliciting barriers and facilitators of good quality care including appropriate antibiotic prescribing rates and enhanced parental selfmanagement. 


\section{METHODS}

We performed a descriptive qualitative study based on naturalistic inquiry. ${ }^{12}$ GPs were questioned about their actual experiences with febrile children during out-of-hours care since this is the best approach to achieve a deeper understanding how these consultations take place in daily practice.

\section{Setting}

The study was carried out among GPs from three different GP cooperatives in the province of Limburg in the Netherlands. This region covers a multi-ethnic population of approximately 607.000 inhabitants with a varying degree of socio-economic status. ${ }^{13}$

\section{Participants}

We approached existing GP groups using email, by contacting larger practices with multiple GPs or GPs involved in pharmacotherapeutic audit meeting groups. Every group that was approached agreed to participate. We used purposive sampling based on different backgrounds of the GPs, variation in experiences, size of practice and level of deprivation of the community served. Thirty-seven GPs participated, of these 24 GPs were male, mean age of all the participants was 47 years (range: $27-64$ years) and the average years of clinical experience was 17 years (range: 0.5-30 years; equal to experience with out-of-hours care). Included were GPs participating in shifts at a GP out-of-hours service.

\section{Ethical considerations}

All participants received written information and provided written informed consent. Data was used anonymously. The study was approved by the Medical Ethics committee of the Maastricht University Medical Centre (NL 13-4-060.4).

\section{Data collection}

Data were collected from July 2013 to September 2013. A focus group guide was prepared using sensitizing concepts. ${ }^{14}$ Questions were derived from existing literature and a priori expert discussions. Questions were directed at the different aspects of a GP's consultation, influencing factors on their management decisions during out-of-hours care and influencing factors on parental consulting behaviour and expectations from the GPs' point of view before, during and after a consultation.

We performed five focus group discussions (FGD) with five to nine GPs per group, facilitated by an experienced and independent moderator. The FGD lasted around 90 minutes and were conducted in GP practices. We achieved data saturation after four FGD 
and performed one more to ensure maximum variation in sampling and to validate the findings. All FGD were audio recorded and transcribed verbatim by EB.

\section{Analysis}

Data was analysed using constant comparison technique; coding and analysing took place simultaneously. ${ }^{15}$ Every interview was coded by two researchers independently (EB, KP). Inductive analysis was used, by first using open schemes. After this, axial coding was applied to relate codes to each other and form categories and subcategories. ${ }^{16,17}$ NVivo software version 9.0 was used for analysis. Inconsistencies about coding were discussed and resolved by consensus. The coding scheme was discussed and adjusted several times among the wider research team. The analysis resulted in six main categories.

\section{Trustworthiness}

Data triangulation was enhanced by including GPs from three different cooperatives and covering different socio-economic areas. Investigator triangulation was realised by involving researchers from different backgrounds providing different perspectives and peer debriefing by discussing findings among the wider research team. Furthermore, a member check of the written transcript was performed among all participating GPs. We provided detailed information about the methodology and background information of the GPs, to help others decide whether the results are transferable to their context. 


\section{RESULTS}

We identified six main categories: (1) Workload and general experience, (2) GPs' perceptions of determinants of consulting behaviour, (3) Parents' expectations from the GP's point of view, (4) Antibiotic prescribing decisions (5) Uncertainty of GPs versus uncertainty of parents, and (6) Information exchange during the consultation.

\section{Workload and general experience}

GPs perceived that children with fever impose a considerable workload during out-of-hours shifts, especially during seasonal incidence peaks of upper respiratory tract infections.

"Especially during winter months at the GP out-of-hours centre, sometimes you see five or six of them in a row." (GP26, FGD4)

GPs generally believed there is a mismatch between parental concerns, not related to symptoms or signs, and their own impression of illness severity during the consultation. The high workload during out-of-hours care in general and the number of children that are not seriously unwell leads to frustration for almost all GPs.

"Of course the point is, in a hundred thousand cases it is nothing. Just a child with a fever. I mean, when you're doing consultations on a Saturday and you've seen thirty children and not one of them was really sick, I'm just saying. (GP1) Then you're fed up for that weekend, yes." (GP3, FGD1)

Some GPs explained that this frustration partially depended on their feeling of unwarranted use of urgent care by parents. They believed that out-of-hours care should be used for urgent medical cases and that providing reassurance to parents of a febrile child should actually take place during regular office hours.

"I believe it's completely logical that parents can consult their own GP during regular officehours because of a fever. But it is not a medical emergency. Because I believe that we should have the time to take care of the real emergencies during out-of-hours care.... So that we can use our resources as sparingly as possible."( GP16, FGD3) 


\section{GPs' perceptions of determinants of consulting behaviour}

GPs perceived four key aspects affect consulting behaviour: parental worries, lack of knowledge, influence of child day care centres and increasing demand for 24-hour availability of medical services. According to GPs, parental worries were the major driving factor behind consultations and these worries and concerns were largely influenced by the duration of symptoms and the degree of fever.

"...That contributes considerably to parental concerns. The height of a fever itself." (GP10, FGD2)

GPs experienced a general lack of knowledge of parents when to consult a GP. They expressed that the inability of parents to employ self-management strategies seemed to increase the number of consultations.

GPs explicitly stated that according to them the impact of child day care centres on consulting behaviour has increased over time. They experienced that defensive advice of day care centres when a child is ill drives just-in-case GP consultations which means parents follow the advice of day-care centres to have a consultation.

"And in the first hours of the evening shift there are those children who get picked up at the day care centre. They [day care centre] advise them there to call a GP because the child has a fever." (GP16, FGD3)

Especially senior GPs said they think this has been reinforced by the emergence of GP outof-hours cooperatives. When GPs managed their own patients' out-of-hours, GPs felt parents were more reluctant to disturb their own GP out-of-hours. While GPs acknowledged that many parents express a wish for 24-hour availability of medical services, many of them agreed that out-of-hours care should be used for emergencies only. GPs in all focus groups expressed a belief that the consultation behaviour exhibited by many parents, with frequent consultations for minor illnesses, represents a failure to take responsibility for their sick children and a 'passing off' of that responsibility to a GP. According to GPs, this might also be influenced by the fact they have seen a trend in which more parents are working during the daytime and expecting care in the out-of-hours setting. 
"People just show up with a child that is playing in the waiting room. He has a fever, so doctor: examine him please. They don't take any responsibility anymore for their sick child." (GP3, FGD1)

GPs mentioned seeing parents expecting a 'routine' consultation in evenings because they believed the GP out-of-hours service is there to provide care when they demand. GPS generally felt that contextual factors like the age of the child and parity of the parents contributed to this behaviour.

GPs explained that this overall feeling of increasing influence of day care centres and increasing demand for 24-hour availability of medical services attributes to their frustration. Mostly because in their eyes out-of-hours care should be used for urgent medical cases and most cases of childhood fever are not a medical emergency.

\section{Parents' expectations from the GP's point of view}

GPs had firmly held beliefs about what parents expected from a consultation from their point of view. Firstly, GPs explicitly expressed that parents expect reassurance. However, they felt that the lack of a long-term doctor-patient relationship and prior knowledge about the patient can sometimes preclude their ability to adequately reassure parents.

"Sharing uncertainty... In my own practice I can tell a mother to come back tomorrow, today I'm confident it's okay. And she trusts me so she takes him home. But when I'm at the GP out-of-hours centre that relationship isn't built in fifteen minutes and I can't do that." (GP1, FGD1)

Secondly, and related to reassurance, the value of a proper physical examination was stressed by many GPs. Some GPs said that a full physical examination was not clinically necessary for some children, because they could tell whether a child was sick by observing general behaviour. However, especially during out-of-hours care, they performed physical examination regularly to reassure parents.

"However, I feel us GPS don't get away with it by saying, look I see your child running around here so I can reassure you he's doing okay. Just see your own GP tomorrow. (GP28) ... So an important part of reassuring is a physical examination? (Moderator) Yes, this is a ritual in some cases because you can tell you're not going to find anything important." (GP24, FGD4) 
Thirdly, most GPs said they expect that parents consult them for antibiotics based on previous experiences. However, GPs' their perception was that expectations for antibiotics have decreased over time, especially due to media attention, campaigns in the general population, and information provided during GP consultations.

"I do believe the fact that the media is telling them antibiotics are not necessary is sinking in." (GP22, FGD3)

\section{Antibiotic prescribing decisions}

GPs mentioned that the decision to prescribe antibiotics depended on different factors of which most are similar to those during routine practice, namely duration of symptoms, what parents want, self-management by parents with little effects and what has already been done by other doctors.

"I believe duration is important, if he's still making a sick impression after four or five days and he does have red ear-drums than I will prescribe antibiotics yes" (GP17, FGD3)

Some GPs believed that the perceived need to obtain antibiotics was closely related to satisfaction with the consultation. This in turn may lead them to prescribing antibiotics sooner because they want to avoid a discussion with parents during these time pressured consultations.

"It has to do with the time pressure you are under. If you have the time to explain and parents feel you understand them then I won't have to prescribe antibiotics. But if you only have ten minutes for a consultation and there is a huge line of patients waiting... and I would rather wait but parents insist on getting antibiotics. Well then I'm not having a discussion. Then I'll provide them with an antibiotic prescription and get them out of the door satisfied." (GP1, FGD1)

Although they acknowledged that this may play a role during all general practice consultations, they believed it to play a bigger role during out-of-hours care because of a lacking long term relationship.

"At the cooperative I tend to give in to parental wishes for antibiotics sooner than in my own practice, because in my own practice I'm not afraid to take on a fight with parents." (GP3O, FGD5) 
GPs often felt pressured, particularly when symptoms have lasted longer and parents had lost their patience.

Well, if a child is acting difficult and it has an ear infection together with a fever, I feel that some parents become pushy. They think they need an antibiotic prescription because they can't go on like this. (GP15, FGD3)

Despite that assumption, still not all GPs explicitly ask if a parent expects antibiotics. However, they perceived that this has improved over time.

"In the past I assumed that this [antibiotics] was what parents wanted. And I didn't ask them directly. And nowadays I do that more often and it turns out that they do not expect antibiotics." (GP2, FGD1)

Many GPs mentioned being used as a second opinion or last resort by parents especially in situations when parents had previous negative experiences.

"It has more to do with the fact they experienced this sort of situation before when they had to come back several times. It was in fact a pneumonia... and this time they want to prevent this from happening again. Therefore, they have a different perspective." (GP9, FGD2)

Although participating GPs said they were reluctant in prescribing antibiotics themselves, it was generally agreed that antibiotics were too often inappropriately prescribed at the outof-hours services. In general, antibiotic prescribing decisions were not straightforward during out-of-hours care.

\section{Uncertainty of GPs versus uncertainty of parents}

GPs perceived that factors that make them (diagnostically) uncertain were different from factors that drive uncertainty and worries among parents. An important factor driving uncertainty for them as GPs was the low incidence of serious bacterial illnesses combined with a high workload. To illustrate this problem, GPs compared diagnosing complicated infections as searching for a needle in a haystack. They experienced that (diagnostic) uncertainty leads to extra careful management decisions and in turn to more antibiotic prescriptions. 
"I'd rather give some children antibiotics too soon, than missing one."(GP3, FGD1)

Additionally, this was further complicated by the fact that assessment and treatment was more difficult in children of whom they had no prior knowledge or relationship.

"In your own practice you can take a medical history without actually seeing the child, and then sometimes considering the illness course and knowing the family I tell them to be patient for some time."(GP9, FGD2)

GPs mentioned that fever without a focus did not directly worry them as long as the child was generally well. On the contrary, a sick child with a fever without a focus did create uncertainty and concerns among both GPs and parents because this implicated a child might need treatment or additional diagnostic testing. Hence, the general appearance of the child is an important diagnostic tool for GPs, and finding a focus was considered vital when the child is generally unwell. According to the GPs parents use different judgement criteria. They often found the fever in itself worrying and especially the height of a fever.

"You know what I think causes this discrepancy? Parents make their assessment based on the temperature and we make our assessment based on the child's appearance." (GP1, FGD1)

In addition, GPs discussed that providing an accurate diagnosis is much more challenging when a specific focus for the fever is missing, as parents will often want to know what the cause of the fever is.

\section{Information exchange during the consultation}

Generally, GPs said that they provided information on the cause of fever to parents, the expected duration of symptoms and self-management strategies such as use of paracetamol. They mainly provide verbal information, and in some cases also written information. Reasons to provide parents with written information were mainly situations when GPs were uncertain whether parents understood what was explained. Few, mainly younger GPs, directed parents to reliable internet websites for information about childhood fever. GPs did perceive that it is more difficult to provide information during outof-hours care, especially because they see parents for the first time. 
"I also think that when parents previously had positive experiences with you [as their own $G P]$, reassurance is probably more effective." (GP9, FGD2)

This was further complicated by the fact that consultations during out-of-hours care were often time pressured.

"Well in that case [when you would explain everything to parents] my consultations would take even longer. You don't have the time to explain everything. You make a selection of what is most necessary, and I believe that is even more important during out-of-hours care.... Because you are dealing with time pressure and you think well this is an evening or weekend shift so that is what it's about... you should provide information to parents to make it through that period." (GP4, FGD1)

In addition to time pressure and a lacking long term relationship, they believed it was harder to provide parents with reassurance when they couldn't provide them with information on the cause of the fever. While some GPs explained that in those cases they just tell parents it's a viral infection, there were also GPs who acknowledged that in some cases this resulted in them prescribing antibiotics, where in their own practice they probably could have reassured parents without knowing the cause of the fever.

"In those cases you see that parents find it more difficult to believe you, than when you have a real diagnosis."(GP13, FGD3)

Most GPs expressed that information exchange within these consultations needs improvement and that this would improve the management of childhood fever. However, because of a lacking long term, trusting relationship and time pressure, they acknowledged that this would be challenging. Therefore, nearly all GPs thought it was even more important to increase parents' general knowledge about fever management in children prior to their children getting sick, and they also stressed a role for the well-baby and maternity centres in this respect.

"I believe they should provide courses at the well-baby centres on what to do when your child is sick." (GP24, FGD4) 


\section{DISCUSSION}

\section{Summary of the main results}

GPs reported that childhood fever contributes a significant burden to their workload when providing out-of-hours care. Compared to routine daytime work, GPs feel they see more febrile children and experience more diagnostic uncertainty and that parents are more worried, expect antibiotics sooner and are not as easy to reassure in the out-of-hours setting. This, in combination with time pressured consultations and the feeling that out-ofhours care should only be used for medical emergencies can lead to frustration in GPs. GPs perceived that parental expectations for antibiotics have decreased over time, and that this is largely due to media campaigns and information provided by doctors. However, they feel overprescribing is still an important problem in these consultations. Lack of a long-term relationship and prior knowledge about the patient are important factors that make these consultations and resulting management decisions challenging. They believe this could be enhanced by improving information exchange at the point of care as well as providing young parents with information before their children get sick.

\section{Comparison with existing literature}

Fever phobia and worries of parents have been described for many years ${ }^{8}$ and parents consider a physical examination as the most important aspect of a GPs' consultation. ${ }^{10}$ GPs perform a physical examination, even though they regard it as providing limited additional information to the medical history and general impression of the child. GPs explained they felt frustrated by a high workload during out-of-hours care because of the fact that only few children were actually sick in their eyes and they felt that parents ought to visit their own GP during office hours. In other words, most GPs felt a consultation for a febrile child during out-of-hours care could be classified as unnecessary in their eyes. A previous systematic review and meta-ethnography showed that clinicians may interpret parents' efforts to establish the need for a consultation as an indicator of expecting antibiotics and parents may hear clinicians' normalising, most likely meant to be reassuring, statements as questioning the need for a consultation. This might lead to both parties feeling challenged and higher antibiotic prescription rates by GPs as a result, while in fact parents only expect reassurance from a consultation. ${ }^{18}$ Nevertheless, there were also GPs in our study that acknowledged that parents expect reassurance and not antibiotics. However they believed that this reassurance should take place during regular office hours by parents their own GP. This is also a possible explanation why GPs felt that increasing influence of day care centres and the wish for a 24-hour society leads to frustration. GP cooperatives were founded to reduce the workload during out-of-hours care. Generally, by dividing shifts across 50-200 
GPs the workload has been successful reduced. ${ }^{7}$ However, the workload coming from consultations for childhood fever specifically might have increased over time because of these stimulating factors.

Previous research has shown that incidence of, and consulting rates for febrile illness in children are high, especially in an out-of-hours setting. ${ }^{1,2,11}$ However, it is also known that the rate of serious bacterial infections is very low, around $1 \%{ }^{19}$ Dealing with low-incidence illnesses is challenging for GPs. ${ }^{20}$ This study confirms that this discrepancy of seeing a lot of children with a fever but only few of them actually being sick in the GPs eyes indeed proposes a diagnostic challenge. This is complicated further by a lacking long-term parental-GP relationship. This concept of trust was also found to be an important determinant of acceptance of management by parents in a previous study on antibiotics for children with respiratory tract infections. ${ }^{21}$ We examined what this means for their management decisions, especially in terms of antibiotics. GPs felt that the high workload complicates their management because of the diagnostic challenge it provides. This concept of finding a needle in a haystack led to a feeling of being careful not to miss anything and providing a proper physical examination. Although participating GPs in this study declared that they prescribe few antibiotics, hypothetically this feeling of being extra careful could also lead to more careful management decisions and drive antibiotic prescription rates.

Interestingly, GPs in the current study state that they infrequently prescribe antibiotics and that the number of parents expecting a prescription decreased over time. On contrary, around one in three consultations for febrile children results in an antibiotic prescription. ${ }^{4}$ This suggests that there is a discrepancy between the GPs' perception on their prescribing behaviour and their actual prescribing behaviour. An explanation could be that the GPS participating in this study are more motivated or aware of overprescribing. This could also explain why they feel that they have a lot of colleagues who are still overprescribing. However, it is also possible that they gave socially acceptable answers or are unaware of the fact that they themselves are still overprescribing.

\section{Strengths and limitations}

This is one of the first qualitative studies that focus on workload and management of febrile children in the GP out-of-hours setting. The strength of this qualitative design is that is gives an in-depth insight into experiences of GPs when working in out-of-hours settings. Childhood fever management is complex and the choice of a qualitative design made it possible to research this complexity. Previous studies on this topic were a structured quantitative study or studies in a different setting like an emergency department where the 
rate of serious infections is considerably higher. ${ }^{22,23}$ This study tells us something on the factors that play a role in the management decisions of these GPs when they prescribe antibiotics to children during out-of-hours care.

There were no GPs who refused to participate in our focus group discussions. We aimed to reduce the influence of the researchers' point of views and opinions by using an independent moderator asking open-ended questions. However, we cannot exclude that socially acceptable answers were given. Our heterogeneous sample improves transferability of the results. However, health care systems and perception of illness are culturally different. Despite of this, we believe we provided enough background information to let others decide whether the results are transferable to their context. In addition, the lacking long-term relationship Dutch GPs face during out-of-hours care is something that might also play a role in countries with different out-of-hours organizational models. For example, GPs working at a NHS service during out-of-hours in the United Kingdom generally also don't have a prior relationship with a patient. ${ }^{6,7}$

\section{Implications for research and practice}

GPs feel they see many children because of a fever during out-of-hours care. It seems that few children are actually sick enough to need treatment, which leads to frustration. It also increases diagnostic uncertainty in the out-of-hours setting where patients and GPs do not know each other. Future research should further investigate parental experiences and explore cultural and national differences. In addition, it should focus on improving information on childhood fever provided in the consulting room and to the general public, especially amongst young parents. A recent study showed that parents of a febrile child might in fact have a stronger need for advice on symptomatic relief, or when they should re-consult than GPs realise. ${ }^{24}$ We have previously shown that an information exchange tool is effective in reducing the number of antibiotic prescriptions and intention to re-consult in children with upper respiratory tract infections ${ }^{25}$ and that such a tool can increase parental and clinician confidence in managing these illnesses. ${ }^{26}$ We believe that this strategy could also be used in children presenting with a fever. However, this might be challenging during out-of-hours care where there is no pre-existing relationship between GPs and parents and where time is limited. Future studies should therefore also focus on providing parental education on fever and self-management to young parents in the general public.

\section{Conclusions}

GPs perceived that children with a fever account for a high workload in out-of-hours GP care which can lead to frustration and provides a diagnostic challenge due to the low 
incidence of serious illnesses and lacking long-term relationship. These factors play an important role in the management decisions of GPs when they prescribe antibiotics to children during out-of-hours care. Improving information exchange during consultations but also in the general public, especially to young parents, could help provide a safety net and in that way enhance self-management, reduce consultation rates, thereby reducing the workload, frustration and diagnostic challenge. Leading to fewer antibiotic prescriptions. 


\section{REFERENCES}

1. National Institute of Clinical Excellence. NICE guideline: feverish illness in children. London: National Institute of Clinical Excellence; 2013.

2. Fleming DM, Smith GE, Charlton JR, Charlton J, Nicoll A. Impact of infections on primary care--greater than expected. Commun Dis Public Health. 2002;5:7-12.

3. Berger RM, Berger MY, van Steensel-Moll H, Dzoljic-Danilovic G, Derksen-Lubsen G. A predictive model to estimate the risk of serious bacterial infections in febrile infants. Eur J Pediatr. 1996;155:468-73.

4. Elshout G, Kool M, Van der Wouden JC, Moll HA, Koes BW, Berger MY. Antibiotic Prescription in Febrile Children: A Cohort Study during Out-of-Hours Primary Care. J Am Board Fam Med. 2012;25:810-8.

5. Otters HB, van der Wouden JC, Schellevis FG, van Suijlekom-Smit LW, Koes BW. Trends in prescribing antibiotics for children in Dutch general practice. I Antimicrob Chemother. 2004;53:361-6.

6. Huibers L, Giesen P, Wensing M, Grol R. Out-of-hours care in western countries: assessment of different organizational models. BMC Health Serv Res. 2009;9:105.

7. Giesen P. SM, Huibers L., Grol R., Wensing M. Quality of after-hours primary care: As narrative review of the Dutch solution. Ann Intern Med. 2011;155:108-13.

8. Crocetti M, Moghbeli N, Serwint J. Fever phobia revisited: have parental misconceptions about fever changed in 20 years? Pediatrics. 2001;107:1241-6.

9. Kallestrup P, Bro F. Parents' beliefs and expectations when presenting with a febrile child at an out-of-hours general practice clinic. Br J Gen Pract. 2003;53:43-4.

10. de Bont EG, Francis NA, Dinant GJ, Cals JW. Parents' knowledge, attitudes, and practice in childhood fever: an internet-based survey. Br J Gen Pract. 2014;64:e10-6.

11. Hay AD, Heron J, Ness A. The prevalence of symptoms and consultations in preschool children in the Avon Longitudinal Study of Parents and Children (ALSPAC): a prospective cohort study. Fam Pract. 2005;22:367-74.

12. Lincoln Y, Guba G. Naturalistic Inquiry: SAGE Publications; 1985.

13. Central Bureau of Statistics. Population of Southern Limburg 2013 [April 20th 2014]. Available from:

http://statline.cbs.nl/StatWeb/publication/?DM=SLNL\&PA=37259NED\&D1=0\&D2=0\&D3=5 5\&D4=51-52\&HDR=T\&STB=G2,G1,G3\&VW=T.

14. Bowen GA. Grounded theory and sensitizing concepts. Int J Qual Methods. 2006;5.

15. Pope C, Ziebland S, Mays N. Qualitative research in health care. Analysing qualitative data. BMJ. 2000;320:114-6. 
16. Corbin J, Straus A. Basics of Qualitative Research: SAGE Publications; 2008. 9781412906449.

17. Charmaz K. Constructing grounded theory: SAGE Publications; 2006. 9780761973539.

18. Cabral C, Horwood J, Hay AD, Lucas PJ. How communication affects prescription decisions in consultations for acute illness in children: a systematic review and metaethnography. BMC Fam Pract. 2014;15:63.

19. Van den Bruel A, Bartholomeeusen S, Aertgeerts B, Truyers C, Buntinx F. Serious infections in children: an incidence study in family practice. BMC Fam Pract. 2006;7:2.

20. Buntinx F, Mant D, Van den Bruel A, Donner-Banzhof N, Dinant GJ. Dealing with low-incidence serious diseases in general practice. Br J Gen Pract. 2011;61:43-6.

21. Brookes-Howell L, Wood F, Verheij T, Prout H, Cooper L, Hood K, et al. Trust, openness and continuity of care influence acceptance of antibiotics for children with respiratory tract infections: a four country qualitative study. Fam Pract. 2014;31:102-10.

22. Sarrell M, Cohen HA, Kahan E. Physicians', nurses', and parents' attitudes to and knowledge about fever in early childhood. Patient Educ Couns. 2002;46:61-5.

23. Poirier MP, Collins EP, McGuire E. Fever phobia: a survey of caregivers of children seen in a pediatric emergency department. Clin Pediatr (Phila). 2010;49:530-4.

24. Cabral C, Ingram J, Hay AD, Horwood J, team T. "They just say everything's a virus"-parent's judgment of the credibility of clinician communication in primary care consultations for respiratory tract infections in children: a qualitative study. Patient Educ Couns. 2014;95:248-53.

25. Francis N, Butler C, Hood K, Simpson S, Wood F, Nuttall J. Effect of using an interactive booklet about childhood respiratory tract infections in primary care consultations on reconsulting and antibiotic prescribing: a cluster randomised controlled trial. BMJ. 2009;339:b2885-b.

26. Francis NA, Phillips R, Wood F, Hood K, Simpson S, Butler CC. Parents' and clinicians' views of an interactive booklet about respiratory tract infections in children: a qualitative process evaluation of the EQUIP randomised controlled trial. BMC Fam Pract. 2013;14:182. 



\section{Patient information leaflets to reduce antibiotic use and reconsultation rates in general practice: a systematic review}

Eefje G.P.M. de Bont Famke Falkenberg Marleen Alink Geert-Jan Dinant Jochen W.L. Cals

BMJ Open. 2015;5(6):e007612. 



\section{ABSTRACT \\ Objective}

Patients' knowledge and expectations may influence prescription of antibiotics. Therefore, providing evidence-based information on cause of symptoms, self-management and treatment is essential. However, providing information during consultations is challenging. Patient information leaflets could facilitate consultations by increasing patients' knowledge, decrease unnecessary prescribing of antibiotics and decrease reconsultations for similar illnesses. Our objective was to systematically review effectiveness of information leaflets used for informing patients about common infections during consultations in general practice.

\section{Design, setting, and participants}

We systematically searched PubMed/MEDLINE and EMBASE for studies evaluating information leaflets on common infections in general practice. Two reviewers extracted data and assessed article quality.

\section{Primary and secondary outcome measures}

Antibiotic use and reconsultation rates.

\section{Results}

Of 2512 unique records, eight studies were eligible (7 randomised, controlled trials, 1 non randomised study) accounting for 3407 patients. Study quality varied from reasonable to good. Five studies investigated effects of leaflets during consultations for respiratory tract infections; one concerned conjunctivitis, one urinary tract infections and one gastroenteritis and tonsillitis. Three of four studies presented data on antibiotic use and showed significant reductions of prescriptions in leaflet groups with a relative risk (RR) varying from 0.53 (0.40 to 0.69$)$ to 0.96 (0.83 to 1.11). Effects on reconsultation varied widely. One large study showed lower reconsultation rates (RR 0.70 (0.53 to 0.91), two studies showed no effect, and one study showed increased reconsultation rates (RR 1.53 (1.03 to 2.27)). Studies were too heterogenic to perform a meta-analysis.

\section{Conclusions}

Patient information leaflets during GP consultations for common infections are promising tools to reduce antibiotic prescriptions. Results on reconsultation rates for similar symptoms vary with a tendency toward fewer reconsultations when patients are provided with a leaflet. Use of information leaflets in cases of common infections should be 
Chapter 7

encouraged. Their contributing role in multi-faceted interventions targeting management of common infections in primary care needs further exploration. 


\section{INTRODUCTION}

Overuse of antibiotics contributes to the growing problem of antimicrobial resistance and is widely recognized as a major public health problem. ${ }^{1}$ Eighty percent of all antibiotics are prescribed in general practice. ${ }^{2,3}$ Most of these antibiotics are used for acute cough and respiratory tract infections, ${ }^{4}$ even though most of these infections are self-limiting and there is little benefit from treatment with antibiotics. ${ }^{5}$ Previous studies have showed that antibiotic prescription is strongly influenced by patients' expectations and that general practitioners (GPs) experience pressure from patients to prescribe antibiotics. ${ }^{6,7}$ The prescription of antibiotics is associated with increased reconsultation rates ${ }^{8}$ and therefore also increases GPs' workloads. Conveying evidence-based information to patients on the cause of symptoms, natural disease course and the expected benefits and harms of treatment is challenging for GPs in often time-pressured consultations. ${ }^{9}$

When asked, most patients appreciate written information ${ }^{10}$ and indicate they would be less likely to consult if they had more information about managing minor illnesses. ${ }^{11,12}$ In addition, the use of written information may improve information retention up to $50 \%$ and patient satisfaction may improve. ${ }^{13,14}$ Patients presenting with a common infection value information on self-management strategies and expected duration of illness. The use of information leaflets to assist a consultation may be a useful tool to convey information, increase patient knowledge and possibly restrict antibiotic prescriptions. ${ }^{15}$

The aim of this systematic review is to study the effect of using patient information leaflets on antibiotic use and reconsultation rates in general practice consultations for common infections. 


\section{METHODS}

\section{Literature search and study selection}

We systematically searched PubMed and EMBASE for original articles using the following Mesh terms: Pamphlets, Primary Health Care, General Practice, General Practitioners, Family Physicians, Family Practice. We then added the following free search terms: "handout," "leaflet," "booklet," "pamphlet," "flyer," "folder," "brochure," "general practice," "general practitioners," "family physicians," "family practice," "family medicine," and "primary health care" in April 2014 (see Appendix 1 for complete search string). We defined no further (language) restrictions, besides the exclusion of studies pertaining to dental practice. After merging records of both search engines, duplicate publications were removed.

We aimed to include randomised controlled and non-randomised intervention trials in which the effect of a written information tool was studied during general practice consultations in developed countries. Information leaflets had to be given to patients in person by general practitioners (GPs) or other GP staff such as nurses. The leaflet should contain information on the infection for which the patients consulted. Hence, we excluded studies with leaflets aimed at prevention, multifaceted studies in which no leaflet specific effect could be extracted, studies concerning decision aids, and studies on patient empowerment tools.

Two reviewers (FCJF, MA) independently screened the first 200 articles by title and abstract. Both reviewers selected the same studies. Thereafter, the remaining abstracts were selected by one reviewer and checked by another. Selected abstracts were discussed with a third reviewer (EGPMdB) and disagreement was resolved by consensus. Then, full text articles of the selected studies were assessed independently by two reviewers (FCJF, MA) for inclusion eligibility. Once again, all articles were discussed with the third reviewer (EGPMdB) and disagreement was resolved by consensus. We checked the reference lists of those selected articles for additional relevant publications.

\section{Data extraction}

A standardized form was used to identify relevant characteristics of the included studies: study methodology, population, setting, intervention and primary and secondary outcome measures. In case of missing methodological information, we tried to obtain this information by contacting the corresponding author. We contacted five authors of which two provided us with additional details. 


\section{Methodological Quality Assessment}

We evaluated the methodological quality of included studies using the criteria of the Cochrane risk of bias tool (Table 7.1). ${ }^{16}$ Two reviewers (FCJF, MA) independently assessed each paper and all articles were discussed with a third reviewer (EGPMdB). Disagreements were resolved by consensus. Each article was rated as "low risk of bias," "high risk of bias," or "unclear risk of bias."

\section{Outcomes and Data Analysis}

Primary outcomes were antibiotic prescription rates and antibiotic use, reconsultation during the same illness episode and intention to reconsult. Reported outcomes and percentages were recalculated as relative risks (RRs). A meta-analysis of aggregated data on the primary outcomes was predefined and planned, depending on the heterogeneity of the methodology and data. Other outcome measures reported by studies were narratively described when considered relevant. 


\section{RESULTS}

\section{Study selection}

The search identified 2512 unique records of which 2490 were excluded following the screening of titles and abstracts. Of the remaining 23 full-text articles, seven studies met the inclusion criteria. One study was added following reference screening of included articles. This resulted in eight articles that became eligible for this review (see Figure 7.1).

\section{Study characteristics}

Table 7.1 shows descriptive data of all included studies. In total, the studies included 3407 patients, both adults and children visiting general practitioners with their parents. Five studies examined the effect of a leaflet on the management of respiratory tract infections. ${ }^{17-21}$ Other leaflets contained information on conjunctivitis, ${ }^{22}$ urinary tract infections, ${ }^{23}$ gastroenteritis and tonsillitis. ${ }^{24}$ Two studies evaluated a combination of interventions in which an information leaflet was given together with another intervention such as delayed antibiotic prescribing. ${ }^{19,22}$ The main outcome measures of all studies are listed in Table 7.1.

\section{Study quality}

Study quality assessment using the Cochrane "risk of bias" criteria are summarised in Table 7.2. ${ }^{16}$ Seven of the eight studies were randomised trials. In general, there was a minimal risk of allocation bias. We identified a high risk of bias for all studies for failing to blind participants and personnel. Overall, the study of Francis et al ${ }^{17}$ had the lowest risk of bias. Agnew et $a^{18}$ had the highest risk of bias. More detailed information about study quality is outlined in Appendix 2.

\section{Results of studies \\ Primary outcomes}

Six of the eight studies described one or more of our predefined outcomes of interest (Table 7.3). ${ }^{17-22}$ We decided not to perform a meta-analysis since the methodology, study populations, and chosen outcome measures were too heterogenic to pool relevant data (Table 7.1).

Two large studies, Francis et $\mathrm{al}^{17}(\mathrm{n}=558)$ and Macfarlane et $\mathrm{al}^{20}(\mathrm{n}=1014)$ determined the effect of an information leaflet for respiratory tract infections on antibiotic prescription. Francis et al's study, ${ }^{17}$ which was of high quality, assessed the effect of a booklet for childhood respiratory infections. Patients managed by a GP using the booklet were exposed to significantly less antibiotic prescription (RR $0.47,95 \% \mathrm{Cl} 0.36$ to 0.64). In Macfarlane et 
$\mathrm{al}^{20}$ the effect of a booklet among adults with lower respiratory tract symptoms was investigated. The booklet led to a non-significant reduction in antibiotic prescription (RR $1.15,95 \% \mathrm{Cl} 0.89$ to 1.48). Four studies focused on the effect of patient information leaflets on actual antibiotic use as reported by patients. ${ }^{17-19,21}$ Francis et al. showed a significant reduction in antibiotic use in the intervention group (RR 0.53, 95\% Cl 0.40 to 0.69). ${ }^{17}$ Three studies, Agnew et $\mathrm{al}^{18}(\mathrm{n}=115)$, Little et $\mathrm{al}^{19}(\mathrm{n}=807)$, and Macfarlane et $\mathrm{al}^{21}(\mathrm{n}=259)$ described the use of patient information leaflets in addition to delaying antibiotic prescription for a respiratory tract infection. ${ }^{18,19,21}$ This caused a significant reduction of antibiotic use in one study examining the effect of a booklet among 259 previously healthy adults presenting with acute bronchitis (RR $0.7695 \% \mathrm{Cl} 0.59$ to 0.97). ${ }^{21}$ It also led to fewer prescriptions in a study among 115 patients where information leaflets on antibiotics were combined with a delay in antibiotic prescription 0.6 (95\% Cl 0.42 to 0.86$){ }^{18}$ Little et al's ${ }^{19}$ study among patients aged 3 years or older, who had signs of an acute, uncomplicated lower respiratory tract infection, showed a non-significant decrease in antibiotic use (RR $0.96,95 \% \mathrm{Cl} 0.83$ to 1.11$)$.

Four studies evaluated reconsultation rates. ${ }^{17,19-21}$ A large study from Macfarlane et al ${ }^{20}$ showed a significant reduction (RR 0.70, 95\% Cl 0.53-0.91). ${ }^{20}$ Two other studies from Francis et al. and Macfarlane et al. did not show a significant reduction in reconsultation for the same illness episode after providing an information leaflet $\left(R 0.8,95 \% \mathrm{Cl} 0.52\right.$ to $1.21^{17}$ and $0.79,95 \% 0.38$ to 1.67 , respectively). ${ }^{21}$ Little et al's ${ }^{19}$ study showed a significant increase in attendance in the month after index consultations in the intervention group (RR 1.53, 95\% Cl 1.03-2.27).

In addition to reconsultation rates, some studies also focused on patients' intention to reconsult for similar illnesses. Francis et al ${ }^{17}$ showed a significant reduction in intention to reconsult among parents in the intervention group ( $R R 0.72,95 \% \mathrm{Cl} 0.63$ to 0.82 ) while Everitt et $\mathrm{al}^{22}$ studying the effect of a conjunctivitis leaflet in a study population of 307 adult and paediatric subjects, found a non-significant reduction in the intention to reconsult for future similar symptoms (RR 0.86, 95\% $\mathrm{Cl} 0.66$ to 1.12 ).

\section{Other outcome measures}

Everitt et $\mathrm{al}^{22}$ showed that patient information leaflets had a positive effect on patient satisfaction. Patients in the intervention group were more satisfied with the GP consultation and provided information. Other studies assessed patients' beliefs in the effectiveness of antibiotics ${ }^{19,22}$ and patients' worries. ${ }^{17,22}$ However, they did not show any significant effects. In the study by Susteric et $\mathrm{al}^{24}{ }^{24}$ among 400 French adults and children consulting a GP with gastroenteritis or tonsillitis, patients and parents who received a 
leaflet showed behaviour significantly closer to that recommended by the leaflet. Francis et $\mathrm{al}^{17}$ investigated the effect of an information booklet on patient enablement but did not find a significant increase. One small study dated from 1981 concerned urinary tract infections. The study investigated if a patient education leaflet given in addition to a prescribed course of antibiotics could increase compliance rates; no significant improvements were found. ${ }^{23}$ 


\section{DISCUSSION}

\section{Main findings}

The findings of this review suggest that the use of information leaflets in general practice consultations are effective in reducing antibiotic prescription by GPs and actual antibiotic use by patients and their intention to reconsult for future similar episodes of illness. It is unclear whether information leaflets also actually affect reconsultation rates.

\section{Relevance and comparison with other studies}

There are many reasons and indications for which a GP might consider handing out a patient information leaflet. A study showed that patient information leaflets are appreciated by patients because they have the potential to enhance patient-physician interaction, health-related knowledge and self-management. ${ }^{25}$ This makes patient information leaflets attractive in general. However, they might not be suitable for every indication, since there are also studies that show that leaflets for example about medication side effects are not used by many patients and have a negative effect in the patients that do use them by increasing anxiety. ${ }^{26}$ Nevertheless, since acute infections are so common, mostly self-managed and the patient-doctor interaction is considered as an important determinant of antibiotic prescriptions we believe that these leaflets do have potential for this indication when used interactively in the consulting room.

Antibiotic use was reduced significantly in three of four studies. The same tendency was seen for antibiotic prescription; there was a significant reduction of prescriptions in one study ${ }^{17}$ and a non-significant reduction in another study. ${ }^{20}$ Seven studies focused on selflimiting infections, which often do not require any antibiotic treatment. Previous studies emphasized that antibiotic prescription by GPs is strongly influenced by patient expectations of antibiotics, and consequently GPs sense patient pressure to prescribe. ${ }^{15}$ This potentially leads to an antibiotic prescription in two out of three consultations despite the lack of a true indication. ${ }^{6}$ Overuse of antibiotics contributes to the growing problem of drug resistance. ${ }^{27}$ Adequate patient education is, therefore, required to adjust the widespread belief among patients that antibiotics are a solution for all infections. In addition, facilitation of communication is necessary to prevent GPs from feeling pressured to prescribe antibiotics when patients do not expect a prescription. A simple intervention like an information leaflet might be a very promising tool to facilitate this dialogue and to reduce unnecessary antibiotic prescriptions.

The studies of Francis et $\mathrm{al}^{17}$ and Everitt et $\mathrm{al}^{22}$ examined the effect of patient information leaflets on future consultation behaviour and showed a significant and a non-significant reduction, respectively, in patients' and parents' intention to reconsult. Actual 
reconsultation rates were significantly lower only in the leaflet intervention group of the largest study with a relative risk of 0.70 (0.53 to 0.90). ${ }^{6}$ This reduction in reconsultation and intention to reconsult could be caused by leaflets containing advice on self-management and self-treatment strategies. Interestingly, one of the studies showed that patient information leaflets also reduced the number of consultations by other household members who acquired the same infection. ${ }^{24}$ If consultation rates can be lowered without decreasing patients' satisfaction and quality of care, this can lead to a reduction in the amount of GP consultations. Yet again, one study showed a significant increase in consultation rates in the leaflet group. ${ }^{19}$ In this case, the leaflet might have triggered patients to recognize signs and symptoms described in the information leaflet, which could lead to additional consultations to obtain advice for symptoms such as ongoing fever or shortness of breath.

Many previous studies investigated the effect of patient education materials. However, the effect of those education materials was mostly assessed in multiple clinical settings and focused on conditions other than common infections. Our search yielded many studies on smoking cessation, asthma self-management, coping studies on cardiovascular diseases, and musculoskeletal problems such as lower back pain. Many of these studies were included in a systematic review evaluating the effect of information materials on low back pain. Variable results were found on reconsultation rates and behavioural improvement. ${ }^{28-}$ ${ }^{30}$ One interventional trial found significant reductions in solicitation of emergency care for non-urgent care of children after providing the parents with educational leaflets. ${ }^{31}$ In another study, families receiving a preventive information leaflet had fewer unnecessary visits for respiratory tract infections. ${ }^{32}$ A Dutch study investigated the effect of a leaflet on minor illnesses handed out by GPs to their patients. A significant decrease in the number of consultations for minor illnesses was seen in the entire population. ${ }^{33}$

\section{Strength and Limitations}

The quality of evidence in the included articles varied from reasonably good to good. All studies scored high risk of "blinding of participants and personnel." This was unsurprising since the nature of a patient information leaflet makes it relatively impossible to blind both GPs and patients. Therefore, all studies had an open label design.

Three studies scored high risk in blinding of outcome assessors. ${ }^{19,21,22}$ This was caused due to the fact that patients wrote down their perceptions and symptoms in a patient diary at home. However, we believe the introduction of an independent outcome assessor to write down this subjective information is not likely to lower the risk of reporting bias. 
Most studies performed an adequate randomisation. Two studies performed cluster randomisation on the practice level. ${ }^{17,24}$ Cluster randomisation could hypothetically increase the risk of post-randomisation recruitment bias, as GPs are aware of their assignment to an intervention group and are able to influence the selection of patients. However, the strength of this strategy is that it avoids contamination between control and intervention groups.

There were some other potential threats to validity. Two studies had a small study population, which could have influenced the results and led to insufficient power to find a significant difference in antibiotic prescriptions and reconsultation rates. ${ }^{18,23}$ Regarding the setting, all studies took place in general practices in Western European countries. Therefore, we do not know to what extend these results are generalizable to non-Western primary care settings. One study was carried out in a training practice, and we are not sure whether this is completely comparable to regular general practices. ${ }^{18}$ For example, GPs working in a training practice might be more aware of their communication skills than GPS working in a regular practice.

One explanation for the differences in the effects of the information leaflets could be that in several studies the information leaflet was handed out by GPs at the end of the consultation, or handed over in a sealed envelope, without further explanation. In one study, the booklet was introduced more interactively during the consultation. ${ }^{17}$ By discussing the information, it is guaranteed that patients are exposed to the leaflet's content. In our opinion, this interactive approach could facilitate more effective communication and GPs may address potential misconceptions about antibiotic prescriptions, thereby enhancing the quality of a consultation and reinforcing the intended effect: to better the knowledge among patients and prescribe fewer antibiotics. This might be one of the reasons why the intervention in this study let to fewer antibiotic prescriptions and intention to reconsult while in other studies it had no effect.

A similar approach was taken in a large multinational European trial with 4264 patients in which important reductions in antibiotic prescriptions for respiratory-tract infections were achieved by using an interactive booklet across language and cultural boundaries. ${ }^{34}$ This study was not included in our systematic review as the use of that interactive booklet was part of a multifaceted complex communication during a training intervention. Hence, the effect of the booklet alone could not be disentangled.

To the best of our knowledge, this is the first systematic review to present the effectiveness of written information used during GP consultations for common infections. Since the aim of this study was not to investigate the effect of preventive leaflets, we only included leaflets that were handed over in person by a GP or medical employee and contained 
information on the reason for the patient consult. In our opinion, the active use of a leaflet during consultation, and the fact that it relates to an acute problem, increases the chance that patients will actually read the leaflet and consider it relevant. Owing to this fact, studies were excluded because they were preventive or seen as educational and not related to a consultation.

There are certain limitations in this review that should be recognized. There was a great variety in study population samples (adults, children or both) and in the primary and secondary outcomes, which were measured both objectively and subjectively. To this heterogeneity, one of the major difficulties of this review is generalizing the evidence of included studies. We did not perform a heterogeneity analysis because of the heterogeneity in methodologies and study populations. We believe that, in this case, methodological heterogeneity is superior to statistical heterogeneity. However, relative risks and applied confidence intervals were calculated for our outcomes of interest to compare and interpret outcome data.

\section{Implications for practice}

Patient information leaflets are generally assumed to have several advantages: saving time in consultation, providing evidence-based patient information and stimulating patients to follow advice correctly. ${ }^{35}$ To make these leaflets accessible to the broad public, the level of (health) literacy should be considered. The usage of plain language reinforced with pictorial representations increases the utilization of educational material. ${ }^{36}$ We also acknowledge that a subgroup of patients presenting in general practice do need antibiotics to treat serious infections. Patient information leaflets should, therefore, also provide patients with information on when they should consult because they might need treatment.

This systematic review indicates that the use of patient information leaflets may be a promising tool to reduce antibiotic use. Therefore, the use of patient information leaflets for common infections in general practice should be encouraged. Included studies mostly focused on the immediate effects of leaflets on reconsultation rates. The use of these patient information leaflets might also decrease consultation rates for similar illnesses in the future. To investigate if such an effect exists, a long term follow-up trial on a large cohort of patients in general practice is necessary. Since communication is the cornerstone of general practice consultation and patients can only typically recall two instructions given in a consultation, ${ }^{37}$ further studies into the effectiveness of leaflets for conditions other than common infections should be propagated. 


\section{Conclusions}

Overall, this review provides evidence that the use of patient information leaflets on common infections during GP consultation may effectively reduce antibiotic prescriptions and antibiotic use and patients' intention to reconsult. Therefore, GPs are encouraged to actively use patient information leaflets during consultations for common infections. 


\section{REFERENCES}

1. Bronzwaer SL, Cars O, Buchholz U, Molstad S, Goettsch W, Veldhuijzen IK, et al. A European study on the relationship between antimicrobial use and antimicrobial resistance. Emerg Infect Dis. 2002;8:278-82.

2. Butler CC, Hillier S, Roberts Z, Dunstan F, Howard A, Palmer S. Antibiotic-resistant infections in primary care are symptomatic for longer and increase workload: outcomes for patients with E. coli UTIs. Br J Gen Pract. 2006;56:686-92.

3. Petersen I, Johnson AM, Islam A, Duckworth G, Livermore DM, Hayward AC. Protective effect of antibiotics against serious complications of common respiratory tract infections: retrospective cohort study with the UK General Practice Research Database. BMJ. 2007;335:982.

4. Monto AS. Epidemiology of viral respiratory infections. Am J Med. 2002:4S-12S.

5. Smith SM, Fahey T, Smucny J, Becker LA. Antibiotics for acute bronchitis. The Cochrane database of systematic reviews. 2014;3:CD000245.

6. Macfarlane J, Holmes W, Macfarlane R, Britten N. Influence of patients' expectations on antibiotic management of acute lower respiratory tract illness in general practice: questionnaire study. BMJ. 1997;315:1211-4.

7. Howie JG. Clinical judgement and antibiotic use in general practice. BMJ. 1976;2:1061-4.

8. Little P, Gould C, Williamson I, Warner G, Gantley M, Kinmonth AL. Reattendance and complications in a randomised trial of prescribing strategies for sore throat: the medicalising effect of prescribing antibiotics. BMJ. 1997;315:350-2.

9. Butler CC, Rollnick S, Pill R, Maggs-Rapport F, Stott N. Understanding the culture of prescribing: Qualitative study of general practitioners' and patients' perceptions of antibiotics for sore throats. BMJ. 1998;317:637-42.

10. Kenny T, Wilson RG, Purves IN, Clark J, Sr., Newton LD, Newton DP, et al. A PIL for every ill? Patient information leaflets (PILs): a review of past, present and future use. Fam Pract. 1998;15:471-9.

11. Moult B, Franck LS, Brady H. Ensuring quality information for patients: development and preliminary validation of a new instrument to improve the quality of written health care information. Health Expect. 2004;7:165-75.

12. McCarthy K, Prentice P. Commissioning health education in primary care. BMJ. 2006;333:667-8.

13. Little P, Dorward M, Warner G, Moore M, Stephens K, Senior J, et al. Randomised controlled trial of effect of leaflets to empower patients in consultations in primary care. BMJ. 2004;328:441. 
14. Sustersic M, Voorhoeve $M$, Menuret $H$, Baudrant $M$, Meneau A, Bosson J. Fiches d'information pour les patients: quel intérêt? L'étude EDIMAP 2010;276:332-9.

15. Mills ME, Sullivan K. The importance of information giving for patients newly diagnosed with cancer: a review of the literature. J Clin Nurs. 1999;8:631-42.

16. Higgins JPT, Green S, (editors). Cochrane handbook for systematic reviews of interventions: The Cochrane Collaboration; 2011.

17. Francis NA, Butler CC, Hood K, Simpson S, Wood F, Nuttall J. Effect of using an interactive booklet about childhood respiratory tract infections in primary care consultations on reconsulting and antibiotic prescribing: A cluster randomised controlled trial. BMJ. 2009;339:374-6.

18. Agnew J, Taaffe M, Darker C, O'Shea B, Clarke J. Delayed prescribing of antibiotics for respiratory tract infections: Use of information leaflets. Ir Med J. 2013;106.

19. Little P, Rumsby K, Kelly J, Watson L, Moore M, Warner G, et al. Information leaflet and antibiotic prescribing strategies for acute lower respiratory tract infection: $A$ randomized controlled trial. JAMA. 2005;293:3029-35.

20. Macfarlane JT, Holmes WF, Macfarlane RM. Reducing reconsultations for acute lower respiratory tract illness with an information leaflet: A randomized controlled study of patients in primary care. Br J Gen Pract. 1997;47:719-22.

21. Macfarlane J, Holmes W, Gard P, Thornhill D, Macfarlane R, Hubbard R. Reducing antibiotic use for acute bronchitis in primary care: Blinded, randomised controlled trial of patient information leaflet. BMJ. 2002;324:91-4.

22. Everitt HA, Little PS, Smith PWF. A randomised controlled trial of management strategies for acute infective conjunctivitis in general practice. BMJ. 2006;333:321-4.

23. Gauld VA. Written advice: compliance and recall. The Journal of the Royal College of General Practitioners. 1981;31:553-6.

24. Sustersic M, Jeannet E, Cozon-Rein L, Marechaux F, Genty C, Foote A, et al. Impact of information leaflets on behavior of patients with gastroenteritis or tonsillitis: A cluster randomized trial in french primary care. J Gen Intern Med. 2013;28:25-31.

25. Moerenhout T, Borgermans L, Schol S, Vansintejan J, Van De Vijver E, Devroey D. Patient health information materials in waiting rooms of family physicians: do patients care? Patient preference and adherence. 2013;7:489-97.

26. Vinker S, Eliyahu V, Yaphe J. The effect of drug information leaflets on patient behavior. Isr Med Assoc J. 2007;9:383-6.

27. Health Do. UK 5 Year Antimicrobial Resistance (AMR) Strategy 2013-2018 progress report2014 April 2015; (April). Available from: 
https://www.gov.uk/government/uploads/system/uploads/attachment_data/file/385733/ UK_AMR_annual_report.pdf.

28. Hazard RG, Reid S, Haugh LD, McFarlane G. A controlled trial of an educational pamphlet to prevent disability after occupational low back injury. Spine. 2000;25:1419-23. 29. Henrotin YE, Cedraschi C, Duplan B, Bazin T, Duquesnoy B. Information and low back pain management: a systematic review. Spine 2006;31:E326-34.

30. Roberts L, Little P, Chapman J, Cantrell T, Pickering R, Langridge J. The back home trial: general practitioner-supported leaflets may change back pain behavior. Spine 2002;27:1821-8.

31. Yoffe SJ, Moore RW, Gibson JO, Dadfar NM, McKay RL, McClellan DA, et al. A reduction in emergency department use by children from a parent educational intervention. Fam Med. 2011;43:106-11.

32. Roberts CR, Imrey PB, Turner JD, Hosokawa MC, Alster JM. Reducing physician visits for colds through consumer education. JAMA. 1983;250:1986-9.

33. Plass AM, Timmermans DR, van der Wal G. Decreasing the number of consultations for minor illnesses of Turkish and Dutch inhabitants of a deprived area in The Netherlands: an intervention study. Fam Pract. 2005;22:51-7.

34. Little P, Stuart B, Francis N, Douglas E, Tonkin-Crine S, Anthierens S, et al. Effects of internet-based training on antibiotic prescribing rates for acute respiratory-tract infections: a multinational, cluster, randomised, factorial, controlled trial. Lancet. 2013;382:1175-82.

35. Dixon-Woods M. Writing wrongs? An analysis of published discourses about the use of patient information leaflets. Soc Sci Med. 2001;52:1417-32.

36. Ferguson LA, Pawlakm R. . Health literacy: The road to improved health ourcomes. J Nurse Pract. 2011:123-9.

37. Watson PW, McKinstry B. A systematic review of interventions to improve recall of medical advice in healthcare consultations. J R Soc Med. 2009;102:235-43. 


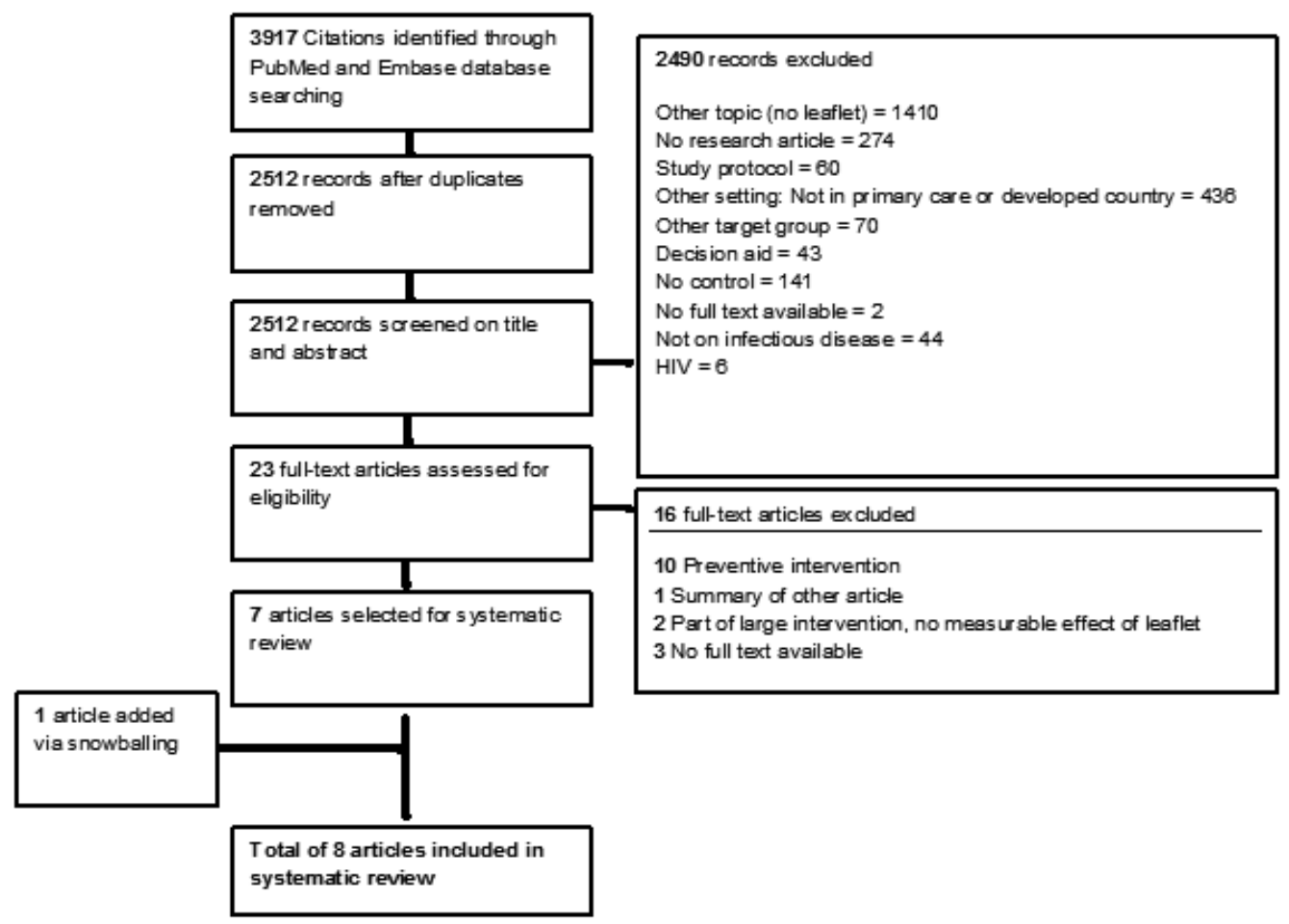

Figure 7.1 Flowchart for the study selection 


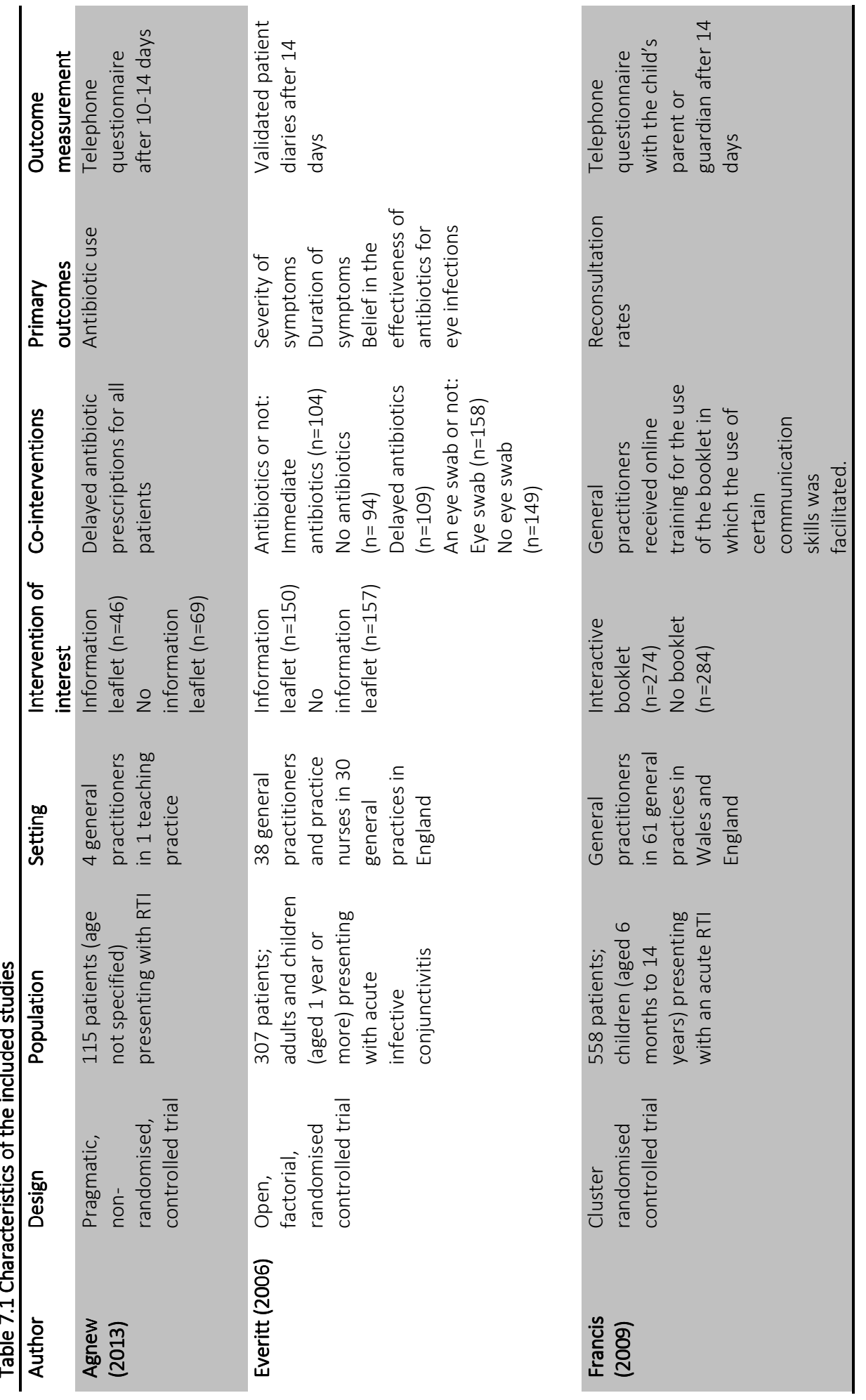




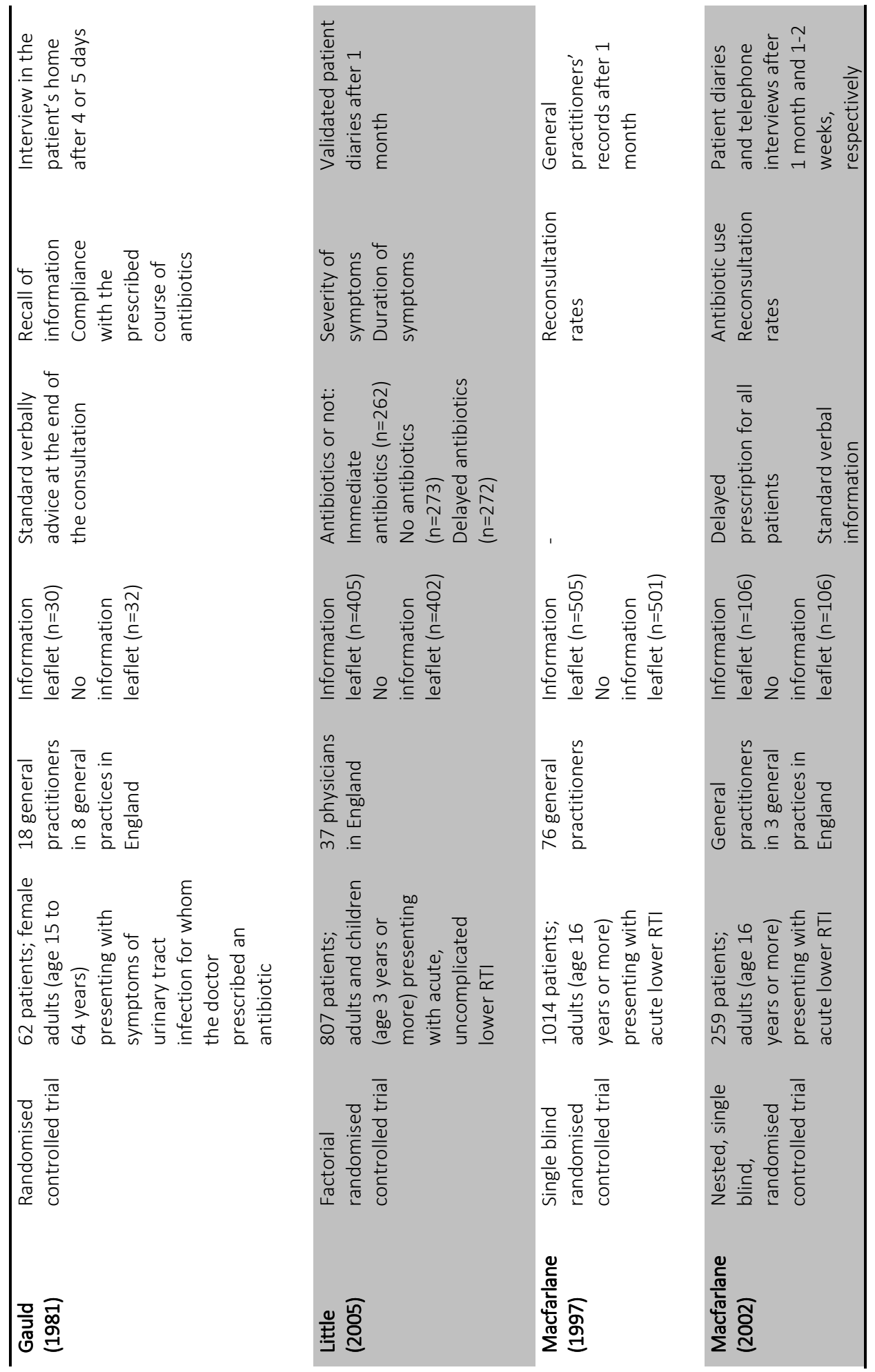




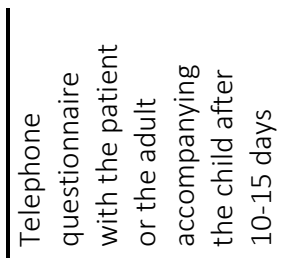

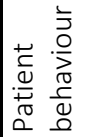

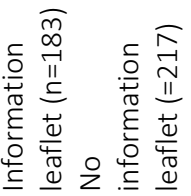

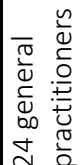

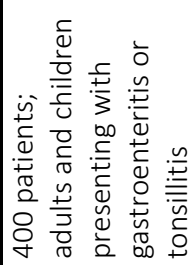

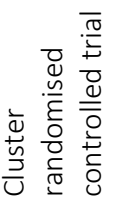

늠

产 
Table 7.2 Risk of bias (summary) of the included studies assessed by Cochrane's risk of bias tool

\begin{tabular}{|c|c|c|c|c|c|c|}
\hline Author & $\begin{array}{l}\text { Sequence } \\
\text { generation }\end{array}$ & $\begin{array}{l}\text { Allocation } \\
\text { concealment }\end{array}$ & $\begin{array}{l}\text { Blinding } \\
\text { participants } \\
\text { and } \\
\text { personnel }\end{array}$ & $\begin{array}{l}\text { Blinding of } \\
\text { outcome } \\
\text { assessors }\end{array}$ & $\begin{array}{l}\text { Incomplete } \\
\text { outcome } \\
\text { data }\end{array}$ & $\begin{array}{l}\text { Selective } \\
\text { outcome } \\
\text { reporting }\end{array}$ \\
\hline $\begin{array}{l}\text { Agnew } \\
\text { (2013) }\end{array}$ & High risk & Low risk & High risk & $\begin{array}{l}\text { Unclear } \\
\text { risk }\end{array}$ & Unclear risk & Low risk \\
\hline $\begin{array}{l}\text { Everitt } \\
\text { (2006) }\end{array}$ & Low risk & Low risk & High risk & High risk & Low risk & Low risk \\
\hline $\begin{array}{l}\text { Francis } \\
\text { (2009) }\end{array}$ & Low risk & Low risk & High risk & Low risk & Low risk & Low risk \\
\hline Gauld (1981) & $\begin{array}{l}\text { Unclear } \\
\text { risk }\end{array}$ & Unclear risk & High risk & Low risk & Low risk & Low risk \\
\hline Little (2005) & Low risk & Low risk & High risk & High risk & Low risk & Low risk \\
\hline $\begin{array}{l}\text { Macfarlane } \\
\text { (1997) }\end{array}$ & $\begin{array}{l}\text { Unclear } \\
\text { risk }\end{array}$ & Low risk & High risk & $\begin{array}{l}\text { Unclear } \\
\text { risk }\end{array}$ & Low risk & Low risk \\
\hline $\begin{array}{l}\text { Macfarlane } \\
\text { (2002) }\end{array}$ & $\begin{array}{l}\text { Unclear } \\
\text { risk }\end{array}$ & Low risk & High risk & High risk & Low risk & Low risk \\
\hline $\begin{array}{l}\text { Susteric } \\
\text { (2013) }\end{array}$ & Low risk & Low risk & High risk & $\begin{array}{l}\text { Unclear } \\
\text { risk }\end{array}$ & Low risk & Low risk \\
\hline
\end{tabular}


Table 7.3 Effect of patient information leaflets on antibiotic prescribing, antibiotic use, reconsultation and intention to reconsult in respiratory tract infections

Antibiotics Reconsultation

\begin{tabular}{|c|c|c|c|c|}
\hline & $\begin{array}{l}\text { Antibiotic } \\
\text { prescribing } \\
R R(95 \% \mathrm{Cl})\end{array}$ & $\begin{array}{l}\text { Antibiotic use } \\
R R(95 \% \mathrm{Cl})\end{array}$ & $\begin{array}{l}\text { Reconsultation } \\
\text { rate } \\
R R(95 \% \mathrm{Cl})\end{array}$ & $\begin{array}{l}\text { Intention to } \\
\text { reconsult } \\
R R(95 \% \mathrm{Cl})\end{array}$ \\
\hline $\begin{array}{l}\text { Agnew (2013) } \\
n=115 \\
\text { Respiratory tract } \\
\text { infection }\end{array}$ & - & $\begin{array}{l}0.6(0.42- \\
0.86)\end{array}$ & - & - \\
\hline $\begin{array}{l}\text { Everitt (2006) } \\
\mathrm{n}=307 \\
\text { Acute conjunctivitis }\end{array}$ & - & - & - & $0.86(0.66-1.12)$ \\
\hline $\begin{array}{l}\text { Francis (2009) } \\
\mathrm{n}=558 \\
\text { Respiratory tract } \\
\text { infection }\end{array}$ & $0.47(0.36-0.64)$ & $\begin{array}{l}0.53(0.40- \\
0.69)\end{array}$ & $0.80(0.52-1.21)^{*}$ & $0.72(0.63-0.82)$ \\
\hline $\begin{array}{l}\text { Little (2005) } \\
n=807 \\
\text { Respiratory tract } \\
\text { infection }\end{array}$ & - & $\begin{array}{l}0.96(0.83- \\
1.11)\end{array}$ & $1.53(1.03-2.27)^{* *}$ & - \\
\hline $\begin{array}{l}\text { Macfarlane (1997) } \\
\mathrm{n}=1014 \\
\text { Respiratory tract } \\
\text { infection }\end{array}$ & $1.15(0.89-1.48)$ & - & $0.70(0.53-0.91)^{* *}$ & - \\
\hline $\begin{array}{l}\text { Macfarlane (2002) } \\
n=259 \\
\text { Respiratory tract } \\
\text { infection }\end{array}$ & - & $\begin{array}{l}0.76(0.59- \\
0.97)\end{array}$ & $0.79(0.38-1.67)^{* *}$ & - \\
\hline
\end{tabular}

$R R=$ relative risk. Expressed as the risk of the outcome for those patients managed by patient leaflets compared to the risk of the outcome for patients managed in the control group (no leaflet)

* within two weeks

** within one month 


\section{Appendix 1 PubMed search strategy (April 2014)}

((handout[All Fields] OR (handout[All Fields] OR handout'[All Fields] OR handouts[All Fields] OR handouts'[All Fields]) OR leaflet[All Fields] OR leaflet'[All Fields] OR leaflet's[All Fields] OR leaflets[All Fields] OR leaflets'[All Fields] OR ("pamphlets"[MeSH Terms] OR "pamphlets"[All Fields] OR "booklet"[All Fields]) OR (("pamphlets"[MeSH Terms] OR "pamphlets"[All Fields] OR "booklet"[All Fields]) OR booklet'[All Fields] OR booklet's[All Fields] OR ("pamphlets"[MeSH Terms] OR "pamphlets"[All Fields] OR "booklets"[All Fields]) OR booklets'[All Fields]) OR (("pamphlets"[MeSH Terms] OR "pamphlets"[All Fields] OR "pamphlet"[All Fields]) OR pamphlet's[All Fields] OR ("pamphlets"[MeSH Terms] OR "pamphlets"[All Fields]) OR pamphlets'[All Fields] OR pamphlett[All Fields]) OR (flyer[All Fields] OR flyer'[All Fields] OR flyer's[All Fields] AND flyers[All Fields] OR flyers'[All Fields]) OR (folder[All Fields] OR folder'[All Fields] OR folders[All Fields] OR ("pamphlets"[MeSH Terms] OR "pamphlets"[All Fields] OR "brochure"[All Fields]) OR (("pamphlets"[MeSH Terms] OR "pamphlets"[All Fields] OR "brochure"[All Fields]) OR brochure'[All Fields] OR brochure's[All Fields] OR ("pamphlets"[MeSH Terms] OR "pamphlets"[All Fields] OR "brochures"[All Fields])))) AND (("primary health care"[MeSH Terms] OR ("primary"[All Fields] AND "health"[All Fields] AND "care"[All Fields]) OR "primary health care"[All Fields] OR ("primary"[All Fields] AND "care"[All Fields]) OR "primary care"[All Fields]) OR ("general practice"[MeSH Terms] OR ("general"[All Fields] AND "practice"[All Fields]) OR "general practice"[All Fields]) OR ("general practitioners"[MeSH Terms] OR ("general"[All Fields] AND "practitioners"[All Fields]) OR "general practitioners"[All Fields]) OR ("physicians, family"[MeSH Terms] OR ("physicians"[All Fields] AND "family"[All Fields]) OR "family physicians"[All Fields] OR ("family"[All Fields] AND "physicians"[All Fields])) OR ("family practice"[MeSH Terms] OR ("family"[All Fields] AND "practice"[All Fields]) OR "family practice"[All Fields]) OR ("family practice"[MeSH Terms] OR ("family"[All Fields] AND "practice"[All Fields]) OR "family practice"[All Fields] OR ("family"[All Fields] AND "medicine"[All Fields]) OR "family medicine"[All Fields]) OR ("primary health care"[MeSH Terms] OR ("primary"[All Fields] AND "health"[All Fields] AND "care"[All Fields]) OR "primary health care"[All Fields]))) NOT dental[title/abstract] 

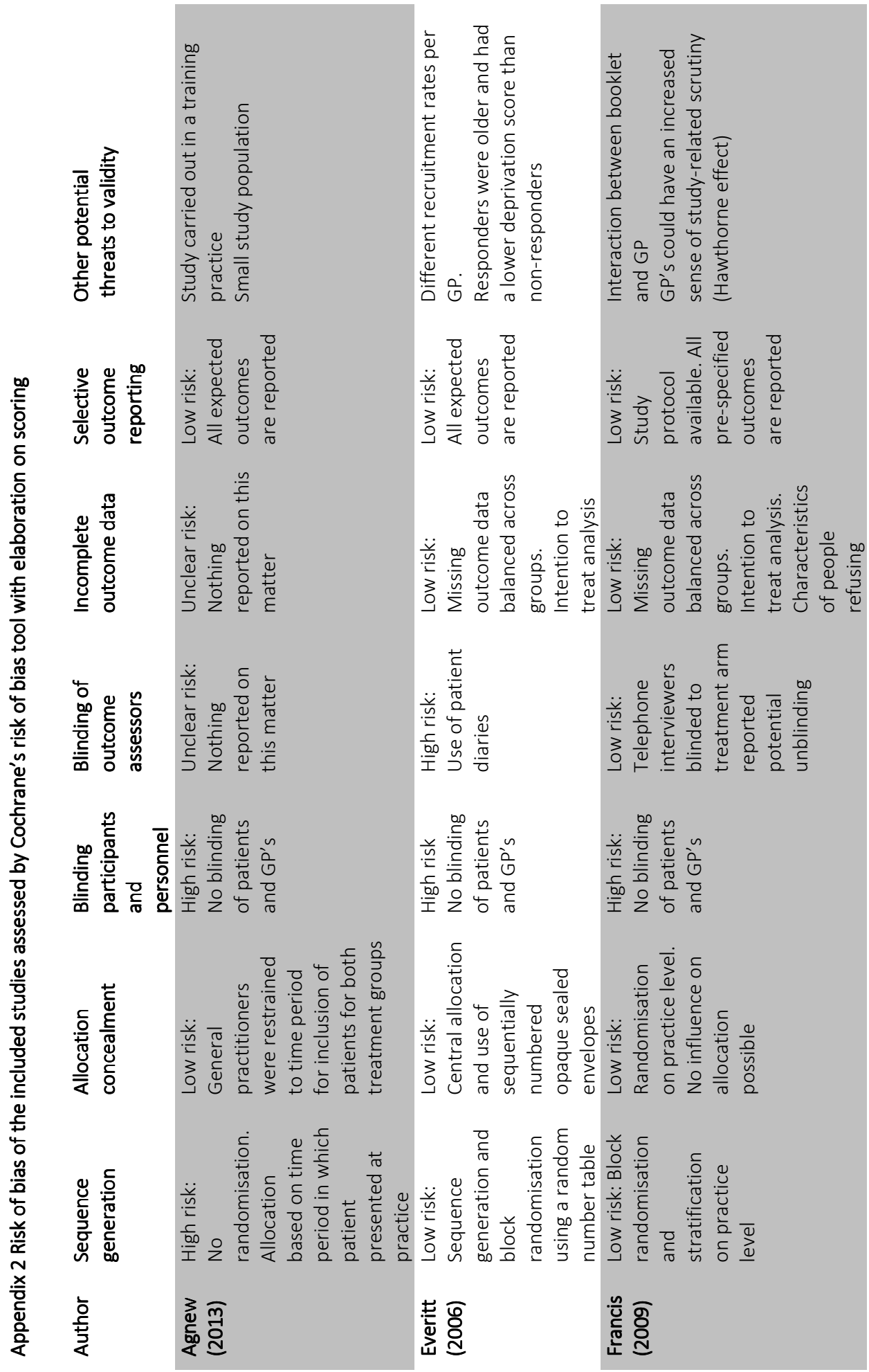


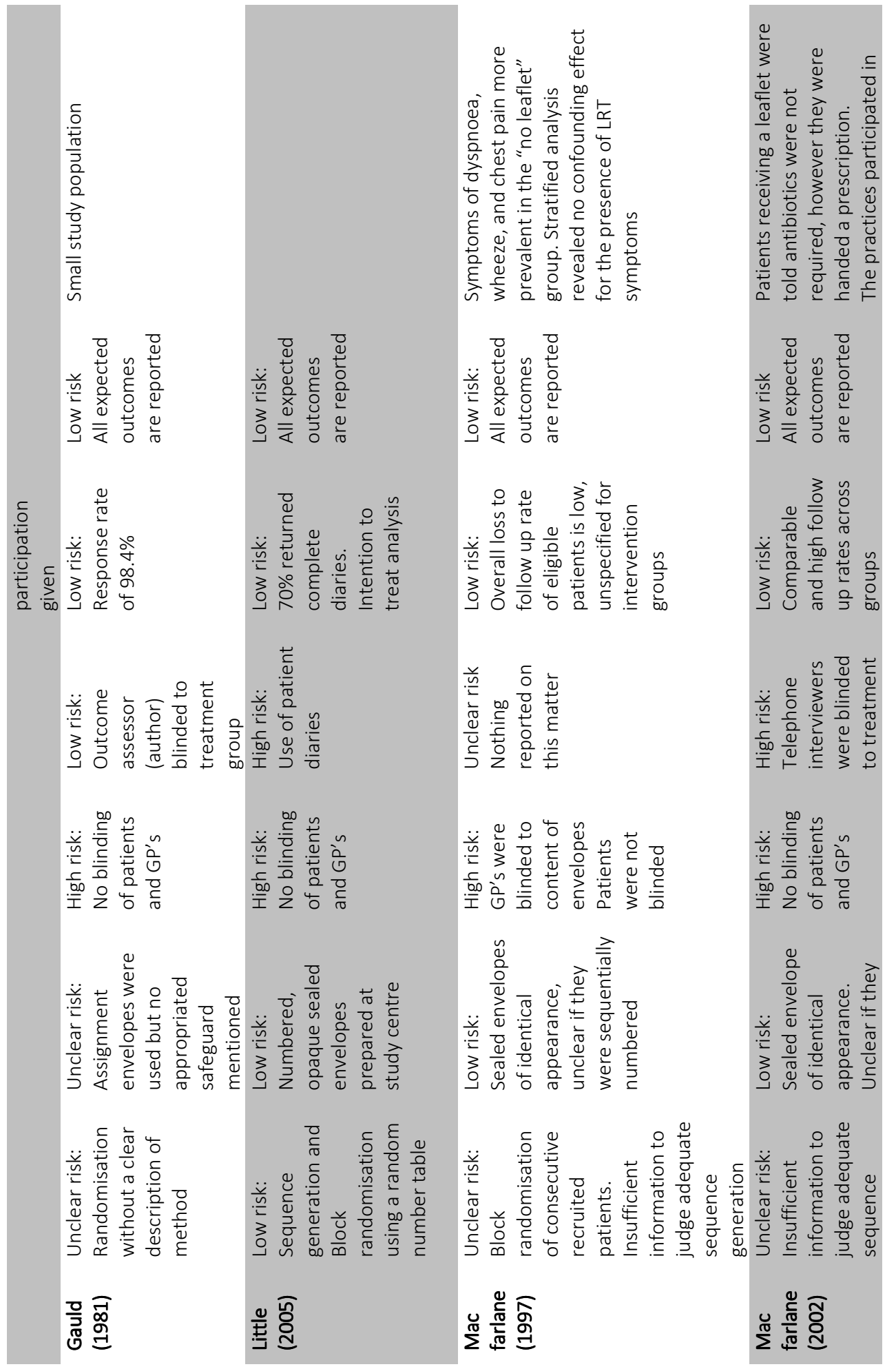




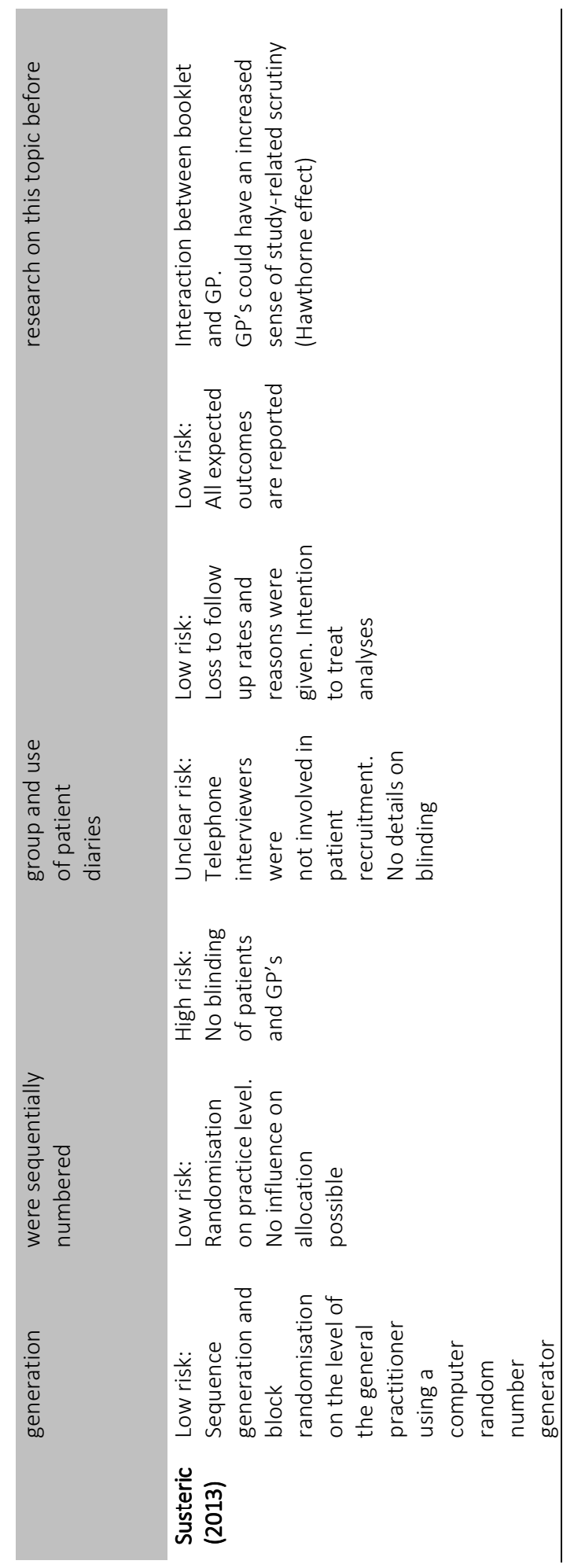




\section{Effect of the}

interactive booklet on

\section{childhood fever}

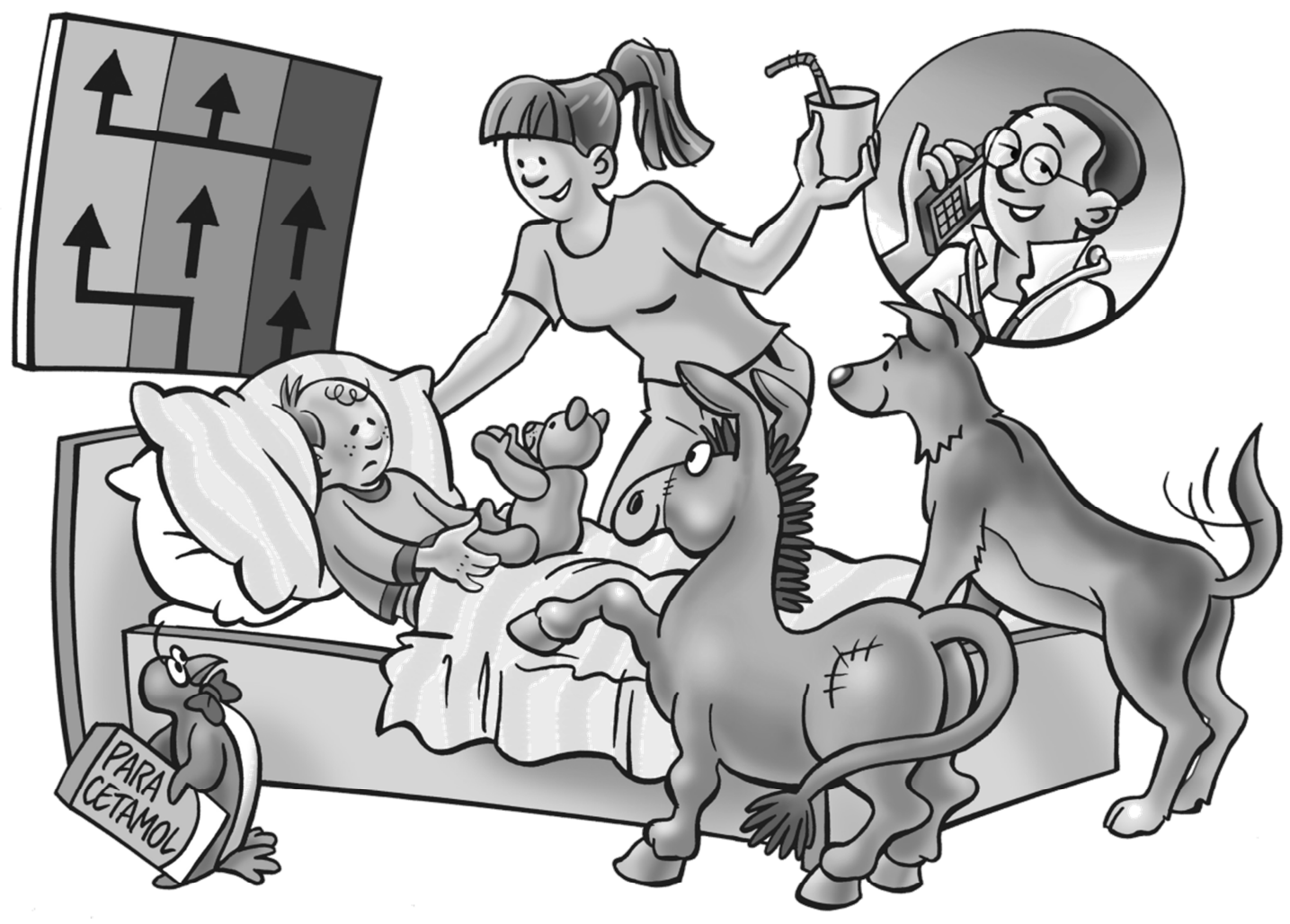



HAPTER 8

An illness-focussed interactive booklet to optimise management and medication for childhood fever and infections in outof-hours primary care: study protocol for a cluster randomised trial

Eefje G.P.M. de Bont Geert-Jan Dinant

Gijs Elshout Gijs van Well Nick A. Francis Bjorn Winkens Jochen W.L. Cals 



\section{ABSTRACT \\ Background}

Fever is the most common reason for a child to be taken to a general practitioner (GP), especially during out-of-hours care. It is mostly caused by self-limiting infections which do not require antibiotic treatment or hospital referral. However, antibiotic prescription rates remain high, especially during out-of-hours care. Anxiety and lack of knowledge among parents, and a feeling of pressure to prescribe antibiotics amongst GPs, are important determinants of excessive antibiotic prescriptions. An illness-focussed interactive booklet for parents has the potential to improve this by providing parents with information about fever management and self-management strategies. This study aims to develop and determine the effectiveness of an interactive booklet on the management (antibiotic prescriptions, (re-)consultations and intention to reconsult, referral rates, parental satisfaction and self-reported adverse events) of children presenting with fever at Dutch GP out-of-hours cooperatives.

\section{Methods and analysis}

A cluster randomised trial (RCT), with 20 GP out-of-hours cooperatives randomised to one of two arms; GP access to the illness-focused interactive booklet or care as usual. GPs working at intervention sites will have access to using the illness-focussed interactive booklet, which was developed in a multistage process. The booklet consists of a traffic light system for parents on how to respond to fever-related symptoms, as well as information on natural course of infections, benefit and harms of (antibiotic) medication, self-management strategies and safety net instructions. Children $<12$ years with a parental reported or physician measured fever are eligible for inclusion in the trial. Primary outcome: antibiotic prescribing during the initial consultation. Secondary outcomes: (intention to) (re)consultation, antibiotic prescriptions during reconsultations, referrals, parental satisfaction and reassurance. Over a period of 6 months including the peak infection winter months a target of 20,000 children will be recruited to be able to find a difference in the antibiotic prescribing rate of $25 \%$ in the control group and $19 \%$ in the intervention group having. Statistical analysis will be performed using descriptive statistics and by fitting two level (GP-out-hours centre and patient) random intercept logistic regressions models. Analysis will be based on intention to treat principle. 


\section{Discussion}

This will be the first and largest cluster RCT that will evaluate the effectiveness of using an illness-focused interactive booklet during GP out-of-hours consultations with febrile children on antibiotic prescriptions. It is hypothesized that the use of the booklet during consultations for febrile children at GP out-of-hours centres will result in a reduced number of antibiotic prescriptions, improved parental satisfaction and reduced intention to reconsult.

\section{Trial registration}

ClinicalTrials.gov, number NCT02594553 October $26^{\text {th }} 2015$. 


\section{BACKGROUND}

Fever is the most common reason for a child to be taken to a general practitioner (GP). Childhood infections constitute $60 \%$ of the annual general practice consultation rates for children under 1 year old and approximately 30\% for children up to 15 years of age. ${ }^{1}$ These rates are even higher during out-of-hours care as fever typically rises during the day. ${ }^{1-3}$ In most cases, fever is caused by a benign (viral) infection and general recommendations given by the GP are sufficient. However, one in three to four children who visit a GP out-ofhours centre because of a fever receive an antibiotic prescription. Most often, this is unnecessary and not recommended in guidelines. ${ }^{4,5}$ Additionally, these prescription rates are nearly twice as high as prescription rates during routine office hours. ${ }^{6}$

Previous studies showed that antibiotic prescribing is strongly influenced by patients' expectations and that GPs experience pressure from patients to prescribe antibiotics. ${ }^{7}$ Parents who visit a GP are often concerned about harmful consequences of fever and serious infections, especially when presenting to a GP on call who is not their personal GP. In many cases these concerns are the result of a lack of experience and knowledge about fever in these parents. ${ }^{2}$ Their worries are increased by a rising temperature but also by conflicting information on how to manage fever from different health care providers, websites or people in their surroundings. ${ }^{8}$ Parents search for reassurance, especially when fever is accompanied by other symptoms.

Although GPs sometimes feel pressured to prescribe antibiotics, most parents of a febrile child in fact do not expect antibiotics. They are however in search of reassurance and consistent, reliable information about fever, specific symptoms and self-management strategies. ${ }^{9}$ Nevertheless, conveying evidence-based information to patients on the cause of symptoms, natural course of the symptoms and the expected benefits and harms of treatment is challenging for GPs especially in time-pressured consultations in the evening and night. ${ }^{10}$ GPs perceive that children with a fever account for a high workload during outof-hours care. ${ }^{11}$ This can lead to frustration and a diagnostic challenge due to the low incidence of serious conditions and a lacking long-term relationship during out-of-hours care. These factors play an important role in GPs' decisions when they prescribe antibiotics to children during out-of-hours care since only few children do have a serious infection such as pneumonia, meningitis or complicated urinary tract infections. Concern about missing these serious infections helps drive fear, consulting and prescribing behavior. However, empowering parents and teaching them alarm symptoms minimises the risk of missing serious infections, and helps to not routinely prescribe antibiotics. ${ }^{11}$ Illness-focused interventions recognise the importance of non-medical influences on the decision to consult or to prescribe antibiotics. Exploring the illness experience of parents of 
children with fever and infections may have potential as it specifically addresses the concerns and questions that parents have when their child is sick. Moreover, it may offer the GP a way to convey consistent written information, enhancing their self-management and providing them with safety net advice when they return home with clear instructions in what case to return or seek contact again. ${ }^{12}$ An illness-focused GP-parent information exchange tool consisting of an interactive booklet has the potential to provide parents with information about symptoms and fever management and consistent information during GP consultations. ${ }^{13,14}$ A strong safety net advice provided by a booklet can hypothetically also provide a disease-focussed solution to GPs by providing them with a way to reduce diagnostic uncertainty in these children, thereby also reducing the number of "better safe than sorry" antibiotic prescriptions. ${ }^{15}$

In summary, anxiety and lack of knowledge among parents, but also GPs feeling pressured to prescribe antibiotics during time pressured and diagnostically challenging consultations are important determinants of excessive antibiotic prescriptions for febrile children and inconsistencies in providing care to this vulnerable group of patients. The CHILdHood Infections (CHILI) study therefore aims to develop and determine the effectiveness of an illness-focussed interactive fever booklet for parents on the management (antibiotic prescriptions, (re-)consultations and intention to re-consult, referral rates, parental satisfaction and self-reported adverse events) of children presenting with fever at Dutch GP out-of-hours cooperatives, as well as on relevant parental outcomes (satisfaction and reassurance).

It is hypothesized that the use of an interactive booklet during consultations for febrile children at GP out-of-hours centres will result in a reduced number of antibiotic prescriptions, improved parental satisfaction and reduced intention to re-consult.

\section{OBJECTIVES}

This study will investigate the following research questions:

What is the effect of the pragmatic use of an interactive booklet in childhood fever related consultations for children $<12$ years, during GP out-of-hours care consultations on:

\section{Primary outcome measure}

$\infty$ Antibiotic prescribing rate during the initial consultation 


\section{Secondary outcome measures based on the complete sample}

$\infty$ Reconsultation rate at the GP out-of-hours cooperative for the same illness episode within two weeks of the initial consultation

$\infty$ (Antibiotic) prescribing rate during reconsultations at the GP out-of-hours cooperative within two weeks of the initial consultation

$\infty$ Reconsultations for fever and fever related conditions at the GP cooperative during out-of-hours care during the 6 month study period

$\infty$ Referral to secondary care during the initial consultation and for the same illness episode within two weeks of the initial consultation

\section{Secondary outcome measures based on telephone survey}

$\infty$ Parent-reported reconsultation rate at the own GP during routine daytime hours for the same illness episode within two weeks of the initial consultation

$\infty$ Parent-reported antibiotic prescribing during reconsultations at the own GP during routine daytime hours for the same illness episode within two weeks of the initial consultation

$\infty$ Parent-reported hospital admission for that illness episode within two weeks of the initial consultation

$\infty$ Parent-reported satisfaction with care and parent-reported satisfaction with providing written information materials (including the interactive booklet)

$\infty$ Parent-reported intention to re-consult the out-of-hours GP centre for a future similar illness episode 


\section{METHODS}

This will be a cluster randomised trial with randomisation on the level of GP out-of-hours cooperative. Recruited GP out-of-hours cooperatives will be randomised to one of two arms; GP access to the illness-focused interactive booklet or care as usual.

\section{Development of the intervention}

The development of the illnessed-focused interactive booklet concerned a multistage process (see Figure 8.1). This process was partially based on the development of a previous booklet for upper respiratory tract infections in children that was proven to be effective. ${ }^{16}$ First, a nationwide survey among parents of young children was conducted to obtain insight in parental knowledge, attitudes and practices regarding fever management. ${ }^{2}$ Second, a more in-depth exploration of determinants and influencing factors of GP out-of-hours consultations was performed in focus group sessions and semi-structured interviews with parents, GPs and triage nurses working or consulting during out-of-hours GP care. .,11 $^{9}$ Through this body of research we identified a number of themes focussed on 'what do parents want when their child has a fever' and 'what do GPs need to provide evidencebased information during childhood fever consultations aimed at the illness experience of parents.' We developed an illness-focussed interactive booklet based on these themes, helped by existing guidelines and expert discussions. The booklet contains the following sections:

$\infty$ A traffic light system for fever in general with advice on when to consult (red) and information on self-management strategies (green, orange) for childhood fever in general as well as specific traffic lights for upper respiratory tract infections (cough, cold and sore throat), acute otitis media (earache) and gastrointestinal symptoms (abdominal pain, vomiting and diarrhoea )helping parents to know when to (re)consult and providing them with self-management strategies as well as a safety net)

$\infty$ Information on the benefits and harms of antibiotic treatment (helping parents to make a balanced choice between necessary and unnecessary/undesired use of antibiotics)

$\infty$ An overview of natural duration of common infections in children with a figure displaying the average duration as well as the number of days when $90 \%$ of children is free of symptoms (helping parents to set realistic expectations on how long their child's illness may last) 
$\infty$ A table with weight-banded paracetamol dosage schemes (helping parents to provide their child with a safe, yet effective dose of analgesics if these are required)

$\infty$ Advice and information on febrile convulsions and skin rash (helping parents to recognise alarm symptoms and differentiate these from other benign and common symptoms)

$\infty$ Safety net advise for fever in general as well as safety net advise for the different common infections (helping GPs to create a safety net and helping parents to act upon alarm symptoms so that children who do develop a serious infection are recognized without any delay and complications)

Semi-structured interviews were held to discuss pilot version of the booklet with GPs, paediatricians and parents. The booklet was then revised in accordance with the feedback that was agreed on by the research group. Subsequently, the readability of the booklet was assessed and when necessary adapted by a professional language expert, including an assessment specifically focussing on readability for lay persons. After this, another round of semi-structured interviews was held. Finally, the lay-out of the booklet was professionally adapted.

The booklet incorporates existing information about fever, alarm symptoms, use of antipyretics and antibiotics and specific infectious diseases that frequently occur in childhood in combination with fever such as upper respiratory tract infections, otitis media, urinary tract infections and gastro-enteritis. ${ }^{17}$ The content of this information is similar to the information which is already provided by GPs during care as usual. The main difference with these existing sources of information is the use of a traffic light system were symptoms and the advice belonging to those symptoms are incorporated in the categories green, orange and red, from most harmless to most urgent respectively. Use of such a traffic light system can also be found in the international NICE guideline were the traffic light is diseased-focused and aimed at health care professionals instead of parents. ${ }^{1}$ The major difference is that this booklet is illness-focused, meaning it is specifically aimed at parents and their unique illness experience and decision to consult a GP. By making this information available in the consulting room it may facilitate communication about caring for a febrile child and address misconceptions GP's still hold about parents and patients expecting antibiotics. The interactive part of the booklet therefore implies that is specifically designed to facilitate the exploration of the illness experience of parents of children with fever and common infections to help GPs to specifically address these concerns and questions that parents have when their child is sick and preventing "better 
safe than sorry antibiotic prescriptions" antibiotic prescriptions during these consultations during out-of-hours care.

Our previous qualitative work among parents having visited out-of-hours care revealed that most parents are in search of consistent, reliable information about fever and specific symptoms, which they often do not find on the internet. Most parents did not receive written information from the GP during the consultation, but most suggested that information about alarm symptoms and self-management strategies would be helpful and that that it would be important that this information came from one, comprehensible and reliable information source without inconsistencies. Hence, another major difference with current available information sources is the fact that all the information is incorporated into one booklet which can be physically handed over and discussed with parents.

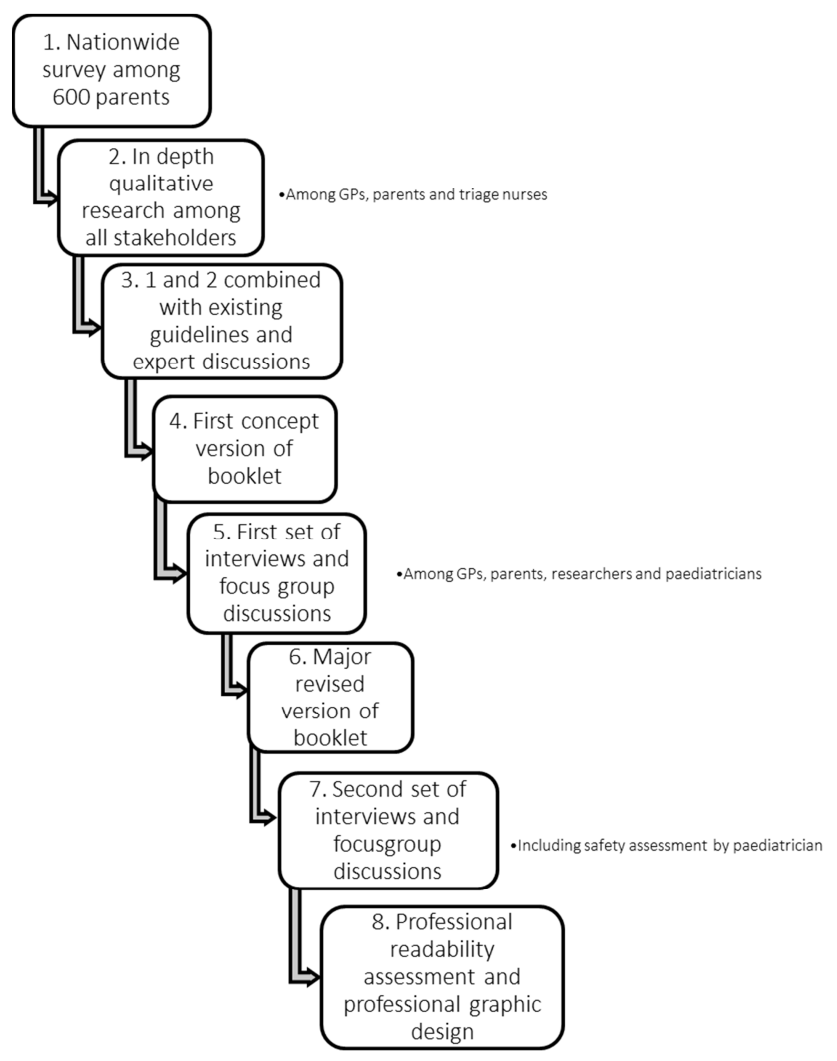

Figure 8.1 Overview of the development process of the interactive booklet 


\section{Setting}

Since the year 2000, GP out-of-hours care in The Netherlands is provided by approximately 120-130 large-scale GP cooperatives, varying from 50 to 200 GPs. ${ }^{18}$ These cooperatives cover primary care by rotating shifts of GPs during evenings, nights and weekends. This means that in almost every consultation, GPs and parents or patients have not met in previous clinical encounters. Out-of-hours care is defined as primary care provided beyond office hours every day between 5 p.m. and 8 a.m. and the entire weekend. ${ }^{18}$ GP out-ofhours centres are essentially intended for urgent help requests that cannot wait until the next day. ${ }^{19}$ There will be 20 large, both rural and urban, GP out-of-hours centres participating in this study, spread across the Netherlands.

\section{Randomisation}

A cluster randomised controlled trial was chosen to reduce the risk of contamination. Based on benchmark data provided by the national organisation of out-of-hours care (InEen) the participating GP out-of-hours cooperatives will be stratified by size (10 small vs. 10 large cooperatives, with a cut-off point of fewer or more than 20500 consultations/year), to ensure equal distribution of size between the intervention and control group. Should the stratification not result in two equal groups of 10 , the cut-off point will be reconsidered. An independent researcher who is not involved in the project will perform a computer based randomisation. Random permuted blocks of two will be generated. This will create ten groups of two GP out-of-hours cooperatives and ensures equal distribution of the intervention and control situation. The randomisation process is graphically shown in figure 8.2. The randomisation outcome will be kept securely and allocation for each cooperative will be provided only after the cooperative has agreed to participate and the stratification variables are provided to the independent researcher. 


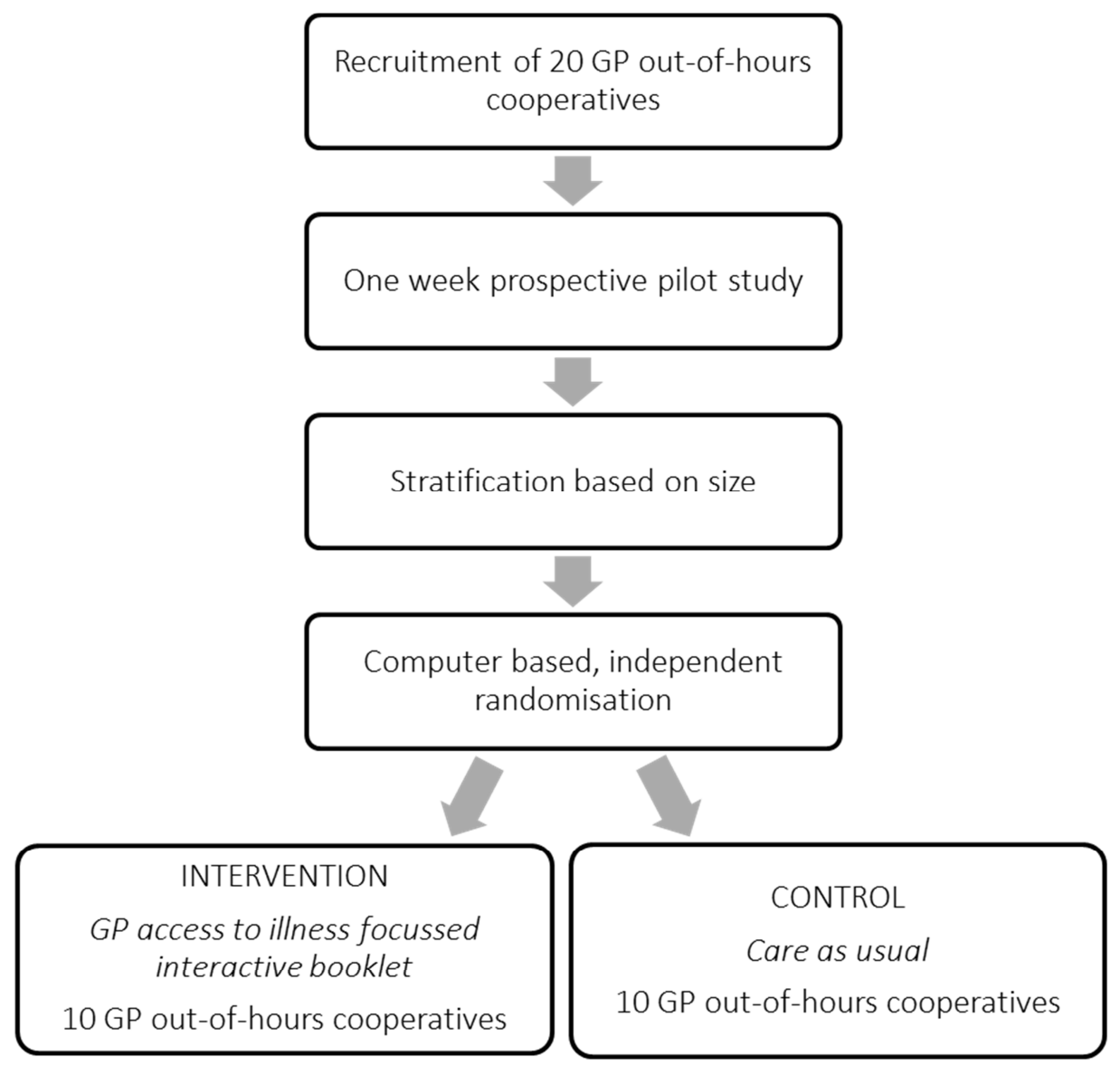

Figure 8.2 Graphical overview of randomisation and inclusion of the CHILI project 


\section{Sample size}

To inform the required sample size, we performed a retrospective cohort study to determine the number of children visiting a GP out-of-hours cooperative. ${ }^{4}$ We identified 17170 contacts for children <12 years, of which 5343 (31.1\%) were fever related and $70 \%$ of these fever related contacts resulted in a face-to-face consultation in data of all contacts of one cooperative providing care to approximately 270,000 inhabitants. This led to a total of 3738 consultations during one year and an average of 15 consultations per day for children with fever and fever-related conditions. The average antibiotic prescription rate we found during this cohort study was $25 \%$, which we set as our baseline prescription rate. Additionally, in those out-of-hours centres which consented to participate in the trial, we performed a pilot study of one week to further investigate consultation rates, with the main consideration that GP out-of-hours centres do vary in size. During this pilot study we found an average of 6 fever related consultations for children per day per out-of-hours centre. Based on the pilot study and the retrospective cohort study, we assumed that 1,000 children per cooperative could be included in 6 months, including the peak infection winter months.

The primary outcome is the antibiotic prescribing rate during the initial consultation (dichotomous). The required number of clusters and participants was based on the following assumptions: (1) Intra-cluster coefficient (ICC) of 0.01 , based on a study that describes the distribution of intra-class correlation coefficients with reference to research in primary care, ${ }^{20}$ (2) alpha of 0.05 , power of 0.80 , (3) proportion of antibiotic prescriptions in control group of $25 \%$ and a proportion of $19 \%$ in the intervention group ( $6 \%$ minimal clinical relevant difference), based on the fact that we would thereby reduce the number of children receiving an antibiotic prescription from one in four to one in five to six and (4) $10 \%$ loss to follow-up and $10 \%$ efficiency loss based on unequal cluster sizes. ${ }^{21} \mathrm{We}$ estimated to include 1,000 children per cluster (GP out-of-hours cooperative) within six months, resulting in a need for 20 clusters to acquire the same power as an individual randomised controlled trial (with an effective sample size of 737 patients in both the intervention and control groups (1,474 in total)). Hence, the total recruitment target for this cluster randomised trial is 20.000 children, recruited at $20 \mathrm{GP}$ out-of-hours centres (10 control, 10 intervention). The chosen reduction in antibiotic prescribing of $6 \%$ is arbitrary and one could discuss that any reduction in antibiotic prescribing as results of a low-cost, easy to implement intervention is clinically relevant in an era of rising antibiotic resistance. 


\section{Recruitment}

We will recruit 20 GP out-of-hours cooperatives that are going to participate and cluster randomise them to GP access to the illness-focused interactive booklet or care as usual (see Table 8.1). All GPs working at the participating GP out-of-hours centres that are in the intervention group (interactive booklet) will be introduced to the study content. GPs are subsequently instructed and trained by means of written instructions on how to use the booklet during consultations.

All cooperatives that will be recruited have to be working with the software system that will be used for data collection (Call manager), we will further specifically recruit cooperatives based on: (1) their geographical location in the Netherlands to ensure a widespread recruitment across the country; (2) the socio-economic status of the community that they are providing care for to ensure the sample will be representative of the rest of the country.

The booklet will be used during consultations with febrile children at the GP out-of-hours cooperative. The child's symptoms will determine which information and advices parents receive from the GP. Inclusion criteria are age between three months and twelve years and the GP deciding this is a fever-related consult. The temperature has to be measured by parents in advance of the consultation or by GPs during consultations. We specifically choose a subjective term for fever and not a temperature cut-off point since parents considering the child to have a fever is, to our opinion, just as important as an actual clinical fever in light of the illness-focused intervention this study.

The primary outcome data will be collected in a coded, automatic, manner and will be supplied by an independent party that is responsible for the electronic patient files software. Since providing written information about a disease can be considered as a variation of care as usual and since we will not be able to trace back the data to individual patients, the ethical committee waived the requirement of obtaining written informed consent during the consultation. Registration of the primary outcome (antibiotic prescriptions during the initial consultation) and secondary outcomes based on the complete sample ((re-)consultations during out-of-hours care, antibiotic prescriptions during re-consultations at the GP out-of-hours cooperative and referral to secondary care) will be based on the electronic database. Parents and GPs are informed about the study through posters at the out-of-hours centre. We will also collect data on secondary outcomes using a telephone survey (intention to re-consult, parental satisfaction with care and the booklet, antibiotic prescriptions during re-consultations at children their personal GP and self-reported adverse events) at three moments during a period of two weeks during month 2, 4 and 6. During these two-week periods, parents of febrile children 
participating in the main study will receive a letter from the triage nurse in the waiting room explaining the study content. Parents are asked to provide informed consent to participate in a telephone survey after two weeks. Participation in the telephone survey will be completely voluntary; meaning parents in the intervention group will receive the booklet during their consultation whether or not they consent to participate in the telephone survey.

Table 8.1 Overview implementation booklet using a cluster randomized controlled trial according to SPIRIT guidelines

\begin{tabular}{llllllll}
\hline Centre/Month & Allocation & 1 & 2 & 3 & 4 & 5 & 6 \\
$\begin{array}{l}\text { GP cooperative 1-10 } \\
\text { (control) }\end{array}$ & $\mathrm{X}$ & & 0 & & 0 & 0 \\
$\begin{array}{l}\text { GP cooperative 11-20 } \\
\text { (intervention) }\end{array}$ & $\mathrm{X}$ & & 0 & 0 & 0 \\
\hline Baselinemeasurents
\end{tabular}

Baseline measurements will take place before implementation of the intervention. Measurement of the primary outcome and secondary outcomes based on the complete sample will go on automatically during the complete study period. The O represents a period of two weeks during which data on secondary outcomes based on the telephone survey will be collected.

\section{Outcome measurement}

\section{Primary outcome measure}

$\infty$ Antibiotic prescribing rate during the initial consultation (baseline/index consultation, dichotomous scale; number of participants with an antibiotic prescription)

\section{Secondary outcome measures based on the complete sample}

$\infty$ Reconsultation rate at the GP out-of-hours cooperative for the same illness episode within two weeks of the initial consultation (within two weeks of initial consultation, number of reconsultations)

$\infty$ (Antibiotic) prescribing rate within two weeks of the initial consultation (hence including antibiotic prescriptions during reconsultations) at the GP out-of-hours cooperative (within two weeks of initial consultation, dichotomous scale; number of participants with an (antibiotic) prescription)

$\infty$ (Re-)consultations for fever and fever related conditions at the GP cooperative during out-of-hours care during the 6 month study period (during complete study period of 6 months, number of consultations and reconsultations)

$\infty$ Referral to secondary care during the initial consultation and for the same illness episode within two weeks of the initial consultation (during index consultation and reconsultations within two weeks, number of referrals) 


\section{Secondary outcome measures based on telephone survey}

$\infty$ Parent-reported reconsultation rate at the own GP during routine daytime hours for the same illness episode within two weeks of the initial consultation (during telephone survey within two weeks of initial consultation, number of self-reported reconsultation)

$\infty$ Parent-reported antibiotic prescribing during reconsultations at the own GP during routine daytime hours for the same illness episode within two weeks of the initial consultation (during telephone survey within two weeks of initial consultation, dichotomous scale; number of self-reported (antibiotic) prescription)

$\infty$ Parent-reported hospital admission for that illness episode within two weeks of the initial consultation (during telephone survey within two weeks of initial consultation, dichotomous scale; number of self-reported hospital admissions)

$\infty$ Parent-reported satisfaction with care and parent-reported satisfaction with providing written information materials ( (during telephone survey within two weeks of initial consultation, dichotomous scale and VAS scale 1-10 on reassurance and satisfaction with care)

$\infty$ Parent-reported intention to re-consult the out-of-hours GP centre for a future similar illness episode (during telephone survey within two weeks of initial consultation, dichotomous scale; number of parents with intention to reconsults for a future similar illness)

\section{Data collection}

During the complete study period from November 2015-May 2016, we will collect anonymised data on baseline characteristics, antibiotics prescriptions, consultation rates and direct referrals to secondary care for febrile children from GP out-of-hours centre databases (Table 8.1). This is the complete study sample. Every time the GP processes patient information for a consultation of a child $<12$ years of age a pop-up screen will occur. GPs then have to answer the question: Did this child have a fever (at home or at the GP cooperative)? (Yes/No). The International Classification of Primary Care (ICPC) coding system will be used to map reasons for consultation. Since the primary outcome data will be collected in a coded, automatic, manner and will be supplied by an independent party that is responsible for the electronic patient files software there will be no data monitoring committee.

Data on secondary outcomes will be collected among a subsample using telephone surveys during three two-week periods (Table 8.1). This will include parents of children also included in the main study. A triage nurse will provide parents with information about the 
study during their visit in these weeks. If parents give their consent, they will be asked to participate in a telephone survey two weeks after the initial consultation. Telephone surveys will be used to question parents about intention to re-consult in the same fever episode and in the future (yes/no), if they received and used antibiotics at re-consultation (yes/no), parental satisfaction (VAS scale), parental reassurance (reassured/not reassured and VAS scale), self-reported complications like hospital admissions, consultations with their own GP before and after the out-of-hours consultation, and their opinion about the booklet (VAS scale, intention to use again, most important section). Measurements will take place during month 2, 4 and 6. The telephone survey data on secondary outcomes will be entered into a Microsoft Access database by two researchers independently.

\section{Analysis}

First, the data will be processed using IBM SPSS Statistics for Windows, using mainly descriptive statistics to summarize the data. Second, statistical analysis will be performed based on intention to treat principle by fitting two level (GP out-of-hours cooperative and patient) random intercept logistic regressions models using MLwiN software. Fixed parameters will be group (intervention vs. control) and size (small vs large cooperative). The clustering in the data will be accounted for by a random intercept at the GP cooperative level. Additional analysis adjusting for compliance will also be performed (access to booklet vs actual use). During data analysis, researchers will be blinded to the group assignment.

\section{Ethics and dissemination}

All data will be obtained, managed and monitored according to the guidelines of Good Clinical Practice. This study was approved by the ethical committee of Zuyderland-Zuyd (METC Z) in Heerlen, the Netherlands (Ref 14-N-171) and is reported in accordance with the Standard Protocol Items:

Recommendations for Interventional Trials (SPIRIT) guideline. ${ }^{22}$ The SPIRIT figure is graphically represented in table 8.1. Findings of the study will be published and the results will be disseminated regardless of the magnitude or direction of effect. 


\section{DISCUSSION}

This study aims to optimize management of febrile children during GP out-of-hours care by giving GPs access to an illness-focussed interactive booklet to be used during consultations for childhood fever and common infection in the out-of-hours setting. Illness in this light refers to the subjective response of the patient, or in this case parent to the child being unwell. How they perceive the origin and significance of this event, how it affects their behaviour, and the steps they take to remedy this situation. ${ }^{23}$ Previous research has shown that alongside specific symptoms that often accompany fever, the decision to consult a GP during out-of-hours care is driven by parental needs for reassurance and reliable consistent information on self-management strategies on one hand, and by non-medical factors like work during the day and the fact that fever typically rises during the early evening on the other hand. ${ }^{9}$ In turn, GPs acknowledge that this decision parents make to consult during out-of-hours care plays an important role in their decision to prescribe antibiotics. ${ }^{11}$ Exploring the illness experience of parents of children with fever and infections may is a potential intervention which can improve these consultations as it specifically addresses the concerns and questions that parents have when their child is sick. On the other hand, a strong safety net advice provided by a booklet can hypothetically also provide a diseasefocussed solution to GPs by providing them with a way to reduce diagnostic uncertainty in these children, thereby also reducing the number of "better safe than sorry" antibiotic prescriptions. $^{15}$

Providing parents of febrile children with safety-net advice during consultations has been proposed previously. ${ }^{12,24}$ However, this will be the first study to explore the impact of using an illness-focused interactive booklet on antibiotic prescriptions, (re-)consultations and intention to re-consult, referral rates, parental satisfaction and self-reported adverse events in febrile children during out-of-hours GP care. An interactive booklet has shown to be a promising intervention to reduce antibiotic prescriptions in different populations and settings in primary care. ${ }^{13,14}$ For example, one study among children with respiratory tract infections showed a $50 \%$ reduction in antibiotic prescriptions. ${ }^{14}$ The clinically relevant difference of $6 \%$ chosen in this study was arbitrary since this is the first study in this setting (out-of-hours care) and also in this country. Additionally, baseline prescription rates differ widely between different settings and countries and baseline prescription rates in The Netherlands are already lower than in many other Western countries. As mentioned in the article, the cosen difference was based on the fact that it would reduce the number of prescriptions to one in four to one in five to six. However, we believe that any significant reduction can be considered clinically relevant in an era of increasing antibiotic resistance. 
Previous research showed that GPs believe that in order to make an intervention suitable for use during out-of-hours care, it needs to be physically available in every consultation room. ${ }^{11}$ On one side because this can act as a reminder to use the intervention, but specifically to avoid having to go through the effort of downloading or printing material in these often time-pressured consultations. This was an important reason to choose a physical booklet during this study. If the booklet turns out to be successful and satisfactory it is our intention to spread it digitally as well as physically.

Every participating GP out-of-hours cooperative is either randomized to GP access to the illness-focused interactive booklet or care as usual. In this case, we believe this design has multiple advantages over an individual randomized controlled trial. It is inappropriate to randomize the intervention on an individual level due to the high risk of contamination. To clarify, communication skills cannot be randomized on a patient level because it would be very demanding for GPs to change communication between every patient. Moreover, GPs can become confused when they have to use different communication skills with different patients. This would result in a risk of exposing parents in the control group to information from the intervention and creating the risk of contamination. This risk is especially high because they do not see febrile children on a fixed rate. To explain, we anticipate that GPS will be triggered by the content of the booklet to improve information provision within the consultation. If the trial was individually randomised then there is a risk that they improve the information they provide to parents in the control group as well. We also believe it is not feasible to randomize on a GP level. A Dutch GP has approximately 12-40 shifts per year, and $50 \%$ of the consultations will not be eligible for recruitment as no young children are physically seen. In other words, if a GP has only 12 shifts a year and only $50 \%$ of the consultations are eligible for recruitment, the chances of that GP actively remembering to hand over a booklet to parents are small, especially if not every GP at one cooperative is working with the booklet. Beside this fact, is it also more practical to provide every consultation room with the necessary material thereby making use of the tool more attractive, accessible and pragmatic in often time-pressured consultations.

However, using a cluster RCT also has its limitations. First, blinding of the participating GPs is very difficult as the transfer from care as usual to the intervention is obviously noticeable. To avoid bias we will blind GPs for the outcome in both groups. Additionally, the outcome accessors will be blinded by coding the dataset. Second, randomization takes place on a GP out-of-hours cooperative level and the cluster effect has to be taken into account. It is possible that participants within one cluster share certain characteristics, e.g. quality of care at the GP out-of-hours cooperative, which might result in a substantial loss of power. Therefore, we choose to correct for the cluster effect in the sample size calculation and in 
the data analysis by using multilevel analysis. Estimation of a required sample size in cluster randomized trials is difficult because the expected effect size, anticipated cluster size and intra-cluster correlation coefficient have to be estimated and reported. ${ }^{25}$ Despite these unknown variables, we believe this is the best methodology for this pragmatic study. ${ }^{26}$ It can be expected, that out-of-hours cooperatives not receiving the illness-focused interactive booklet during the intervention may progressively loose interest to include patients. To prevent this, those centres allocated to the control arm, will be informed that they will receive the information exchange tool after the study period as an incentive.

The average antibiotic prescription rate found in our cohort study which is chosen as the baseline antibiotic prescribing proportion is lower than the $35 \%$ antibiotic prescription rate found in previous studies in adults and children. 5,14,27 As we know from previous studies, antibiotic prescription rates vary extensively between GPs. Therefore, we have purposefully chosen to use broad inclusion criteria and not to select specific causes of fever in children. By doing so, we aim to get as close as possible to actual practice and considerations of GPs' prescribing decisions. This means that we expect that not every child in the intervention group will receive the booklet because of various, realistic reasons like a language barrier, a specific disease that is not described in the booklet or because parents simply do not wish to receive the booklet. Moreover, GPs will differ in their own perceived need to use such an interactive booklet during consultations. While some may use it in all their consultations for children with fever, some may never use it. This probably reflects the use of current information materials, mostly patient leaflets. ${ }^{28}$ We choose to perform a pragmatic study, allowing for this variation, but also facilitating possible future implementation in daily practice. 


\section{REFERENCES}

1. National Institute of Clinical Excellence. NICE guideline: feverish illness in children. London: National Institute of Clinical Excellence; 2013.

2. de Bont EG, Francis NA, Dinant GJ, Cals JW. Parents' knowledge, attitudes, and practice in childhood fever: an internet-based survey. Br J Gen Pract. 2014;64:e10-6.

3. Walsh A, Edwards H, Fraser J. Parents' childhood fever management: community survey and instrument development. J Adv Nurs. 2008;63:376-88.

4. de Bont EG, Lepot JM, Hendrix DA, Loonen N, Guldemond-Hecker Y, Dinant GJ, et al. Workload and management of childhood fever at general practice out-of-hours care: an observational cohort study. BMJ Open. 2015;5:e007365.

5. Elshout G, Kool M, Van der Wouden JC, Moll HA, Koes BW, Berger MY. Antibiotic Prescription in Febrile Children: A Cohort Study during Out-of-Hours Primary Care. J Am Board Fam Med. 2012;25:810-8.

6. Otters HB, van der Wouden JC, Schellevis FG, van Suijlekom-Smit LW, Koes BW. Trends in prescribing antibiotics for children in Dutch general practice. J Antimicrob Chemother. 2004;53:361-6.

7. Macfarlane J, Holmes W, Macfarlane R, Britten N. Influence of patients' expectations on antibiotic management of acute lower respiratory tract illness in general practice: questionnaire study. BMJ. 1997;315:1211-4.

8. Walsh A, Edwards H. Management of childhood fever by parents: literature review. J Adv Nurs. 2006;54:217-27.

9. de Bont EG, Loonen N, Hendrix DA, Lepot JM, Dinant GJ, Cals JW. Childhood fever: a qualitative study on parents' expectations and experiences during general practice out-ofhours care consultations. BMC Fam Pract. 2015;16:131.

10. Butler CC, Rollnick S, Pill R, Maggs-Rapport F, Stott N. Understanding the culture of prescribing: qualitative study of general practitioners' and patients' perceptions of antibiotics for sore throats. BMJ. 1998;317:637-42.

11. de Bont EG, Peetoom KK, Moser A, Francis NA, Dinant GJ, Cals JW. Childhood fever: a qualitative study on GPs' experiences during out-of-hours care. Fam Pract. 2015;32:449-55.

12. Jones $\mathrm{CH}$, Neill S, Lakhanpaul M, Roland D, Singlehurst-Mooney $\mathrm{H}$, Thompson $\mathrm{M}$. Information needs of parents for acute childhood illness: determining 'what, how, where and when' of safety netting using a qualitative exploration with parents and clinicians. BMJ Open. 2014;4:e003874. 
13. de Bont EG, Alink M, Falkenberg FC, Dinant GJ, Cals JW. Patient information leaflets to reduce antibiotic use and reconsultation rates in general practice: a systematic review. BMJ Open. 2015;5:e007612.

14. Francis N, Butler C, Hood K, Simpson S, Wood F, Nuttall J. Effect of using an interactive booklet about childhood respiratory tract infections in primary care consultations on reconsulting and antibiotic prescribing: a cluster randomised controlled trial. BMJ. 2009;339:b2885-b.

15. Horwood J, Cabral C, Hay AD, Ingram J. Primary care clinician antibiotic prescribing decisions in consultations for children with RTIs: a qualitative interview study. $\mathrm{Br} J$ Gen Pract. 2016;66:e207-13.

16. Francis N, Wood F, Simpson S, Hood K, Butler CC. Developing an 'interactive' booklet on respiratory tract infections in children for use in primary care consultations. Patient Educ Couns. 2008;73:286-93.

17. Berger MY, Boomsma LJ, Albeda FW, Dijkstra RH, Graafmans TA, Van der Laan JR, et al. NHG-Standaard Kinderen met koorts. Huisarts en Wetenschap. 2008.

18. Giesen P. SM, Huibers L., Grol R., Wensing M. Quality of after-hours primary care: As narrative review of the Dutch solution. Ann Intern Med. 2011;155:108-13.

19. Giesen P., Franssen E., Mokking H., van den Bosch W., van Vugt A., R. G. Patients either contacting a general practice cooperative or accident and emergency department out of hours: a comparison. . Emerg Med J. 2006;23:731-4.

20. Adams G, Gulliford MC, Ukoumunne OC, Eldridge S, Chinn S, Campbell MJ. Patterns of intra-cluster correlation from primary care research to inform study design and analysis. J Clin Epidemiol. 2004;57:785-94.

21. van Breukelen GJ, Candel MJ, Berger MP. Relative efficiency of unequal versus equal cluster sizes in cluster randomized and multicentre trials. Stat Med. 2007;26:2589603.

22. Chan AW, Tetzlaff JM, Gotzsche PC, Altman DG, Mann H, Berlin JA, et al. SPIRIT 2013 explanation and elaboration: guidance for protocols of clinical trials. BMJ. 2013;346:e7586.

23. Helman CG. Disease versus illness in general practice. J R Coll Gen Pract. 1981;31:548-52.

24. Cabral C, Ingram J, Hay AD, Horwood J, team T. "They just say everything's a virus"-parent's judgment of the credibility of clinician communication in primary care consultations for respiratory tract infections in children: a qualitative study. Patient Educ Couns. 2014;95:248-53. 
25. Yudkin PL, Moher M. Putting theory into practice: a cluster randomized trial with a small number of clusters. Stat Med. 2001;20:341-9.

26. Campbell MK, Mollison J, Steen N, Grimshaw JM, Eccles M. Analysis of cluster randomized trials in primary care: a practical approach. Fam Pract. 2000;17:192-6.

27. Cals JW, Butler CC, Hopstaken RM, Hood K, Dinant GJ. Effect of point of care testing for $C$ reactive protein and training in communication skills on antibiotic use in lower respiratory tract infections: cluster randomised trial. BMJ. 2009;338:b1374. 

HAPTER 9

An illness-focussed interactive booklet to optimize management and medication for childhood fever and infections in outof-hours primary care: a cluster randomized controlled trial

Eefje G.P.M. de Bont Geert-Jan Dinant

Gijs Elshout Gijs van Well Nick A. Francis Bjorn Winkens Jochen W.L. Cals 



\section{ABSTRACT \\ Purpose}

Fever is the most common reason for a child to be taken to a physician, yet unwarranted antibiotic prescriptions remain high. We aimed to determine the effect on antibiotic prescribing of providing an illness-focussed interactive booklet on fever in children to outof-hours primary care providers.

\section{Methods}

A two armed cluster randomized trial, at 20 out-of-hours general practice centres in the Netherlands. Children $<12$ years with fever were included. Family Physicians (FPs) at 10 intervention sites had access to an illness-focussed interactive booklet between Nov 2015 and June 2016. Primary outcome was antibiotic prescribing during index consultations. Analysis was performed by fitting two level random intercept logistic regressions models using MLwiN and complier average causal effect analysis.

\section{Results}

25355 children were included by 3518 FPs. The booklet was used in 28.5\% (3407/11945) of consultations. Access to the booklet did not result in a significant difference in antibiotic prescribing (OR $0.90,95 \% \mathrm{Cl} 0.79$ to $1.02,25.2 \%$ and $23.5 \%$ ICC 0.005 ). FP use of the booklet significantly reduced antibiotic prescribing during index consultation (OR 0.83, 95\% $\mathrm{Cl} 0.74$ to 0.94 , reduction of $25.2 \%$ to $21.9 \%$, ICC 0.002 ). Children managed by FPs with access to the booklet were less likely to receive any drug prescription. Parents showed a reduced intention to reconsult for similar illnesses.

\section{Conclusions}

We did not find sufficient evidence that providing access to an illness-focussed interactive booklet on childhood fever in out-of-hours primary care reduces antibiotic prescribing. However, use of the booklet led to reduced antibiotic and overall medication prescriptions, and parents were less inclined to consult for future similar illnesses. 


\section{INTRODUCTION}

Fever is the most common reason for a child to be taken to a doctor and most consultations take place in general practice. ${ }^{1}$ Since many parents work during the day, and fever typically rises in the early evening, these rates are even higher during out-of-hours care. $^{1,2}$ In most cases, fever is caused by benign (viral) infections, and general recommendations given by a Family Physician (FP) are sufficient. ${ }^{3}$ However, one in three to four children who visit FP out-of-hours care with a fever receive an antibiotic prescription. ${ }^{4,5}$ These prescription rates are nearly twice as high as prescription rates during routine office hours. ${ }^{6}$

Consultations are generally driven by parental concerns about harmful consequences of fever, and these concerns can be more prominent when needing to consult a FP on call who is not their personal FP. ${ }^{7}$

Previous studies have demonstrated that antibiotic prescribing is strongly influenced by patients' expectations and that FPs experience pressure from patients to prescribe antibiotics. ${ }^{8}$ Most parents of a febrile child in fact do not expect antibiotics, but seek reassurance and consistent, reliable information about fever, specific symptoms and selfmanagement strategies. ${ }^{7,9,10}$ Nevertheless, conveying evidence-based information to parents is challenging for FPs. Even more so in time-pressured consultations in the evening and night. ${ }^{11}$ A systematic review showed that information leaflets during Family Physicians consultations for common infections are promising tools to provide parents with a safety net and to reduce antibiotic prescriptions. However, there were no studies performed during out-of-hours care or in childhood fever consultations. ${ }^{12}$

The CHILdhood Infections (CHILI) study therefore aimed to develop, and determine the effectiveness of an illness-focussed interactive fever booklet for parents on the management of children presenting with fever at FP out-of-hours care. 


\section{METHODS}

\section{Study design and participants}

We performed a cluster randomized controlled trial with randomization on the level of FP out-of-hours centres. Recruited FP out-of-hours centres were randomized to one of two arms; FP access to the illness-focussed interactive booklet or care as usual. FPs working at the intervention centres were given access to the booklet and were free to use them during childhood fever consultations at their own discretion (FP use of booklet). A full detailed description of the development of the intervention and the methods that were used has been previously published. ${ }^{13}$

20 FP out-of-hours centres across the Netherlands providing care for 3557206 residents participated in this trial from Nov 2015 to June 2016. FP out-of-hours care is defined as primary care provided beyond office hours every day between 5 p.m. to 8 a.m. and the entire weekend. ${ }^{14}$ Since the year 2000, FP out-of-hours care in The Netherlands is provided by approximately 120-130 large-scale FP centres. Per FP centre, 50 to 200 FPs rotate shifts, providing out of hours care to residents of one specific region in which their daytime practice is located. ${ }^{14}$ Hence, in most out-of-hours consultations patients will not consult with their own FP. FP out-of-hours centres are essentially intended for urgent help requests that cannot wait until the next day. Furthermore, Dutch FPs function as gatekeepers for secondary care. Only those children who need treatment from a paediatrician will be referred in case the FP decides this is medically indicated.

Inclusion criteria for patients were: age between three months and twelve years, and the FP recording the consultation as a fever-related consultation. This study was approved by the ethical committee of Zuyderland-Zuyd (METC Z) in Heerlen, the Netherlands (Ref 14-N171).

\section{Procedures and outcomes}

The content of the illness-focussed interactive booklet was developed in a multistage process using a nationwide survey among parents, focus group sessions and semistructured interviews with parents, FPs and triage nurses working or consulting during outof-hours FP care, extensive literature research and expert discussions., ${ }^{7,15}$ The booklet contained the following sections:

$\infty$ A traffic light system for childhood fever in general with advice on when to consult a FP (red symptoms) and information on self-management strategies, as well as specific traffic lights for infections of the upper respiratory tract (cough, cold and 
sore throat), acute otitis media (earache) and gastrointestinal symptoms (abdominal pain, vomiting and diarrhoea)

$\infty$ Information on the benefits and harms of antibiotic treatment

$\infty$ An overview of natural duration of common infections in children

$\infty$ A table with weight-banded paracetamol dosage schemes

$\infty$ Advice and information on febrile convulsions and skin rash

The booklet was designed to be used in the final part of a clinical consultation facilitating an interactive discussion between parents and FPs, by which we mean that FPs had the possibility to highlight and mark specific signs, symptoms and questions which were relevant for that specific child and provide parents with a tailored advice and safety net for that specific clinical problem. Thereby not only making sure that the advice FPs gave was tailored to parents their specific questions, but also facilitating communication and solving misconceptions between parents and FPs' about their expectations of the consultation.

The primary outcome (antibiotic prescriptions during the index consultation yes/no), and secondary outcomes based on the complete sample ((re-)consultations during out-of-hours care yes/no, antibiotic prescriptions during re-consultations at the FP out-of-hours centre yes/no, overall medication prescriptions during index consultation and two weeks follow-up yes/no, and referral to secondary care yes/no) data was collected in a coded, automatic manner from the FP out-of-hours centre databases, and was supplied by an independent party that is responsible for the electronic patient files software (Labelsoft Clinical IT B.V., CompuGroup Medical AG ,Phoenix, AZ, USA). Every time the FP closed the patient file of a child aged $<12$ years a pop-up screen occurred: Did this child have a fever (at home or during the consultation)? This pop-up occurred after the parents had already left the consultation room. Children for whom the FP selected yes were included in the study. FPs working at intervention sites had an additional question: Did you hand out the booklet? The International Classification of Primary Care (ICPC) coding system was used to map reasons for consultation.

In addition to the automatic registration in the complete study sample, data on secondary outcomes was collected among a subsample of parents using telephone surveys during three two-week periods during month 2, 4 and 6. A triage nurse provided parents with information about the study during their visit in these weeks. If parents in this subsample gave written informed consent, they were asked to participate in a telephone survey two weeks after the index consultation. Telephone surveys were used to question parents about intention to re-consult in the same fever episode and in the future (yes/no), if they received and used antibiotics at re-consultation (yes/no), parental satisfaction (VAS scale), 
parental reassurance (reassured/not reassured and VAS scale), self-reported complications, consultations with their own FP, and their opinion about the booklet (VAS scale, intention to use again, most important section).

\section{Randomization and masking}

We chose cluster randomization to reduce the risk of contamination. We stratified participating FP out-of-hours centres by size (10 smallest vs. 10 largest centres, with a cutoff point of fewer or more than 20500 consultations/year), to ensure equal distribution of size between the intervention and control group. A blinded, independent researcher performed a computer based randomization with random permuted blocks of two. Allocation for each centre was provided only after the centre agreed to participate.

\section{Statistical analysis}

The primary outcome was antibiotic prescribing rate during the index consultation (dichotomous). The required number of clusters and participants was based on the following assumptions: (1) Intra-cluster coefficient (ICC) of $0.01,{ }^{16}$ (2) alpha of 0.05 , power of 0.80 , (3) proportion of antibiotic prescriptions in control group of $25 \%$ and a proportion of 19\% in the intervention group, (4) 10\% loss to follow-up and $10 \%$ efficiency loss based on unequal cluster sizes. ${ }^{17}$ This resulted in a need for 20 clusters to acquire the same power as an individual randomized controlled trial (with an effective sample size of 737 patients in both groups (1474 in total) for an individual RCT based on chi-square test). Taking the cluster effect into account, the total recruitment target for this cluster randomized trial was 20000 children, recruited at $20 \mathrm{FP}$ out-of-hours centres (10 control, 10 intervention).

To inform the required sample size, we performed a retrospective cohort study. ${ }^{4}$ We identified an average of 15 consultations per day for children with fever, and fever-related conditions. Based on this cohort study and a pilot study, we assumed that 1,000 children per centre could be included in 6 months.

Initial descriptive statistics and frequencies were generated to summarize the data using IBM SPSS Statistics for Windows version 21.0. Statistical analyses were then performed based on intention-to-treat principle by fitting two level (FP out-of-hours centre and patient) random intercept logistic regressions models using MLwiN software version 2.22. Fixed parameters were group (intervention vs. control), and size (small vs. large centre). The clustering in the data was accounted for by a random intercept at the FP centre level. We also checked whether the results changed after including gender, age and socioeconomic status (SES) of the patients to this model. We expected compliance (use of 
the booklet) to be lower than $100 \%$ due to the nature and pragmatic design of the trial. Unfortunately, there were no previous comparable trials or studies that provided us with an indication of how high this level compliance would be. We therefore chose to perform pre-specified additional secondary analyses adjusting for compliance (control vs actual use of booklet instead of control vs. access to booklet) using complier average causal effect (CACE) analysis. ${ }^{13}$ Randomization ensures that, on average, the proportion of compliers in the control group would have been the same as that in the access to booklet group. ${ }^{18}$ Hereby, we estimated the proportion of unobserved (would-be) compliers in the control group from the proportion observed in the treatment group. This analysis was based on the assumption that there could only be compliers and never-takers, since FPs in the control arm had no access to the booklet. We also assumed that there would be no effect of randomization on the outcome (exclusion restriction). We then calculated the OR adjusted for compliers and corrected for stratification during randomization based on centre size (small vs. large centre). ${ }^{18,19}$ During outcome data analysis, researchers were blinded to the group assignment. 


\section{RESULTS}

A total of 106014 contacts for children took place at the 20 participating centres during the trial period. Of these contacts, $36.1 \%$ were fever related, and $77.3 \%$ of these fever related telephone contacts resulted into a face to face consultation with a FP. 3518 FPs (range per centre 73 FPs to 273 FPs) recruited 25355 children (11945 in intervention and in 13410 control group, varying from 366 children to 2756 children per centre, equally divided across groups) into the trial by (Figure 9.1). Baseline patient characteristics of the study population are shown in table 9.1. The distribution of age, gender, socioeconomic status and ICPC diagnosis were similar over the intervention and control groups and between clusters.

Table 9.1 Patient characteristics of children recruited in control and intervention group (FP access to booklet)

\begin{tabular}{|c|c|c|c|}
\hline & $\begin{array}{l}\text { Control } \\
n=13410\end{array}$ & $\begin{array}{l}\text { FP access to } \\
\text { booklet } \\
n=11945\end{array}$ & $\begin{array}{l}\text { Total } \\
\mathrm{N}=25355\end{array}$ \\
\hline Age in years - Mean (SD) & $3.2(2.7)$ & $3.3(2.7)$ & $3.2(2.7)$ \\
\hline Male sex- $n=(\%)$ & $\begin{array}{l}7100 \\
(52.9 \%)\end{array}$ & $6313(52.9 \%)$ & $\begin{array}{l}13413 \\
(52.9 \%)\end{array}$ \\
\hline \multicolumn{4}{|l|}{ Socioeconomic status parents } \\
\hline Low & $\begin{array}{l}2261 \\
(16.9 \%)\end{array}$ & $1826(15.4 \%)$ & $4087(16.2 \%)$ \\
\hline Middle & $\begin{array}{l}9055 \\
(67.8 \%)\end{array}$ & $8459(71.5 \%)$ & $\begin{array}{l}17514 \\
(69.5 \%)\end{array}$ \\
\hline High & $\begin{array}{l}2032 \\
(15.2 \%)\end{array}$ & $1550(13.1 \%)$ & $3582(14.2 \%)$ \\
\hline \multicolumn{4}{|l|}{ ICPC top 3} \\
\hline A03.00 Fever & $\begin{array}{l}2471 \\
(18.5 \%)\end{array}$ & $2174(18.2 \%)$ & $4645(18.4 \%)$ \\
\hline $\begin{array}{l}\text { R74.00 Acute upper respiratory tract } \\
\text { infection }\end{array}$ & $\begin{array}{l}2653 \\
(19.8 \%)\end{array}$ & $2357(19.9 \%)$ & $5010(19.8 \%)$ \\
\hline H71.00 Acute otitis media acuta/myringitis & $\begin{array}{l}1872 \\
(14.0 \%) \\
\end{array}$ & $1604(13.5 \%)$ & $3476(13.8 \%)$ \\
\hline
\end{tabular}

$S D=$ standard deviation, ICPC = International Classification of Primary Care, Socioeconomic status numbers do not add up to totals in column due to missing data

In the intervention group, the booklet was used in 3407 (28.5\%) encounters (range over centres $23.1 \%$ to $38.5 \%$ ). Antibiotic prescribing was not significantly different at centres with FP access to the booklet and control centres (OR 0.90, 95\% $\mathrm{Cl} 0.79$ to1.02, ICC 0.005, Table 9.2). There were no significant differences in reconsultation rates at the out-of-hours centres within two weeks of the index consultation for the same illness episode. We found 
no significant differences in out-of-hours reconsultation rates within six months following randomization or referral rates to secondary care at index consultation (Table 9.2).

Children in the access to booklet group, were less likely to receive a prescription for any medication, including non-antibiotic medication, (OR 0.87, 95\% $\mathrm{Cl} 0.77$ to 0.97 , ICC 0.004). Most commonly prescribed non-antibiotic medications were xylomethazoline, salbutamol and ibuprofen, see supplementary table 9.5. Adjusting for gender, age and socioeconomic status had no effect on any of the outcomes. Mean antibiotic prescription rates varied between the three most common ICPC codes, as is shown in table 9.3. Amoxicillin was the most commonly prescribed antibiotic, accounting for $76.1 \%$ of all antibiotic prescriptions in the trial.

When correcting for compliance, there was a significant reduction in antibiotic prescribing in those children managed by a FP using the booklet during the consultation $(n=3407)$ compared to children managed by FPs in the control group (OR 0.83, 95\% Cl 0.74 to 0.94 , ICC 0.002, Table 9.2). This significant effect on antibiotic prescribing for FP use of booklet maintained during two week follow-up (including the index consultation) (OR $0.84,95 \% \mathrm{Cl}$ 0.75 to 0.95 , ICC 0.002). After correcting for compliance we also found no significant differences in out-of-hours reconsultation rates within six months following randomization or referral rates to secondary care at index consultation (Table 9.2). Children for whom the booklet was actually used, were also less likely to receive a prescription for any medication, including non-antibiotic medication, (OR $0.77,95 \% \mathrm{Cl} 0.70$ to 0.86 , ICC 0.001).

The OR for antibiotic prescriptions during index consultations based on the complier adjusted average causal effect (CACE) analysis was 0.71 (95\% $\mathrm{Cl} 0.63$ to 0.79 ). The OR for any prescription during index consultations based on the complier adjusted analysis was 0.62 (95\% Cl 0.57 to 0.69). The ICC for compliance was 0.09. Table 9.6 in the supplementary materials shows the patient characteristics for the groups access to booklet vs. use of booklet and no use of booklet in the intervention group, in supplementary table 9.7 the same is shown for parents participating in the telephone survey. 
Table 9.2 FP access and use of booklet - Primary outcome and secondary outcome measures based on the complete sample

$\begin{array}{lllll}\begin{array}{l}\text { Control } \\ n=13410\end{array} & \begin{array}{l}\text { Access to } \\ \text { booklet }\end{array} & \begin{array}{l}\text { OR access to } \\ \text { booklet }\end{array} & \begin{array}{l}\text { Use of } \\ \text { booklet }\end{array} & \begin{array}{l}\text { OR use of } \\ \text { booklet }\end{array} \\ & {[95 \% \mathrm{Cl}]} & n=3407 & {[95 \% \mathrm{Cl}]}\end{array}$

Adjusted OR use of booklet (age,gender,SES) [95\% Cl]

\section{Primary outcome}

\section{Antibiotic prescription \\ consultation \\ Secondary outcomes} 3375 (25.2\%) 2809 (23.5\%) $0.90[0.79$ to 1.02]

\section{6}

(21.9\%)

$0.83[0.74$ to

$0.94]^{*}$

0.85 [0.75 to

$0.97]^{* \wedge}$

Reconsultation

861

$\mathrm{OOH}$ within two

(5.5\%)

741 (5.4\%)

$0.95[0.83$

165

to1.09]

(4.3\%)

$0.97[0.80$

0.95 [0.79 to 1.15]

weeks

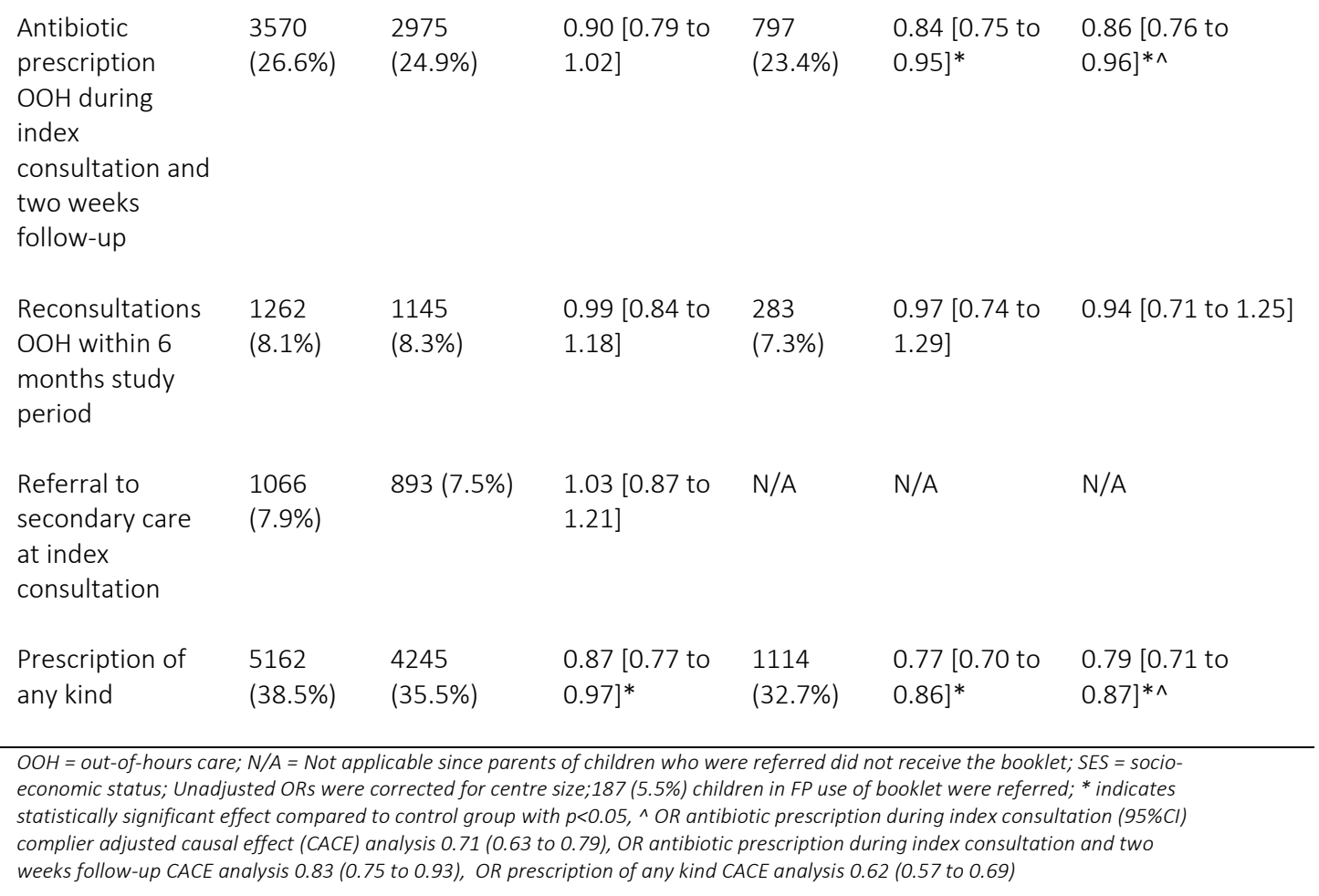


Table 9.3 Antibiotic prescribing rates for different ICPC codes

\begin{tabular}{|c|c|c|c|}
\hline & $\begin{array}{l}\text { Control } \\
n=(\% \text { within ICPC) }\end{array}$ & $\begin{array}{l}\text { Access to booklet } \\
n=(\% \text { within ICPC) }\end{array}$ & $\begin{array}{l}\text { Use of booklet } \\
n=(\% \text { within ICPC) }\end{array}$ \\
\hline A03.00 Fever & 191/2471 (7.7\%) & $144 / 2174(6.6 \%)$ & $51 / 835(6.1 \%)$ \\
\hline $\begin{array}{l}\text { R74.00 Acute upper } \\
\text { respiratory tract infection }\end{array}$ & $486 / 2653$ (18.3\%) & $359 / 2357$ (15.2\%) & $102 / 789$ (12.9\%) \\
\hline $\begin{array}{l}\text { H71.00 Acute otitis } \\
\text { media/myringitis }\end{array}$ & 1246/1872 (66.6\%) & $1034 / 1604$ (64.5\%) & 289/449 (64.4\%) \\
\hline
\end{tabular}

Parents and children in the subsample (telephone interview), were comparable to parents in the main study (supplementary table 9.7). Of the 553 participating parents in the telephone survey, $36.0 \%$ indicated they received the booklet. In the control group $2.8 \%$ of parents reported receiving written patient information or referral to a website with patient information. $23.5 \%$ of parents (130/553) reported having visited their own FP before consulting during out-of-hours care, with no significant difference between intervention and control. We observed a significant reduction in intention to reconsult for similar illnesses among parents in the access to booklet group (OR 0.55, 95\% $\mathrm{Cl} 0.35$ to 0.85 , reduction from $84.4 \%$ to $75.6 \%$, ICC $<0.001$, Table 4 ).

Table 9.4 Effects of intervention on parental reported secondary outcome measures based on telephone survey

\begin{tabular}{|c|c|c|c|c|}
\hline & & $\begin{array}{l}\text { Control } \\
(n=250)\end{array}$ & $\begin{array}{l}\text { Access to booklet } \\
(n=303)\end{array}$ & $\begin{array}{l}\text { Use of booklet } \\
(n=109)\end{array}$ \\
\hline \multicolumn{2}{|c|}{$\begin{array}{l}\text { Reconsultation with own FP } \\
\text { within two weeks - } n=(\%)\end{array}$} & $73(29.2 \%)$ & $104(34.3 \%)$ & 37 (33.9\%) \\
\hline \multicolumn{2}{|c|}{$\begin{array}{l}\text { Antibiotic prescription by own FP } \\
\text { during reconsultations within two } \\
\text { weeks }-n=(\%)\end{array}$} & 26/73 (35.6\%) & 27/104 (26.0\%) & $12(32.4 \%)$ \\
\hline \multicolumn{2}{|c|}{$\begin{array}{l}\text { Hospital admission within two } \\
\text { weeks }-n=(\%)\end{array}$} & $17(6.8 \%)$ & $21(6.9 \%)$ & $6(5.5 \%)$ \\
\hline \multicolumn{5}{|c|}{ Satisfaction with care } \\
\hline$\infty$ & $\begin{array}{l}\text { Satisfaction VAS score } \\
(1-10) \text { - Median (IQR) }\end{array}$ & $8.0(7.0$ to 8.0$)$ & $8.0(7.0$ to 9.0$)$ & $8.0(7.0$ to 9.0$)$ \\
\hline$\infty$ & $\begin{array}{l}\text { Reassurance VAS score } \\
(1-10) \text { - Median (IQR) }\end{array}$ & $8.0(7.0$ to 8.0$)$ & $8.0(7.0$ to 8.0$)$ & $8.0(8.0$ to 9.0$)$ \\
\hline$\infty$ & $\begin{array}{l}\text { VAS score booklet (1- } \\
10) \text { - Median (IQR) }\end{array}$ & & - & $8.0(8.0$ to 9.0$)$ \\
\hline \multicolumn{2}{|c|}{$\begin{array}{l}\text { Intention to reconsult for similar } \\
\text { illness }-n=(\%)\end{array}$} & $211(84.4 \%)$ & $229(75.6 \%)^{*}$ & $78(71.6 \%)^{*}$ \\
\hline
\end{tabular}




\section{DISCUSSION}

FPs having access to an illness-focussed interactive booklet on childhood fever and common infections in fever-related consultations used the booklet in one in three fever related consultations in out-of-hours general practice. FP access to the booklet did not significantly reduce antibiotic prescriptions at index consultations. However, our prespecified analysis correcting for actual use of the booklet found a reduction in antibiotic prescriptions at index consultation, overall medication prescriptions and intention to reconsult for future similar illnesses.

This is one of the largest cluster RCTs ever performed in general practice and the first one assessing the effectiveness of a booklet for one of the most common reasons for childhood consultations and antibiotic prescriptions. We chose a cluster randomized design because individual randomization would have led to a high risk of contamination. Specific considerations for choosing a cluster RCT design are described elsewhere. ${ }^{13}$

FPs believe that interventions for use during out-of-hours need to be readily available in every consultation room. ${ }^{15}$ Widespread availability means that they can act as a reminder to use them. This was also the reason a paper booklet was used in an era of internet and smartphone applications. The cluster design enabled us to provide every consultation room at intervention centres with the necessary material making it more pragmatic. However, a cluster RCT has important limitations.

By the cluster randomization and pragmatic nature of the trial we aimed to get as close as possible to actual practice and to the considerations of FPs' prescribing decisions in childhood fever consultations. As in everyday practice, we anticipated that not every child in the intervention group would receive a booklet. Moreover, FPs were only provided with brief email instructions about use of the intervention. We specifically decided not to provide a special more intensive training or meeting as this would make the intervention more costly, and would be unlikely to happen in actual daily practice. A recent Cochrane Review on this subject backed up such an approach. ${ }^{20}$ We chose to perform a pragmatic study, allowing for variation and facilitating possible implementation into daily practice.

Since we expected compliance (use of the booklet) to be lower than $100 \%$, but had no comparable data informing us what actual compliance would likely be we had to consider and pre-specify additional analyses correcting for compliance during the design of this study. ${ }^{13}$ The chosen complier CACE analysis enabled us to evaluate the effect of actually receiving the booklet on antibiotic prescriptions in a more robust way than simply undertaking a per-protocol analysis alongside the intention-to-treat analysis. Estimation of 
CACE is however dependent upon potentially challengeable assumptions that cannot be tested, which means that a risk of post-randomization recruitment bias cannot be completely excluded. ${ }^{18,21}$ However, as is shown in table 6 (supplementary material) characteristics of those children where the booklet was used were comparable to those in which the booklet was not used. The only difference noticeable difference was the percentage of children with ICPC code A03.00 for Fever and R74.00 for Acute upper respiratory tract infection between use and no use of booklet groups. This could suggest FPs were more likely to use the booklet in cases of fever without a specific diagnosis. Furthermore, best available statistical models and software do not allow for correction of the cluster effect in a CACE analysis with a dichotomous outcome. Nevertheless, an increasing number of studies have shown that a CACE analysis is much closer to the real world intention-to-treat estimates of treatment effects. ${ }^{8,21,22}$

Our trial shows that handing out patient information leaflets about childhood fever during routine out-of-hours care is very uncommon, as only $2.8 \%$ of parents consulting at control centres reported receiving such information. This shows that even in the bread-and-butter condition of childhood fever, uptake and hand-out of available patient information materials (either written or online) is very low in routine care, yet crucial for parents to learn about self-management strategies and alarm symptoms. However, provision of patient information materials is largely a clinician behaviour, and could be influenced by relatively light-touch interventions such as desk or computer prompts, or even dissemination of the results of this and other similar studies.

Blinding of the participating FPs for the intervention was not possible, but to minimize the risk of bias we blinded FPs to the outcome in both groups, and blinded outcome assessors. In terms of generalisability, more than one in three active FPs in The Netherlands took part in the study, and we believe that this population is representative of the wider FP population in The Netherlands. In addition, The Netherlands has one of the lowest antibiotic prescribing rates in the world. One could expect the effect of the booklet to be larger in countries with higher antibiotic prescribing rates.

We found a statistical significant reduction in antibiotic prescriptions from $25.2 \%$ in the care as usual group to $21.9 \%$ in the actual use of booklet group. This was lower than the $6 \%$-points ( $25 \%$ versus $19 \%$ ) which was chosen for the sample size calculation. Our findings are in keeping with a previous UK study that found a significant reduction in antibiotic prescribing from use of an interactive booklet about childhood respiratory tract infections 
during in-hours general practice. ${ }^{23}$ The previous study reported a larger reduction in antibiotic prescribing than was found in our study, but only in those who agreed to participate. Our study included all fever-related consultations and therefore provides results which are more likely to be indicative of real world effects. Other studies examining the effect of information leaflets on antibiotic prescriptions in primary care have mainly been undertaken among adults and focused on specific symptoms, such as acute cough. ${ }^{12}$ Ideally, these behavioural interventions should be combined with other interventions aimed at reducing unwarranted antibiotic prescriptions, such as improved diagnostics, point-of-care tests, interactive workshops ${ }^{24}$, and peer comparison. ${ }^{25}$

\section{Conclusions}

This low-cost and light-touch intervention focused on the illness experience of parents, and would be easy to implement into routine care. We found insufficient evidence to conclude that simply providing access to a booklet on childhood fever during out-of-hours care results in reduced antibiotic prescriptions. However, correcting for actual use of the booklet, we found a reduction in antibiotic prescriptions. The reduction in antibiotic prescribing found in this implementation study of all children seen at out of hours care with fever seems modest. However, it provides evidence of the likely 'real world' benefits of this intervention, and it is likely that evidence of its efficacy in those that use it could increase use. It is therefore highly relevant to the aims of reducing antimicrobial resistance. 


\section{REFERENCES}

1. National Institute of Clinical Excellence. NICE guideline: feverish illness in children. London: National Institute of Clinical Excellence; 2013.

2. de Bont EG, Francis NA, Dinant GJ, Cals JW. Parents' knowledge, attitudes, and practice in childhood fever: an internet-based survey. Br J Gen Pract. 2014;64:e10-6.

3. Cioffredi LA, Jhaveri R. Evaluation and Management of Febrile Children: A Review. JAMA pediatrics. 2016;170:794-800.

4. de Bont EG, Lepot JM, Hendrix DA, Loonen N, Guldemond-Hecker Y, Dinant GJ, et al. Workload and management of childhood fever at general practice out-of-hours care: an observational cohort study. BMJ Open. 2015;5:e007365.

5. Elshout G, Kool M, Van der Wouden JC, Moll HA, Koes BW, Berger MY. Antibiotic Prescription in Febrile Children: A Cohort Study during Out-of-Hours Primary Care. J Am Board Fam Med. 2012;25:810-8.

6. Otters HB, van der Wouden JC, Schellevis FG, van Suijlekom-Smit LW, Koes BW. Trends in prescribing antibiotics for children in Dutch general practice. J Antimicrob Chemother. 2004;53:361-6.

7. de Bont EG, Loonen N, Hendrix DA, Lepot JM, Dinant GJ, Cals JW. Childhood fever: a qualitative study on parents' expectations and experiences during general practice out-ofhours care consultations. BMC Fam Pract. 2015;16:131.

8. Macfarlane J, Holmes W, Macfarlane R, Britten N. Influence of patients' expectations on antibiotic management of acute lower respiratory tract illness in general practice: questionnaire study. BMJ. 1997;315:1211-4.

9. Cabral C, Ingram J, Lucas PJ, Redmond NM, Kai J, Hay AD, et al. Influence of Clinical Communication on Parents' Antibiotic Expectations for Children With Respiratory Tract Infections. Ann Fam Med. 2016;14:141-7.

10. Mangione-Smith R, Zhou C, Robinson JD, Taylor JA, Elliott MN, Heritage J. Communication practices and antibiotic use for acute respiratory tract infections in children. Ann Fam Med. 2015;13:221-7.

11. Butler CC, Rollnick S, Pill R, Maggs-Rapport F, Stott N. Understanding the culture of prescribing: qualitative study of general practitioners' and patients' perceptions of antibiotics for sore throats. BMJ. 1998;317:637-42.

12. de Bont EG, Alink M, Falkenberg FC, Dinant GJ, Cals JW. Patient information leaflets to reduce antibiotic use and reconsultation rates in general practice: a systematic review. BMJ Open. 2015;5:e007612.

13. de Bont EG, Dinant GJ, Elshout G, van Well G, Francis NA, Winkens B, et al. An illness-focused interactive booklet to optimise management and medication for childhood 
fever and infections in out-of-hours primary care: study protocol for a cluster randomised trial. Trials. 2016;17:547.

14. Giesen P. SM, Huibers L., Grol R., Wensing M. Quality of after-hours primary care: As narrative review of the Dutch solution. Ann Intern Med. 2011;155:108-13.

15. de Bont EG, Peetoom KK, Moser A, Francis NA, Dinant GJ, Cals JW. Childhood fever: a qualitative study on GPs' experiences during out-of-hours care. Fam Pract. 2015;32:449-55.

16. Adams G, Gulliford MC, Ukoumunne OC, Eldridge S, Chinn S, Campbell MJ. Patterns of intra-cluster correlation from primary care research to inform study design and analysis. J Clin Epidemiol. 2004;57:785-94.

17. van Breukelen GJ, Candel MJ, Berger MP. Relative efficiency of unequal versus equal cluster sizes in cluster randomized and multicentre trials. Stat Med. 2007;26:2589603.

18. Dunn G, Maracy M, Dowrick C, Ayuso-Mateos JL, Dalgard OS, Page H, et al. Estimating psychological treatment effects from a randomised controlled trial with both non-compliance and loss to follow-up. Br J Psychiatry. 2003;183:323-31.

19. White IR. Uses and limitations of randomization-based efficacy estimators. Stat Methods Med Res. 2005;14:327-47.

20. O'Sullivan JW, Harvey RT, Glasziou PP, McCullough A. Written information for patients (or parents of child patients) to reduce the use of antibiotics for acute upper respiratory tract infections in primary care. Cochrane Database Syst Rev. 2016;11:CD011360.

21. Jo B. Model misspecification sensitivity analysis in estimating causal effects of interventions with non-compliance. Stat Med. 2002;21:3161-81.

22. Gillespie D, Hood K, Farewell D, Butler CC, Verheij T, Goossens H, et al. Adherenceadjusted estimates of benefits and harms from treatment with amoxicillin for LRTI: secondary analysis of a 12-country randomised placebo-controlled trial using randomisation-based efficacy estimators. BMJ Open. 2015;5:e006160.

23. Francis N, Butler C, Hood K, Simpson S, Wood F, Nuttall J. Effect of using an interactive booklet about childhood respiratory tract infections in primary care consultations on reconsulting and antibiotic prescribing: a cluster randomised controlled trial. BMJ. 2009;339:b2885-b.

24. Little P, Stuart B, Francis N, Douglas E, Tonkin-Crine S, Anthierens S, et al. Effects of internet-based training on antibiotic prescribing rates for acute respiratory-tract infections: a multinational, cluster, randomised, factorial, controlled trial. Lancet. 2013;382:1175-82. 
25. Meeker D, Linder JA, Fox CR, Friedberg MW, Persell SD, Goldstein NJ, et al. Effect of Behavioral Interventions on Inappropriate Antibiotic Prescribing Among Primary Care Practices: A Randomized Clinical Trial. JAMA. 2016;315:562-70. 


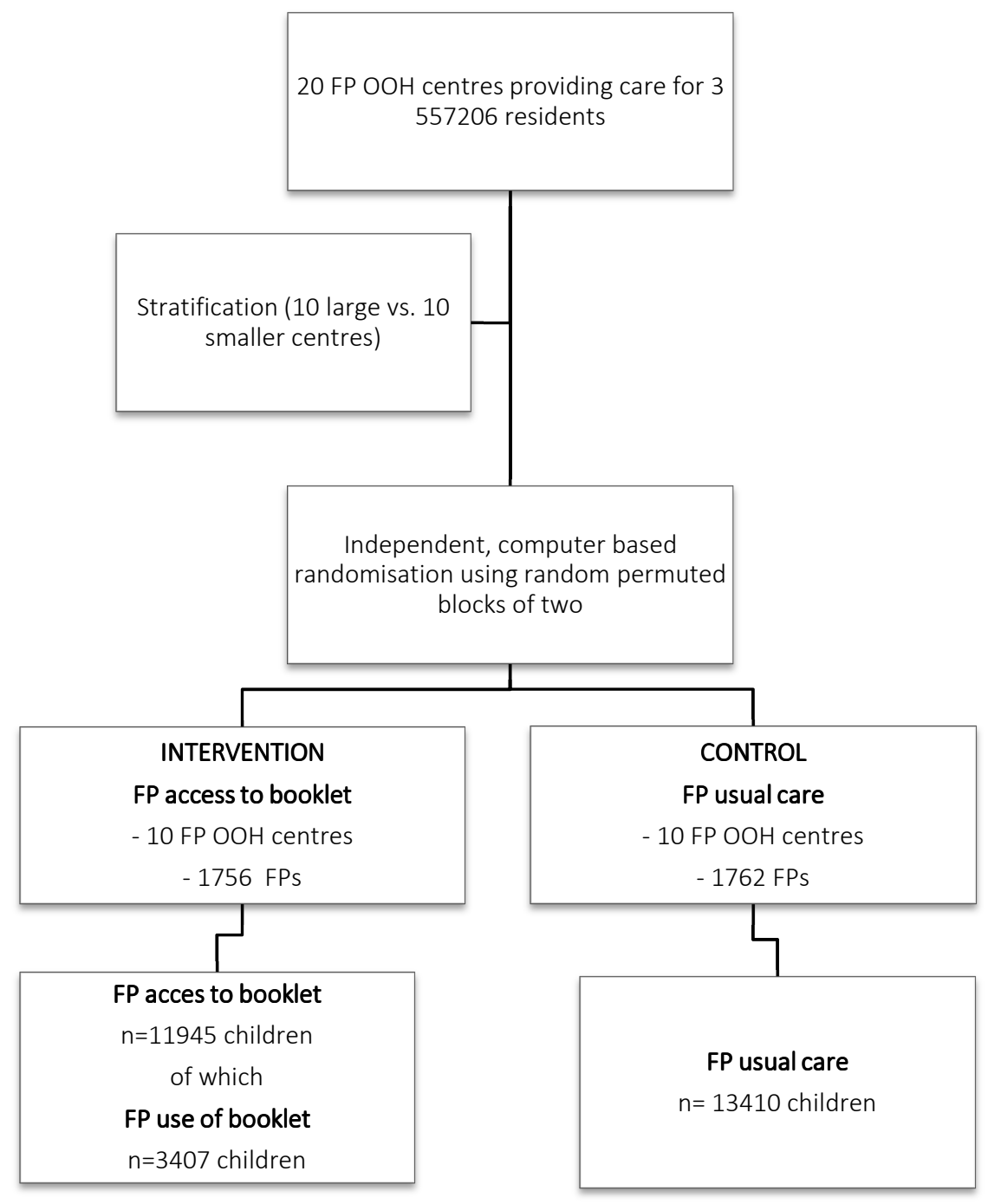

Figure 9.1 Study profile and inclusion; FP = Family Physician 
SUPPLEMENTARY TABLES

Table 9.5 Top 3 non-antibiotic prescriptions

\begin{tabular}{llll}
\hline & $\begin{array}{l}\text { Control } \\
\mathrm{n}=13410\end{array}$ & $\begin{array}{l}\text { Access to booklet } \\
\mathrm{n}=11945\end{array}$ & $\begin{array}{l}\text { Use of booklet } \\
\mathrm{n}=3407\end{array}$ \\
Xylomethazoline nasal spray & $366(2.7 \%)$ & $200(1.7 \%)$ & $65(1.9 \%)$ \\
Salbutamol inhaler & $313(2.3 \%)$ & $248(2.1 \%)$ & $56(1.6 \%)$ \\
Ibuprofen & $99(0.7 \%)$ & $97(0.8 \%)$ & $22(0.7 \%)$ \\
\hline
\end{tabular}

Table 9.6 Patient characteristics between FP access to booklet vs. actual use of booklet

\begin{tabular}{|c|c|c|c|}
\hline & $\begin{array}{l}\text { Use of booklet } \\
n=3407\end{array}$ & $\begin{array}{l}\text { No use of booklet } \\
n=8538\end{array}$ & $\begin{array}{l}\text { Access to booklet } \\
n=11945\end{array}$ \\
\hline Age in years - Mean (SD) & $2.9( \pm 2.4)$ & $3.4( \pm 2.7)$ & $3.3( \pm 2.7)$ \\
\hline Male sex $-n=(\%)$ & $1786(52.4 \%)$ & 4527 (53.0\%) & $6313(52.9 \%)$ \\
\hline \multicolumn{4}{|l|}{ Socioeconomic status parents } \\
\hline Low & $574(17.1 \%)$ & $1252(14.8 \%)$ & $1826(15.4 \%)$ \\
\hline Middle & $2360(70.1 \%)$ & 6099 (72.0\%) & 8459 (71.5\%) \\
\hline High & $431(12.8 \%)$ & $1119(13.2 \%)$ & $1550(13.1 \%)$ \\
\hline \multicolumn{4}{|l|}{ ICPC top 3} \\
\hline A03.00 Fever & $832(24.4 \%)$ & $1342(15.8 \%)$ & $2174(18.2 \%)$ \\
\hline $\begin{array}{l}\text { R74.00 Acute upper respiratory } \\
\text { tract infection }\end{array}$ & $788(23.1 \%)$ & 1569 (18.4\%) & 2357 (19.9\%) \\
\hline $\begin{array}{l}\text { H71.00 Acute otitis media } \\
\text { acuta/myringitis }\end{array}$ & $449(13.2 \%)$ & $1155(13.6 \%)$ & 1604 (13.5\%) \\
\hline
\end{tabular}

$S D=$ standard deviation

Table 9.7 Patient characteristics between telephone survey and total population

\begin{tabular}{lll} 
& $\begin{array}{l}\text { Telephone survey } \\
n=553\end{array}$ & $\begin{array}{l}\text { Total } \\
\mathrm{N}=25355\end{array}$ \\
Age in years - Median (IQR) & $3.5( \pm 2.6)$ & $3.2( \pm 2.7)$ \\
Male sex- $n=(\%)$ & $296(53.5 \%)$ & $13413(52.9 \%)$ \\
Socioeconomic status parents & & \\
Low & $77(14.0 \%)$ & $4087(16.2 \%)$ \\
Middle & $406(73.8 \%)$ & $17514(69.5 \%)$ \\
High & $67(12.2 \%)$ & $3582(14.2 \%)$ \\
ICPC top 3 & & \\
A03.00 Fever & & \\
R74.00 Acute upper respiratory tract infection & $113(20.4 \%)$ & $4645(18.4 \%)$ \\
H71.00 Acute otitis media acuta/myringitis & $125(22.6 \%)$ & $5010(19.8 \%)$ \\
\hline SOCiOeconomic status numbers do not add up to totats
\end{tabular}

Socioeconomic status numbers do not add up to totals in column due to missings 


\section{Medication}

management in

childhord fever and

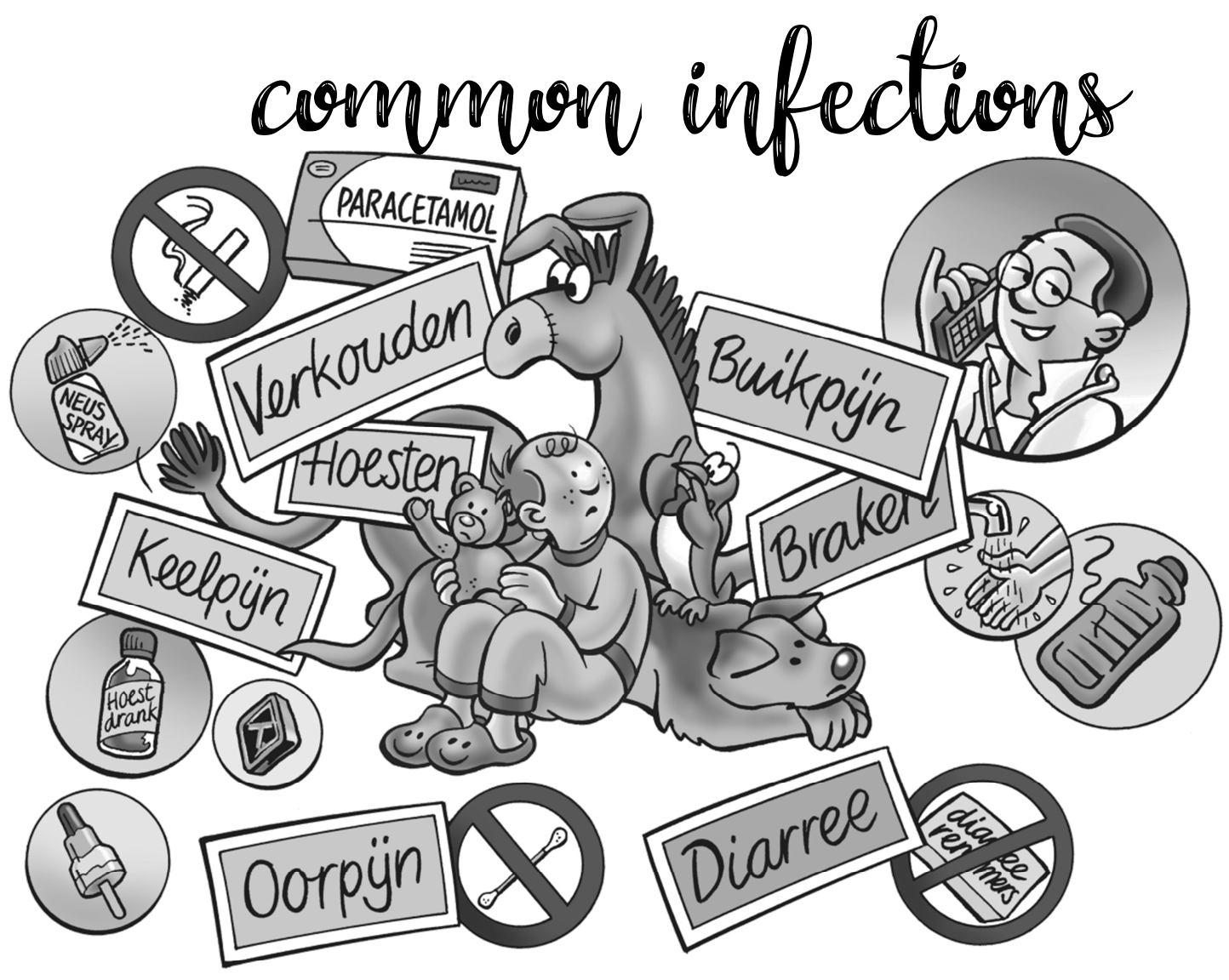





\section{Medication management of febrile children: a qualitative study on pharmacy employees' experiences}

Jacqueline P. Stakenborg

Eefje G.P.M. de Bont Kirsten K. Peetoom

Marjorie H. Nelissen-Vrancken Jochen W. L. Cals 



\section{ABSTRACT \\ Background}

While fever is mostly self-limiting, antibiotic prescription rates for febrile children are high. Although every parent who receives a prescription visits a pharmacy, we have limited insight into pharmacy employees' experiences with these parents. Pharmacy employees do however exert an important role in ensuring children receive correct dosages and in advising parents on administration of antibiotics.

\section{Objective}

To describe pharmacists' and pharmacy assistants' experiences with parents contacting a pharmacy for their febrile child, and to identify ways of improving medication management of these children.

\section{Setting}

Community pharmacies in the Netherlands.

\section{Method}

A qualitative study including 24 Dutch pharmacy employees was conducted, performing four focus group discussions among pharmacy employees. Analysis was based on constant comparative technique using open and axial coding.

\section{Main outcome measure}

Pharmacy employees' experiences with parents contacting a pharmacy for their febrile child.

\section{Results}

Three categories were identified: (1) workload and general experience, (2) inconsistent information on antibiotic prescriptions, (3) improving communication and collaboration. Pharmacy employees experienced that dosing errors in antibiotic prescriptions occur frequently and doctors provide inconsistent information on prescriptions. Consequently, they have to contact doctors, resulting in a higher workload for both stakeholders. They believe this can be improved by providing the indication for antibiotics on prescriptions, especially when deviating from standard dosages. 


\section{Conclusion}

Pharmacy employees experience a high amount of dosing errors in paediatric antibiotic prescriptions. Providing the indication for antibiotics in febrile children on prescriptions, especially when deviating from standard dosages, can potentially reduce dosage errors and miscommunication between doctors and pharmacy employees. 


\section{INTRODUCTION}

Fever is a common symptom in children and the most common reason for parents to consult primary care services, especially during out-of-hours care. ${ }^{1,2}$ Guidelines are conservative concerning the use of antibiotics even in cases of fever with a focus, since fever is mostly self-limiting. ${ }^{3,4}$ Furthermore, parents generally do not expect an antibiotic prescription when consulting with their febrile child. ${ }^{5,6}$ Nevertheless, antibiotic prescription rates for febrile children in general practice are high, especially during out-of-hours care where one in three to four children receive an antibiotic. ${ }^{4,7}$ Re-consultations with a general practitioner (GP) during the same illness period are common and are associated with parental uncertainty and fear of complications. Parents experience a lack of knowledge on self-management strategies. Furthermore, a lack of consistency in the information given to patients may result in confusing advice. ${ }^{2,8-10}$

Previous studies showed that dosage errors in paediatric prescriptions are common. Children are exposed to a higher rate of dangerous medication errors compared to adults. ${ }^{11}$ Furthermore, problems with administration of antibiotics occur in more than $30 \%$. Parents find it difficult to administer medication to their child and children tend to be more sensitive to side effects. Parents find it hard to continue prescribed medication when these side effects occur. ${ }^{12-14}$

Dosing of antibiotics in children is complex for doctors. ${ }^{15}$ In the 1940 s, dosing was based on weight, from the 1960s also on age. These same dosing regimens seem to have been followed for the last 50 years. Currently there is a lack of recent evidence to support these recommendations, especially, since children's body compositions have changed in the last decades, leading to many children being under-dosed. ${ }^{15,16}$ Furthermore, the quality of prescribing varies amongst GPs. ${ }^{17}$ High prescription rates, problems with antibiotic administration and incorrect dosing drive antimicrobial resistance, non-compliance, and ineffective treatment of febrile children. ${ }^{12}$

Because dosing of antibiotics in children is complex, the pharmacy exerts an important role in medication management for children. They also play a central role in advising parents on correct antibiotics administration and how to deal with side effects. However, evidence with regards to what happens at the pharmacy following a GPs' consultation is lacking. In order to improve medication management and antibiotic prescribing for febrile children, it is important to learn about pharmacy employees' experiences with these children. 


\section{Aim of the study}

This qualitative study aims to study pharmacy employees' experiences with parents contacting the pharmacy for a febrile child and to identify ways of improving medication management for these children.

\section{Ethical approval}

This study was approved by the Medical Ethics Committee of the Maastricht University Medical Centre (NL METC 15-4-061). Participants' data were encoded by numbering, ensuring anonymity of the included subjects. Written informed consent was obtained from all participants. 


\section{METHOD}

We performed a qualitative study based on naturalistic inquiry using focus group discussions with pharmacy employees to study their experiences with parents of febrile children contacting pharmacies. ${ }^{18}$

\section{Setting}

This study was carried out among pharmacists and pharmacy assistants: pharmacy employees from four different pharmacies in Limburg, the Netherlands. Focus group discussions were held at the participating pharmacies.

\section{Subjects}

Pharmacists in the area were approached by email with the request to participate in this study. Focus groups were organized with a minimum of five subjects, including at least one pharmacist in each group. Employees from one pharmacy represented one group. We recruited pharmacies using purposeful sampling with the aim of achieving maximum variation between groups with regards to size of the pharmacy (client number), the number of pharmacy employees, and the community deprivation level. To obtain a more heterogeneous representation we included an out-of-hours pharmacy and pharmacies that had employees who previously worked out-of-hours. Out-of-hours pharmacies open only during the evening, nights and weekends.

\section{Data collection}

Focus group discussions were used to generate insight into the experiences among pharmacy employees. ${ }^{19}$ We prepared a topic list using sensitizing concepts. Questions were distilled into this topic list after literature research and a priori expert discussions. ${ }^{20}$ Questions covered multiple aspects related to contacts with parents of febrile children at the pharmacy and medication management for these children. Covered topics were: workload and general experience, information provision, reasons for parents to contact the pharmacy, frequently asked questions/problems and medication management (prescriptions, dosing control). Data saturation was achieved after the third focus group. To validate the presumed saturation we performed one extra focus group. The discussions lasted 45-60 minutes and were facilitated by an independent moderator. Group dynamics and non-verbal communication were studied by two observers and noted in a researchdiary. The discussions were audio-recorded and transcribed verbatim by JS. 


\section{Data analysis}

We analysed data using the constant comparison technique. Data collection and analysis took place simultaneously from February-April 2015. ${ }^{20,21 .}$ Every focus group was analysed independently by two researchers (EB and JS), both present at the focus groups. Analysis was performed prior to the next focus group, thereby allowing room for refinement and adjustment of data collection. The topic list was discussed and adjusted several times among the wider research team. ${ }^{21}$ Categories were derived using inductive content analysis, first using open and finally axial coding, ${ }^{20,21}$ NVivo software version 9.0 was used to facilitate data analysis. Discussion in the wider research team resolved inconsistencies by consensus.

\section{Trustworthiness}

To enhance trustworthiness we embedded several strategies in our study. Data triangulation was used by including pharmacies with different sizes, areas and working hours. Methodological triangulation was enhanced by using a research-diary. The moderator had a different background (pharmacist) than the two researchers (medicine), strengthening the investigator triangulation. Data collection and analysis were performed by two researchers independently. Peer debriefing was organized with the wider research team. A member check of the written transcript was performed among the participants. In order to let others decide to what extent the results of this study are transferable to their context, we provided a detailed description of the methodology and subjects included. An audit trail was created to allow for replicability. ${ }^{22}$ We used the criteria included in Consolidated criteria for reporting qualitative research (COREQ) to report important aspects of the research team, study methods, context of the study, findings, analysis and interpretations. 


\section{RESULTS}

Nine pharmacies were approached; six consented to participate of which four were used for a focus group before saturation was reached. A lack of time was given as the reason for those not consenting to participate. We included three regular pharmacies, one of which also has opening hours on Saturdays, and one out-of-hours pharmacy. Pharmacies from rural and urban areas were included and varied in size with respect to the number of employees and clients. Five pharmacists and 19 pharmacy assistants participated (2 male, 22 female). Mean age was 39 years (range: 23-64 years), average years of working experience was 17 (range: 0-42 years), 7 of the 19 pharmacy employees working at the regular pharmacies (37\%) also had experience of working out-of-hours.

We identified three main categories from the data: (1) workload and general experience, (2) inconsistent information on antibiotic prescriptions, (3) improving communication and collaboration. Figure 10.1 shows an overview of the main categories. Table 10.1 shows a tabulated form of the identified categories and the respondents' quotes.

\section{Workload and general experience}

Pharmacy employees working during office hours experienced a minimal workload imposed by parents contacting them for their febrile child. In contrast, pharmacy employees working out-of-hours perceived a strikingly higher workload and stated that antibiotic prescriptions for febrile children, mostly prescribed by GPs, are one of the most frequent prescribed medications. Pharmacy employees with experience of both types of services confirmed an evident difference in workload between them.

"Coincidentally, I checked it [the number of antibiotic prescriptions for children] last weekend. I stopped counting when I got to 26 amoxicillin prescriptions starting from Friday night until Sunday morning. After this, there were at least another 5-6 prescriptions, so in total around 30 amoxicillin prescriptions for children." (FG 2, pharmacy employee (PE) 3, pharmacy assistant)

They stated that they observe a seasonal influence and difference between age categories.

"We do see a lot of parents of febrile children, especially in the winter period, when the rate of infections is higher." (FG 2, PE 11, pharmacy assistant)

They explained that parents of febrile children contact the pharmacy either with an antibiotic prescription or for over-the-counter (OTC) drugs, rarely for advice. They 
perceived parents don't contact a pharmacy but rather a GP when problems occur with administration of medication or when their child has side effects from antibiotics.

They experienced that once parents contact the pharmacy, they seem impatient and restless, especially during out-of-hours care. According to them, this might be caused by the fact that they have been waiting at the doctor's office and then at the pharmacy so want to go home with their child as soon as possible.

"Yes and they want to go home with their child because they were waiting in the doctor's waiting room, and then you still have to prepare it [the prescription] and they have to wait for this. So I constantly feel the impatience of these parents when I am doing this." (FG 3, PE 13, pharmacist)

Pharmacy employees expressed understanding for this impatience and restlessness but also felt that this might add to suboptimal information provision for these parents about the prescribed medication and/or care for their child. They explained they have the perception that during a GP's consultation little attention is paid to the fact that pharmacies are important to inform parents about this.

"And we would like to explain something. Like today, the doctor wrote 2 millilitres, 3 times a day, a prescription for a completely different dosage to the one we will deliver. So they [the parents] will have to administer 4 millilitres, 3 times a day, so you want to explain this carefully. Parents will not ask anything, they just want to go home and they think: 'Yes I know everything.' But then, a few days later they contact us, stating that the dosage we provided was incorrect." (FG 3, PE 13, pharmacist)

Some perceived that this also contributes to their feeling that parents are distrustful towards them and sometimes irritated when dosages are checked and/or adjusted, questions are asked and when different and/or additional information is provided with regards to what the doctor explained.

Pharmacy employees experienced that parents in general attach more credibility to what the doctor has told them compared to what they are trying to explain. This makes it difficult for them to give advice and adjust medication management, while this is often necessary and one of their primary tasks. Pharmacy employees expressed their frustration.

"I feel parents are sometimes distrustful towards us: 'Yes, but didn't the doctor write that down?!'” (FG 2, PE 11, pharmacy assistant) 


\section{Inconsistent information on antibiotic prescriptions}

Pharmacy employees experienced that prescribing doctors are inconsistent and often incomplete with regards to what information they provide on antibiotic prescriptions for children.

"Most of the time, they just write down: '10 kilograms, please calculate'." (FG 1, PE 3, pharmacy assistant)

There is inconsistency with regards to whether doctors calculate the dosage and whether they mention the indication for the antibiotic on the prescription. Furthermore, pharmacy employees stated that dosage errors, as in errors in the calculated dosage provided on the prescription by the GP according to guidelines, occur frequently in paediatric antibiotic prescriptions.

"There is almost no doctor's prescription that is correct anymore." (FG 1, PE 5, pharmacy assistant)

Frequent dosage errors and inconsistent information on antibiotic prescriptions result in problems when checking them. They perceived no problems with the correction of the dosage itself since all pharmacies follow the same guidelines but problems do arise from the fact that they often lack relevant information on prescriptions for revision of the dosage.

"Do you feel limited by not knowing certain information?" (moderator) "Absolutely." (FG 1, PE 1, pharmacy assistant)

Consequently, pharmacy employees frequently have to consult the prescribing doctor, resulting in a higher workload for both stakeholders. They explained this leads to frustration and/or irritation for pharmacy employees and most likely for prescribing doctors, and parents. Furthermore they experienced that parents seem to find it confusing when there is discussion about a prescription after a doctor's visit and that this leads to parental uncertainty.

"This [having a discussion about a dosage with a doctor] also makes parents insecure." (FG 3, PE 18, pharmacy assistant) 
In some pharmacies, employees expressed tension regarding these fever-related contacts and experienced this as a burden. They perceived that some doctors feel criticized or irritated when they consult them about a dosage or indication for an antibiotic.

"Yes, and what are you supposed to do then, should you under-dose? No, then you unfortunately have to contact them again and hope they won't be angry. And ask if it [the dosage] could please be a little bit higher." (FG 1, PE 5, pharmacy assistant)

\section{Improving communication and collaboration}

As was mentioned, prescribing doctors are contacted when there are questions about the prescribed antibiotic and/or the amount of the dosage.

"Because you often don't know the reason why a doctor advises a particular dosage, so indeed, you have to contact them." (FG 2, PE 11, pharmacy assistant)

Pharmacy employees stated that it would be timesaving and beneficial if doctors mentioned the indication for the antibiotic, especially when deviating from standard dosages. It would facilitate double-checking dosages and prescriptions, thereby increasing medication safety for these children and reducing unnecessary contact with prescribing doctors. Since most prescriptions are provided by GPs, they believed this message would be most relevant for them.

"It would be a lot more convenient if they provided the indication on the prescription. In this way we would be able to organize it much easier." (FG 3, PE 17, pharmacy assistant)

They also explained that sometimes when contacting the prescribing GP, it appears that the doctor deviated from the standard dosage after consultation with a specialist doctor. In these cases, pharmacy employees found it even more important to mention this on a prescription, thereby avoiding miscommunication.

"When you have contacted a specialist doctor, put this in the free text. It just takes a small effort and it saves us both the effort of having a phone call." (FG 3, PE 13, pharmacist)

In some pharmacies there were already specific agreements between the pharmacy and the doctors. These agreements allowed pharmacy employees to correct the antibiotic dose 
in cases of under-dosing and in some pharmacies mentioning the indication for the antibiotic on the prescription was already incorporated in their work process.

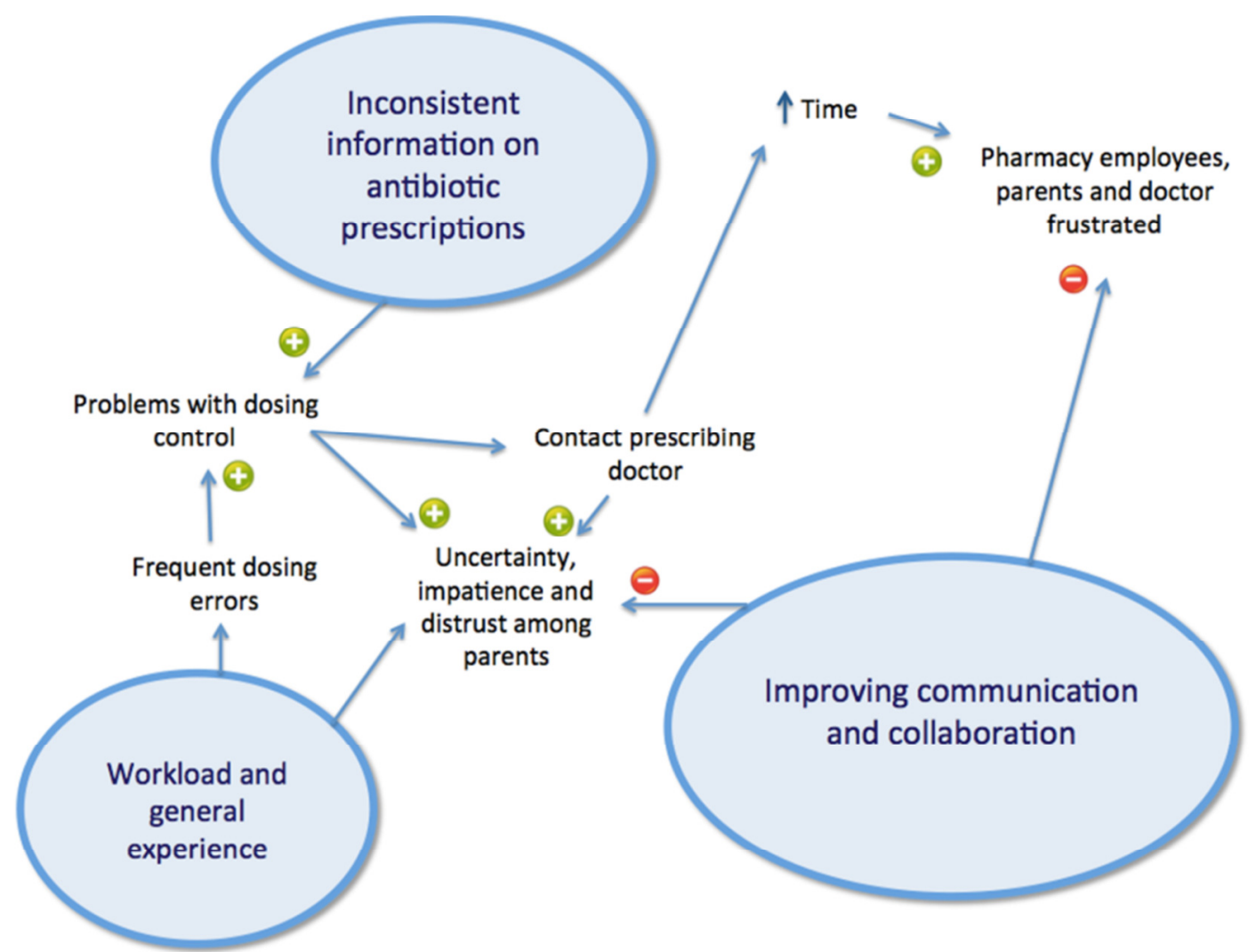

Figure 10.1 Identified categories - All closely interwoven: workload and general experience, inconsistent information on antibiotic prescriptions and improving communication and collaboration. 
Table 10.1 Tabulated form of the identified categories and the respondents' quotes

\section{Identified category Workload and general experience} Workload

Workload

General experience

General experience

General experience

Inconsistent information on antibiotic prescriptions

Inconsistency in providing prescriptions, incomplete prescriptions
Respondents' quotes

"Coincidentally, I checked it [the number of antibiotic prescriptions for children] last weekend. I stopped counting when I got to 26 amoxicillin prescriptions starting from Friday night until Sunday morning. After this, there were at least another 5-6 prescriptions, so in total around 30 amoxicillin prescriptions for children." (FG 2, pharmacy employee (PE) 3, pharmacy assistant)

"We do see a lot of parents of febrile children, especially in the winter period, when the rate of infections is higher." (FG 2, PE 11, pharmacy assistant)

"Yes and they want to go home with their child because they were waiting in the doctor's waiting room, and then you still have to prepare it [the prescription] and they have to wait for this. So I constantly feel the impatience of these parents when I am doing this." (FG 3, PE 13, pharmacist)

"And we would like to explain something. Like today, the doctor wrote 2 millilitres, 3 times a day, a prescription for a completely different dosage to the one we will deliver. So they [the parents] will have to administer 4 millilitres, 3 times a day, so you want to explain this carefully. Parents will not ask anything, they just want to go home and they think: 'Yes I know everything.' But then, a few days later they contact us, stating that the dosage we provided was incorrect." (FG 3, PE 13, pharmacist)

"I feel parents are sometimes distrustful towards us: 'Yes, but didn't the doctor write that down?!'” (FG 2, PE 11, pharmacy assistant)

"Most of the time, they just write down: '10 kilograms, please calculate'." (FG 1, PE 3, pharmacy assistant)

Dosage errors correct anymore." (FG 1, PE 5, pharmacy assistant) 
information?" (moderator)

"Absolutely." (FG 1, PE 1, pharmacy assistant)

"This [having a discussion about a dosage with a doctor] also makes parents insecure." (FG 3, PE 18, pharmacy assistant)

"Yes, and what are you supposed to do then, should you under-dose? No, then you unfortunately have to contact them again and hope they won't be angry. And ask if it [the dosage] could please be a little bit higher." (FG 1, PE 5, pharmacy assistant)

Improving communication and collaboration

"Because you often don't know the reason why a doctor advises a particular dosage, so indeed, you have to contact them." (FG 2, PE 11, pharmacy assistant)

"It would be a lot more convenient if they provided the indication on the prescription. In this way we would be able to organize it much easier." (FG 3, PE 17, pharmacy assistant)

"When you have contacted a specialist doctor, put this in the free text. It just takes a small effort and it saves us both the effort of having a phone call." (FG 3, PE 13, pharmacist) 


\section{DISCUSSION}

\section{Summary of the main results}

Pharmacy employees report that they see a lot of parents with antibiotic prescriptions for their febrile child during out-of-hours care, mostly provided by GPs. Errors in dosing are strikingly common in paediatric antibiotic prescriptions and doctors are inconsistent with regards to the information they provide on antibiotic prescriptions. This can decrease the pharmacist's ability to check the dosage on a prescription, leading to a risk of unsafe medication management in these children and frequent contacts with prescribing doctors which likely leads to frustration for all those involved. Pharmacy employees suggest that if we want to improve medication management for febrile children, doctors and especially GPs should consider providing an indication on prescriptions, especially when deviating from standard dosages.

\section{Strengths and limitations}

This is the first qualitative study that provides an in-depth insight into pharmacy employees' experiences with parents of febrile children. The results of this study give clear guidance for the improvement of medication management for febrile children.

Despite efforts to make participants feel comfortable and safe by conducting the focus group discussions in their work environment, they may have given socially acceptable answers, thereby holding back valuable information. The different perspectives, member check, peer debriefings, investigator and data triangulation did, however, help us to increase trustworthiness.

Since health care systems are culturally different, we do not know to what extent these results are transferable to other countries. They are likely not transferable to countries where antibiotics can be bought over-the-counter. Also, in some other countries is it already required to mention the indication on prescriptions. However, we did use purposeful and heterogenic sampling and the path from GP's office to pharmacy is common in other countries. We provided a detailed explanation of our methods and sample, allowing others to decide on transferability to their contexts. ${ }^{23}$

\section{Comparison with existing literature}

Previous research has shown that the attendance rate of febrile children at primary care services is high, especially out-of-hours. ${ }^{1,2}$ This study shows that pharmacy employees experience the same. An explanation for this might be that antibiotic prescription rates for febrile children are higher during out-of-hours care compared to the rate during office hours. $^{4,24}$ 
Previous studies aimed at improving safety in antibiotic medication management in children were mainly performed in secondary, paediatric care settings, where medication management is much more controlled than in a primary care setting. ${ }^{17,25}$

Although the recommendations from this study might be partially applicable to other patient groups, they are specifically formulated for febrile children in primary care. Since prescriptions and consultations are high, but more importantly because dosing is complex and dosing errors occur frequently in this group. ${ }^{11,26}$

Mentioning the indication on prescriptions might reduce patients' privacy. To our opinion, more efficient collaboration between pharmacy employees and doctors does however counterbalance this since safety for febrile children might be enhanced. Requiring indications being written on all prescriptions is already implemented in health care systems of other countries than the Netherlands. In the Netherlands this is only required for certain medications, not yet for antibiotics. Mentioning the indication on prescriptions is also known to have a positive impact on patient safety. ${ }^{27}$ This study shows that collaboration between GPs and pharmacies is not only crucial in the management of a chronic disease but for all patient groups. ${ }^{17,28}$

\section{Implications for research and practice}

Pharmacy employees perceived that parents visiting a pharmacy are restless, impatient and distrustful towards them. This was not earlier described in literature. Future research should further investigate parental experiences with pharmacies. It should also focus on implementing a standardized system with regards to information provided on antibiotic prescriptions for children by GPs. Future research must focus on how information provision at pharmacies might be improved.

The following concrete ideas for improvement of prescriptions were proposed: (1)mentioning the indication for the antibiotic prescription at least when deviating from standard dosages, (2)mentioning any prior consultation with a specialist doctor about the dosage or other reasons for deviating from guidelines on choice and dosage of antibiotics.

\section{CONCLUSION}

Pharmacy employees experience frequent dosing errors in paediatric antibiotic prescriptions and feel doctors are inconsistent with regards to the information they provide on prescriptions. According to them, providing an indication for an antibiotic prescription in febrile children, especially when deviating from standard dosages, can potentially increase safety in medication management for febrile children by reducing dosage errors and miscommunication between doctors and pharmacies. 


\section{REFERENCES}

1. Hay AD, Heron J, Ness A. The prevalence of symptoms and consultations in preschool children in the Avon Longitudinal Study of Parents and Children (ALSPAC): a prospective cohort study. Fam Pract. 2005;22:367-74.

2. Huibers LA, Moth G, Bondevik GT, Kersnik J, Huber CA, Christensen MB, et al. Diagnostic scope in out-of-hours primary care services in eight European countries: an observational study. BMC Fam Pract. 2011;12:30.

3. Fields E, Chard J, Murphy MS, Richardson M. Assessment and initial management of feverish illness in children younger than 5 years: summary of updated NICE guidance. BMJ. 2013;346.

4. Elshout G, Kool M, Van der Wouden JC, Moll HA, Koes BW, Berger MY. Antibiotic Prescription in Febrile Children: A Cohort Study during Out-of-Hours Primary Care. J Am Board Fam Med. 2012;25:810-8.

5. de Bont EG, Loonen N, Hendrix DA, Lepot JM, Dinant GJ, Cals JW. Childhood fever: a qualitative study on parents' expectations and experiences during general practice out-ofhours care consultations. BMC Fam Pract. 2015;16:131.

6. de Bont EG, Francis N.A.F, Dinant GJ, Cals JWL. Parents' knowledge, attitudes, and practice in childhood fever: an internet-based survey. Br J Gen Pract. 2014;64(618):e10-6.

7. de Bont EG, Lepot JM, Hendrix DA, Loonen N, Guldemond-Hecker Y, Dinant GJ, et al. Workload and management of childhood fever at general practice out-of-hours care: an observational cohort study. BMJ Open. 2015;5:e007365.

8. Walsh A, Edwards H, Fraser J. Influences on parents' fever management: beliefs, experiences and information sources. J Clin Nurs. 2007;16:2331-40.

9. Eskerud JR, Andrew M, Stromnes B, Toverud EL. Pharmacy personnel and fever: a study on perception, self-care and information to customers. Pharm World Sci. 1993;15:156-60.

10. Eskerud JR, Brodwall A. General practitioners and fever: a study on perception, self-care and advice to patients. Pharm World Sci. 1993;15:161-4.

11. Bauters TG, Nguyen BT, Buyle F, Schelstraete P, De Cock P, De Jaeger A, et al. Clinical pharmacy and pediatrics: why focus on antibiotics? Pharm World Sci. 2006;28:3-5.

12. de Jong J, Niehoff ML, de Vries TW, de Jong-van den Berg LTW. Daily practice of oral antibiotic therapy: problems in at least $30 \%$ of the children. Pharmacoepidemiol Drug Saf. 2009;18:213.

13. Kaushal R, Barker KN, Bates DW. How can information technology improve patient safety and reduce medication errors in children's health care? Arch Pediatr Adolesc Med. 2001;155:1002-7. 
14. McPhillips HA, Stille CJ, Smith D, Hecht J, Pearson J, Stull J, et al. Potential medication dosing errors in outpatient pediatrics. J Pediatr. 2005;147:761-7.

15. Ahmed U, Spyridis N, Wong IC, Sharland M, Long PF. Dosing of oral penicillins in children: is big child= half an adult, small child= half a big child, baby= half a small child still the best we can do? BMJ. 2011;343.

16. Ekins-Daukes S, McLay JS, Taylor MW, Simpson CR, Helms PJ. Antibiotic prescribing for children. Too much and too little? Retrospective observational study in primary care. $\mathrm{Br}$ J Clin Pharmacol. 2003;56:92-5.

17. Muijrers PE, Grol RP, Sijbrandij J, Janknegt R, Knottnerus JA. Pharmaceutical care and its relationship to prescribing behaviour of general practitioners. Pharm World Sci. 2006;28:302-8.

18. Lincoln YS, Guba EG. Naturalistic inquiry: Sage Publications; 1985.

19. Gill P, Stewart K, Treasure E, Chadwick B. Methods of data collection in qualitative research: interviews and focus groups. Br Dent J. 2008;204:291-5.

20. Bowen G. Grounded theory and sensitizing concepts. Int J Qual Methods. 2008;5:12-23.

21. Pope C, Ziebland S, Mays N. Qualitative research in health care. Analysing qualitative data. BMJ. 2000;320:114-6.

22. Bryman A. Triangulation. Thousand Oaks, CA: Sage Publications; 2003.1142-1143.

23. Morgan DJ, Okeke IN, Laxminarayan R, Perencevich EN, Weisenberg S. Nonprescription antimicrobial use worldwide: a systematic review. Lancet Infect Dis. 2011;11:692-701.

24. Otters HB, van der Wouden JC, Schellevis FG, van Suijlekom-Smit LW, Koes BW. Trends in prescribing antibiotics for children in Dutch general practice. J Antimicrob Chemother. 2004;53:361-6.

25. Aseeri MA. The impact of a pediatric antibiotic standard dosing table on dosing errors. J Pediatr Pharmacol Ther. 2013;18:220-6.

26. Bernius M, Thibodeau B, Jones A, Clothier B, Witting M. Prevention of pediatric drug calculation errors by prehospital care providers. Prehosp Emerg Care. 2008;12:486-94. 27. Al-Khani S, Moharram A, Aljadhey H. Factors contributing to the identification and prevention of incorrect drug prescribing errors in outpatient setting. Saudi Pharm J. 2014;22:429-32.

28. West R, Isom M. Management of patients with hypertension: general practice and community pharmacy working together. Br J Gen Pract. 2014;64:477-8. 

Risks and benefits of paracetamol in children with fever

Paul L. Brand Geert-Jan Dinant

Gijs van Well Jochen W.L. Cals 



\section{SUMMARY}

$\infty$ Paracetamol is the most frequently used antipyretic for children worldwide, and most guidelines recommend it as the first-choice agent to combat fever. It is debatable, however, whether it is necessary or desirable to suppress fever.

$\infty$ Providing correct information about the cause and treatment of fever can reduce parents' help-seeking behaviour.

$\infty$ The use of paracetamol is effective in treating a combination of pain and fever, and can be recommended in such cases, but doctors should be reticent about recommending paracetamol for children who only have a fever; fever as such does not need to be treated.

$\infty$ The effect of paracetamol on the general wellbeing of children with only a fever has not been unequivocally proven.

$\infty$ Research has shown that paracetamol is not effective in preventing febrile seizures or their recurrence.

$\infty$ Research suggests that suppressing fever with paracetamol adversely affects the immune response, and that there is a risk of mild side-effects and hepatotoxicity. 
A mother visits her family doctor with her two-year-old son as he has a fever. He does not show signs of pain and has no other specific symptoms. Physical examination reveals a temperature of $39.0^{\circ} \mathrm{C}$ and signs of upper airways infection. There are no signs of a serious infection and urinalysis shows no abnormalities. The doctor reassures the mother, upon which she asks him whether she should give her son paracetamol to suppress the fever.

This article summarises the advantages and disadvantages of paracetamol use, and attempts to answer the question in what circumstances doctors should advise parents to give their feverish child paracetamol, and when they should definitely not do so.

\section{Importance of knowledge about fever and paracetamol use}

Forty percent of children will visit a doctor with a fever at least once a year during their first two years of life. ${ }^{1}$ The cause is usually an innocent infection, which does not require treatment. Nevertheless, many parents frequently consult a doctor as they are afraid there might be a serious underlying infection. Fever in children is often a source of concern and anxiety in their parents, which influences the doctor's advice and explanations in the consulting room. ${ }^{2}$ Parents' knowledge about the causes and treatment of fever is generally limited: $50-70 \%$ of parents do not know the definition of fever, and many parents think that fever should always be suppressed. ${ }^{3}$

Paracetamol is the most frequently used antipyretic worldwide, and most guidelines recommend it as the first-choice agent to combat fever. ${ }^{4}$ Although no exact figures are available about the total use of paracetamol by children in the Netherlands - as it can be bought without prescription at chemists and supermarkets - practical experience and the literature show that parents frequently give their children paracetamol when they have a fever. ${ }^{5}$ It is questionable whether this is necessary or desirable from a medical point of view.

It is important for doctors - especially general practitioners, paediatricians and staff at child health clinics - to give appropriate and consistent advice to parents about the effectiveness of paracetamol in suppressing fever. This can help allay parents' fears and improve their knowledge about fever and the measures that they can take at home, so as to reduce their help-seeking behaviour. ${ }^{6}$

We used a systematic search strategy in PubMed and the Cochrane Library to find relevant articles on fever and antipyretics in children. The search terms and the corresponding flow diagram are shown in table 11.1 and figure 11.1. Our review included 69 articles; the 25 most important of them have been included in the reference list to the present paper. 


\section{What is fever and how do antipyretics work?}

Fever means an increase in body temperature beyond the normal daily variation. In terms of numbers, it implies a temperature above the internationally accepted rectally determined normal value of 38 Celsius $\left({ }^{\circ} \mathrm{C}\right) .{ }^{7}$ Fever is not the same as hyperthermia, in which the body's temperature rises as a result of increased exposure to heat or impaired heat dissipation. Fever is initiated and regulated by the thermoregulatory centre in the hypothalamus, under the influence of endogenous pyrogens as well as exogenous pyrogens like bacteria and viruses which invade the body. Agents involved in this process include the cytokines interleukin- 1 and interleukin- 6 and tumour necrosis factor- $\alpha$. They raise the body temperature by influencing the body's 'thermostat' in the hypothalamus, via mediators like prostaglandin-2. This causes the body to produce more heat and to retain it by vasoconstriction and shivering. Negative feedback by the hypothalamic-pituitary axis ensures that, in principle, the temperature does not exceed $42^{\circ} \mathrm{C}^{8}$ The antipyretic mechanism of paracetamol in this cascade is incompletely known, but the agent is known to inhibit the enzymes cyclo-oxygenase 1 and 2 and the mediator prostaglandin-2. ${ }^{9}$

\section{Possible advantages of using paracetamol}

The main ideas behind treating fever in children are to improve their general wellbeing (improved sleeping, eating and drinking behaviour), speeding up recovery and preventing complications, such as febrile seizures. For which of these outcomes has paracetamol proved to be effective?

Studies undertaken some twenty to thirty years ago found that the use of paracetamol is associated with a greater lowering of the body temperature than placebo. ${ }^{10,11}$ The 'number needed to treat' (NNT) to suppress the fever in one child within two hours is $1.5 .^{10}$ This means doctors have to treat three children with paracetamol to free two of these children of fever within two hours. In another study of children with fever, whose average temperature before treatment was $38.9^{\circ} \mathrm{C}$, the temperature in the paracetamol group had fallen to $37.9^{\circ} \mathrm{C}$ after three to five hours, compared to $39.2^{\circ} \mathrm{C}$ in the placebo group. ${ }^{11} \mathrm{~A}$ striking fact is that the antipyretic effect of paracetamol has only been studied in a handful of trials, all of them involving fewer than 50 children.

\section{Fever and general wellbeing}

Surprisingly little research has been done into the effect of paracetamol on children's general wellbeing. A study among 225 children in Canada found improved activity levels and alertness in the children who were given paracetamol compared to those given a placebo, but no improvement in general wellbeing or food and liquids intake. ${ }^{12}$ The various 
studies into general wellbeing or 'comfort' assessed these outcome measures in different ways, making it difficult to compare even what little evidence is available. ${ }^{10}$ It seems plausible, however, that lowering the body temperature as such results in a subjectively improved sense of general wellbeing.

\section{Fever and pain}

If a child has both fever and pain, the effect of paracetamol on their general wellbeing will possibly be caused mostly by the analgesic effect, rather than by the antipyretic effect. There have not been any studies of children with fever that reported a difference in pain between paracetamol and placebo as an outcome measure. A randomised study among 97 children with an acute inflammation of the throat found that the children who were given paracetamol had less pain than the children given placebo. Unfortunately, the article did not mention body temperatures. ${ }^{13}$ A comparable randomised study of 77 children with acute sore throat reported the same findings for pain as an outcome measure, and also a significant drop in body temperature, without however providing detailed data in degrees Celsius. Unfortunately, it did not look at wellbeing. ${ }^{14}$

\section{Fever and febrile seizures}

Can paracetamol prevent febrile seizures? Parents tend to be shocked and frightened if their child has a febrile seizure. Recurrence of such seizures upon recurrence of a fever occurs in a third of all patients. ${ }^{15}$ There is ample evidence, however, that antipyretics, including paracetamol, do not reduce the risk of febrile seizures or their recurrence. ${ }^{16}$ This may be caused by the fact that the seizures develop during the first few hours of fever, as the body temperature rises quickly. Irregular administration of paracetamol and the resulting temperature oscillations might thus actually increase the risk of recurrence, but no research findings are available to confirm this. Counselling parents after a febrile convulsion in children aged between 6 months and 5 years should therefore focus on the innocuous nature of febrile seizures in children and on the evidence that paracetamol does not reduce the risk of recurrence of the seizure. ${ }^{17}$

In summary, nearly all studies into the effect of paracetamol in children have been smallscale and mostly non-randomised. In addition, parents' willingness to take part in such studies is very limited. ${ }^{12,18}$ Although paracetamol does effectively reduce fever, its effect in terms of improving general wellbeing has not been sufficiently studied. Paracetamol has proved to be ineffective in preventing febrile seizures or their recurrence. 


\section{Possible disadvantages of using paracetamol}

\section{Suppressing the immune system}

There is ongoing debate on the question whether fever as an isolated symptom should actually be treated, since fever is a physiological phenomenon that appears to have a favourable effect on the immune system and as such speeds up the process of recovering from an illness. This argumentation is supported by the findings of a study which showed that the skin of children with chicken pox took significantly longer to heal in the children given paracetamol. ${ }^{19}$ Another study found that in children with malaria who used paracetamol, the presence of the malaria parasite could be demonstrated for an average of $16 \mathrm{~h}$ longer than in those not given paracetamol. ${ }^{20}$ On the other hand, there have also been studies that found no negative effect on the duration of the illness. ${ }^{12}$ Two randomised studies into the effect of paracetamol to prevent fever among children who had been vaccinated found that although the groups treated with paracetamol had less fever after the vaccination, their antibody response was significantly lower than that in the placebo group. ${ }^{21}$ These findings support the hypothesis that paracetamol suppresses the immune response.

\section{Side-effects and toxicity}

Like any medicine, paracetamol carries a risk of side-effects, toxicity and dosage errors. Paracetamol is well tolerated if used in correct dosage; side-effects like gastro-intestinal symptoms and allergic reactions are very rare and do not differ from the side-effects found in placebo groups, as was shown in a recent meta-analysis. ${ }^{22}$ But it is precisely since sideeffects are very rare and do not constitute the primary outcome measure, that none of the studies have been sufficiently powered to find a statistically significant and clinically relevant difference. Unlike side-effects, dosage errors have proved to be common. Up to $50 \%$ of parents give incorrect dosages (nearly always too high). ${ }^{2,5}$ Repeated inadvertent overdosing can cause hepatotoxicity. ${ }^{23}$ Table 11.3 presents an overview of paracetamol dosages recommended for children by the Dutch Society of General Practitioners (NHG). ${ }^{4}$ As regards long-term effects, an epidemiological study found that the risk of asthma, eczema and allergic rhinitis might be higher for children who have used more paracetamol at a younger age, although it could not prove that this was actually a causal relation. The effect may have been confounded by the fact that children who later develop asthma have had more airways infections involving fever when they were younger, and so were treated with paracetamol more frequently at the time. ${ }^{24}$ 
In summary, fever appears to have been retained in evolution because it is one of the body's physiological defence mechanisms against pathogens, and the use of paracetamol might inhibit this favourable effect. The use of paracetamol by children particularly carries a risk of dosage errors, with repeated overdosing possibly leading to hepatotoxicity.

\section{Other antipyretic therapies}

In other countries than the Netherlands, children with a fever are frequently given nonsteroidal anti-inflammatory drugs (NSAIDs) like ibuprofen. In view of its limited antiinflammatory effects, paracetamol is usually not regarded as an NSAID. Some studies have shown that ibuprofen lowers the body temperature faster than paracetamol, but this superior effect seems to disappear after a few hours. ${ }^{18}$ Other studies have found little difference in efficacy between paracetamol and ibuprofen as regards lowering the body temperature. ${ }^{22,25}$ NSAIDs are generally not recommended in the Netherlands, in view of the risk of side-effects like renal function disorders and gastro-intestinal symptoms, as well as the contradictory research findings on the difference in efficacy for children with fever. ${ }^{4}$

Other ways to reduce the body temperature, like cold baths and undressing, are likely to cause mainly discomfort. In addition, these measures will ultimately not address the central regulatory mechanism for fever, but only cause peripheral vasoconstriction, which can actually lead to an increase in core temperature. ${ }^{10}$

\section{Conclusion}

Paracetamol is effective and can be recommended for treating a combination of fever and pain. The effect of paracetamol on the general wellbeing of children with a fever but no pain has not been unequivocally established. There are indications that reducing fever by means of paracetamol could unfavourably affect the immune response and thus the full recovery.

Many of the studies of paracetamol reported in the literature have used body temperature as the primary outcome measure. This is understandable, as it can be easily and objectively measured. However, reducing fever is not a goal in itself for sick children. Future research should focus on the effects of paracetamol on the general wellbeing of children with a fever, preferably assessed using a uniform, internationally comparable method. Until that time, doctors are right to be reticent about recommending paracetamol for children with a fever, unless the children are also in pain (as in an acute otitis media). Fever as such does not need to be treated with paracetamol. 


\section{TABLES AND FIGURES}

Table 11.1 Search terms and search strategy in PubMed and Cochrane Library, carried out on 16 September 2013, into articles on the use of paracetamol by children

\begin{tabular}{lll}
\hline & MeSH terms & Free-text PubMed terms \\
Topic & fever, febrile & fever, febrile \\
Intervention & antipyretics, acetaminophen, & antipyretics, acetaminophen, \\
& paracetamol & paracetamol \\
Patient characteristics & child, infant, adolescent & children, child \\
\hline
\end{tabular}

PubMed Search: ("child"[MeSH Terms] OR "child"[All Fields] OR "children"[All Fields]) AND

(("antipyretics"[MeSH Terms] OR "antipyretics"[All Fields] OR "antipyretics"[Pharmacological Action]) OR ("acetaminophen"[MeSH Terms] OR "acetaminophen"[All Fields] OR "paracetamol"[All Fields]) OR ("acetaminophen"[MeSH Terms] OR "acetaminophen"[All Fields])) AND (("fever"[MeSH Terms] OR "fever"[All Fields]) OR ("fever"[MeSH Terms] OR "fever"[All Fields] OR "febrile"[All Fields])) AND ((English[lang] OR Dutch[lang] OR German[lang]) AND (("infant"[MeSH Terms] OR "child"[MeSH Terms] OR "adolescent"[MeSH Terms]) OR "infant"[MeSH Terms] OR "infant"[MeSH Terms:noexp] OR "child"[MeSH Terms:noexp] OR "child, preschool"[MeSH Terms] OR "infant, newborn"[MeSH Terms])) MeSH = 'medical subject heading'

Table 11.3 Recommended dosages of paracetamol (based on weight and when used for less than three days) by the Dutch Society of General Practitioners (NHG)

\begin{tabular}{|c|c|c|}
\hline Weight and age & $\begin{array}{l}\text { Oral maximum } 90 \mathrm{mg} / \mathrm{kg} / \text { day (drink } 24 \\
\mathrm{mg} / \mathrm{mL} \text { ) }\end{array}$ & Rectal maximum $90 \mathrm{mg} / \mathrm{kg} /$ day \\
\hline $3 \mathrm{~kg}$ (birth) & $2 \mathrm{~mL} 4$ times a day & 1 supp of $120 \mathrm{mg} 2$ times a day \\
\hline $6 \mathrm{~kg}$ (3 months) & $4 \mathrm{~mL} 4$ times a day & 1 supp of $120 \mathrm{mg} 3$ times a day \\
\hline $10 \mathrm{~kg}$ (12 months) & $6 \mathrm{~mL} 4$ times a day & 1 supp of $240 \mathrm{mg} 3$ times a day \\
\hline 15 kg (3 years) & $\begin{array}{l}9 \mathrm{~mL} 4 \text { times a day or } 1 \text { tablet of } 240 \\
\mathrm{mg} 4 \text { times a day }\end{array}$ & 1 supp of $240 \mathrm{mg} 4$ times a day \\
\hline $20 \mathrm{~kg}$ (5 years) & 1,5 tablets of $240 \mathrm{mg} 4$ times a day & 1 supp of $500 \mathrm{mg} 3$ times a day \\
\hline $25 \mathrm{~kg}$ (7 years) & 1 tablet of $500 \mathrm{mg} 4$ times a day & 1 supp of $500 \mathrm{mg} 4$ times a day \\
\hline $30 \mathrm{~kg}$ (9 years) & 1 tablet of $500 \mathrm{mg} 5$ times a day & 1 supp of $500 \mathrm{mg} 4$ times a day \\
\hline $42.5 \mathrm{~kg}$ (12 years) & 1 tablet of $500 \mathrm{mg} 6$ times a day & 1 supp of 1000 mg 3 times a day \\
\hline
\end{tabular}

Supp = suppository 


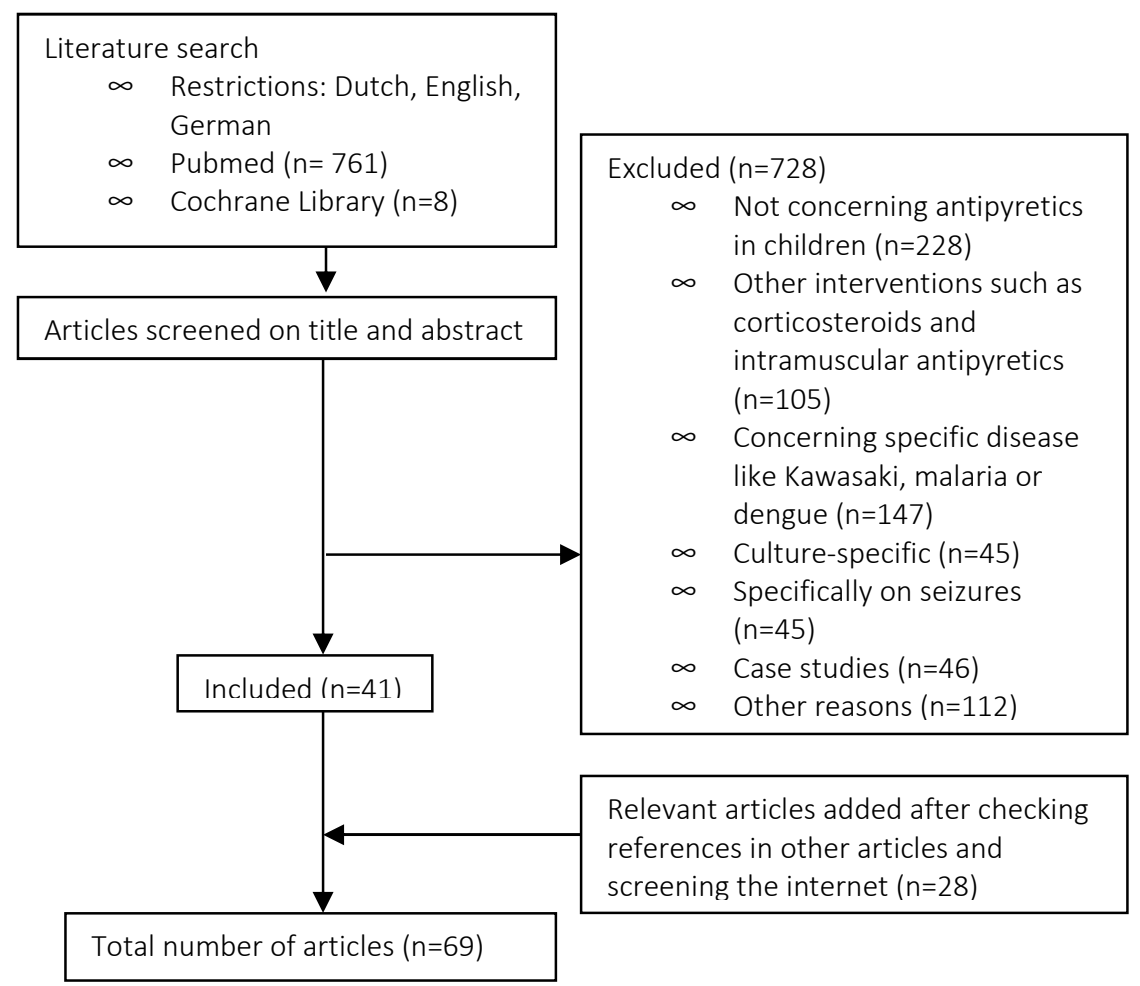

Fig 11.1 Flowchart showing selection of suitable articles after systematic search in PubMed and Cochrane Library. Numbers of articles shown in parentheses

NB. All 69 articles were used for the present paper; 25 of them were included in the reference list. Other reasons for excluding articles were that they reported on studies only concerning intoxication, or pharmacokinetics, or that they were commentaries or duplicates. 


\section{REFERENCES}

1. Hay AD, Heron J, Ness A. The prevalence of symptoms and consultations in preschool children in the Avon Longitudinal Study of Parents and Children (ALSPAC): a prospective cohort study. Fam Pract. 2005;22:367-74.

2. Crocetti M, Moghbeli N, Serwint J. Fever phobia revisited: have parental misconceptions about fever changed in 20 years? Pediatrics. 2001;107:1241-6.

3. Taveras EM, Durousseau S, Flores G. Parents' Beliefs and Practices Regarding Childhood Fever. Pediatr Emerg Care. 2004;20:579-87.

4. Berger MY, Boomsma LJ, Albeda FW, Dijkstra RH, Graafmans TA, Van der Laan JR, et al. NHG-Standaard Kinderen met koorts. Huisarts en Wetenschap. 2008.

5. Walsh A, Edwards H. Management of childhood fever by parents: literature review. J Adv Nurs. 2006;54:217-27.

6. Andrews T, Thompson M, Buckley DI, Heneghan C, Deyo R, Redmond N, et al. Interventions to influence consulting and antibiotic use for acute respiratory tract infections in children: a systematic review and meta-analysis. PLoS ONE. 2012;7:e30334.

7. National Institute of Clinical Excellence. NICE guideline: feverish illness in children. London: National Institute of Clinical Excellence; 2013.

8. Kumar V, Robbins SL. Robbins basic pathology. 8th ed. Philadelphia, PA: Saunders/Elsevier; 2007.

9. Graham GG, Scott KF. Mechanism of action of paracetamol. Am J Ther. 2005;12:46-55.

10. Meremikwu M, Oyo-Ita A. Paracetamol versus placebo or physicalmethods for treating fever in children. Cochrane Database Syst Rev. 2002:CD003676.

11. Kauffman RE, Sawyer LA, Scheinbaum ML. Antipyretic efficacy of ibuprofen vs acetaminophen. Am J Dis Child. 1992;146:622-5.

12. Kramer MS, Naimark LE, Roberts-Brauer R, McDougall A, Leduc DG. Risks and benefits of paracetamol antipyresis in young children with fever of presumed viral origin. Lancet. 1991;337:591-4.

13. Ruperto N, Carozzino L, Jamone R, Freschi F, Picollo G, Zera M, et al. A randomized, double-blind, placebo-controlled trial of paracetamol and ketoprofren lysine salt for pain control in children with pharyngotonsillitis cared by family pediatricians. Ital J Pediatr. 2011;37:48.

14. Schachtel BP, Thoden WR. A placebo-controlled model for assaying systemic analgesics in children. Clin Pharmacol Ther. 1993;53:593-601.

15. Offringa M, Hazebroek-Kampschreur AA, Derksen-Lubsen G. Prevalence of febrile seizures in Dutch schoolchildren. Paediatr Perinat Epidemiol. 1991;5:181-8. 
16. Rosenbloom E, Finkelstein $\mathrm{Y}$, Adams-Webber T, Kozer E. Do antipyretics prevent the recurrence of febrile seizures in children? A systematic review of randomized controlled trials and meta-analysis. Eur J Paediatr Neurol. 2013.

17. Brouwer OF, Kamphuis DJ, Begeer JH. Koortsconvulsies: prognose en behandeling Nederlands Tijdschrift voor de Geneeskunde. 1996;140:1801-4.

18. Hay AD, Costelloe C, Redmond NM, Montgomery AA, Fletcher M, Hollinghurst S, et al. Paracetamol plus ibuprofen for the treatment of fever in children (PITCH): randomised controlled trial. BMJ. 2008;337:a1302.

19. Doran TF, De Angelis C, Baumgardner RA, Mellits ED. Acetaminophen: more harm than good for chickenpox? The Journal of pediatrics. 1989;114:1045-8.

20. Brandts $\mathrm{CH}$, Ndjave M, Graninger W, Kremsner PG. Effect of paracetamol on parasite clearance time in Plasmodium falciparum malaria. Lancet. 1997;350:704-9.

21. Prymula R, Siegrist CA, Chlibek R, Zemlickova H, Vackova M, Smetana J, et al. Effect of prophylactic paracetamol administration at time of vaccination on febrile reactions and antibody responses in children: two open-label, randomised controlled trials. Lancet. 2009;374:1339-50.

22. Perrott DA, Piira T, Goodenough B, Champion GD. Efficacy and safety of acetaminophen vs ibuprofen for treating children's pain or fever: a meta-analysis. Arch Pediatr Adolesc Med. 2004;158:521-6.

23. Heubi JE, Barbacci MB, Zimmerman HJ. Therapeutic misadventures with acetaminophen: hepatoxicity after multiple doses in children. The Journal of pediatrics. 1998;132:22-7.

24. Heintze K, Petersen KU. The case of drug causation of childhood asthma: antibiotics and paracetamol. Eur J Clin Pharmacol. 2013;69:1197-209.

25. Purssell E. Systematic review of studies comparing combined treatment with paracetamol and ibuprofen, with either drug alone. Arch Dis Child. 2011;96:1175-9. 
HAPTER 12

Amoxicillin and paracetamol dosing in

children: playing safe

Bram Peters

Eefje G.P.M. de Bont Jochen W.L. Cals

Ned Tijdschr Geneeskd. 2016;160:D345. 



\section{ABSTRACT}

Amoxicillin and paracetamol are the two oral drugs most frequently used by children. Dosing recommendations for both are insufficiently transparent and ambiguous, partly due to lack of scientific evidence regarding their most effective dosage. This article challenges general practitioners, paediatricians, youth health staff, ENT specialists, pharmacists and guideline authors to take a critical look at the current dosing recommendations. This should be guided by the Dutch paediatric formulary but should present more unequivocal basic dosing recommendations: (1) dosing recommendations and dosing practice based on body weight rather than on age; (2) a daily dosage regime for paracetamol for general pain symptoms of $60 \mathrm{mg} / \mathrm{kg} /$ day distributed over 4 doses; (3) a daily dosage regime for amoxicillin of $60 \mathrm{mg} / \mathrm{kg} /$ day distributed over 4 doses for uncomplicated common infections; (4) indicating the daily dosage, number of doses a day, duration, indication and the child's body weight on all antibiotics prescriptions for children, to ensure safer medication for children and to avoid unnecessary consultations between pharmacists and doctors. 
A five-year-old girl is prescribed a course of amoxicillin by her family doctor, to be taken as an oral solution ( $50 \mathrm{mg} / \mathrm{mL}, 5 \mathrm{~mL}$ thrice daily for 7 days), for a bilateral otitis media. The mother is given the advice to also give her $300 \mathrm{mg}$ paracetamol 4 times a day, also as an oral solution. The pharmacist's assistant finds she has to phone the family physician as the antibiotics dosage is too low for a child weighing $20 \mathrm{~kg}$. She also advises the mother to give the child only $180 \mathrm{mg}$ paracetamol 4 times daily. After the mother gets back home, the packaging of the paracetamol potion she bought at the chemist's tells her that she can give her daughter $180 \mathrm{mg}$ paracetamol up to 6 times a day. Slightly confused by this, she phones the out-of-hours general practice service for further advice.

Amoxicillin and paracetamol are among the drugs most frequently used by children below the age of 18 years in the Netherlands. ${ }^{1,2}$ In 2014, over 350,000 prescriptions for amoxicillin were dispensed for children alone. ${ }^{3}$ The scientific literature tends to focus especially on the correct indications for the use of paracetamol by children and on the evidence-based and minimised prescription of antibiotics. Much less attention is given to correct and unequivocal dosing recommendations once a doctor has decided to prescribe or recommend these drugs.

The Dutch association for paediatric medicine (NVK), the Dutch association for hospital pharmacists and the Royal Dutch Pharmacists' Association (KNMP) have all recognised the Dutch paediatric formulary as the official guideline for medication dosage for children. ${ }^{4}$ The formulary intends to promote uniform dosing instructions, but due to insufficient evidence to determine the optimal dosage, its dosing recommendations for amoxicillin and paracetamol are often complex. In addition, the Dutch College of General Practitioners $(\mathrm{NHG})$ has its own guidelines, featuring different dosage tables for these drugs.

As a result, there is too much room for interpretation. This is problematic for prescribers, as the recommendations do not suit the everyday practice setting in which they work, as well as for parents who are faced with different recommendations by different care providers or in patient information leaflets, which may lead to anxiety and the ensuing help-seeking behaviour. ${ }^{1}$ The emergence of electronic prescription systems also calls for unequivocal dosing recommendations. This article challenges general practitioners, paediatricians, youth health staff, ENT specialists, pharmacists and authors of guidelines to take a critical look at the confusing prescription instructions, and presents an unequivocal proposal, based on the available literature, to make the dosing instructions for amoxicillin and paracetamol clearer and better suited to routine practice. 


\section{Basing dosage on body weight}

Despite the fact that the paediatric formulary recommends dosing by body weight, patient information leaflets, packaging and guidelines often give recommendations based on age. ${ }^{5-}$

${ }^{7}$ This age is often, more or less arbitrarily, linked to a weight category, which can be highly confusing when weight and age categories do not match (table 12.1 and 12.2). In the doctor's office, working with age categories has the advantage that the child's age is always known, and that it has always been common usage to prescribe specific dosages in terms of, e.g., 2.5 and $5 \mathrm{~mL}$ dosing spoons for amoxicillin oral solution.

In the case of amoxicillin, the dosing instruction based on age categories is derived from one publication from 1963. Based on dosing schemes for oral penicillin $\mathrm{G}$, a general dosing recommendation was formulated based on age categories for all penicillins for children, regardless of indication, by simply extrapolating adult dosages to children. These recommendations have remained essentially unchanged since. ${ }^{8,9}$

As the prevalence of obesity among children rises, children in the same age category may differ considerably in weight, resulting in a real and relevant risk of underdosing or overdosing. This can lead to therapy failure and an elevated risk of resistance in the case of amoxicillin. ${ }^{8,9}$ The relatively low recommended age-based dosage for paracetamol may result in inadequate pain relief among heavier children. As a consequence, parents may start to give their child more paracetamol than is advisable, or they may get the idea that paracetamol does not work and ask for stronger drugs.

The dosing recommendations in the Dutch paediatric formulary distinguish between mild and acute pain, but parents and doctors often find it hard to distinguish between mild and severe pain, especially in infants and toddlers. ${ }^{10}$ This makes it impossible to give a simple and unequivocal dosage prescription or advice. This is illustrated in Table 12.1, which shows an overview of dosage recommendations given for a two-year-old child with middle ear infection, as well as the differences that result when dosage is not based on age but on body weight.

\section{Amoxicillin $60 \mathrm{mg} / \mathrm{kg} / \mathrm{dag}$}

The optimal dosage of amoxicillin for children is unknown, partly due to a lack of sound pharmacological and clinical studies among children. ${ }^{8,11}$ The Dutch paediatric formulary recommends that children with a body weight below $40 \mathrm{~kg}$ should be given $40-90 \mathrm{mg} / \mathrm{kg}$ a day, in 2-3 doses, and suggests that $50 \mathrm{mg} / \mathrm{kg} /$ day is usually sufficient. ${ }^{6,7}$ The choice 
between high or low dosage depends on how ill the child is and on the resistance pattern. ${ }^{6,7}$ This broadly defined dosage advice appears to be mainly based on the heterogeneous resistance pattern for pneumococci in Europe, as recommendations for normal amoxicillin dosages internationally range from 25 to $50 \mathrm{mg} / \mathrm{kg} /$ day. Populations characterised by the presence of less sensitive strains of pneumococci require higher dosages (75-90 mg/kg/day) for effective treatment. ${ }^{6}$

From a practical point of view, it is questionable how feasible the current broadly defined dosage advice is. Amoxicillin is mainly prescribed in primary and secondary care for young children with common uncomplicated infections, usually of the airways. Since the resistance level of pneumococci in the Netherlands is low, a high dosage is often unnecessary in Dutch medical practice. ${ }^{5}$ It would therefore be clearer if the dosage advice for amoxicillin made a distinction between common uncomplicated infections and complicated infections.

The assessment of the daily dosage for which this can be safely done is based on the time during which the serum concentration of an antibiotic remains above the minimal inhibitory concentration ( $T_{>\text {MIC }}$ ). Assuming a target value for $T_{>\text {MIC }}$ of at least $40-50 \%$ of the dosing interval, and a MIC value of $2 \mathrm{mg} / \mathrm{L}$ as the limit for penicillin resistance, a daily dosage of at least $60 \mathrm{mg} / \mathrm{kg} /$ day is sufficient for two daily doses. ${ }^{6,12,13}$ The clinical efficacy of two daily doses of amoxicillin, without additional side-effects, has also been reported in scientific studies. ${ }^{614-16}$ As a result, the recommendation of two daily doses has also been incorporated in the WHO guidelines for the treatment of children with uncomplicated pneumonia. ${ }^{16}$ Although missing a dose will more easily lead to an insufficient amoxicillin concentration in a regime with two daily doses than in one with three daily doses, this will be compensated by a higher overall compliance rate, as two daily doses are easier to administer for parents with children attending school or day-care centres.

Thus, amoxicillin for common uncomplicated infections in children, such as otitis media or lower airways infection, can be given in a daily dosage of at least $60 \mathrm{mg} / \mathrm{kg} /$ day in two doses, with a maximum daily dosage of $3 \mathrm{~g}$. For complicated and more severe infections, a more broadly defined dosage recommendation for amoxicillin could indicate the room for interpretation by the treating doctor.

\section{Paracetamol $60 \mathrm{mg} / \mathrm{kg} /$ day}

Pharmacological data to optimise pain relief dosages for paracetamol in children are also lacking. ${ }^{17}$ The available literature on analgesia by means of paracetamol is difficult to 
interpret, as pain assessment scales are insufficiently comparable and there are cultural and psychological differences regarding pain. Effective pain relief appears to require a minimal paracetamol serum concentration of $10 \mathrm{mg} / \mathrm{L}^{18,19}$ Since the current dosing recommendations are based not only on pharmacokinetic and pharmacodynamic considerations but also on the potential risk of hepatotoxicity due to cumulative dosages, it is questionable whether the therapeutic serum levels are being reached with the current recommendations. ${ }^{17,19,20}$ These considerations have resulted in a confusing variety of dosing recommendations. Apart from pain, the formularies also still mention fever as an indication for treatment with paracetamol, but the added value offered by paracetamol in case of fever alone has not been proven. ${ }^{1}$

The recommendations for treating children with paracetamol need to be clarified and simplified. A child older than one month who has acute pain, whether mild or severe, can be given a daily oral dosage of paracetamol of $60-90 \mathrm{mg} / \mathrm{kg} /$ day, in four doses, with a maximum daily dosage of $4 \mathrm{~g} /$ day for a maximum of three days. In routine practice, a daily dosage of $60 \mathrm{mg} / \mathrm{kg} /$ day in 4 doses provides enough opportunities to satisfactorily complete the treatment with the available tablets, suppositories and oral solutions.

To prevent confusion among parents, doctors need to explain the difference between the dosage they recommend and the dosages recommended on the packaging of over-thecounter paracetamol preparations.

\section{Standardised prescribing}

The information offered on prescriptions is often limited, despite existing guidelines for writing out prescriptions and the availability of electronic prescribing systems. Pharmacists and their assistants frequently encounter dosage errors in prescriptions of antibiotics for children. ${ }^{21}$ This results in extra work for both the prescriber (doctor) and the supplier (pharmacist), as well as in delays and anxiety for the parents as the therapy is changed. ${ }^{21}$ As a consequence, parents will be less attentive to the instructions for use that pharmacists provide, which may lead to incorrect use of the medication. ${ }^{21}$

If prescribers stick to the system of 'daily dosage, number of doses a day, duration, indication and child's body weight' (in Dutch 'dagdosis, aantal giften per dag, duur, indicatie, en gewicht kind', acroniem: DADIG), it makes it easier for them to communicate with the pharmacists about the nature of the prescription, by entering the right information in the free text box on the prescription form. In the case of an antibiotics prescription, the prescriber should provide the following information on the prescription 
form for amoxicillin: (a) daily dosage (60 mg/kg/day); (b) number of doses a day (2); (c) duration (e.g. 7 days); (d) indication (e.g. otitis media); (e) the child's body weight (e.g. 20 $\mathrm{kg}$ ). If necessary, the pharmacist can discuss with the parents what would be the most suitable dosage form, and ensure the correct delivery to parents of the prescribed medication and suitable instructions for use.

\section{Conclusion}

Current dosage instructions for the two medicines most frequently prescribed to children, paracetamol and amoxicillin, offer too much room for interpretation. Children are not simply small adults. The Dutch paediatric formulary is the right source for Dutch doctors to decide on the medication dosage for children. All professions involved, as well as the Dutch College of General Practitioners, should recognise and follow the paediatric formulary. The formulary should provide the dosage instructions in a more practical form, with unequivocal basic daily dosages, based on body weight: $60 \mathrm{mg} / \mathrm{kg} /$ day in two doses for amoxicillin, and in four doses for paracetamol. As always, it is the exceptions that prove the rule. Provided that the basic instructions in all formularies are clear and apply to the great majority of cases, the exceptions, such as more serious infections or postoperative acute pain, will also be given a suitable place. This will provide prescribers and pharmacists with better guidance, enabling all of them to offer the same unequivocal prescriptions and recommendations for the two medicines most frequently used by children. 


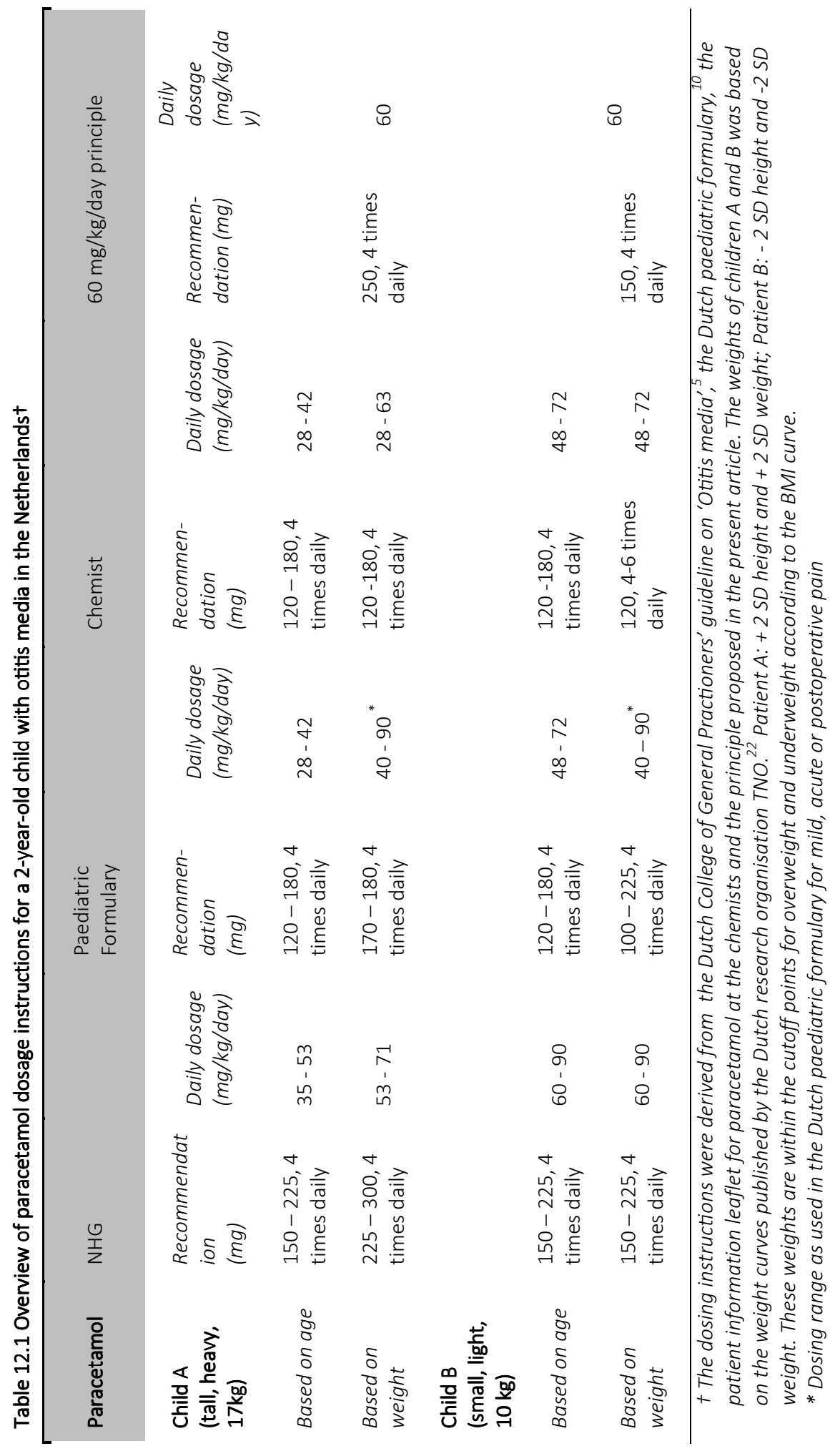




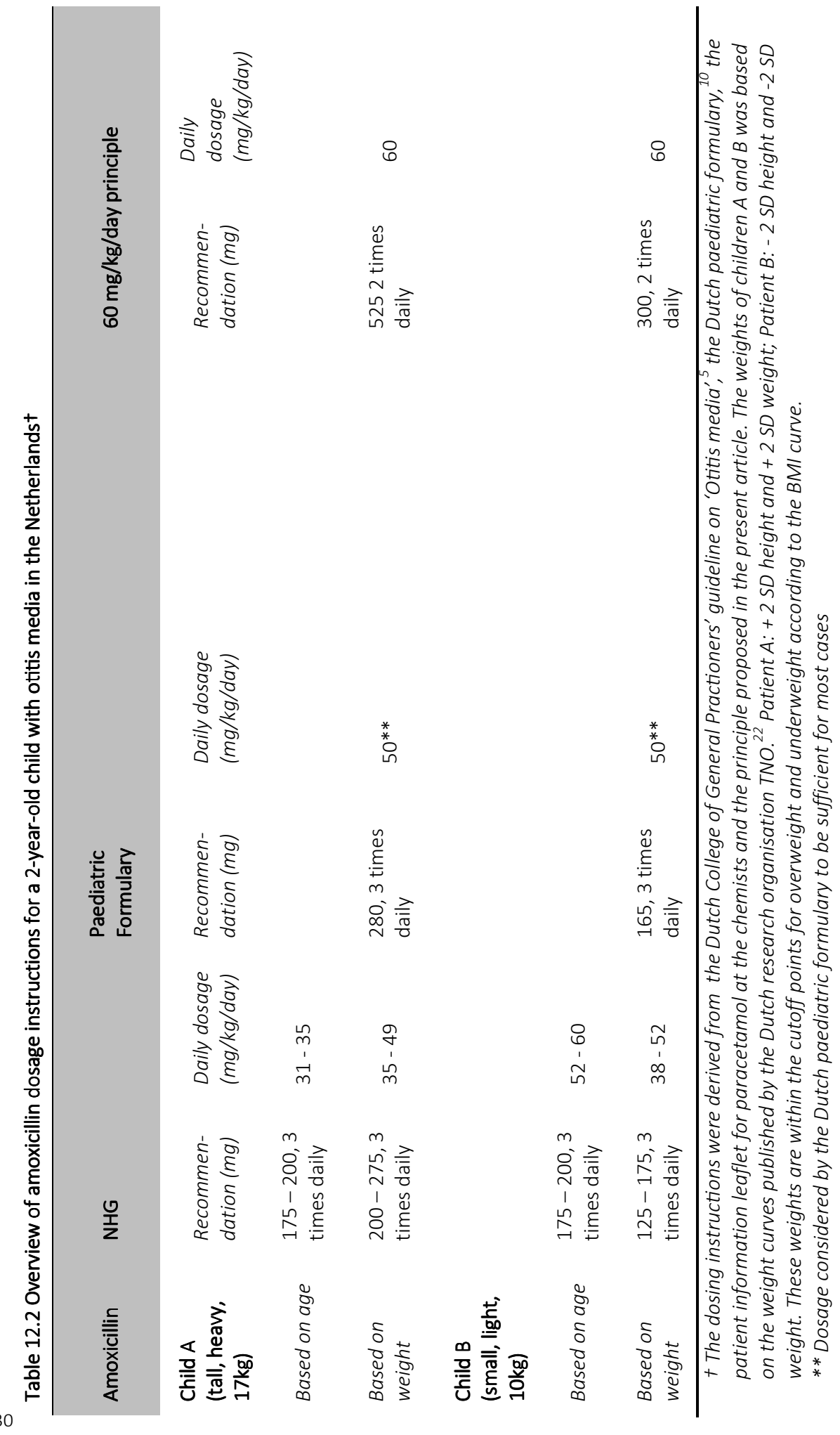




\section{REFERENCES}

1. de Bont EG, Brand PL, Dinant GJ, van Well GT, Cals J. Wel of geen paracetamol bij kinderen met koorts? Ned Tijdschr Geneeskd. 2014;158:A6636.

2. Sturkenboom MC, Verhamme KM, Nicolosi A, Murray ML, Neubert A, Caudri D, et al. Drug use in children: cohort study in three European countries. BMJ. 2008;337:a2245.

3. GIP databank: Aantal uitgiftes naar leeftijd en geslacht voor ATC-code J01CA 2016 [cited 2016]. Available from: http://www.gipdatabank.nl/databank.asp?tabel=03Iftges|\&geg=vs\&item=J01CA.

4. Prescriptor. Kinderformularium als bron voor het off-label voorschrijven 2013 [cited 2016]. Available from: http://www.prescriptor.nl/nl/wat/kinderformularium.

5. Damoiseaux RAMJ VR, Eekhof JAH, Bennebroek Gravenhorst FM, Schoch AG, Burgers JS, Bouma M, Wittenberg J. NHG-Standaard Otitis media acuta bij kinderen. Huisarts en Wetenschap. 2014;57:648.

6. EMA, Amoxicilline: Public Assessment Report for paediatric studies submitted in accordance with Article 45 of Regulation (EC) No1901/2006 [cited 2016 Januari]. Available from:

http://www.hma.eu/fileadmin/dateien/Human_Medicines/CMD_h_Paediatric_Regulation /Assessment_Reports/Article_45_work-sharing/Amoxicillin_2010_07_45PaedPAR.pdf.

7. Nederlands Kenniscentrum voor Farmacotherapie bij Kinderen. Label dosisadvies Kinderformularium: Amoxicilline.2015 18 Dec 2015. Available from: http://www.kinderformularium.nl/geneesmiddel/7/amoxicilline.

8. Ahmed U, Spyridis N, Wong IC, Sharland M, Long PF. Dosing of oral penicillins in children: is big child= half an adult, small child= half a big child, baby= half a small child still the best we can do? BMJ. 2011;343.

9. Saxena S, Ismael Z, Murray ML, Barker C, Wong IC, Sharland M, et al. Oral penicillin prescribing for children in the UK: a comparison with BNF for Children age-band recommendations. Br J Gen Pract. 2014;64:e217-22.

10. Label dosisadvies Kinderformularium [cited 2016 Januari]. Available from: http://www.kinderformularium.nl/geneesmiddel/21/paracetamol.

11. Bielicki JA, Barker Cl, Saxena S, Wong IC, Long PF, Sharland M. Not too little, not too much: problems of selecting oral antibiotic dose for children. BMJ. 2015;351:h5447.

12. Calbo E, Garau J. Application of pharmacokinetics and pharmacodynamics to antimicrobial therapy of community-acquired respiratory tract infections. Respiration. 2005;72:561-71. 
13. Fonseca W, Hoppu K, Rey LC, Amaral J, Qazi S. Comparing pharmacokinetics of amoxicillin given twice or three times per day to children older than 3 months with pneumonia. Antimicrob Agents Chemother. 2003;47:997-1001.

14. Thanaviratananich S, Laopaiboon M, Vatanasapt P. Once or twice daily versus three times daily amoxicillin with or without clavulanate for the treatment of acute otitis media. Cochrane Database Syst Rev. 2013;12:CD004975.

15. Vilas-Boas AL, Fontoura MS, Xavier-Souza G, Araujo-Neto CA, Andrade SC, Brim RV, et al. Comparison of oral amoxicillin given thrice or twice daily to children between 2 and 59 months old with non-severe pneumonia: a randomized controlled trial. J Antimicrob Chemother. 2014;69:1954-9.

16. World Health Organization. Revised WHO classification and treatment of childhood pneumonia at health facilities2014 Feb 2016. Available from: http://www.who.int/maternal_child_adolescent/documents/child-pneumoniatreatment/en/.

17. Anderson BJ. What we don't know about paracetamol in children. Paediatr Anaesth. 1998;8:451-60.

18. Gibb IA, Anderson BJ. Paracetamol (acetaminophen) pharmacodynamics: interpreting the plasma concentration. Arch Dis Child. 2008;93:241-7.

19. Anderson BJ, Woollard GA, Holford NH. A model for size and age changes in the pharmacokinetics of paracetamol in neonates, infants and children. $\mathrm{Br} \mathrm{J}$ Clin Pharmacol. 2000;50:125-34.

20. Cranswick N, Coghlan D. Paracetamol efficacy and safety in children: the first 40 years. Am J Ther. 2000;7:135-41.

21. Jacqueline P.G. Stakenborg, Eefje G.P.M. de Bont, Kirsten K.B. Peetoom, Marjorie H.J.M.G. Nelissen-Vrancken, Jochen W.L. Cals. Medication management of febrile children: a qualitative study on pharmacy employees' experiences IJCP (submitted). 2016. 


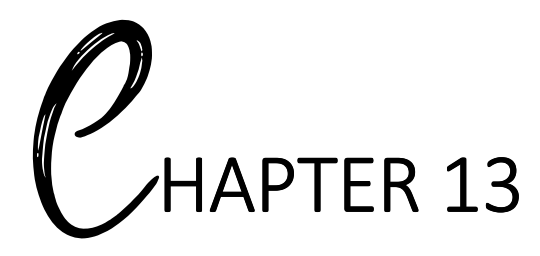

General discussion 



\section{GENERAL DISCUSSION}

The general discussion will be used to place the findings of this thesis in a broader context putting together the results presented in the previous chapters of this thesis, including two cohort studies, a survey among a sample of 1000 parents, qualitative research among 20 parents, 37 GPs and 24 pharmacy employees, three reviews of which one systematic review and a cluster randomised controlled trial in GP out-of-hours care in which more than 3500 GPs recruited more than 25000 children in 6 months. The first part will focus on the content of this thesis and start with our main findings and provide an in depth overview showing current management of childhood fever in a 24-hour society. This is followed by an elaboration on why communication and consistent information is one of the main ways to improve current management of childhood fever and diminish antibiotic resistance. The second part of this discussion will focus on methodological considerations and why we specifically chose to do a pragmatic trial. Finally, the third and last part of this discussion will present practice implications.

\section{Main findings}

Our studies show that fever is the most common reason for a child to be seen by a GP during out-of-hours care, with one in three contacts for children under the age of 12 years being fever related. ${ }^{1}$ Most telephone contacts take place for children aged 1 to 5 years, and of all fever related contacts $70 \%$ results in a face-to-face GP consultation. Subsequently, antibiotics are prescribed during one in four consultations, while serious infections that require treatment are rare. ${ }^{1}$

Parents of febrile children are still anxious and search for reassurance from a GP as a professional when fever is accompanied by other symptoms. They seek reassurance from medical professionals in need for support that they are correctly caring for their child and specifically value a thorough physical examination. ${ }^{2}$ Our findings demonstrate, in accordance with previous research, that parents of a febrile child do not expect antibiotics but are mainly in search of reassurance and consistent, reliable information about fever and specific symptoms. GPs on the other hand perceive that children with a fever account for a high workload during out-of-hours care which can lead to frustration and a diagnostic challenge due to the low incidence of serious illnesses and lacking long-term relationship. ${ }^{3}$ These factors play an important role in their management decisions when they prescribe antibiotics. 
Improving information exchange during consultations by using an illness-focussed booklet, which can be used interactively, can help to provide a safety net and in that way enhance self-management and reduce "better safe than sorry" antibiotic prescriptions. ${ }^{4}$ GP access to such a booklet alone does not significantly reduce antibiotic prescriptions. However, actual use of an illness-focussed interactive booklet does lead to a reduction in antibiotic prescriptions, overall medication prescriptions and intention to reconsult for future similar illnesses among parents. ${ }^{5}$ In the next part of this discussion these findings are discussed in a broader context and compared to the existing literature.

\section{Workload and current management of childhood fever in a 24-hour society}

Society and the field of general practice have undergone enormous changes over the last decades. At present, we live in an era of two-income households, the internet as a source of information, and shared decision making in consultations. To illustrate how big some of these changes are, more than $75 \%$ of families in the Netherlands are now two-income households, whereas this was lower than $10 \%$ half a century ago. ${ }^{6}$ This means that the chance of parents noticing or acting on a fever during out-of-hours hours instead of during the day probably increased as well. Furthermore, some decades ago information about medicine and health was restricted to those who had access to a library, while parents and patients these days have access to an unlimited amount of reliable and unreliable information about their health everywhere in the world, 24-hours a day, on the internet. Interestingly, GPs' management of childhood fever in the The Netherlands has even undergone changes throughout the chapters of this thesis itself. While chapter four shows that an important reason for parents to contact a GP is the duration of a fever, the advice to consult a doctor if a fever persists longer than three days is no longer an advice in the new national guideline of the Dutch College of General Practitioners (NHG) which appeared after this chapter was written. All these changes over time have influenced the way patients think about the role of general practice and physicians, and access to general practice during out-of-hours-care.

Out-of-hours care is defined as primary care provided beyond office hours every day between 5 p.m. and 8 a.m. and the entire weekend. ${ }^{7}$ Since the year 2000, GP out-of-hours care in The Netherlands is organised in large-scale cooperatives or out-of-hours centres. There are 120-130 GP out-of-hours centres in the Netherlands, varying from 50-200 GPs. ${ }^{7}$ These centres cover primary care by rotating shifts of local GPs during evenings, nights and weekends. Although these are the same GPs working in the area during the day, this means that in almost every consultation, GPs and parents or patients have not met in previous 
clinical encounters. In the Netherlands, patients and parents who contact an out-of-hours GP centre are triaged by telephone by trained assistants to determine if a face-to-face contact is needed. The assistant then determines if alarming signs are present based on the Dutch triage system (NTS). If there are no alarm signs, the assistant will refrain to giving a telephone advice. When one or more alarming signs are present, a face-to-face contact is scheduled. GP out-of-hours care cooperatives or centres were founded to reduce the workload during out-of-hours care. Generally, by dividing shifts across 50-200 GPs the workload has been successfully reduced. ${ }^{7}$ However, out-of-hours GP care is becoming more and more crowded over the last decade. In 2005 one in five people contacted an outof-hours centre at least once a year while in 2016 this number had already increased to one in four. ${ }^{8}$ In addition, the workload coming from consultations for childhood fever specifically might have increased over time because of these stimulating factors. As one of our studies shows, GPs who worked before the time of out-of-hours centres felt that patients and parents formerly were much more aware that they were contacting their GP who worked during the day and sometimes felt troubled when they were calling them up for advice. 3 GP out-of-hours centres nowadays are a normal and accepted part of our health care system. However, they are based on the idea that they are intended for urgent care questions which cannot wait until the next day. The fact that the number of nonurgent care questions seems to increase therefore causes frustration. Even more so, because of the increasing administrative demand GPs experience during regular working hours. These changes however, are understandable if you look at them from patients and parents' point of view.

This thesis shows that alongside specific symptoms that often accompany fever, the decision to consult a GP during out-of-hours care is driven by parental needs for reassurance and reliable consistent information on self-management strategies on one hand, and by non-medical factors like parents having to work during the day and the fact that fever typically rises during the early evening on the other hand. ${ }^{2}$ Childhood fever is one of the best illustrations to explain these non-medical factors by. Say a parent picks his or her sick child up from day care at the end of the day, the exact moment that a fever starts increasing due to circadian rhythms. Whereas half a century ago they could simply observe their child the next day, parents nowadays have to consider the fact that they probably have to work the following day. This thesis has shown, in agreement with other studies that parents actively search for information before contacting a GP. ${ }^{9}$ As suggested previously, we found that this information does not always reassure parents, but even raises anxiety in some cases. ${ }^{10}$ Some parents might be advised by websites or by their day care centre to 
consult a GP just in case. They contact the out-of-hours centre for advice, which results in a $70 \%$ chance that they have to come in for a consultation based on the triage system. If they consult, the GP they see is likely not their personal GP. Parents don't see this as a problem, since they simply want their child to be assessed. ${ }^{2}$ However, serious infections are rare and dealing with low-incidence illnesses is challenging for GPs, ${ }^{11}$ specifically in situations where GPs have no prior relationship with patients and parents. A large Belgian cohort study showed that only 283 children out of 8962 acute illness episodes were hospitalised with a serious infection (0.03\%). ${ }^{12}$ In other words, because GPs see many children but only few of them are seriously ill, they have to be constantly aware that this child might be the needle in the hay stack that is in fact seriously ill. A lacking prior relationship not only influences diagnostic decisions, but also management decisions. This concept of trust was also found to be an important determinant of acceptance of management by parents in a previous study on antibiotics for children with respiratory tract infections. ${ }^{13}$ Concerns about missing serious infections drive fear, consultations and in turn prescribing behaviour. ${ }^{2}$ This is likely one of the important reasons one in three to four children receives a "better safe than sorry" antibiotic prescription during out-of-hours care. ${ }^{14}$ A Dutch study showed that the appropriateness of antibiotic prescriptions is not worse during out-of-hours care. ${ }^{15}$ Unfortunately, this study does not show specific results for the indication fever. The authors do however show that children present more often during out-of-hours care and that more antibiotics are prescribed for children than for adults.

Because of these societal changes we believe that consultation behaviour of parents itself is something that will be challenging, though not impossible, to influence. If they do consult, it is up to the GP to make sure that their management is as optimal as it can be. In this light, most of this thesis is focused GPs' management decisions and their role in targeting antibiotic resistance as an increasingly serious threat to global public health. However, GPs also have to consider the safety of that specific child that is sitting in front of them. Things to consider that have not been discussed in this thesis are the risk of side effects, but also the fact that there are studies which show negative implications of early exposure to antibiotics like a higher risk of developing eczema, ${ }^{16}$ asthma, ${ }^{17}$ arthritis ${ }^{18}$ and even obesity. ${ }^{19}$ In the next paragraph, we will therefore elaborate on why and how we believe current management can be improved and why communication and consistent information provision is one of the keys in improving antibiotic prescriptions in this setting. 
Rational antibiotic use in General Practice: communication and consistent information is the key

There are several ways to distinguish different interventions aimed at improving management of childhood fever and antibiotic prescriptions. One of the ways is to divide them into disease-focused versus illness-focused interventions, or in other words doctorfocused versus patient-focused interventions. ${ }^{20}$

A promising diseased focused intervention which we considered to evaluate in children with fever is a point-of-care test. Point-of-care tests for acute infections like C-reactive protein (CRP) are minimally invasive (finger-prick) tests and can potentially exclude serious infections within minutes and subsequently guide judicious antibiotic and antipyretic usage and referral decisions in the GP out-of-hours services. Although CRP has shown to be effective in adults with acute cough, ${ }^{21}$ the same cannot be concluded for children with a fever. A recent large, well designed study among 2773 children showed that a CRP value $<5$ $\mathrm{mg} / \mathrm{L}$ rules out serious infection. However, routine use in primary care would result in a great risk of over diagnosis considering the fact that only one in forty children with a raised CRP level will have a serious infection. ${ }^{22,23}$ Another recent Belgian study among 2227 children found that CRP did not influence antibiotic prescribing. The authors concluded that systematic point-of-care CRP testing without guidance is not an effective strategy to reduce antibiotic prescribing for non-severe acute infections in children in primary care. ${ }^{24}$ Alongside CRP testing, there are other point-of-care tests that are currently being developed like tests for respiratory viruses. A recent Dutch study examined the diagnostic performance and clinical feasibility of such a recently developed diagnostic point-of-care test for respiratory viruses. The authors found that point-of-care tests for respiratory viruses might contribute to an evidence-based diagnosis of respiratory tract infections (RTIs) with a test specificity varying from $99 \%$ to $100 \%$ for different viruses and could thereby positively influence prescription of antibiotics by GPs. ${ }^{25}$ Another Dutch secondary care validation study examined the diagnostic performance of a combination of tumour necrosis factor-related apoptosis-inducing ligand (TRAIL), interferon gamma induced protein-10 (IP-10), and C-reactive protein (CRP) compared to an expert panel diagnosis. ${ }^{26}$ The authors found mean positive predictive values from $60.5-62.1 \%(\mathrm{Cl} 49.9-70.1$ and 49.2-73.4) depending on the unanimity of the panel diagnosis and mean negative predictive values varying from 97.8-98.3\% (Cl 95.6-98.9 and 96.1-99.3). ${ }^{26}$ Unfortunately, these findings are not generalizable to primary care where the incidence of serious infections is much lower and the subsequent diagnostic value therefore will be different. In addition, the combination of these biomarkers is not available as a point-of-care test in 
primary care. Therefore, all these potential tests are not yet implementable in primary healthcare and their impact on clinical decision making should be further assessed. Especially since presence of a virus does not necessarily rule out the presence of a serious bacterial infection which does require treatment.

Interestingly, one of the reasons that the relevance of biomarkers in management decisions in febrile children or children with RTIs might be different than their relevance in adults with acute cough might be the role of clinician's gut feelings. There are studies showing that a clinician's gut feeling that something is wrong is not only of the strongest diagnostic tools that they have in these children ${ }^{12,27}$ but also a strong predictor of antibiotic prescription or referral to secondary care. ${ }^{28}$ Therefore, other type of interventions have to be considered.

Illness-focused interventions recognise the importance of non-medical influences on the decision to consult or to prescribe antibiotics. Previous studies showed that antibiotic prescribing is strongly influenced by patients' expectations and that GPs experience pressure from patients to prescribe antibiotics. ${ }^{29}$ Exploring the illness experience of parents of children with fever and infections may have potential as it specifically addresses the concerns and questions that parents have when their child is sick. The key part of the interactive booklet which was developed and studied in this thesis was a traffic light system aimed at parents. A traffic light system can also be found in the international NICE guideline for childhood fever ${ }^{30}$ and the guideline from Dutch Society of Paediatrics (NVK). ${ }^{31}$ The big difference between these traffic lights and the traffic light in the booklet is the fact that they are doctor, or disease orientated whereas the booklet's traffic light system is parent, or illness orientated. Parents consulting a GP feel the traffic light has turned to orange, or even red, and it is up to the GP to turn that traffic light back to green in cases of benign (viral) infections thereby empowering parents in their self-management strategies. ${ }^{32}$

Using communication to elicit patients' expectations and agenda has previously been proven to be very successful in restricting antibiotic prescriptions in adults with acute cough. ${ }^{21}$ Moreover, improved communication may offer the GP a way to convey consistent written information, enhancing their self-management and providing them with safety net advice when they return home with clear instructions in what case to return or seek contact again. ${ }^{33}$ This is in line with the findings of a recent study among children with RTIs where the effect of an online training for GPs and an information booklet for parents was examined in regular GP practices (daytime). The authors found a reduction in antibiotic 
prescription rates from $33 \%$ in the control group to $21 \%$ in the intervention group. ${ }^{34}$ Due to the design of the study, it is unfortunately not possible to distinguish the effect from the online training from the effect of the information booklet. The fact that the authors found a much larger effect than we found in our trial can be explained by several factors like the different setting and patient population and the content and intensity of the intervention (training vs. no training). Conversely, another previously mentioned Belgian study found that use of a booklet with safety net instructions doubled antibiotic prescribing, except when this booklet was combined with a CRP point-of-care test. ${ }^{24} \mathrm{~A}$ potential explanation for this surprising finding according to the authors is the fact that parental concerns can potentially settle in the GPs' mind. This finding is contradictory to the findings in our study, this could be caused by the difference in setting (personal GP vs. out-of-hours care) on one hand, but more likely also the content of the booklet and the way it was used in the consulting room. Our intervention was designed to be used at the end of a consultation, whereas the intervention in this Belgian study started off with three questions at the beginning of the consultation: 'Are you concerned about the illness of your child?', 'What exactly concerns you?', and 'Why does this concern you?' This fact could have indeed influenced the GPs' clinical decision process, thereby altering its effect on antibiotic prescribing.

During the design of our intervention it became clear that GPs and parents expected that communication was the crucial element to improve childhood fever related consultations and that they believed that most progress was to be made during out-of-hours care. ${ }^{2,3}$ Parents were in search of a consistent source of written information which they could use again. There is evidence that it is indeed critical that the information that is provided to parents of a sick child is not only transferred verbally since $40-80 \%$ of medical information provided by healthcare practitioners is forgotten immediately. Moreover, $50 \%$ of what is remembered is incorrect. ${ }^{35}$ These outcomes are even worse in times of stress, something which is unmistakably going on in cases of fever phobia. ${ }^{36}$ Moreover, using this information interactively, or in other words actively discussing the information in a tailored way with parents, may facilitate communication and improve misconceptions between parents and GPs' their expectations. The traffic light makes this information and communication child specific, thereby empowering parents. In addition, it provides GPs with a tool to manage this common bread and butter condition.

Based on these findings, we concluded that an illness-focused GP-parent information exchange tool consisting of an interactive booklet could provide parents with information 
about symptoms and fever management and consistent information during GP consultations. ${ }^{4,37}$ A strong safety net advice provided by a booklet could hypothetically also provide a disease-focussed solution to GPs by providing them with a way to reduce diagnostic uncertainty in these children, thereby also reducing the number of "better safe than sorry" antibiotic prescriptions. ${ }^{14}$ We found a statistical significant reduction in antibiotic prescriptions from $25.2 \%$ in the care as usual group to $21.9 \%$ in the actual use of booklet group. Although this is a modest effect, the intervention was very low-cost and light-touch. In other words, it could be implemented tomorrow by simply providing GPs with booklets. The reduction in antibiotic prescribing found in this thesis of all children seen at out of hours care with fever, therefore provides evidence of the likely 'real world' benefits of this intervention, and are therefore highly relevant to the aims of reducing antimicrobial resistance.

Critics may say that providing written, consistent information is already part of current best practice. We found that only $2 \%$ of parents in the control group received written information or advice about a website. This shows that it is in fact not common practice. This is something which can be improved by emphasizing the importance of communication and use of written information and referral to reliable websites in medical school and specialists training.

Other promising interventions that have not been discussed here aimed at battling antibiotic resistance in a broader perspective are amongst others aimed at responsible use of antibiotics, surveillance, and infection prevention and control. ${ }^{38}$ Considering the modest effect of our intervention, it goes without saying we believe the solution to antibiotic resistance and fever phobia among parents does not lie within one simple intervention, but within a combination of all these interventions. However, the basis is most likely the fundament of general practice and medicine, which is still communication and providing consistent information. 


\section{Methodological considerations \\ Bottom-up design}

One major strength of this project was the fact that everything, from the research question to the final design of the intervention was developed completely bottom up from a user centred, or parents-GPs centred, perspective. By combining in depth qualitative research among all stakeholders with quantitative data from GP out-of-hours centres, we were able to design an intervention which is completely based on the needs and wishes of parents and doctors. Patient (parental) participation was a key aspect of the entire project. Because parental needs vary in specific cases of disease focus and illness severity, we included a traffic light system which allowed GPs to highlight specific information and provide a safety net advice which was relevant for that child in that specific situation. Parents valued the traffic light system as the most important aspect of the booklet. These needs might have been overlooked if it was not for the qualitative base on which the next parts of the project were built upon.

\section{Real life pragmatic trials and effectiveness versus efficacy}

Clinical trials can be divided into explanatory and pragmatic. Explanatory trials generally measure efficacy, or in other words the benefit of a treatment under ideal conditions. Pragmatic trials are aimed at determining effectiveness, or, put otherwise, the benefit of a treatment in clinical practice. ${ }^{39}$ We specifically chose a pragmatic, large scale designed study because we believe this gives a more realistic picture of what would happen if an intervention targeting antibiotic prescriptions will be implemented on a large scale, in comparison to other studies performed with a more strict research design. While designing our trial, we used the PRECIS (PRagmatic Explanatory Continuum Indicator Summary) and later the PRECIS-2 tool, to make sure that our trial design matches our pragmatic intentions. ${ }^{40}$ Our trial scored 4 (rather pragmatic) to 5 (very pragmatic) on all domains in the tool. However, our design has its limitations. The effect size we found for GP use of the booklet is modest. This can partially be explained by the fact that we specifically chose not to train GPs in using the booklet at the interventions site and that the intervention was only used in one in three consultations. In other words, ways of improving the uptake of the intervention have to be considered during (future) implementation. A promising way of improving uptake could be to provide an online training tool, or by integrating the use of the intervention in an educational session during farmaco-therapeutic audit meeting groups (FTO). Furthermore, because of this design, an in depth parental experience is lacking and more qualitative outcomes cannot be taken into account. This can be solved by performing a process evaluation, something which we have partially done using telephone 
surveys among a subsample of parents. Unfortunately, we were not able to perform a process evaluation among participating GPs and parents.

\section{Complier adjusted average causal effect analysis}

Although we had a strong base for this study and intervention, it is just as important to have a strong analysis at the end of a study. We chose to perform a cluster RCT because of reasons which are described elsewhere. ${ }^{41}$ Because randomization took place on a GP outof-hours centre level, the cluster effect had to be taken into account during the actual analysis. We therefore performed a multilevel analysis by fitting two level (GP out-of-hours centre and patient) random intercept logistic regressions models. Because of the pragmatic design of this study, we expected that not every GP was going to use the intervention. We therefore used an innovative analysis method called a complier average causal effect (CACE) analysis which enabled us to evaluate the effect of actually receiving the booklet on antibiotic prescriptions in a more robust way than simply undertaking a per-protocol analysis alongside the intention-to-treat analysis. Estimation of CACE is however dependent upon potentially challengeable assumptions that cannot be tested. ${ }^{42,43}$ Furthermore, since this is such a new method, best available statistical models and software do not allow for correction of the cluster effect in a CACE analysis with a dichotomous outcome. Nevertheless, an increasing number of studies showed that a CACE analysis is much closer to the real world intention-to-treat estimates of treatment effects. ${ }^{29,43,44}$ Additionally, the ICC of 0.005 for antibiotic prescriptions at index consultations that we found suggests that the cluster effect for the primary outcome was likely to be very small. It has been shown that in cases where the ICC and the ICC for compliance are small, standard CACE analysis which does not correct for the cluster effect is acceptable. ${ }^{43}$

\section{Practice implications}

As suggested in previous studies, future studies should not only aim at parents of children at the moment they are sick, but also at parents of healthy young children in the general public. By informing them about future illnesses and self-management strategies, before children actually get sick, parental self-efficacy and their health care seeking might improve. A potential public health setting to educate parents about fever before their children become sick are well-child clinics. ${ }^{45}$ This is a potential setting not only to improve parental knowledge and self-management, but also to reduce illness absenteeism due to fever and common infections among children and parents thereby reducing subsequent societal costs and impact. ${ }^{46}$ 
Because of parents' call for one consistent line of information, future studies should also look into the possibility of using a similar intervention by paediatricians in secondary care. ${ }^{32}$

An aspect of childhood fever in out-of-hours primary care which has not been discussed in this thesis is the Dutch triage system (NTS). ${ }^{47}$ As mentioned previously in this discussion, patients and parents who contact an out-of-hours GP centre are triaged by telephone by trained assistants to determine if a face-to-face contact is needed. The assistant then determines if alarming signs are present. As is shown in this thesis, more than $70 \%$ of the febrile children whose parents call a GP out-of-hours centre eventually come in for a faceto-face consultation. ${ }^{1}$ Conversely, only few of them are seriously ill. A previous Dutch study showed that more than $50 \%$ of the children who visited a GP out-of-hours centre had one or more alarm sign or symptom. Since serious infections in primary care are very rare with an incidence lower than $1 \%{ }^{48}$ the subsequent predictive value of these alarm symptoms which are used in the triage system are very low. This results in many false-positive predictions of a serious infection. ${ }^{49}$ This is important because dealing with low-incidence illnesses is challenging for GPs. ${ }^{11}$ The interactive booklet and consistent information which is studied in this thesis obviously does not affect the triage system itself. However, we do hypothesise that by improving parental self-management, fewer parents will call a GP centre during out-of-hours care. By reducing the number of telephone contacts for selflimiting fever, the diagnostic value of the triage system in childhood fever will hopefully improve, thereby reducing the "finding a needle in a hay stack" experience many GPS described previously when it comes to childhood fever. ${ }^{3}$ This will then in turn hopefully reduce antibiotic prescriptions.

As said, the solution to improving antibiotic prescriptions and fever phobia among parents probably does not lie within one simple intervention, but within a combination of different interventions aimed at, amongst others, surveillance, infection prevention and responsible use of antibiotics. This is in line with a Cochrane Review which concluded that multi-faceted interventions combining physician, patient and public education in a variety of venues and formats were the most successful in reducing antibiotic prescribing for inappropriate indications. ${ }^{50}$ Researchers in the field of antibiotic resistance have to consider pragmatic studies, if possible combining these different interventions that are available. It will however be challenging to study the combinations of these interventions on one hand, and to keepsake the implementability on the other hand. 


\section{Conclusion}

Childhood fever is indeed the most common reason for parents to consult a GP during outof-hours care. Parents of a febrile child do not necessarily expect antibiotics and are in search of consistent, reliable information about fever and relevant symptoms. GPs on the other hand perceive that children with a fever account for a high workload during out-ofhours care which can lead to frustration and a diagnostic challenge due to the low incidence of serious illnesses and a lacking long-term relationship. We found that improving information exchange during consultations by using an illness-focussed booklet, which can be used interactively, can help provide a safety net and in that way enhance selfmanagement and reduce antibiotic prescriptions. Further research is needed to show whether this effect can be increased by making information material consistent across public health, including well-child clinics, primary care, including out-of-hours care and secondary care. Thereby ensuring one consistent source and flow of information for parents before, during, and even after children develop fever and common infection episodes. 


\section{REFERENCES}

1. de Bont EG, Lepot JM, Hendrix DA, Loonen N, Guldemond-Hecker Y, Dinant GJ, et al. Workload and management of childhood fever at general practice out-of-hours care: an observational cohort study. BMJ Open. 2015;5:e007365.

2. de Bont EG, Loonen N, Hendrix DA, Lepot JM, Dinant GJ, Cals JW. Childhood fever: a qualitative study on parents' expectations and experiences during general practice out-ofhours care consultations. BMC Fam Pract. 2015;16:131.

3. de Bont EG, Peetoom KK, Moser A, Francis NA, Dinant GJ, Cals JW. Childhood fever: a qualitative study on GPs' experiences during out-of-hours care. Fam Pract. 2015.

4. de Bont EG, Alink M, Falkenberg FC, Dinant GJ, Cals JW. Patient information leaflets to reduce antibiotic use and reconsultation rates in general practice: a systematic review. BMJ Open. 2015;5:e007612.

5. de Bont EG, Dinant GJ, Elshout G, van Well G, Francis NA, Winkens B, et al. An illness-focussed interactive booklet to optimize management and medication for childhood fever and infections in out-of-hours primary care: a cluster randomized controlled trial (under review). 2018.

6. Marjolein Korvorst, Traag T. De verdeling van arbeid en zorg tussen vaders en moeders. Centraal Bureau voor de Statistiek. 2010.

7. Giesen P. SM, Huibers L., Grol R., Wensing M. Quality of after-hours primary care: As narrative review of the Dutch solution. Ann Intern Med. 2011;155:108-13.

8. Ineen. Benchmarkbulletin huisartsenposten 20162017 [01-01-2018]. Available from:

https://ineen.nl/assets/files/assets/uploads/170824_Benchmarkbulletin_2016_Huisartsenp osten.pdf.

9. Ertmann RK, Soderstrom M, Reventlow S. Parents' motivation for seeing a physician. Scand J Prim Health Care. 2005;23:154-8.

10. Walsh A, Edwards H, Fraser J. Influences on parents' fever management: beliefs, experiences and information sources. J Clin Nurs. 2007;16:2331-40.

11. Buntinx F, Mant D, Van den Bruel A, Donner-Banzhof N, Dinant GJ. Dealing with low-incidence serious diseases in general practice. Br J Gen Pract. 2011;61:43-6.

12. Verbakel JY, Lemiengre MB, De Burghgraeve T, De Sutter A, Aertgeerts B, Bullens $\mathrm{DM}$, et al. Validating a decision tree for serious infection: diagnostic accuracy in acutely ill children in ambulatory care. BMJ Open. 2015;5:e008657.

13. Brookes-Howell L, Wood F, Verheij T, Prout H, Cooper L, Hood K, et al. Trust, openness and continuity of care influence acceptance of antibiotics for children with respiratory tract infections: a four country qualitative study. Fam Pract. 2014;31:102-10. 
14. Horwood J, Cabral C, Hay AD, Ingram J. Primary care clinician antibiotic prescribing decisions in consultations for children with RTIs: a qualitative interview study. $\mathrm{Br} J$ Gen Pract. 2016;66:e207-13.

15. Debets VE, Verheij TJ, van der Velden AW, Use SWsWGoSoA. Antibiotic prescribing during office hours and out-of-hours: a comparison of quality and quantity in primary care in the Netherlands. Br J Gen Pract. 2017;67:e178-e86.

16. Schmitt J, Schmitt NM, Kirch W, Meurer M. Early exposure to antibiotics and infections and the incidence of atopic eczema: a population-based cohort study. Pediatr Allergy Immunol. 2010;21:292-300.

17. Droste JH, Wieringa MH, Weyler JJ, Nelen VJ, Vermeire PA, Van Bever HP. Does the use of antibiotics in early childhood increase the risk of asthma and allergic disease? Clin Exp Allergy. 2000;30:1547-53.

18. Horton DB, Scott Fl, Haynes K, Putt ME, Rose CD, Lewis JD, et al. Antibiotic Exposure and Juvenile Idiopathic Arthritis: A Case-Control Study. Pediatrics. 2015;136:e33343.

19. Scott FI, Horton DB, Mamtani R, Haynes K, Goldberg DS, Lee DY, et al. Administration of Antibiotics to Children Before Age 2 Years Increases Risk for Childhood Obesity. Gastroenterology. 2016;151:120-9 e5.

20. Helman CG. Disease versus illness in general practice. J R Coll Gen Pract. 1981;31:548-52.

21. Cals JW, Butler CC, Hopstaken RM, Hood K, Dinant GJ. Effect of point of care testing for $C$ reactive protein and training in communication skills on antibiotic use in lower respiratory tract infections: cluster randomised trial. BMJ. 2009;338:b1374.

22. Verbakel JY, Lemiengre MB, De Burghgraeve T, De Sutter A, Aertgeerts B, Shinkins $B$, et al. Should all acutely ill children in primary care be tested with point-of-care CRP: a cluster randomised trial. BMC Med. 2016;14:131.

23. Verbakel JY, Lemiengre MB, De Burghgraeve T, De Sutter A, Aertgeerts B, Shinkins $B$, et al. Erratum to: Should all acutely ill children in primary care be tested with point-ofcare CRP: a cluster randomised trial. BMC Med. 2017;15:93.

24. Lemiengre MB, Verbakel JY, Colman R, De Burghgraeve T, Buntinx F, Aertgeerts B, et al. Reducing inappropriate antibiotic prescribing for children in primary care: a cluster randomised controlled trial of two interventions. Br J Gen Pract. 2018;68:e204-e10.

25. Bruning AHL, de Kruijf WB, van Weert $H$, Willems WLM, de Jong MD, Pajkrt D, et al. Diagnostic performance and clinical feasibility of a point-of-care test for respiratory viral infections in primary health care. Fam Pract. 2017;34:558-63. 
26. van Houten CB, de Groot JAH, Klein A, Srugo I, Chistyakov I, de Waal W, et al. A host-protein based assay to differentiate between bacterial and viral infections in preschool children (OPPORTUNITY): a double-blind, multicentre, validation study. Lancet Infect Dis. 2017;17:431-40.

27. Van den Bruel A, Thompson M, Buntinx F, Mant D. Clinicians' gut feeling about serious infections in children: observational study. Br Med J. 2012;345:e6144-e.

28. Turnbull S, Lucas PJ, Redmond NM, Christensen H, Thornton H, Cabral C, et al. What gives rise to clinician gut feeling, its influence on management decisions and its prognostic value for children with RTI in primary care: a prospective cohort study. BMC Fam Pract. 2018;19:25.

29. Macfarlane J, Holmes W, Macfarlane R, Britten N. Influence of patients' expectations on antibiotic management of acute lower respiratory tract illness in general practice: questionnaire study. BMJ. 1997;315:1211-4.

30. Fields E, Chard J, Murphy MS, Richardson M. Assessment and initial management of feverish illness in children younger than 5 years: summary of updated NICE guidance. BMJ. 2013;346.

31. Nijman RG, Oteman N, Oostenbrink R. Guideline for febrile children in the hospital setting; relevance for general practitioners and paediatricians. Ned Tijdschr Geneeskd. 2014;158:A7331.

32. de Bont EG, Cals JW. Voor elk kind met koorts een eigen 'stoplicht'? Ned Tijdschr Geneeskd. 2014;158.

33. Jones $\mathrm{CH}$, Neill S, Lakhanpaul M, Roland D, Singlehurst-Mooney $\mathrm{H}$, Thompson $\mathrm{M}$. Information needs of parents for acute childhood illness: determining 'what, how, where and when' of safety netting using a qualitative exploration with parents and clinicians. BMJ Open. 2014;4:e003874.

34. Dekker ARJ, Verheij TJM, Broekhuizen BDL, Butler CC, Cals JWL, Francis NA, et al. Effectiveness of general practitioner online training and an information booklet for parents on antibiotic prescribing for children with respiratory tract infection in primary care: a cluster randomized controlled trial. J Antimicrob Chemother. 2018.

35. Kessels RP. Patients' memory for medical information. J R Soc Med. 2003;96:21922.

36. Crocetti M, Moghbeli N, Serwint J. Fever phobia revisited: have parental misconceptions about fever changed in 20 years? Pediatrics. 2001;107:1241-6.

37. Francis N, Butler C, Hood K, Simpson S, Wood F, Nuttall J. Effect of using an interactive booklet about childhood respiratory tract infections in primary care 
consultations on reconsulting and antibiotic prescribing: a cluster randomised controlled trial. BMJ. 2009;339:b2885-b.

38. Dar OA, Hasan R, Schlundt J, Harbarth S, Caleo G, Dar FK, et al. Exploring the evidence base for national and regional policy interventions to combat resistance. Lancet. 2016;387:285-95.

39. Sedgwick P. Explanatory trials versus pragmatic trials. BMJ. 2014;349:g6694.

40. Loudon K, Treweek S, Sullivan F, Donnan P, Thorpe KE, Zwarenstein M. The PRECIS2 tool: designing trials that are fit for purpose. BMJ. 2015;350:h2147.

41. de Bont EG, Dinant GJ, Elshout G, van Well G, Francis NA, Winkens B, et al. An illness-focused interactive booklet to optimise management and medication for childhood fever and infections in out-of-hours primary care: study protocol for a cluster randomised trial. Trials. 2016;17:547

42. Dunn G, Maracy M, Dowrick C, Ayuso-Mateos JL, Dalgard OS, Page H, et al. Estimating psychological treatment effects from a randomised controlled trial with both non-compliance and loss to follow-up. Br J Psychiatry. 2003;183:323-31.

43. Jo B. Model misspecification sensitivity analysis in estimating causal effects of interventions with non-compliance. Stat Med. 2002;21:3161-81.

44. Gillespie D, Hood K, Farewell D, Butler CC, Verheij T, Goossens H, et al. Adherenceadjusted estimates of benefits and harms from treatment with amoxicillin for LRTI: secondary analysis of a 12-country randomised placebo-controlled trial using randomisation-based efficacy estimators. BMJ Open. 2015;5:e006160.

45. Peetoom KK, Smits JJ, Ploum LJ, Verbakel JY, Dinant GJ, Cals JW. Does well-child care education improve consultations and medication management for childhood fever and common infections? A systematic review. Arch Dis Child. 2017;102:261-7.

46. Peetoom KKB, Crutzen R, Bohnen J, Verhoeven R, Nelissen-Vrancken H, Winkens B, et al. Optimising decision making on illness absenteeism due to fever and common infections within childcare centres: development of a multicomponent intervention and study protocol of a cluster randomised controlled trial. BMC Public Health. 2017;18:61.

47. van lerland $Y$, van Veen M, Huibers L, Giesen P, Moll HA. Validity of telephone and physical triage in emergency care: the Netherlands Triage System. Fam Pract. 2011;28:33441.

48. Van den Bruel A, Bartholomeeusen S, Aertgeerts B, Truyers C, Buntinx F. Serious infections in children: an incidence study in family practice. BMC Fam Pract. 2006;7:23.

49. Elshout $G$, van lerland $Y$, Bohnen AM, de Wilde M, Moll HA, Oostenbrink R, et al. Alarming signs and symptoms in febrile children in primary care: an observational cohort study in the Netherlands. PLoS ONE. 2014;9:e88114. 
50. Arnold SR, Straus SE. Interventions to improve antibiotic prescribing practices in ambulatory care. Cochrane Database Syst Rev. 2005:CD003539. 

$V_{\text {alorisation }}$

253 

Most of this thesis is focused on the scientific value of our research into childhood fever in general practice. Nevertheless, in the end one of the most important reasons to perform scientific research is to translate that same research to concrete revenues for actual daily life and practice. This translational process is called valorisation. I hope that readers of this thesis see that this process of valorisation is intertwined in almost every chapter of this dissertation which they have read so far. This chapter will explicitly focus on and summarize that process, first discussing the societal relevance of our research, then zooming in on the concrete revenues of our findings and further on discussing future and innovative perspectives.

\section{Societal relevance of childhood fever and translation of this thesis}

Fever is the most common reason for a child to be seen by a GP during out-of-hours care, with one in three contacts for children under the age of 12 years being fever related. ${ }^{1}$ If parents consult with a febrile child, it is up to the GP to make sure that their management is as optimal as it can be. This is sometimes challenging for several reasons. First of all, GPS have to consider the safety of the individual child that is sitting in front of them. Things they have to bear in mind which are discussed in chapter $6^{2}$ and the discussion chapter of this thesis are the risk of missing a serious infection, thereby delaying treatment and risking long-term damage to the child versus overtreatment on the other side, leading to side effects, but also possible negative implications of early exposure to antibiotics like a higher risk of developing eczema, ${ }^{3}$ asthma, ${ }^{4}$ arthritis ${ }^{5}$ and even obesity. ${ }^{6}$ Second, on a more societal level GPs also have to consider their management decisions taking into account increasing antibiotic resistance as a threat to global health. Many studies have shown that antibiotic resistance is increasing and there is an increasing gap between the burden of infections due to multidrug-resistant bacteria and the development of new antibiotics to tackle the problem. ${ }^{7}$ To illustrate, approximately 25000 people in Europe die every year from antibiotic-resistant bacteria. ${ }^{7}$ Furthermore, in the US an estimated 2 million illnesses and 23000 deaths a year are caused by antibiotic resistance. ${ }^{8,9}$ One of the main causes for antibiotic resistance is overuse of antibiotics. It is this overuse that we tried to understand and grasp in the earlier chapters of this thesis, ${ }^{2,10,11}$ and tried to improve by development of an the interactive booklet as an intervention ${ }^{12,13}$ which, if indeed used, can reduce "better safe than sorry" antibiotic prescriptions. In other words, the findings of this thesis are not only relevant for GPs, clinicians working with children, parents and children but for almost every individual in our society. That is to say, the consequences of antibiotic resistance are everyone's problem. Achievements in modern medicine, such as major surgery, organ transplantation, treatment of preterm babies, and cancer chemotherapy, which we today 
take for granted, would not be possible without access to effective treatment for bacterial infections. ${ }^{9}$ Though the effect we found was modest, the reduction in antibiotic prescribing found in this thesis of all children seen at out of hours care with fever provide evidence of the likely 'real world' benefits of this intervention, and are therefore highly relevant to the aims of reducing antimicrobial resistance. Extrapolated to the Netherlands, with an average of 1000 children per 6 months per cooperative, 122 cooperatives in total and an average of 1 in 3 to 4 children to receive an antibiotic prescription, around 2000 prescriptions can be prevented in the Netherlands alone by simply providing parents with a booklet for which no special training is required.

The interactive booklet which was studied in this thesis was specifically designed and studied in such a way that it can be implemented tomorrow. As said, it is very low-cost and light-touch and does not require any specific training or instructions. In other words, it could be implemented tomorrow by simply providing GPs with booklets and making sure they use them. Our trial shows that handing out patient information leaflets about childhood fever during routine out-of-hours care is very uncommon, as only $2.8 \%$ of parents consulting at control centres reported receiving such information. We believe that this number of $2.8 \%$ shows that even in the bread-and-butter condition of childhood fever, uptake and hand-out of available patient information materials (either written or online) is extremely low in routine care, yet crucial for parents to learn about self-management strategies and alarm symptoms. This is something which can be improved by emphasizing the importance of communication and use of written information and referral to reliable websites in medical school and specialists training. Furthermore, it is important to think about other approaches to make sure GPs actually use the booklet and information since merely providing GPs with the booklet did not result in a reduction of antibiotic prescriptions. Strategies to consider are for example using additional platforms, other than printed material, where the booklet can be made available like online or through a smartphone application. Another important strategy on which we are already working is writing articles in national journals and giving lectures at (inter-)national conferences explaining the relevance of the use of the booklet and information in childhood fever to clinicians in everyday practices.

As explained in the discussion of this thesis, the booklet should ideally be combined with other interventions aimed at reducing unwarranted antibiotic prescriptions, such as improved diagnostics, point-of-care tests, interactive workshops ${ }^{14}$, and peer comparison through audit-and-feedback. ${ }^{15}$ In addition, in the next paragraph I will discuss why and how 
the information used in the booklet and the booklet itself can also be used in different settings, for example before children get sick.

\section{Innovativeness and future perspectives of childhood fever management}

We performed one of the largest cluster RCTs ever in general practice and the first one assessing the effectiveness of a booklet for one of the most common reasons for childhood consultations and antibiotic prescriptions. The basis and innovative part of the interactive booklet which was developed and studied in this thesis was a traffic light system aimed at parents. As described in the discussion of this thesis, a traffic light system can also be found in the international NICE guideline for childhood fever ${ }^{16}$ and the guideline from Dutch Society of Paediatrics (NVK). ${ }^{17}$ The big difference between these traffic lights and the traffic light in the booklet is the fact that they are doctor, or disease-orientated whereas the booklet's traffic light system is parent, or illness-orientated. Parents consulting a GP feel the traffic light has turned to orange, or even red, and it is up to the GP to turn that traffic light back to green in cases of benign (viral) infections thereby empowering parents in their self-management strategies. ${ }^{18}$

As is suggested in the previous chapters, future studies should not only aim at parents of children at the moment they are sick, but also at parents of healthy young children in the general public. By informing them about future illnesses and self-management strategies before children actually get sick, parental self-efficacy and their health care seeking might improve. A potential public health setting to educate parents about fever before their children become sick are well-child clinics. ${ }^{19}$ This is a potential setting not only to improve parental knowledge and self-management, but also to reduce illness absenteeism due to fever and common infections among children and parents thereby reducing subsequent societal costs and impact. ${ }^{19}$ Another potential setting where there is room for improvement are children's day-care centres. Previous studies have shown that illness absenteeism due to fever and common infections is substantial and mostly driven by unrealistic concerns and negative attitude towards fever of both childcare staff and parents, resulting in illness absenteeism from childcare, work absenteeism among parents and healthcare service use. ${ }^{20}$ It is for that reasons that the findings of this thesis resulted in a spin-off project focusing on this setting. We developed a multicomponent intervention consisting of an educational session, a decision tool, the information booklet (as developed in this thesis) and an online video to be used in childcare centers. Results of the cluster randomised trial examining the effects of this multicomponent intervention to optimise decision making among childcare staff on illness absenteeism due to fever and common 
infections in 0-4 year-old attending childcare will follow later in $2018 .^{20}$ Because of parents' call for one consistent line of information, future studies should also look into the possibility of using a similar intervention by paediatricians in secondary care. ${ }^{18}$

As said, the interactive booklet on childhood fever which was developed and studied throughout this thesis can be implemented tomorrow in general practice thereby improving parental self-management and reducing unwarranted antibiotic prescriptions. The solution to improving antibiotic prescriptions and fever phobia among parents probably does not lie within one simple intervention, but within a combination of different interventions aimed at amongst others surveillance, infection prevention and responsible use of antibiotics before, during and after children get sick. 


\section{REFERENCES}

1. de Bont EG, Lepot JM, Hendrix DA, Loonen N, Guldemond-Hecker Y, Dinant GJ, et al. Workload and management of childhood fever at general practice out-of-hours care: an observational cohort study. BMJ Open. 2015;5:e007365.

2. de Bont EG, Peetoom KK, Moser A, Francis NA, Dinant GJ, Cals JW. Childhood fever: a qualitative study on GPs' experiences during out-of-hours care. Fam Pract. 2015.

3. Schmitt J, Schmitt NM, Kirch W, Meurer M. Early exposure to antibiotics and infections and the incidence of atopic eczema: a population-based cohort study. Pediatr Allergy Immunol. 2010;21:292-300.

4. Droste JH, Wieringa MH, Weyler JJ, Nelen VJ, Vermeire PA, Van Bever HP. Does the use of antibiotics in early childhood increase the risk of asthma and allergic disease? Clin Exp Allergy. 2000;30:1547-53.

5. Horton DB, Scott FI, Haynes K, Putt ME, Rose CD, Lewis JD, et al. Antibiotic Exposure and Juvenile Idiopathic Arthritis: A Case-Control Study. Pediatrics. 2015;136:e33343.

6. Scott FI, Horton DB, Mamtani R, Haynes K, Goldberg DS, Lee DY, et al. Administration of Antibiotics to Children Before Age 2 Years Increases Risk for Childhood Obesity. Gastroenterology. 2016;151:120-9 e5.

7. ECDC/EMEA. Technical Report. The bacterial challenge: time to react 2009. Available from:

https://ecdc.europa.eu/sites/portal/files/media/en/publications/Publications/0909_TER_Th e_Bacterial_Challenge_Time_to_React.pdf

8. US Centers for Disease Control and Prevention. Antibiotic resistance threats in the United States 2013. Available from: https://www.cdc.gov/drugresistance/threat-report2013/pdf/ar-threats-2013-508.pdf.

9. Laxminarayan R, Duse A, Wattal C, Zaidi AK, Wertheim HF, Sumpradit N, et al. Antibiotic resistance-the need for global solutions. Lancet Infect Dis. 2013;13:1057-98.

10. de Bont EG, Francis NA, Dinant GJ, Cals JW. Parents' knowledge, attitudes, and practice in childhood fever: an internet-based survey. Br J Gen Pract. 2014;64:e10-6.

11. de Bont EG, Loonen N, Hendrix DA, Lepot JM, Dinant GJ, Cals JW. Childhood fever: a qualitative study on parents' expectations and experiences during general practice out-ofhours care consultations. BMC Fam Pract. 2015;16:131.

12. de Bont EG, Alink M, Falkenberg FC, Dinant GJ, Cals JW. Patient information leaflets to reduce antibiotic use and reconsultation rates in general practice: a systematic review. BMJ Open. 2015;5:e007612. 
13. de Bont EG, Dinant GJ, Elshout G, van Well G, Francis NA, Winkens B, et al. An illness-focused interactive booklet to optimise management and medication for childhood fever and infections in out-of-hours primary care: study protocol for a cluster randomised trial. Trials. 2016;17:547.

14. Little P, Stuart B, Francis N, Douglas E, Tonkin-Crine S, Anthierens S, et al. Effects of internet-based training on antibiotic prescribing rates for acute respiratory-tract infections: a multinational, cluster, randomised, factorial, controlled trial. Lancet. 2013;382:1175-82.

15. Meeker D, Linder JA, Fox CR, Friedberg MW, Persell SD, Goldstein NJ, et al. Effect of Behavioral Interventions on Inappropriate Antibiotic Prescribing Among Primary Care Practices: A Randomized Clinical Trial. JAMA. 2016;315:562-70.

16. Fields E, Chard J, Murphy MS, Richardson M. Assessment and initial management of feverish illness in children younger than 5 years: summary of updated NICE guidance. BMJ. 2013;346.

17. Nijman RG, Oteman N, Oostenbrink R. Guideline for febrile children in the hospital setting; relevance for general practitioners and paediatricians. Ned Tijdschr Geneeskd. 2014;158:A7331.

18. de Bont EG, Cals JW. Voor elk kind met koorts een eigen 'stoplicht'? Ned Tijdschr Geneeskd. 2014;158.

19. Peetoom KK, Smits JJ, Ploum LJ, Verbakel JY, Dinant GJ, Cals JW. Does well-child care education improve consultations and medication management for childhood fever and common infections? A systematic review. Arch Dis Child. 2017;102:261-7.

20. Peetoom KKB, Crutzen R, Bohnen J, Verhoeven R, Nelissen-Vrancken H, Winkens B, et al. Optimising decision making on illness absenteeism due to fever and common infections within childcare centres: development of a multicomponent intervention and study protocol of a cluster randomised controlled trial. BMC Public Health. 2017;18:61. 


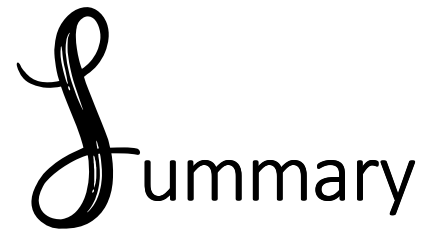

261 



\section{SUMMARY}

Fever is the most common reason for a child to be taken to a general practitioner (GP). In most cases, fever is caused by a benign (viral) infection and general recommendations given by GPs are sufficient. However, many children who visit an out-of-hours GP centre because of a fever receive an antibiotic prescription. Since many parents work during the day and fever typically rises in the early evening, consultation and prescription rates are even higher during out-of-hours care. This thesis shows the results of over 11 articles, including 2 cohort studies, a survey among a sample of 1000 parents, and qualitative research among 20 parents, 37 GPs and 24 pharmacy employees, as well as 3 reviews, including a systematic review and a randomised controlled trial in which over 3,500 GPS and over 25,000 children participated over a six-month period.

As described in chapter 1 , childhood fever related consultations at an out-of-hours GP centre are further complicated for several reasons. First, the GPs and parents may not know each other and thus not have a long-term parental-GP relationship. This is complicating because a trusting relationship between a GP and patient is one of the founding pillars of general practice. In addition to the lack of a long-term parental-GP relationship, out-of-hours GPs also have to trust a colleague whom they might not know to provide adequate follow-up to their out-of-hours care. Having to hand over this responsibility, together with a lacking prior relationship, might cause a more defensive way of working during out-of-hours care. In terms of antibiotic prescriptions, this could mean more prescriptions for children for whom during their regular practice an adequate followup advice might have sufficed. Additionally, we believe GPs often feel pressured to prescribe antibiotics, although only a limited number of parents actually expect a prescription. This could imply that GPs' assumptions are not always in line with the expectations of parents. Taken together, these factors probably cause unnecessary antibiotic prescribing and referrals, while decreasing parental self-management.

A potential way of addressing these difficulties, which was proven to be effective among children with respiratory tract infections, is an illness-focused interactive booklet. Illnessfocused interventions recognise the importance of non-medical influences on the decision to consult or to prescribe antibiotics. We believed exploring the illness experience of parents of children with fever and infections had potential, since this would allow GPs to specifically address the concerns and questions that parents have when their child is sick. An illness-focused intervention could potentially also provide a disease-focused solution to 
GPs by providing them with a way to enable parental self-management and thereby reduce diagnostic uncertainty, leading to fewer "better safe than sorry" antibiotic prescriptions.

Although the possible explanations and solutions that are given here might seem plausible, most of these were based on logical reasoning at the start of this thesis and therefore hypothetical. In fact, we did not know exactly how high the workload caused by childhood fever consultation was during out-of-hours care. We also did not know what happens with children when parents consult an out-of-hours GP centre in terms of antibiotic prescriptions and referrals, nor whether the suggested intervention would also be something which GPs and parents needed in childhood fever related consultations. In this thesis I aimed to find these answers: first, by examining what currently occurs, using a combined quantitative and qualitative approach; second, to see if and how there was room for improvement by using an intervention; and third, to examine whether such an intervention could effectively reduce antibiotic prescriptions, consultations and reconsultations, and improve satisfaction of all stakeholders without causing complications.

Monitoring trends in antibiotic prescribing is important to assess the necessity of interventions aimed at antibiotic resistance. Therefore, in chapter two, in a cohort study we investigated prescription rates over time and for different age categories for oral and topical antibiotics among children ( $\leq 12$ years) in 2000-2010, using data from a large GP database. One in six children received at least one oral antibiotic prescription per year in 2000-2010. While topical prescription rates steadily increased in 2005-2010 and remained stable in 2006-2010, prescription rates for oral antibiotics increased significantly in 20002005 and then significantly decreased in 2006-2010. As clinical guidelines remained the same over this period, the effects could be attributed to the initiation of the Dutch nationwide pneumococcal vaccination campaign in 2006.

The next step was to zoom in on GP out-of-hours care in chapter three using another cohort study. In order to develop interventions to increase parental self-management strategies, it is important to know how childhood fever contacts are currently managed during out-of-hours care. Therefore, for children under the age of 12 seen at a large out-ofhours GP centre in the Netherlands, we assessed the number of childhood fever related contacts and consultations, and the resulting antibiotic prescriptions, paediatric referrals and re-consultations. We found that childhood fever did account for a large workload at the out-of-hours GP centre. One in three contacts was fever related and $70 \%$ of those febrile children were called in to be assessed by a GP. One in four consultations for 
childhood fever resulted in antibiotic prescribing and most consultations were managed in primary care without referral.

In chapter four we aimed to determine public parental knowledge, attitudes and practices, with regard to fever in young children, in a nationwide online survey among parents with young children in the general population. We found that knowledge, attitudes and practices concerning childhood fever varied among parents with young children. Parents generally expect a thorough physical examination and information, but not a prescription for medication (antibiotics or antipyretics), when consulting with a feverish child. We believe general practitioners must be aware of these expectations, as these provide opportunities to enhance consultations in general and prescription strategies in particular.

Subsequently, using in-depth interviews, in chapter five we aimed to provide a comprehensive overview of why parents consult a GP out-of-hours, what they generally experience and expect, and how they use and would desire information to be given before, during and after a consultation for childhood fever. We discovered that parents were inexperienced in self-management strategies and had a subsequent desire for reassurance; this played a pivotal role in seeking out-of-hours help for childhood fever. These factors provided clues to optimise information exchange between GPs and parents, by providing written, tailored, consistent information on self-management strategies for current and future fever episodes.

In chapter six we aimed to explore the experiences of GPs regarding childhood fever consultations during out-of-hours care using a focus-group study, thereby eliciting barriers and facilitators of good quality care, including appropriate antibiotic prescribing rates and enhanced parental self-management. We found that GPs believe children with a fever account for a high workload during out-of-hours GP care, which provides a diagnostic challenge due to the low incidence of serious illnesses and the lacking long-term relationship. This can lead to frustration and drives antibiotics prescription rates. GPS believed improving information exchange during consultations and in the general public to young parents could help provide a safety net, thereby enhancing self-management, and reducing consultations, workload and subsequent antibiotic prescriptions.

As found in chapters five and six, an information leaflet was a potential intervention that might improve childhood fever related out-of-hours consultations that was mentioned by both GPs and parents. The aim of the systematic review in chapter seven was therefore to 
study the effect of using patient information leaflets on antibiotic use and re-consultation rates in GP consultations for common infections. We found that patient information leaflets used during GP consultations for common infections are promising tools to reduce antibiotic prescriptions. The effect on re-consultation rates for similar symptoms varied, with a tendency toward fewer re-consultations when patients were given a leaflet.

By integrating the prior quantitative and qualitative studies described in the previous chapters, we were able to develop an intervention in the form of an interactive booklet. The content of the booklet was developed completely bottom-up in a multistage process, using the described nationwide survey among parents, focus group sessions and semistructured interviews with parents, GPs and triage nurses, as well as extensive literature research and expert discussions. The main part of the booklet was a traffic light system for childhood fever aimed at parents, with advice on when to consult a GP (red symptoms) and information on self-management strategies, as well as specific traffic lights for infections of the upper respiratory tract (cough, cold and sore throat), acute otitis media (earache) and gastrointestinal symptoms (abdominal pain, vomiting and diarrhoea).

In chapter eight we describe the study protocol of the cluster randomised controlled trial, conducted among 20 out-of-hours GP centres, on the effect of the pragmatic use of an interactive booklet in childhood fever related GP out-of-hours care consultations for children under the age of 12 . Subsequently, in chapter nine results are presented of the effect study. Twenty out-of-hours GP centres across the Netherlands providing care for 3,557,206 residents participated in this trial, from November 2015 to June 2016. GPs at 10 intervention sites had access to the illness-focused interactive booklet. In total, over 25,000 children successfully participated in this study over six months, involving over 3,500 GPs. Improving information exchange during consultations by using an illness-focused booklet, which can be used interactively, can help provide a safety net and in that way enhance selfmanagement and reduce "better safe than sorry" antibiotic prescriptions. GP access to such a booklet alone does not significantly reduce antibiotic prescriptions (antibiotic prescription rates of $25.2 \%$ in the control group and $23.5 \%$ in the access to booklet group). However, actual use of an illness-focused interactive booklet does lead to a reduction in antibiotic prescriptions ( $25.2 \%$ vs. $21.9 \%, \mathrm{P}<0.05)$, overall medication prescriptions $(38.5 \%$ vs. $32.7 \%, \mathrm{P}<0.05)$ and intention to re-consult for future similar illnesses among parents (84.4\% vs. $71.6 \%, \mathrm{P}<0.05)$. 
This thesis primarily focuses on reducing unnecessary use of medication and antibiotic prescriptions. However, it is important to acknowledge that there are children who do require medication. Evidence regarding what happens at the pharmacy following a GP's consultation was lacking. In chapter ten, we therefore described pharmacy employees' experiences with childhood fever using another focus-group study. Pharmacy employees experienced a high number of dosing errors in paediatric antibiotic prescriptions. Providing the indication for antibiotics in febrile children on prescriptions, especially when deviating from standard dosages, can potentially reduce dosage errors and miscommunication between doctors and pharmacy employees.

When GPs do decide to recommend the use of paracetamol or to prescribe an antibiotic, it is important that this happens in a correct and safe manner. In chapter eleven we therefore describe the risk and benefits of paracetamol in children with fever and argue why the use of paracetamol is effective and recommendable in treating a combination of pain and fever, although doctors should be reticent about recommending paracetamol for children who only have a fever, since a fever as such does not need to be treated. In chapter twelve we describe how we believe amoxicillin and paracetamol dosing can be improved by basing dosing recommendations and practice on body weight rather than on age, using a daily dosage regime for paracetamol and amoxicillin of $60 \mathrm{mg} / \mathrm{kg} /$ day and by indicating the daily dosage, number of doses a day, duration, indication and the child's body weight on all antibiotics prescriptions for children.

The last chapter of this thesis is chapter thirteen, the general discussion of this thesis. This chapter is used to place the findings of this thesis in a broader context and is divided into three parts. Part one of this discussion focused on the content of this thesis, describing our main findings and providing an in-depth overview showing current management of childhood fever in a 24-hour society. I then elaborate why we believe communication and consistent information is key to improving antibiotic resistance and current management of childhood fever. Part two focuses on methodological considerations and why we specifically chose a pragmatic trial even considering its limitations. Finally, the third and last part focuses on the future and is used to formulate practice implications of this thesis.

In conclusion, providing parents of feverish children with information helps to reduce unnecessary (antibiotic) prescriptions during out-of-hours care and reduces intention to reconsult for future similar illnesses. Further research is needed to show whether the effect we found can be increased by using the same information before children get sick, and 
when they get so sick they need to be treated in secondary care. Thereby ensuring one consistent source and flow of information for parents before, during and even after children get sick. 
$f_{\text {amenvatting }}$ 



\section{SAMENVATTING}

Koorts is de meest voorkomende reden waarom kinderen door een huisarts worden gezien. Koorts wordt meestal veroorzaakt door een onschuldige (virus) infectie waarvoor algemeen advies van de huisarts voldoende is. Toch krijgen veel kinderen met koorts alsnog antibiotica. Doordat steeds meer ouders overdag werken, en koorts in de vroege avond stijgt, zijn het aantal kinderen dat wordt gezien door de huisarts en het aantal voorschriften dat hieruit volgt op de huisartsenpost nog hoger dan in de dagpraktijk. In deze thesis worden de resultaten beschreven van meer dan 11 artikelen, waaronder 2 cohortonderzoeken, een vragenlijst onderzoek onder 1000 ouders, kwalitatief onderzoek onder 20 ouders, 37 huisarts en 24 apotheekmedewerkers, drie reviews waaronder een systematische review en een gecontroleerd gerandomiseerd onderzoek waaraan meer dan 3500 huisartsen deelnamen en meer dan 25000 kinderen werden geïncludeerd in 6 maanden tijd.

Zoals beschreven in hoofdstuk 1, zijn er echter nog meer redenen waarom deze consulten voor kinderen met koorts op de huisartsenpost complex zijn. Allereerst kennen huisartsen en ouders elkaar niet. Er is geen sprake van een lange termijn behandelrelatie wat moeilijk is, omdat dit een belangrijke basis is van het huisartsen vak. Daarnaast moeten huisartsen op de huisartsenpost het opvolgen van een kind overdragen aan collega's, die ze misschien niet eens kennen, terwijl ze normaal zelf een kind enkele uren of dagen later terug kunnen zien. Het overdragen van deze verantwoordelijkheid, samen met het gebrek aan een lange termijn behandelrelatie kan leiden tot defensiever handelen op de huisartsenpost. Kijkend naar antibiotica voorschriften, houdt dit in dat meer kinderen een voorschrift krijgen, terwijl ze normaliter alleen de volgende dag zouden worden terug gezien door de huisarts. Daarnaast zijn er huisartsen die het gevoel hebben dat ouders antibiotica eisen, dit terwijl slechts enkele ouders echt antibiotica verwachten. Dit kan betekenen dat aannames van huisartsen niet altijd overeenkomen met daadwerkelijke verwachtingen van ouders. Al deze beschreven factoren samen leiden tot onnodige antibiotica voorschriften en verwijzingen en verminderen zelfzorg door ouders.

Een potentiele manier om dit alles te verbeteren welke effectief was bij kinderen met hoestklachten is een interactief boekje gericht op het illness perspectief van ouders. IIIness gerichte interventies zijn gericht op de niet medische factoren die de keuze om naar een arts te komen of om antibiotica voor te schrijven beïnvloeden. Wij geloofden dat het onderzoeken van ouders hun illness ervaringen in het geval van koorts en infecties bij hun kind potentie had, omdat dit huisartsen in staat kan stellen om specifieke verwachtingen en vragen van ouders te onderzoeken en beantwoorden. 
Diezelfde illness gerichte interventie kan daarmee voor de huisarts een disease gerichte (of medische) oplossing zijn doordat het stimuleren van zelfmanagement van ouders en goede uitleg over alarmsignalen de diagnostische onzekerheid van de huisarts mogelijk kan verminderen. Dit kan weer leiden tot minder "betere het zekere voor het onzekere nemen" antibiotica recepten.

Bij aanvang van deze thesis waren al deze bevindingen echter niet meer dan hypotheses en speculaties. We wisten niet hoe hoog de werklast voor kinderen met koorts op de huisartsenpost echt was. We wisten ook niet hoeveel kinderen verwezen werden en hoeveel kinderen precies naar huis gingen met antibiotica. We wisten ook niet of de beschreven potentiele interventie überhaupt een voorbeeld was van iets dat huisartsen en ouders ook konden gebruiken op de huisartsenpost bij kinderen met koorts. Ik heb in deze thesis daarom geprobeerd om hier antwoorden op te geven door eerst te onderzoeken wat er gebeurde op de huisartsenpost. Hiervoor combineerden we diverse kwantitatieve en kwalitatieve onderzoekstechnieken waardoor we ook diepgaand ouders en huisartsen hun ervaringen in kaart konden brengen. Vervolgens onderzochten we of er behoefte was aan verbetering en op welke manier ouders en huisartsen dachten dat dit verbeterd kon worden. Als laatste onderzochten we of de ontwikkelde interventie effectief het aantal antibioticavoorschriften en (re-)consulten kon verminderen en de tevredenheid kon doen toenemen zonder te zorgen voor complicaties.

Bijhouden van antibiotica trends is belangrijk om de noodzaak voor interventies gericht op antibioticaresistentie in te schatten. In hoofdstuk 2 onderzochten we middels een cohortonderzoek daarom orale en lokale antibiotica voorschrijfpercentages gedurende een periode van 2000-2010 voor verschillende leeftijdscategorieën bij kinderen jonger dan 12 jaar door gebruik te maken van een grote huisartsendatabase. Eén op de zes kinderen ontving minimaal één voorschrift voor antibiotica per jaar van 2000-2010. Terwijl lokale antibiotica voorschriften van 2000-2005 stegen en daarna gelijk bleven, stegen orale voorschriften ook van 2000-2005 maar daalden deze significant tussen 2005-2010. Gezien het feit dat de richtlijnen in deze periode niet veranderden is een mogelijk verklaring voor deze afname de invoering van de landelijke pneumokokkenvaccinatie in 2006.

De volgende stap was inzoomen op de huisartsenpost. Dit deden we in hoofdstuk 3 met nog een cohortonderzoek. Om interventies te ontwikkelen die zelfredzaamheid en zelfzorg van ouders stimuleren moesten we eerst weten hoe contacten voor kinderen met koorts op dat moment verliepen op de huisartsenpost. We onderzochten daarom het aantal contacten en consulten, het aantal antibiotica voorschriften, verwijzing en re-consulten 
voor kinderen jonger dan twaalf jaar op een grote huisartsenpost in Nederland gedurende een heel jaar. We constateerden dat koorts bij kinderen inderdaad bijdraagt aan een hoge werkbelasting op de huisartsenpost. Eén op de drie contacten voor kinderen was koorts gerelateerd en $70 \%$ van de ouders die belden kwam met hun kind fysiek ook langs voor een consult met de huisarts. Bij één op de vier consulten werd antibiotica voorgeschreven en minder dan $10 \%$ van de kinderen werd verwezen.

In hoofdstuk vier hebben we geprobeerd de publieke kennis, opvattingen en het handelen van ouders van jonge kinderen te onderzoeken door een landelijk vragenlijst onderzoek in de algemene bevolking uit te voeren. We vonden dat kennis, opvattingen en handelen varieerden tussen ouders van jonge kinderen. Ouders verwachtten een gedegen lichamelijk onderzoek van hun kind, maar geen voorschrift (voor antibiotica of andere middelen) wanneer zij een arts consulteerden. Het is belangrijk dat huisartsen zich bewust zijn van deze verwachtingen, omdat dit hen de mogelijkheid biedt om consulten in het algemeen te verbeteren, en voorschrijven specifiek.

In hoofdstuk vijf zijn we vervolgens de diepte in gegaan met semigestructureerde interviews en onderzochten we waarom ouders een huisartsenpost consulteren, wat ze algemeen ervaren en verwachten en of en hoe ze informatie voor, tijdens en na een consult voor hun kind met koorts willen ontvangen. We ontdekten dat ouders weinig ervaring hadden met zelfzorg bij koorts en daarom geruststelling zochten bij de huisartsenpost of ze het goede deden voor hun kind. Ouders zochten consistente, geschreven, voor hun specifieke informatie over zelfzorgadviezen. Idealiter zouden ze deze informatie ook bij toekomstige koorts episodes willen kunnen gebruiken. Deze factoren gaven aanwijzingen hoe informatie uitwisseling tussen huisartsen en ouders kon worden verbeterd.

In hoofdstuk zes exploreerden we met een focusgroep onderzoek de ervaringen van huisartsen met kinderen met koorts op de huisartsenpost. Hiermee probeerden we in kaart te brengen welk hinderende en bevorderende factoren voor goede zorg een rol speelden, inclusief zinvol gebruik van antibioticagebruik en zelfzorg van ouders. We concludeerden dat huisartsen ook daadwerkelijk het gevoel hebben dat ze veel kinderen met koorts op de huisartsenpost zien. Dit is diagnostisch uitdagend omdat slechts enkele kinderen ernstig ziek zijn en ze ouders en het kind niet kennen. Ze vergeleken dit met het zoeken naar aan naald in een hooiberg. Dit kan leiden tot frustratie en meer antibiotica voorschriften dan noodzakelijk. Huisartsen geloofden net als ouders dat het verstrekken van informatie 
tijdens consulten, maar ook vooraf in de algemene populatie ouders kan voorzien van een vangnet of veiligheidsadvies en daarmee hun zelfmanagement kan verbeteren. Dit kan weer tot minder consulten en een langere werkbelasting leiden, wat onnodige antibiotica voorschriften voorkomt.

Zoals ondervonden in hoofdstuk vijf en zes leek informatievoorziening de sleutel tot verbetering van consulten voor kinderen met koorts op de huisartsenpost. Het doel van de systematische review in hoofdstuk zeven was daarom om het effect van informatieboekjes bij infecties na te gaan op antibiotica voorschriften en reconsulten in de huisartsenpraktijk. We lieten in dit hoofdstuk zien dat informatieboekjes die gebruikt werden tijdens huisarts consulten voor veelvoorkomende infecties leidden tot minder antibiotica voorschriften. Het effect op reconsulten voor gelijkende symptomen of klachten varieerden tussen studies met een neiging tot minder reconsulten.

Door de kwalitatieve en kwantitatieve studies uit de voorgaande hoofdstukken te combineren waren we in staat een interventie te ontwikkelen in de vorm van een boekje dat interactief gebruikt kon worden. De inhoud van het boekje werd in meerdere fases samengesteld in samenwerking met alle belangrijke betrokkenen door gebruik te maken van het beschreven landelijke vragenlijst onderzoek onder ouders, focusgroep sessies en semi-gestructureerde interviews met ouders, huisartsen en triagisten van de huisartsenpost, uitgebreid literatuuronderzoek en expert discussies. Het belangrijkste onderdeel van het boekje was een stoplichtsysteem over koorts bij kinderen gericht op ouders. Het stoplicht bevatte advies wanneer ouders een arts moesten raadplegen (rood) en informatie over zelfmanagement strategieën (oranje en groen). Ook waren er specifieke stoplichten voor bovenste luchtweginfecties (hoesten, verkoudheid en keelpijn), otitis medica acuta (oorpijn) en gastro-intestinale klachten (buikpijn, braken en diarree). In hoofdstuk acht wordt het protocol van het gerandomiseerde onderzoek op het effect van het pragmatisch gebruik van het boekje tijdens consulten voor kinderen jonger dan twaalf jaar met koorts op twintig huisartsenposten in Nederland beschreven.

In hoofdstuk negen wordt het daadwerkelijke effect van de studie beschreven. Twintig huisartsenposten verspreid over Nederland, zorg dragend voor 3557206 Nederlanders deden mee in deze studie tussen november 2015 en juni 2016. Huisartsen op tien huisartsenposten hadden toegang tot het boekje. In totaal werden er meer dan 25000 kinderen geïncludeerd door meer dan 3500 huisartsen. Het interactief gebruik van een informatieboekje tijdens consulten voor kinderen met koorts op de huisartsenpost kan een 
vangnet voor ouders verzorgen en daarmee hun zelfzorg verbeteren. Hierdoor neemt het aantal "beter het zekere dan het onzekere" antibiotica voorschriften af. Alleen gekeken naar de beschikbaarheid van het boekje vonden we geen verschil in antibioticavoorschriften (25.2\% op controleposten en $23.5 \%$ op interventieposten). Wanneer we corrigeerden voor gebruik van het boekje vonden we wel dat antibioticavoorschriften afnamen ((25.2\% vs. $21.9 \%, P<0.05)$. Ook nam het totale aantal recepten (inclusief andere middelen dan antibiotica) af wat mogelijk verklaard kon worden doordat ouders informatie in plaats van een recept geboden werd (38.5\% vs. 32.7\%, $\mathrm{P}<0.05$ ). De intentie om voor soortgelijke klachten terug te komen (intentie tot reconsulteren) nam ook af onder ouders waarbij de huisarts toegang had tot het boekje (84.4\% vs. $71.6 \%, \mathrm{P}<0.05)$.

Deze thesis is primair gericht op het verminderen van onnodig gebruik van medicatie en antibiotica bij kinderen met koorts. Het is echter belangrijk te erkennen dat er kinderen zijn die wel medicatie nodig hebben. We misten vervolgens echter nog de kant en ervaring van apotheken die volgen op het consult met de huisarts waarbij een recept wordt uitgeschreven. Daarom onderzochten we met een focusgroep onderzoek in hoofdstuk tien hoe medewerkers van apotheken contacten met ouders van kinderen met koorts ervaren. Apotheek medewerkers ervaren veel doseringsfouten bij antibiotica voorschriften voor kinderen. Het verstrekken van de indicatie voor het uitschrijven van het antibioticum, vooral wanneer wordt afgeweken van standaarddoseringen kan leiden tot minder doseringsfouten en miscommunicatie tussen huisartsen en apotheken.

Als huisartsen besluiten paracetamol te adviseren of antibiotica voor te schrijven dan moet dit op een goede en veilige manier gebeuren. We omschreven daarom in hoofdstuk elf de voor- en nadelen van het gebruik van paracetamol bij kinderen met koorts. In dit hoofdstuk zetten we uiteen waarom paracetamol effectief en aan te raden is bij koorts gecombineerd met pijn, maar waarom dokters terughoudend moeten zijn in het adviseren van paracetamol bij alleen koorts. Koorts alleen hoeft niet behandelt te worden. Vervolgens beschrijven we in hoofdstuk twaalf hoe wij denken dat doseren van amoxicilline en paracetamol kan worden verbeterd. Samengevat resulteerden dit in de volgende concrete adviezen: doseringsadviezen moeten worden gebaseerd op gewicht en niet leeftijd, gebruik van een dagdosering van $60 \mathrm{mg} / \mathrm{kg} / \mathrm{dag}$ voor zowel paracetamol als amoxicilline is een goede vuistregel, vermeld op het recept het aantal gewenste giften op een dag, de duur van gebruik, de indicatie en het gewicht van het kind. 
Het laatste hoofdstuk van deze thesis is hoofdstuk dertien, de algemene discussie van deze thesis. Dit hoofdstuk wordt gebruikt om de bevindingen van de thesis in een bredere context te plaatsen en is ingedeeld in drie delen. Het eerste deel is gericht op de inhoud van deze thesis waarin de belangrijkste bevindingen worden samengevat en we laten zien hoe we omgaan met koorts bij kinderen in onze 24-uurs maatschappij. Vervolgens ga ik in op het feit waarom we geloven dat communicatie en consistente informatievoorziening een van de sleutelpunten is waarmee we de zorg voor kinderen met koorts kunnen verbeteren en onnodige antibioticavoorschriften kunnen terugdringen. Het tweede deel van deze discussie is gericht op methodologische overwegen en de vraag waarom we specifiek voor een pragmatische trial hebben gekozen ondanks dat deze ook nadelen kent. Als laatste ga ik in het derde en laatste deel van dit hoofdstuk in op wat de bevindingen uit deze thesis nu daadwerkelijk in de praktijk inhouden en wat er in de toekomst nodig is om de zorg nog verder te verbeteren op dit gebied. Samengevat helpt het voorlichten van ouders van kinderen met koorts het aantal antibioticavoorschriften op de huisartsenpost te verminderen en geven ouders bovendien aan in de toekomst minder snel terug te gaan voor dezelfde klachten. Meer onderzoek is nodig om te laten zien of het gevonden effect kan worden vergroot door dezelfde informatie ook te geven aan ouders voordat kinderen ziek worden, of wanneer ze zo ziek zijn dat ze naar een kinderarts moeten. Dit zou ons in staat stellen om één consistente bron en lijn van informatie te waarborgen, voor, tijdens en nadat kinderen ziek zijn. 
$D_{\text {ankwoord }}$ 

Bedankt. Bedankt dat je de moeite hebt genomen dit boek open te slaan en er iets uit te lezen. Dat feit en idee maakt dat ik dit met plezier schrijf. Zij die mij kennen weten namelijk dat ik nog altijd in sprookjes geloof en de wonderlijke wereld van een verhaal een van de mooiste creaties vind die een mens kan maken. Ik was geloof ik zeven jaar oud toen ik besloot ooit een boek te willen schrijven. So far so good zou je zeggen dus. De bedoeling was echter dat het een kinderboek zou zijn. Of in ieder geval een verhaal dat kinderen net zo lief zouden lezen als volwassenen. Kinderboeken zijn namelijk voor iedereen weet je, jong en oud. Aangezien de meeste hoofdstukken van dit boek wel over kinderen gaan, maar de inhoud van het verhaal voor hun niet heel aantrekkelijk zal zijn (of ja het is maar hoe je het bekijkt) zal dit hoofdstuk iets anders worden opgeschreven.

Laat ik omdat dat logisch is bij het begin beginnen. Dit verhaal begint en eindigt in Stein en begint en eindigt met een man. Jochen. "Wij" schrijven links, maar gooien rechts. Smeren links, maar snijden rechts. Zijn opgegroeid in Stein in de "aimed" straat en komen uit een lijn van roodharigen. Toch zaten er jaren (we zullen het vaag houden, ik wil je immers bedanken), 47 huizen en een volledig andere genenpool tussen. De woorden bedankt, mentor en inspirator kunnen niet dekken wat ik je zou willen zeggen dus doe ik het anders. Je weet dat ik vind dat ik de beste broers van deze wereld en van alle andere werelden heb en er geen hogere onderscheiding of aanzien in mijn ogen is. En dat is precies wat ik je zou willen noemen als ik er nog een mocht kiezen; broer (of brother from another mother). Ik hoop dat we in de toekomst net zulke bijzondere projecten samen mogen blijven doen als we in het verleden hebben gedaan. Is het nu dan eindelijk tijd voor dat stuk in de BMJ christmas edition?

In datzelfde dorp werkte een huisarts die later mijn andere promotor zou zijn (ik verzin dit niet mensen). Geert-Jan, ik liet ooit een briefje achter op je bureau met de woorden "gelukkig blijken de meest wijze mannen heel normaal te blijven." Hoewel ik daar nog steeds volledig achter sta, is het toch niet helemaal de beste omschrijving. In mijn ogen ben je namelijk juist bijzonder. Zoals Harry Potter Professor Perkamentus aan zijn zijde had, zo had ik/hadden wij jou om ons aan te moedigen op die momenten dat we het nodig hadden. De dropjes en zuurtjes (voor de HP kenners) zijn in jou geval dan pakjes chocomel en wellicht zou een baard je ook best staan bedenk ik me nu. Bedankt dat je deur altijd open staat en dat jij hoogstpersoonlijk garant staat voor het feit dat er op Deb 1 geen drempels in die deuren zitten. 
Natuurlijk waren er onderweg op Zweinstein, a.k.a. het Debyeplein veel collega's die deze reis de moeite waard hebben gemaakt. Eva, buddy, waar was ik zonder jou? Niet bovenop Rue Tesny in ieder geval. Bedankt voor al je adviezen en de gezelligheid. Ik ben benieuwd of er mensen zijn die terwijl ze dit lezen nog steeds niet weten wie nu Eva en wie nu Eefje is en stilletjes vind ik dat helemaal niet erg als het betekent dat ze me verwarren met jou.

Mark bedankt voor de koffie, je briljante, bizarre, heerlijk verfrissende theorieën en ideeën. Door jou kijk ik uit naar tien uur's ochtends en voel ik me niet alleen als ik op mijn sokken loop.

Nicole, Krista en sinds kort ook Jolijn, Lennart en Ruud. Lieve roomies. Wat was en is het fijn met jullie om alle AIOTHO hoogte- en dieptepunten te delen. Ik hoop dat we nog lang dezelfde kamer en/of verhalen mogen delen.

Annerika, Esther en Anneke. Bedankt voor de spierpijn, de cappuccino's, het kunnen verdragen van de overlast van mijn "even binnenwippen" en gewoon voor jullie liefheid.

Mascha en Paddy, bedankt voor jullie geweldige hulp en steun. Zonder jullie was er geen telefonisch databestand en zat ik nu nog data te cleanen, maar was het bovendien een stuk minder gezellig geweest.

Bedankt aan de meer dan 25000 kinderen, 3500 huisartsen en 20 huisartsenposten voor jullie deelname aan het CHILI project. Wat is het fijn om te zeggen dat bij zo'n omvangrijk project een van de grootste problemen waar ik tegenaan liep het feit was dat het boekje (de interventie) massaal gestolen werd door huisartsen en ik nu nog wekelijks mailtjes ontvang van mensen die een boekje willen ontvangen.

Bedankt lieve Ine, rots in onze Debyetoren, zonder jou was er geen Deb. Briljante Babette, zullen we elkaar voor altijd hondenfoto's blijven sturen en nog lang "Op 1 Lijn" blijven zitten? Bedankt ook Ellen, Jean, Job, Onno, Marjan, Luc, Daniel, Loes, Ramon, Donna, Jelle, Robert, Maartje, Floor, Angel, Anouk, Francine, Martine, Merijn, Jeanny, Janine, Jerôme, Hélène, Frits, Karin, Susanne en Judith. Kirsten wat was het leuk om jou als CHILI buddy erbij te krijgen en wat is het ongelofelijk knap hoe je alles combineert. 
Bedankt ook alle coauteurs en collega's voor jullie geweldige teamwork, Bjorn, Yvonne, Gijs, Gijs (nee dit is niet per ongeluk), Albine, Paul, Marjorie, Christian, Inge, Nicole en Bram. Nick and other GRIN'ers. Thank you for all the inspiration and the greatest social evenings.

En bedankt geweldige, onmisbare WESP studenten. Nicole, Dagmar, Julie, Jacqueline, Marleen, Famke, Jolijn en Rachel (wat is toch de sneltoets voor die accent grave?). Ik meen het wanneer ik zeg dat ik jullie werk en inzet voor dit project nooit maar dan ook nooit had kunnen missen. Zonder jullie was er immers geen CHILI. Jullie zijn geen huiselfen.

De mensen die ik onderweg tegenkwam tijdens mijn huisartsenopleiding. Lieve MCOB'ers, Martijn, Mirte, Marjon, Marion, Eefke, Joy, Astrid, Hannie, Jennifer en Wendy. Wat ben ik ongelofelijk blij dat ik jullie terug ga zien als huisarts. Luciënne je zei ooit dat je je afvroeg wat je me moest leren. Ik hoop dat je je beseft dat het juist precies dat is dat je me hebt geleerd. Een goede arts is eerlijk over zijn onzekerheden en een nog betere arts durft ze ook te laten zien. Hans, bedankt dat je me leerde dat je soms met niets zeggen het meeste zegt en bedankt voor de hulp bij het afslepen van onze MG...

Bedankt Rob, Sigrid, Martien, Marianne, Marieke, Marlous en Guy. Wat was het heerlijk om op jullie SEH te werken.

MC Nuth, lieve Miranda, Moniek, Suzy, Natascha, Ruby, Sandra, Rinske en Anne. Wat was het een prachtjaar en wat mis ik jullie allemaal. Van de vrijdaglunches tot jullie interesse en steun, bedankt. Norbert. Je hebt me genoeg stof tot nadenken gegeven voor mijn hele leven. Wat hebben we gelachen, associatief afgedwaald en wat heb je me veel geleerd over mezelf. Bedankt voor je blijvende interesse en dat je me zo beschermend met alles in het diepe durfde te laten zwemmen. Daarvan leerde ik het meest.

Mijn mede AIOTHO bestuursleden/LOVAH wetenschap, wat sprong ik graag met jullie op de bres en op de fiets met LOVAH cycling.

Mede AIOS Christianne, Anne, Anna, Sanne, Raphael, Jeanny, Jos, Maud, Rinske, Julie, Bart, Malou, Ilse, Carlijn, Ehsan, Frank, Marlieke, Nicole, Jack, Koen, Marieke, Rachel, Stephanie, Yon en begeleiders Henk, Katrien, Cecile en Gerrie. Wat hebben we veel gepraat en wat heb ik daar veel van geleerd. Van de hilarische momenten (Marieke hoe verzamel je ze?) tot de bloedserieuze zaken, ik zou vandaag de dag niet dezelfde mens en dokter zijn zonder jullie. 
In diezelfde straat in Stein die ik eerder noemde stond een huis of beter gezegd een warm thuis. Lieve paps, pepke, van vroeger schreeuwend langs de kantlijn "puppypowerrrr" wanneer ik mijn speer wegwierp, tot voor dag en dauw opstaan om me naar een of andere exotische coschap plek te brengen, jij bent er altijd. Wat was het heerlijk om met een jukebox in onze woonkamer op te groeien. Ik hou van je om je rust, je liefde en wie je bent en papa, ik lijk steeds meer op jou...

Mama, moeps, memke. Er zijn denk ik weinig meisjes die kunnen vertellen dat ze twee biologische moeders hebben. Mijn mama de kinderfysiotherapeut, voor wie niets te veel leek, die altijd rondrende en een baan combineerde met drie kinderen in een tijd dat dit nog niet gebruikelijk was. En dan mijn mama de humanistiek docente, die op haar 62e in een rolstoel in Utrecht nog even haar Mastertitel haalde, die weet dat het soms wel te veel mag zijn en die alles, maar dan ook alles voor ons doet. Wat heb ik veel geleerd van allebei die mama's en lieve vrouw waar was ik zonder jou. Met mach 3 door Stein scheuren met je scootmobiel "om even een flesje te komen geven", of "even naar Venlo rijden" omdat je dochter geen dekbed heeft. Bedankt voor alles, als ik ooit half de mens word die jij en papa zijn dan ben ik gelukkig.

Dat warme thuis werd mede mogelijk gemaakt door twee superhelden. Kleine meisjes en zusjes geloven immers niet zomaar in sprookjes. Dat doen ze, omdat ze zien dat ze echt zijn. Ik zou niemand anders aan mijn zijde kunnen hebben op mijn verdediging dan jullie. Broers, ridders, getuigen en beste vrienden, bedankt dat jullie dit zusje altijd het gevoel hebben gegeven dat ze erbij hoort. Jullie hebben me net op een goede manier zoveel geprikkeld dat ik altijd meer wil zijn dan maar gewoon, omdat ik jullie trots wil maken. "Because I have a brother, I'll always have a friend."

Er is dan ook niets kritischer dan de blik van een zusje als het op vrouwen voor haar broers aankomt. En man wat hebben jullie deze zus trots gemaakt. Ellen en Nicole, het is door jullie dat ik niet begrijp dat ik als kind zijnde geen zusje wilde. Prachtige, lieve zorgzame vrouwen, bedankt voor wie jullie zijn en alles dat ik van jullie mag leren. Bedankt voor jullie prachtige meiskes.

Kaatje, Izzy, Flo en ons aanstaande "Bo(o)ntje" bedankt voor alle natte kusjes, de lachjes en knuffels. Deze tante loopt over van haar liefde voor jullie en belooft dat ze altijd daar zal zijn om samen oneindig veel boekjes te lezen. 
Je vraagt je af hoeveel geluk een mens kan hebben want in Stein heb ik zo net iets na de helft van mijn huidige leven nog een warm thuis gevonden. Lieve familie Janssen. Bedankt dat ik erbij mag horen, bedankt voor al jullie hulp, voor de kilometers die we samen wandelen Jan en de heerlijke kookkunsten en zorgzaamheid Miriam, maar vooral bedankt voor Sander. Ik schrijf dit deel terwijl ik het gesmak van jullie kleinzoon door de babyfoon hoor en het is mede door jullie dat hij de man en vader is waar wij zoveel van houden. Kimmetje, Kimberley, wat ben ik als je schoonzus trots op jou en Roy. Trots op jullie prachtige huis en trots op de vrouw die je bent geworden.

Het is niet toevallig dat er op de kaft van dit proefschrift een hond staat. Een van de plenaire sprekers op een recent LOVAH congres heeft een keer een uur lang beargumenteerd waarom hij dacht dat een hond een van de beste manieren zou zijn om de volksgezondheid te stimuleren en man wat ben ik dat met hem eens. Een hond is goed voor je lichaam en beweging, maar vooral goed voor je hart en geest. Lieve, lieve, lieve trouwe viervoeters wat heb ik jullie nodig gehad. Lieve Penny, Pietje, kleine drs. P. Met je 2,5kg ben je een ware dochter voor ons en volwaardig gezinslid en samen met Gina mijn Hedwig. Ik wacht op de dag dat je me daadwerkelijk antwoord geeft als ik je iets vraag. Tot die tijd weet ik stiekem toch dat wij elkaar als geen ander begrijpen en aanvoelen. Lieve Gina, Riko, Tirza, Suetje, Woeke, en Sem, bedankt voor alle fijne wandelingen, de troost, maar bovenal jullie ontnuchterende enthousiasme. "Noem me geen hond, ik ben niet zo lief, zo eerzaam, zo trouw, ik ben slechts mens."

Buiten die twee warme nesten wonen en woonden natuurlijk nog veel meer familieleden elders. Opa's, oma's, ooms, tantes en neven, nichten en vrienden die voelen als familie, bedankt voor jullie lieve belangstelling in de loop van de jaren. Wat mis ik diegene van jullie die er helaas niet meer bij kunnen zijn ontzettend.

Michel bedankt voor de heerlijke koffie momentjes, Jolanda bedankt voor je looks ;) en Gabby bedankt voor alles dat je altijd voor iedereen doet.

Familie Janssen in bredere zin, Diana, Leike, John, Philomien, Leon, Marie-Louise, Bep, Jos, Piet, Stella, Huub en Martha bedankt voor alle polonaises, dat geen feestje jullie te laat of te gek is en bedankt voor jullie lieve interesse. Oma Wies en ome André als ik ooit oud mag worden met half het plezier en de humor die jullie twee hebben dan ben ik tevreden. Lieve oma Trudy, ik ken geen enkele andere oma van boven de 90 die nu nog kan vertellen op 
welk tijdstip, van welk dagdeel, op welke datum ze op een willekeurige dag 50 jaar geleden een gedichtje bedacht. Bijzondere vrouwen. Wat zullen de opa's trots zijn.

Truus, jij was als familie. Bedankt dat je me hebt leren fluiten, ik beloof dat ik er nooit mee zal ophouden.

Dan zijn er de mensen die niet door bloed of genen familie zijn, maar die het feitelijk wel zijn door de blauwe das die we al meer dan 25 jaar delen. Scouting Stein. Cindy, Elien, Loek, Jason, Siobhan, Luuk, Lucca, Inge, Tim, Louk, Bianca, Christianne, Dion, Frenk, Vincent, Nick, Bram, Lindsey, Arja, Britt, Anne, Inge, Janneke, Rick, Maaike, Tom, Roel, alle welpjes en iedereen die ik nu niet noem die er ook bij hoort bedankt. Bedankt voor de heerlijke weekenden, kampvuren, huilen van het lachen, verstop partijen waarbij we met 20 man door een vloer zakken en bedankt dat ik bij jullie mag horen.

Ook is er de familie die je zelf kiest. Vrienden. Lieve Math, Renée, Anna, Tom, Nicole, Stef, Liv, Tris, Anouk en iedereen die ik nu vergeet. Jullie zijn mijn Griffoendor. Bedankt voor al jullie interesse, de fijne momenten en dat jullie zijn wie jullie zijn.

Lieve Marjolein. Wil je voor altijd mijn Yin zijn als ik jouw Yang ben? Mijn Ron Wemel (woman lees die boeken nou eens)? $\mathrm{Er}$ is niemand die zo anders is als ik en me juist daardoor zo goed begrijpt. Wat ben ik trots op jou, Martijn, Rens en Clim.

Chickies. Aniek, Bjel, Denise, Frederique en Natascha. Heerlijke, mooie vrouwen van me. Wat zijn jullie belangrijk. Van het samen zijn in onderwijsgroepen, gniffelend in de steegjes van Valencia, tot samen vriendinnen voor het leven. Ik hoop dat ik over twintig jaar nog altijd koffie, etentjes, sauna, zwembaantjes, gesprekken over onzin en gesprekken over de dingen die het leven de moeite waard maken met jullie heb.

Lennon. Mijn hart klopt niet voor jou, het gloeit niet voor jou, het brandt niet voor jou, nee het is een regelrecht denderend inferno. Die hittegolf deze zomer? Dat was ik. Knaapje, makkertje, vriendje van me, papa's kloontje, ik hou meer van jou dan ik in woorden kan uitdrukken. Het is jij die dit hele boek in ander perspectief hebt geplaatst. Jij, wiens stoplicht twee weken na je geboorte plots binnen een paar minuten dieprood kleurde en mij bewees dat het niet pluis gevoel er eerder was dan je koorts of andere symptomen. Ik hoop dat je mag worden wie je bent en je vooral voor altijd in sprookjes blijft geloven. Jij bent er immers één voor ons. 
Zoals ik eerder schreef begint en eindigt dit hoofdstuk met een man. Sander. Zelfs al had ik je niet zo een enorme hunk gevonden als dat ik je vind, dan was ik nog voor je gevallen. Je bent mijn maatje, mijn andere helft, mijn lief, mijn tegenpool, mijn in voor en tegenspoed, mijn ridder op het witte paard, mijn "Happily Ever After", oftewel mijn man. Dit boek was er nooit geweest zonder jou. Bedankt voor je liefde, je trots, je creativiteit en je onevenaarbare kookkunsten. Bedankt dat ik mezelf kan zijn en dat ik me nooit hoef te verantwoorden. Bedankt dat je samen met mij onze dromen wilt najagen, ons sprookjeskasteel hebben we al. Ik kan over onze belevenissen samen een apart boek schrijven, wie had dat gedacht toen we als twee tieners voor elkaar vielen. Zoals Walt Disney ooit zei en op onze trouwuitnodiging stond: "Once in a while, right in the middle of an ordinary life, love gives us a fairytale." 

$P_{\text {ublations }}$ 



\section{International publications}

Eefje G.P.M. de Bont, Geert-Jan Dinant, Gijs Elshout, Gijs T. van Well, Nick A. Francis, Bjorn Winkens, Jochen W.L. Cals. Booklet for Childhood Fever in Out-of-Hours Primary Care: A Cluster-Randomized Controlled Trial. Ann Fam Med. 2018;16(4):314-321.

Maria Kelly, Laura J. Sahm, Frances Shiely, Ronan O'Sullivan, Eefje G.P.M. de Bont, Aoife Mc Gillicuddy, et al. Parental knowledge, attitudes and beliefs on fever: a cross-sectional study in Ireland. BMJ Open. 2017;7:e015684.

Eefje G.P.M. de Bont, Geert-Jan Dinant, Gijs Elshout, Gijs T. van Well, Nick A. Francis, Bjorn Winkens, Jochen W.L. Cals. An illness-focused interactive booklet to optimise management and medication for childhood fever and infections in out-of-hours primary care: study protocol for a cluster randomised trial. Trials. 2016;17:547. DOI 10.1186/s13063-016-16678.

Jacqueline P. Stakenborg, Eefje G.P.M. de Bont, Kirsten K.B. Peetoom, Marjorie H. NelissenVrancken, Jochen W.L. Cals. Medication management of febrile children: a qualitative study on pharmacy employees' experiences. International journal of clinical pharmacy. 2016;38:1200-9.

Eefje G.P.M. de Bont, Famke Falkenberg, Marleen Alink, Geert-Jan Dinant, Jochen W.L. Cals. Patient information leaflets to reduce antibiotic use and reconsultation rates in general practice: a systematic review. BMJ Open. 2015;5(6):e007612.

Eefje G.P.M. de Bont, Nicole Loonen, Dagmar A.S. Hendrix, Julie M.M. Lepot, Geert-Jan Dinant, Jochen W.L. Cals. Childhood fever: a qualitative study on parents' expectations and experiences during general practice out-of-hours care consultations. BMC Fam Pract. 2015;16(1):131.

Eefje G.P.M. de Bont, Kirsten K.B. Peetoom, Albine Moser, Nick A. Francis, Geert-Jan Dinant, Jochen W.L. Cals. Childhood fever: a qualitative study on GPs' experiences during out-ofhours care. Family Practice, 2015;1-7 doi:10.1093/fampra/cmv029.

Eefje G.P.M. de Bont, Julie M.M. Lepot, Dagmar A.S. Hendrix, Nicole Loonen, Yvonne Guldemond-Hecker, Geert-Jan Dinant, Jochen W.L. Cals. Workload and management of 
childhood fever at general practice out-of-hours care: an observational cohort study. BMJ Open. 2015;5(5):e007365.

Eefje G.P.M. de Bont, Nick A. Francis, Geert-Jan Dinant, Jochen W.L. Cals. Parents' knowledge, attitudes, and practice in childhood fever: an internet-based survey. Br J Gen Pract. 2014;64(618):e10-6.

Jochen W.L. Cals, Leon L. de Bock, Paul J. Beckers, Nick A. Francis, Rogier M. Hopstaken, Kerenza Hood, Eefje G.P.M. de Bont, Cristopher C. Butler, Geert-Jan Dinant. Enhanced communication skills and C-reactive protein point-of-care testing for respiratory tract infection: 3.5-year follow-up of a cluster randomized trial. Ann Fam Med. 2013;11:157-64.

Jochen W.L. Cals, Mirjam E. van Leeuwen, Fleur H. Chappin, Eefje G.P.M. de Bont, Geert-Jan Dinant, Cristopher C. Butler. "How Do You Feel about Antibiotics for This?" A Qualitative Study of Physician Attitudes towards a Context-Rich Communication Skills Method. Antibiotics. 2013;2:439-49.

Eefje G.P.M. de Bont, Inge H.M. van Loo, Nicole H.T.M Dukers-Muijrers, Christian J.P.A. Hoebe, Catharina A. Bruggeman, Geert-Jan Dinant, Jochen W. L. Cals. 'Oral and topical antibiotic prescriptions for children in Dutch general practice 2000-2010'. Arch Dis Child. 2013;98(3):228-31.

Jochen W.L. Cals, Eefje G.P.M. de Bont. Minor incised traumatic laceration. BMJ. 2012;345:e6824.

\section{National publications}

Eefje G.P.M. de Bont, Jochen W.L Cals. Een uitgesteld antibioticarecept bij luchtweginfecties. Huisarts Wet. 2018; 9: 68.

Eefje G.P.M. de Bont, Jochen W.L. Cals. iFOBT bij onderbuikklachten? Ned Tijdschr Geneeskd. 2018;162:D2875

Thera Habben-Jansen, Hans Berg, Marjolijn Wegdam-Blans, Theo Verheij en Eefje G. P.M. de Bont. Centrale rol huisarts in zorgnetwerk antibioticaresistentie. Huisarts Wet. 2018; 4: 38-39.

Eefje G.P.M. de Bont. Minder antibiotica bij luchtweginfecties. Huisarts Wet. 2018; 2: 76. 
Angel Schols, Eefje G.P.M. de Bont. Geen preventieve medicatie bij koortsconvulsies. Huisarts Wet. 2017; 60:608.

Bram Peters, Eefje G.P.M. de Bont, Jochen W. L. Cals. Amoxicilline en paracetamol doseren bij kinderen: te veel speelruimte. Ned Tijdschr Geneeskd. 2016; 160:D345.

Eefje G.P.M. de Bont. Een beslisboom voor kinderen met infecties. Huisarts Wet. 2016; 59: 85.

Eefje G.P.M. de Bont, Jochen W.L. Cals. Beslisregels voor kinderen met koorts weinig beslissend op de huisartsenpost. Ned Tijdschr Geneeskd. 2015; 159: A9316.

Eefje G.P.M. de Bont. Stand van zaken: Kinderen met koorts op de HAP. Huisarts Wet. 2015; 58:547.

Eefje G.P.M. de Bont, Kirsten K.B. Peetoom, Jochen W.L. Cals. Komt een kind met koorts bij de dokter: Wat ziet de kinderarts niet?" Kinderarts \& Wetenschap. 2015.

Eefje G.P.M. de Bont, Paul L. Brand, Geert-Jan Dinant, Gijs T. van Well, Jochen W.L. Cals. Wel of geen paracetamol bij kinderen met koorts? Ned Tijdschr Geneeskd. 2014; 158:A6636.

Eefje G.P.M. de Bont, Jochen W.L. Cals. Voor elk kind met koorts een eigen 'stoplicht'? Ned Tijdschr Geneeskd. 2014; 158:A7649.

Jochen W.L. Cals, Leon de Bock, Paul J. Beckers, Nick A. Francis, Rogier M. Hopstaken, Kerenza Hood, Eefje G.P.M. de Bont, Cristopher C. Butler, Geert-Jan Dinant. Praten en prikken bij luchtweginfecties: 3,5 jaar follow-up. Huisarts Wet. 2014; 57: 6-9.

Eefje G.P.M. de Bont. Geen paracetamol én ibuprofen bij kind met koorts. Huisarts Wet. $2014 ; 57 ; 279$.

Eefje G.P.M. de Bont, Jochen W.L Cals. PEARLS: Kraanwater reinigt wonden effectief. Huisarts Wet. 2012; 55:533.

Eefje G.P.M. de Bont, Jochen W.L Cals. Spreekuur! "Snijwond". Huisarts Wet. 2012; 55: 423.

Eefje G.P.M. de Bont, Jochen W.L Cals. Plakken of hechten? Wondsluiting van ongecompliceerde traumatische wonden. Modern Medicine. 2011;1:4-7. 


\section{Book chapter}

Eefje G.P.M. de Bont en Jochen W.L. Cals, 2016. Koorts en koortsstuipen. In: Just A.K. Eekhof, Arie Knuistingh Neven, Sjoerd Bruggink, Marissa Scherptong-Engbers, Kleine kwalen bij kinderen; 74-81. Houten, Bohn Staflau van Loghum.

\section{Awards, prizes and recognitions}

2017 Early career research prize of the Society for Academic Primary Care Best abstract by a young academic, therefore invited plenary speaker at the The South West Regional Conference of the Society for Academic Primary Care at Oxford University

2014 CAPHRI Presentation Award

Best oral presentation during the annual CAPHRI research meeting, Maastricht University

2014 Best young author award

Best research paper of the year for authors $<40$ years in Nederlands Tijdschrift voor Geneeskunde

2013 Student prize Maastricht University

Best graduation thesis of the Faculty of Health, Medicine and Life Sciences, Maastricht University

2013 Prof. Huygenprijs

Best research proposal by a GP trainee, Netherlands

2012 Medical Doctor-Clinical investigator degree

Awarded with distinction, cum laude

2012 Poster prize MMSRC/CISS

Best poster presentation at the MMSRC/CISS conference, Maastricht University

2011 Top 3\% award

Award for top 3\% students at Maastricht University

2010 Top 3\% award

Award for top 3\% students at Maastricht University 
Uurriculum vitae 



\section{CURRICULUM VITAE}

Eefje de Bont was born on Friday the $13^{\text {th }}$ of March 1987 in Sittard, the Netherlands. She grew up in Stein, The Netherlands as the daughter of Karel and Else and sister of Carl and Nik de Bont. Eefje completed secondary school at Groenewald College in Stein and started her Health Sciences study in 2005 at Maastricht University with a specialisation in Movement Sciences and Bioregulation and Health. After graduating as an honours student in 2008 she started her four year clinical investigatorphysician Master's programme (arts-klinisch onderzoeker),

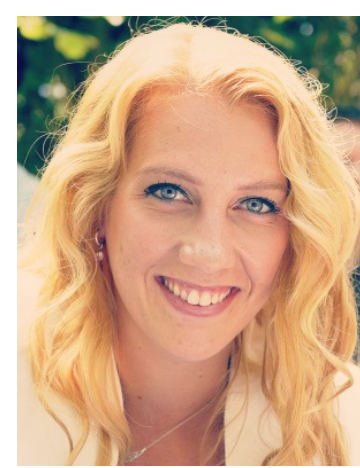
during which she combined her medical training with clinical research. Her last internship at the department of Family Medicine resulting in her Master thesis which is the second chapter of this PhD thesis. For this chapter she received the 2012 UM award for best Master thesis of the Faculty of Health, Medicine and Life sciences. After graduating cum laude in 2012 she immediately started her GP training and PhD at the department of Family Medicine in Maastricht under the supervision of Prof. dr. Jochen Cals and Prof. dr. GeertJan Dinant who also supervised her in her previous Master internships. Together with her supervisors she developed a new research line at the department aimed at improving management of childhood fever in general practice. She finished her vocational training in family medicine in 2018 and she will continue combining her clinical work as a GP with post-doctoral research at the department of Family Medicine.

In her free time Eefje enjoys running, cycling, yoga and reading and has been an active member of Scouting Stein since she was five years old, where she still supervises children in weekly activities. This was also where she met her husband Sander Janssen many years ago. They are currently living happily in Stein, together with their dog Penny and their son Lennon. 
